BRUNO SANCHES MASIERO

\title{
CONTROLE ATIVO DE RUÍDO PARA TRANSFORMADORES DE POTÊNCIA EM CAMPO
}




\title{
CONTROLE ATIVO DE RUÍDO PARA TRANSFORMADORES DE POTÊNCIA EM CAMPO
}

\author{
Dissertação apresentada à Escola Po- \\ litécnica da Universidade de São Paulo \\ para obtenção do Título de Mestre em \\ Engenharia Elétrica.
}




\title{
CONTROLE ATIVO DE RUÍDO PARA TRANSFORMADORES DE POTÊNCIA EM CAMPO
}

\author{
Dissertação apresentada à Escola Po- \\ litécnica da Universidade de São Paulo \\ para obtenção do Título de Mestre em \\ Engenharia Elétrica.
}

Área de Concentração:

Sistemas Eletrônicos

Orientador:

Prof. Dr. Vítor Heloiz Nascimento 
Este exemplar foi revisado e alterado em relação à versão original, sob responsabilidade única do autor e com a anuência de seu orientador.

São Paulo, 6 de agosto de 2007.

Bruno Sanches Masiero

Prof. Dr. Vítor Heloiz Nascimento

FICHA CATALOGRÁFICA

Masiero, Bruno Sanches

Controle ativo de ruído para transformadores de potência em campo / B.S. Masiero -- ed.rev. -- São Paulo, 2007.

$152 \mathrm{p}$.

Dissertação (Mestrado) - Escola Politécnica da Universidade de São Paulo. Departamento de Engenharia de Sistemas Eletrônicos.

1. Acústica (Simulação) 2. Controle adaptativo de ruído 3. Otimização combinatória 4. Sensores virtuais I. Universidade de São Paulo. Escola Politécnica. Departamento de Engenharia de Sistemas Eletrônicos II. t. 
Esta dissertação é dedicada aos meus avós

Dervile e Irma Masiero e Luiz e Maria Sanches. 


\section{AGRADECIMENTOS}

Em especial ao meu pai Prof. Dr. Paulo C. Masiero, pelo apoio, dedicação e pelas importantes sugestões dadas para a elaboração desta dissertação. Saiba que você é meu grande exemplo de vida.

À minha mãe Vera L. S. Masiero e à minha irmã Livia S. Masiero, pelo apoio, motivação e carinho.

Ao Prof. Dr. Vítor H. Nascimento, pela orientação, dedicação e importantes discussões. Obrigado por não permitir que eu me contentasse com pouco.

Ao Prof. Dr. Sylvio R. Bistafa, pela sugestão do tema, pela condução do projeto e por todo auxílio dado.

Ao colega Eng. Flávio P. Ribeiro, pelas frutíferas discussões e auxílio em todas as fases do projeto.

À AES Eletropaulo, pelo financiamento desta pesquisa e aos funcionários da AES Eletropaulo, por assegurarem a realização da pesquisa em campo.

Aos amigos da Politécnica Rugby ${ }^{\star}$, equipe que levarei para sempre na memória.

Dank an meine Freundin Stephanie C. Pfaff für ihre Geduld und Liebe. 


\section{RESUMO}

É cada vez maior a preocupação com a poluição sonora gerada pelos transformadores de potência de subestações elétricas. Atualmente, o controle desse tipo de ruído é feito utilizando-se métodos passivos, que são caros e dificultam a manutenção dos transformadores. Uma alternativa para os métodos passivos é o controle ativo de ruído (ANC). Apesar de extensas pesquisas realizadas nas últimas três décadas, ainda não existem soluções comercialmente viáveis para o ANC de transformadores. As dificuldades para a aplicação bem sucedida do ANC para transformadores foram investigadas por meio de simulações e de testes com protótipo. Os três maiores obstáculos identificados foram: o posicionamento dos transdutores eletroacústicos; a obtenção de atenuação em uma região longe do transformador, usando um número reduzido de fontes de controle e de sensores de erro, os últimos colocados ainda na região de campo acústico próximo; e a identificação robusta do caminho secundário com baixa razão sinal/ruído. Os dois primeiros problemas foram abordados, analisando-se algumas alternativas de soluções. Algoritmos genéticos (GA) foram utilizados para a otimização da posição dos transdutores do sistema ANC. O desempenho desses algoritmos depende fortemente da modelagem acústica realizada e verificou-se que o método de Usry, escolhido para modelar o campo primário do transformador, não forneceu estimativa adequada. Usando um modelo mais simples de fonte primária, constatou-se a importância da função de mérito para o desempenho do GA. Também foi verificado que a otimização conjunta das posições dos transdutores fornece o mesmo resultado, e em menor tempo, que a otimização das posições das fontes de controle e dos sensores de erro separadamente. Simulações realizadas com uma nova estratégia de sensores virtuais (baseada no janelamento das fontes de controle) mostra que é possível aumentar o nível de atenuação longe do transformador, mesmo com um número pequeno de fontes de controle e sensores de erro. Testes com um protótipo de sistema ANC foram feitos em laboratório e em campo e os resultados desses testes são discutidos detalhadamente.

Palavras-chave: Controle Ativo de Ruído. Ruído de Transformadores de Potência. Simulação Acústica. Algoritmos de Otimização. Sensores Virtuais. 


\begin{abstract}
Concern regarding noise pollution caused by power transformers in electrical substations is increasing. Nowadays, this kind of noise is controlled using passive methods, which are expensive and make transformer maintenance more difficult. An alternative to passive methods is active noise control (ANC). However, despite extensive research undertaken in the last three decades, there is still no viable commercial solution for the active control of transformer noise. The difficulties for a successful implementation of an ANC solution in the case of power transformer noise are investigated through simulations and tests with a prototype. The three main obstacles found were: the positioning of the electro-acoustic transducers; the achievement of sufficient attenuation in a region far from the transformer, using a small number of control sources and error sensors (when the latter are positioned on the region of acoustic near-field); and the robust identification of the secondary path in a low signal/noise situation. The two former problems were dealt with, and some alternative solutions were analyzed. Genetic algorithms (GA) were used for the optimization of the transducers' position. The performance of these algorithms is strongly related to the acoustical model used and it was verified that the Usry method, used for modelling the transformers primary field, did not result in an adequate estimate. Using a simplified model for the primary source, the importance of the cost function in the GA's performance was made evident. It was also verified that the joint optimization of transducers' position provides the same result, and in shorter time, as the independent optimization of control source and error sensor positions. Simulations with a new virtual sensor strategy (based on windowing the control sources) show that it is possible to increase attenuation levels in a region far from the transformer, even with a small number of control sources and error sensors. Laboratory and field tests with an ANC system prototype were undertaken and the results of these tests are thoroughly discussed.
\end{abstract}

Keywords: Active Noise Control. Power Transformer Noise. Acoustic Simulation. Optimization Algorithms. Virtual Sensors. 


\section{LISTA DE FIGURAS}

$1 \quad$ Espectro do ruído emitido $\ldots \ldots \ldots \ldots \ldots$. . . . . . . . . . . . 17

$2 \quad$ Diagrama de um sistema de controle ativo de ruído . . . . . . . . . . . . . 20

$3 \quad$ Sistema de controle ativo proposto por Conover . . . . . . . . . . . . . . . 21

$4 \quad$ Volume de controle por onde passa uma onda acústica. . . . . . . . . . . . 29

$5 \quad$ Dipolo acústico $\ldots \ldots \ldots \ldots \ldots \ldots$

$6 \quad$ Atenuação em Campo Distante para $0^{\circ} \ldots \ldots$. . . . . . . . . . . . 36

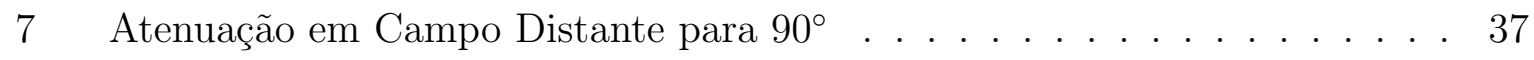

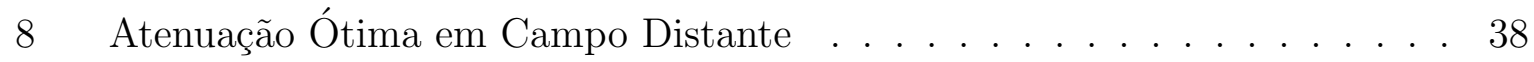

$9 \quad$ Volumes e suas superfícies limítrofes. . . . . . . . . . . . . . . . . . 44

10 Máxima atenuação possível. . . . . . . . . . . . . . . . . . . . . . . . . . . 48

11 Esquema de um problema generalizado de estimação. . . . . . . . . . . . . 51

12 Controle direto em duto . . . . . . . . . . . . . . . . . . . . 54

13 Identificação do sistema ANC. . . . . . . . . . . . . . . . . . . . . . . 54

14 Diagrama de blocos simplificado do sistema ANC. . . . . . . . . . . . . . 55

15 Diagrama de blocos do sistema ANC usando o algoritmo FxLMS. . . . . . 56

16 Diagrama de blocos do sistema FxLMS completo. . . . . . . . . . . . . . . 57

17 Diagrama de blocos de um ANC usando FxLMS multicanal . . . . . . . . 60

18 Diagrama de blocos de para um sinal de erro . . . . . . . . . . . . . . . . 60

19 Fonte Imagem $\ldots \ldots \ldots$. . . . . . . . . . . . . . . . . . . . . . . . 69

20 Um sensor de erro e uma fonte de controle . . . . . . . . . . . . . . . . . . 72

21 Dois sensores de erro e uma fonte de controle . . . . . . . . . . . . . . . . . 73

22 Três sensores de erro e uma fonte de controle . . . . . . . . . . . . . . . . . 74

23 Quatro sensores de erro e uma fonte de controle . . . . . . . . . . . . . . . 75

24 Quatro sensores de erro e duas fontes de controle . . . . . . . . . . . 76 
25 Quatro sensores de erro e três fontes de controle . . . . . . . . . . . . . . 77

26 Um sensor de erro e três fontes de controle . . . . . . . . . . . . . . . . . . 78

27 Espalhamento de onda . . . . . . . . . . . . . . . . . . . . . . . . . 81

28 Exemplo do método de Usry . . . . . . . . . . . . . . . . . . . . . . 82

29 Nível sonoro estimado pelo método de Usry . . . . . . . . . . . . . . . . . 85

$30 \quad$ Disposição das fontes de controle ao redor do octopolo. . . . . . . . . . . . . 90

$31 \quad$ Pressão sonora em campo aberto. . . . . . . . . . . . . . . . . . . . . . . . 91

32 Pressão sonora com presença de solo. . . . . . . . . . . . . . . . . . . . . . 92

33 Exemplo da métrica 1. . . . . . . . . . . . . . . . . . . . . . . 93

34 Exemplo da métrica 2. . . . . . . . . . . . . . . . . . . . 93

35 Exemplo da métrica $3 . \quad \ldots \ldots \ldots$. . . . . . . . . . . . . . . 94

36 Exemplo do método cíclico após uma iteração $\ldots$. . . . . . . . . . . . 96

37 Exemplo do método cíclico após duas iterações $\ldots \ldots$. . . . . . . . . . . . . 96

38 Diagrama de bloco de um sistema com sensor virtual. . . . . . . . . . . . . 101

39 Diagrama do sistema modelado. . . . . . . . . . . . . . . 105

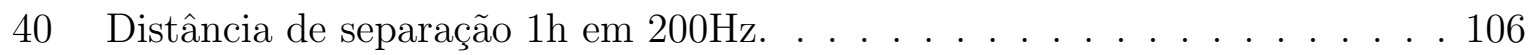

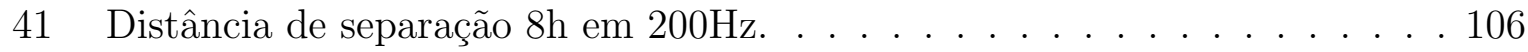

42 Distância de separação 8h em 200Hz. . . . . . . . . . . . . . . . . . . . 107

43 Distância de separação 1 h em $400 \mathrm{~Hz}$.

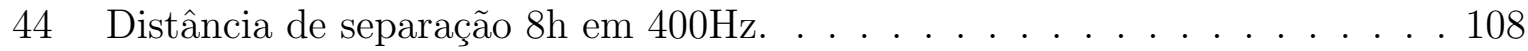

45 Distância de separação 8h em 400Hz. . . . . . . . . . . . . . . . . . . . . . 109

$46 \quad$ Diagrama do sistema modelado para estudo do JFS. . . . . . . . . . . . . . 111

47 Janela de pesos calculada para $\psi=0^{\circ}$. . . . . . . . . . . . . . 112

$48 \quad$ Janela de pesos calculada para $\psi=90^{\circ}$. . . . . . . . . . . . . . . . . 112

49 Janela de pesos calculada com fontes secundárias fixas. . . . . . . . . . . . 113

$50 \quad$ Janela de pesos calculada com sensores de erro fixos. . . . . . . . . . . . . 114 
51 Sensores virtuais estimados corretamente. . . . . . . . . . . . . . . . . 116

52 Sensores virtuais estimados muito ao lado. . . . . . . . . . . . . . . . . . 116

53 Sensores virtuais estimados muito antes. . . . . . . . . . . . . . . . . . . 117

54 Sensores virtuais estimados muito à frente. . . . . . . . . . . . . . . . . . . 117

55 Superfície de controle grande. . . . . . . . . . . . . . . . . . . . . . . 118

56 Curvas de Audibilidade . . . . . . . . . . . . . . . . . . . . . . . . . . . . . 121

57 Pontos de medição de ruído ao redor dos transformadores. . . . . . . . . . . 123

58 Pontos de medição próximos ao radiador traseiro. . . . . . . . . . . . . . . 125

59 Protótipo do sistema ANC. . . . . . . . . . . . . . . . . 127

60 Resposta em freqüência e diretividade do microfone ECM8000. . . . . . . . . 128

61 Esquema do gerador de referência. . . . . . . . . . . . . . . . . . . . . . . . 129

62 Espectro em microfone de erro com e sem controle. . . . . . . . . . . . . . 131

63 Transformador com transdutores do sistema ANC. . . . . . . . . . . . . . . 134

64 Teste com uma fonte de controle e dois sensores de erro. . . . . . . . . . . 135

65 Teste com uma fonte de controle e três sensores de erro. . . . . . . . . . . . 136

66 Teste com duas fontes de controle e três sensores de erro. . . . . . . . . . . 137

67 Teste com duas fontes de controle e quatro sensores de erro. . . . . . . . . 139

68 Teste com três fontes de controle e quatro sensores de erro. . . . . . . . . . 140

69 Teste com três fontes de controle e quatro sensores de erro. . . . . . . . . . . 141

$70 \quad$ Teste com quatro fontes de controle e quatro sensores de erro. . . . . . . . 142 


\section{LISTA DE TABELAS}

$1 \quad$ Nível de Pressão Sonora medido em campo. . . . . . . . . . . . . . . . . . 86

$2 \quad$ Nível de Pressão Sonora estimado pelo método de Usry. . . . . . . . . . . . . . 86

$3 \quad$ Níveis de Ruído para Ambientes Externos - em dB(A) . . . . . . . . . . . . 122

$4 \quad$ Níveis sonoros medidos no entorno do transformador T2. . . . . . . . . . . . 124

5 Níveis sonoros medidos na janela do prédio vizinho. . . . . . . . . . . . . . 124

$6 \quad$ Níveis de pressão sonora em pontos próximos ao radiador. . . . . . . . . . 125

7 Atenuação para uma fonte de controle e dois sensores de erro. . . . . . . . 136

$8 \quad$ Atenuação para uma fonte de controle e três sensores de erro. . . . . . . . 137

$9 \quad$ Atenuação para duas fontes de controle e três sensores de erro. . . . . . . . . 138

10 Atenuação nos três sensores de erro para duas fontes de controle. . . . . . . 138

11 Atenuação nos quatro sensores de erro para duas fontes de controle. . . . . 139

12 Atenuação nos quatro sensores de erro para três fontes de controle. . . . . 140

13 Atenuação para três fontes de controle e quatro sensores de erro. . . . . . . . 141

14 Atenuação para as três fontes de controle reposicionadas. . . . . . . . . . . . 141

15 Atenuação para quatro fontes de controle e quatro sensores de erro. . . . . 143 


\section{SUMÁRIO}

\begin{tabular}{lll}
\hline 1 & Introdução & 16
\end{tabular}

1.1 Ruído de Transformadores de Potência . . . . . . . . . . . . . . . . . . . . 16

1.2 Controle Ativo de Ruído . . . . . . . . . . . . . . . . . . . . . . . . . . . . . . . . 19

1.3 Controle Ativo de Ruído de Transformadores . . . . . . . . . . . . . . . . . 20

1.4 Motivação e Objetivos . . . . . . . . . . . . . . . . . . . . . . 23

1.5 Discussão Inicial $\ldots \ldots \ldots$. . . . . . . . . . . . . . . . . . . . . . . . . . . . . . 24

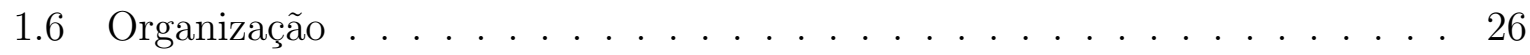

$\begin{array}{lll}2 & \text { Fundamentos de Acústica } & 27\end{array}$

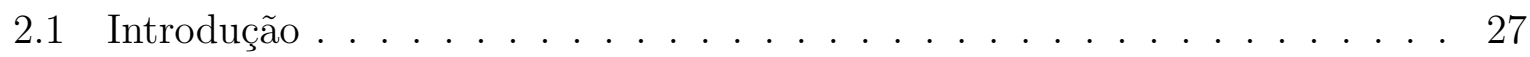

2.2 Ondas Sonoras $\ldots \ldots \ldots \ldots$

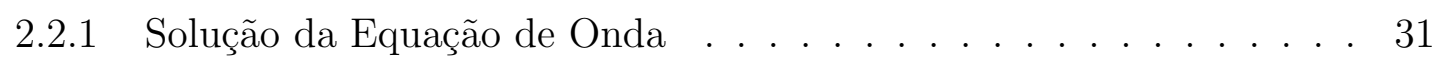

2.2 .2 Fontes Pontuais de Radiação Esférica . . . . . . . . . . . . . . . . . 31

2.3 Potência Sonora . . . . . . . . . . . . . . . . . . . . . . . . . . . 33

2.4 Supressão de Potência Sonora Irradiada em Campo Livre . . . . . . . . . . . 34

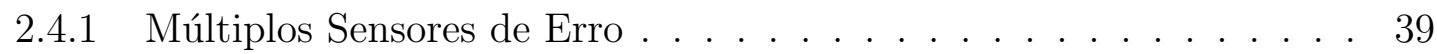

$2.4 .2 \quad$ Múltiplas Fontes Secundárias _ . . . . . . . . . . . . . . . . . . . . 40

2.5 Distribuição Contínua de Fontes . . . . . . . . . . . . . . . . . . . . . 42

2.5 .1 A Solução da Equação de Onda Não-Homogênea . . . . . . . . . . . . 43

2.5.2 A Solução da Equação de Green para o Espaço Livre . . . . . . . . 45

\begin{tabular}{|ll|}
\hline 3 & Sistemas de Controle Ativo de Ruído
\end{tabular}

3.1 Introdução . . . . . . . . . . . . . . . . . . . . . 47

3.2 Filtros Adaptativos . . . . . . . . . . . . . . . . . . . . . . . . . . . . 49 
$3.2 .1 \quad$ Filtros FIR . . . . . . . . . . . . . . . . . . . . . . 49

3.2 .2 Algoritmo de Adaptação . . . . . . . . . . . . . . . . 50

3.2.2.1 Filtro Ótimo de Wiener . . . . . . . . . . . . . . . . . 50

$3.2 .2 .2 \quad$ Algoritmo LMS . . . . . . . . . . . . . . . . 51

3.3 Técnicas de Controle Adaptativo $\ldots \ldots \ldots \ldots \ldots \ldots$

3.3 .1 Controle Direto . . . . . . . . . . . . . . . . . . . . 54

3.3 .2 Controle FxLMS $\ldots \ldots \ldots \ldots \ldots \ldots$

3.3 .3 Estimativa do Caminho Secundário . . . . . . . . . . . . . . 57

3.3 .4 Controle Ativo Multicanal . . . . . . . . . . . . . . . . . . . . 59

3.3.5 Estimação do Caminho Secundário Multicanal . . . . . . . . . . . . 63

$4 \quad$ Projeto do Sistema Físico $\quad 64$

4.1 Introdução . . . . . . . . . . . . . . . . . . . . . . . . . 64

4.2 Modelagem do Sistema Acústico $\ldots \ldots \ldots \ldots$. . . . . . . . . 67

4.2 .1 Efeito do Solo . . . . . . . . . . . . . . . . . . . . . . . . . . . . . 68

4.3 Influência da Quantidade de Transdutores $\ldots \ldots \ldots \ldots$. . . . . 70

4.4 Modelagem do Campo Sonoro Primário . . . . . . . . . . . . . . . . 71

$4.4 .1 \quad$ O Método de Usry $\ldots \ldots \ldots \ldots \ldots \ldots$

$4.4 .2 \quad$ Programação do Método de Usry $\ldots \ldots \ldots \ldots$. . . . . . . 83

4.4 .3 Discussão $\ldots \ldots \ldots \ldots \ldots \ldots$

4.5 Otimização do Posicionamento $\ldots \ldots \ldots \ldots \ldots \ldots \ldots$. . . . . . . 87

$4.5 .1 \quad$ Algoritmos Genéticos . . . . . . . . . . . . . . . . . . . 88

4.5 .2 Simulações $\ldots \ldots \ldots$. . . . . . . . . . . . . . . . . . . . . . . . 89

4.5.2.1 Influência da Função de Mérito . . . . . . . . . . . . . . 89

4.5.2.2 Influência da Ordem da Otimização . . . . . . . . . . . . . 92

4.6 Conclusão . . . . . . . . . . . . . . . . . . . . . . . . . . . . . . . 97

$\begin{array}{lll}5 & \text { Sensores Virtuais } & 99\end{array}$ 
5.1 Introdução $\ldots \ldots \ldots \ldots \ldots$

5.2 Sensor Virtual por Função de Transferência ． . . . . . . . . . . . . . . 100

5.3 Sensor Virtual por Extrapolação $\ldots \ldots$. . . . . . . . . . . . . . . . . . . 102

5.4 Sensores Virtuais por Janelamento das Fontes Secundárias . . . . . . . . 103

5.5 Comparação entre os Métodos de Sensores Virtuais ． . . . . . . . . . . 104

$5.5 .1200 \mathrm{~Hz} \ldots \ldots \ldots \ldots \ldots \ldots \ldots \ldots$

$5.5 .2400 \mathrm{~Hz} \ldots \ldots \ldots \ldots \ldots \ldots$

5.5 .3 Discussão $\ldots \ldots \ldots \ldots$. . . . . . . . . . . . . . . . . 109

5.6 Robustez do método JFS . . . . . . . . . . . . . . . . . . . . . . . . . 110

5.6 .1 Quanto à Variação de Fase da Fonte Primária . . . . . . . . . . . . 110

5.6 .2 Quanto ao Posicionamento da Fonte Secundária . . . . . . . . . . 113

5.6 .3 Quanto ao Posicionamento do Sensor de Erro . . . . . . . . . . . . 114

5.6 .4 Discussão $\ldots \ldots \ldots \ldots \ldots \ldots \ldots$

5.7 Outras Simulações com o método JFS . . . . . . . . . . . . . . . . . . 115

5.8 Conclusão . . . . . . . . . . . . . . . . . . . . . . . . . . . . . . . 119

\begin{tabular}{lll}
\hline & Medições em Campo & 120
\end{tabular}

6.1 Introdução $\ldots \ldots \ldots \ldots \ldots$

6.2 Análise do Ruído de Transformadores . . . . . . . . . . . . . . . . . . . . 122

6.3 Descrição dos Equipamentos $\ldots \ldots \ldots \ldots \ldots \ldots$

6.3 .1 Gerador de Referência . . . . . . . . . . . . . . . . . . 128

6.4 Testes em Laboratório . . . . . . . . . . . . . . . . . . . . . . . . . . . . 129

6.4 .1 Testes em Campo Aberto . . . . . . . . . . . . . . . . . . . . 131

6.5 Testes de Interferência Eletromagnética . . . . . . . . . . . . . . . . . . . . 132

6.6 Testes de Controle Acústico na Subestação . . . . . . . . . . . . . . . . . . 133

6.6 .1 Uma Fonte de Controle e Um Sensor de Erro . . . . . . . . . . . . . 135

6.6 .2 Uma Fonte de Controle e Dois Sensores de Erro . . . . . . . . . . . 135 
6.6 .3 Uma Fonte de Controle e Três Sensores de Erro . . . . . . . . . . . 136

6.6 .4 Duas Fontes de Controle e Três Sensores de Erro . . . . . . . . . . 137

6.6.5 Duas Fontes de Controle e Quatro Sensores de Erro . . . . . . . . . 138

6.6 .6 Três Fontes de Controle e Quatro Sensores de Erro . . . . . . . . . 139

6.6.7 Quatro Fontes de Controle e Quatro Sensores de Erro . . . . . . . . . 142

6.6 .8 Discussão . . . . . . . . . . . . . . . . . . . . . . . . . . . . . . . 143

6.7 Conclusões . . . . . . . . . . . . . . . . . . . . . . . . . . . . . . . . . . 143

\begin{tabular}{lll}
\hline 7 & Conclusões & 145
\end{tabular}

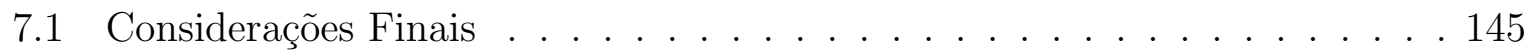

7.2 Contribuições $\ldots \ldots \ldots$. . . . . . . . . . . . . . . . . . 147

7.3 Publicações $\ldots \ldots \ldots \ldots$. . . . . . . . . . . . . . . . . . . . . . . . . . . . . .

7.4 Trabalhos Futuros . . . . . . . . . . . . . . . . . . . . . . . . . . . . . 148

\begin{tabular}{lr}
\hline Referências & 149
\end{tabular} 


\section{INTRODUÇÃO}

\subsection{Ruído de Transformadores de Potência}

O ruído é definido como um som desagradável e indesejável. Esta é uma definição bastante subjetiva, e a efetiva diferença entre som e ruído está "no ouvido de quem ouve". Como atualmente transformadores precisam ser instalados próximos a áreas habitadas, é inevitável concluir que sempre haverá reclamações quanto ao nível de ruído emitido por esses aparelhos. Algumas pessoas podem até se sentir mais calmas com o "zumbido" provocado pelos transformadores, mas geralmente isto não é o que ocorre, garantindo o status de ruído ao som emitido por eles.

O nível de ruído produzido por um transformador é geralmente definido pelo seu projeto. Ajustes ainda em fase de projeto podem ser feitos tentando minimizar sua emissão de ruído, mas isto acaba encarecendo o projeto, e a preocupação com o nível de ruído emitido acaba sendo negligenciada pela maioria dos fabricantes de transformadores de potência.

Segundo o tutorial sobre ruído de transformadores da fabricante "Federal Pacific Company" [1], o ruído emitido pelos transformadores é causado por um fenômeno chamado magnetostricção. A magnetostricção ocorre quando um corpo metálico é colocado em um campo magnético. Os dipolos magnéticos do metal se orientam buscando o alinhamento com o campo magnético externo, resultando em expansão (geralmente de apenas alguns micrometros) do material. Apesar de haver histerese, quando o campo magnético é anulado o material retorna à sua forma original. Como o transformador é excitado por corrente alternada, a cada meio ciclo de onda seu núcleo se expande e se comprime, fazendo com que o transformador vibre com o dobro da freqüência de rede com que é alimentado. Então, para um transformador em uso na rede elétrica brasileira, com freqüência de $60 \mathrm{~Hz}$, a vibração e, conseqüentemente, o ruído terá freqüência fundamental de $120 \mathrm{~Hz}$.

Por causa das perdas causadas pela corrente de Foucault, os núcleos são feitos de várias placas metálicas sobrepostas [1]. Como as placas não se expandem de maneira 


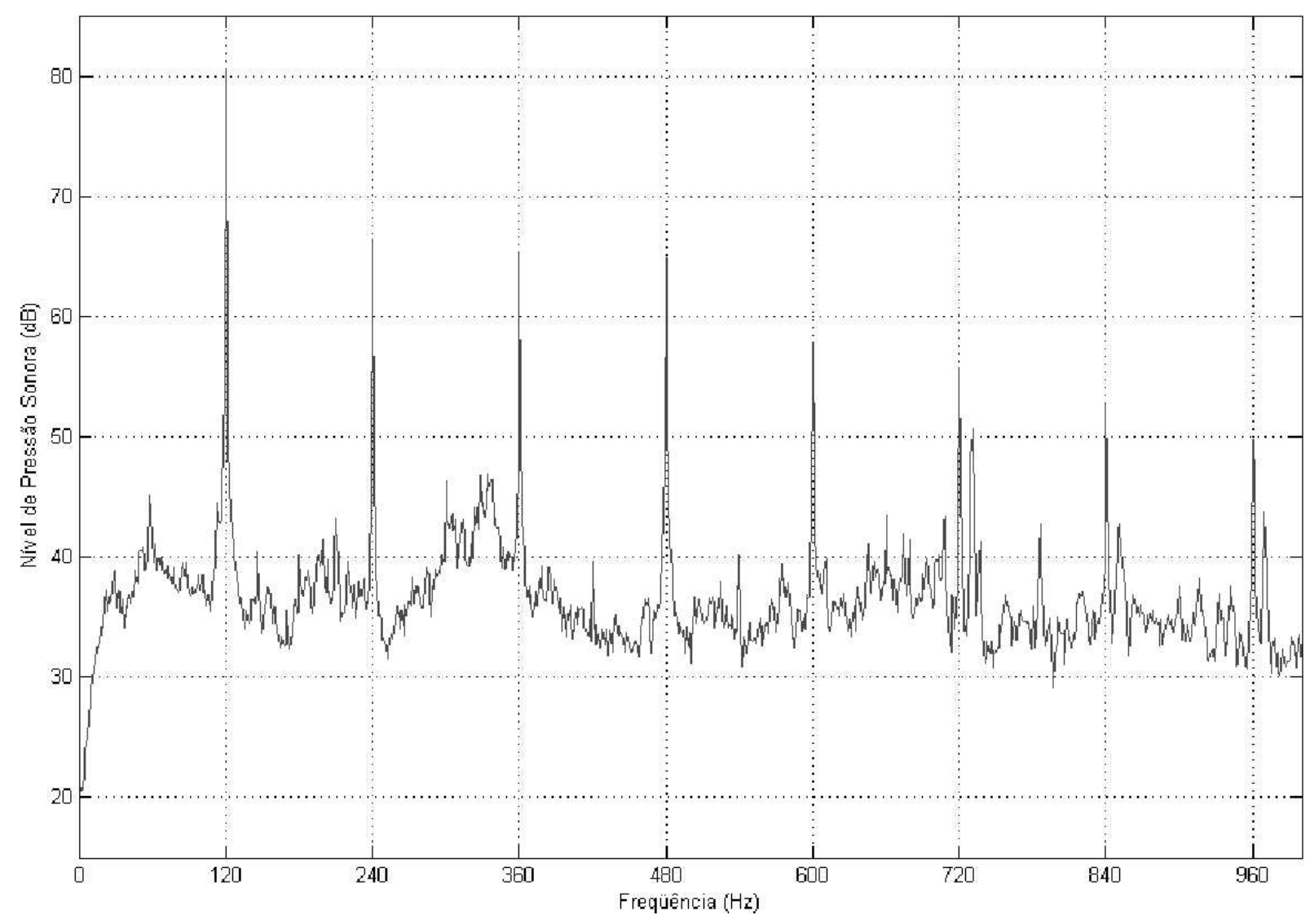

Figura 1: Espectro do ruído emitido pelo transformador de potência foco deste estudo, medido em um único ponto a $2 \mathrm{~m}$ da parede do mesmo. Este espectro foi obtido no período noturno, com o transformador operando com carga normal. Apenas as primeiras harmônicas são mostradas.

uniforme sob influência do campo magnético, verifica-se que o núcleo vibra de maneira caótica no interior do transformador. Com isso, o ruído produzido pelo transformador não será um tom puro na freqüência fundamental. Em qualquer medição in situ verificase que o ruído emitido por transformadores é composto das freqüências múltiplas pares (harmônicas pares) da freqüência da rede elétrica, como pode ser visto na figura 1. Notase também que a energia está concentrada principalmente nas primeiras harmônicas do ruído, principalmente de 120 a 480Hz. Esta informação é importante, pois garante a aplicabilidade da técnica de controle ativo de ruído (do inglês: active noise control, ANC).

Sabe-se que quando uma corrente elétrica atravessa um condutor imerso em um campo magnético, uma força mecânica atua sobre esse condutor. Logo, essas forças atuam sobre os condutores das bobinas do transformador, que estão imersas no campo magnético que vaza do núcleo ferromagnético quando ele é excitado. Como a excitação é por corrente alternada, essas forças acabam gerando vibração e ruído (chamado ruído de carga), mas agora de tom puro, somente no dobro da freqüência da excitação [1]. Em geral, o nível 
sonoro do ruído de carga é suplantado pelo do ruído do núcleo ferromagnético, podendo, portanto, ser ignorado. A diferença entre o ruído com o transformador sem carga e em carga máxima geralmente não é maior do que $2 \mathrm{~dB}$, de acordo com Vér et al. [2].

Sabe-se então que o núcleo e as bobinas do transformador irão produzir zumbido e vibração quando magnetizados. O núcleo geralmente se encontra dentro de um tanque, podendo o espaço restante entre o núcleo e as paredes do tanque ser preenchido (1) com líquido, geralmente óleo; (2) com vapor ou gás, como nitrogênio ou fluorcarbono e (3) com ar. Esses fluidos são usados para controlar a temperatura do núcleo. Em um fluxo contínuo, eles absorvem o calor do núcleo e fluem para radiadores no exterior do tanque, onde liberam o calor no ambiente. O fluxo do fluido e a bomba hidráulica que força esse fluxo produzem ruído, mas geralmente em um nível bem inferior ao nível de ruído provocado pela vibração do núcleo.

O transformador foco deste projeto é do tipo preenchido com líquido (óleo). Como o óleo é um fluido incompressível, ele transmite eficientemente a vibração e o ruído do núcleo para as paredes do tanque. Gases em geral também são bons condutores acústicos. De fato, exceto se o núcleo for imerso em vácuo, haverá transmissão sonora para o exterior.

O núcleo do transformador é fixado ao tanque por juntas rígidas, soldadas na sua base. A superfície inferior do tanque é então a superfície que apresenta maior vibração e, conseqüentemente, maior emissão de ruído. A não ser que a base do transformador esteja muito próxima ao solo, ela atuará como uma fonte de ruído irradiando em todas as direções, já que o ruído é de baixa freqüência.

Atualmente, os métodos mais comumente utilizados para o controle do ruído em subestações transformadoras de distribuição (STD) são métodos passivos. Uma possibilidade é a inserção de uma barreira acústica entre a fonte sonora primária (o transformador) e os receptores (a comunidade que habita o seu redor). A atenuação obtida neste caso depende da relação entre o comprimento de onda, a distância entre a fonte e o receptor e a dimensão física e o posicionamento da barreira, sendo a atenuação em baixas freqüências de no máximo 12dB quando as edificações vizinhas são casas térreas ou assobradadas. Assim, no caso de prédios de apartamentos próximos a uma STD, a sombra acústica gerada pela barreira será insuficiente para atenuar o ruído percebido nos andares superiores.

Outra possibilidade para a atenuação do ruído de transformadores comumente utilizada é o enclausuramento, que consiste em construir uma estrutura que aprisione toda a energia do ruído em seu interior. A atenuação causada pelas paredes dessa estrutura será diretamente proporcional à freqüência e à razão massa por área da parede. Logo, 
para se conseguir boa atenuação nas baixas freqüências, é necessário que as paredes sejam bastante pesadas, tornando a construção destas estruturas de enclausuramento bastante caras. Além disso, essas estruturas interferem com os cabos e buchas isoladoras dos transformadores, dificultam as atividades de manutenção do transformador, dificultam a ventilação do transformador e uma vez construídas, são bastante difíceis de serem removidas.

Uma alternativa para os métodos passivos são os métodos ativos, ou ANC. O método ativo, em contraste com os métodos passivos, apresenta melhor desempenho para ruídos em baixa freqüência, não atrapalha o fluxo de ar ao redor do transformador, pode ser alterado ou movido facilmente e apresenta desempenho superior para o controle de ruídos tonais, como é o caso do ruído de transformadores.

\subsection{Controle Ativo de Ruído}

O ANC consiste de um sistema eletroacústico usado para cancelar o campo primário (indesejado) com base no princípio da superposição; especificamente, um ruído de mesma amplitude e fase oposta ao ruído primário - o "anti-ruído" - é reproduzido por fontes secundárias de forma que ao ser combinado com o ruído gerado pela fonte primária resulta no cancelamento de ambos os ruídos.

A figura 2(a) mostra o diagrama de blocos de um sistema ANC com controle direto. Neste tipo de configuração, um sinal de referência $x(t)$ é extraído da fonte primária de ruído - esse sinal de referência deve ser bem correlacionado ao ruído que se deseja cancelar. Um microfone de erro amostra o sinal de erro $e(t)$ composto pela superposição do ruído primário e do "anti-ruído". Tanto o sinal de referência como o sinal de erro são fornecidos a um controlador, que filtra $x(t)$ gerando o sinal de controle $y(t)$. A filtragem realizada pelo controlador deve ser tal que quando $y(t)$ é reproduzido pela fonte de controle, a potência de $e(t)$ amostrada no microfone de erro seja a mínima possível. O controlador deve ser adaptativo, para manter a potência de $e(t)$ a mínima possível, mesmo com variações no sistema.

O sistema pode ser representado sob a ótica de sistemas lineares como é mostrado na figura 2(b). Aqui $W(z)$ é a função de transferência do controlador, $S(z)$ é a função de transferência entre a entrada da fonte secundária e a saída do sensor de erro, chamada de caminho secundário, e $P(z)$ é a função de transferência entre o sinal de referência e a saída do sensor de erro, chamada de caminho primário. 


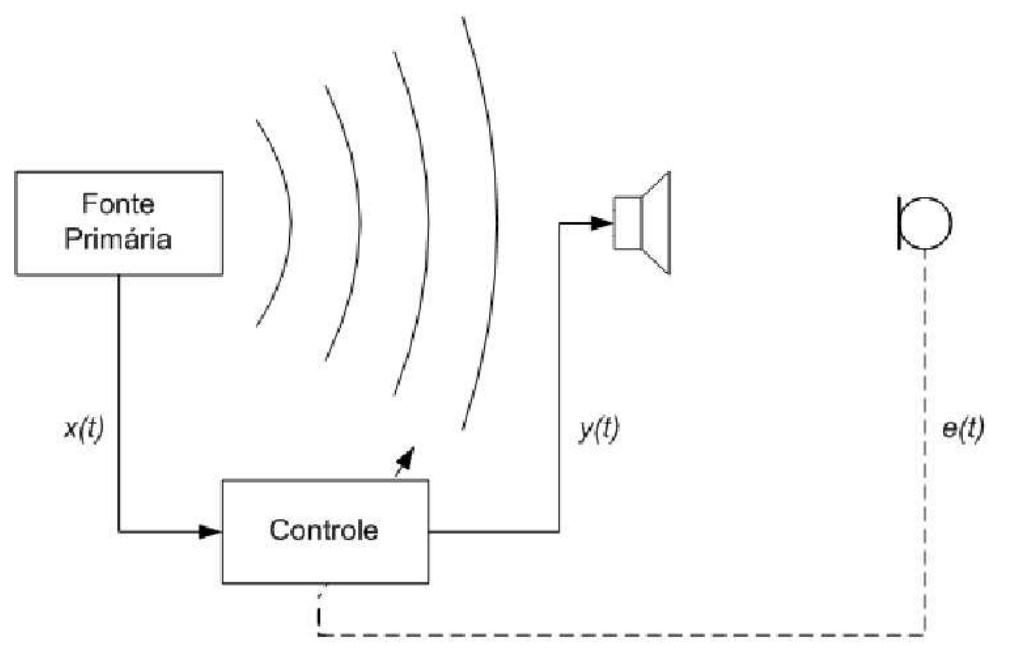

(a)

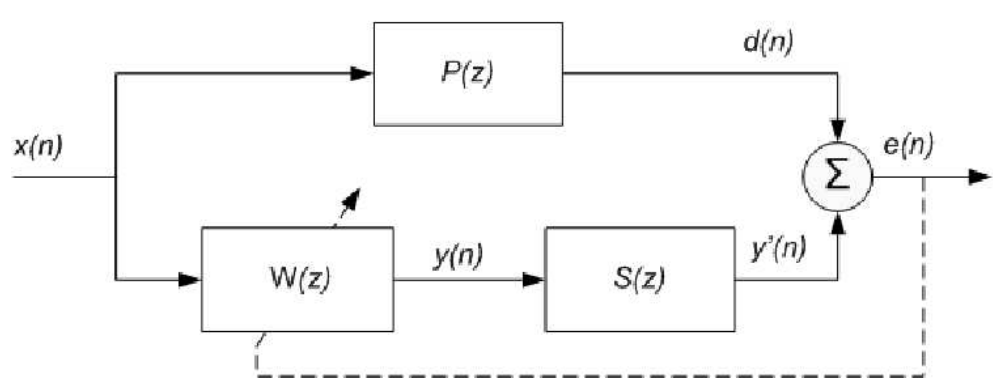

(b)

Figura 2: (a) Diagrama de bloco de um sistema ANC com controle direto. (b) Configuração eletricamente equivalente. Baseado na referência [3].

Pode-se então dizer que um sistema ANC é composto de duas partes: 1) o sistema de controle e 2) o sistema físico. O sistema de controle é representado no diagrama de blocos da figura 2(b) pelo bloco $W(z)$, enquanto o sistema físico, constituído pela fonte de controle, o caminho secundário e o sensor de erro, é representado pelo bloco $S(z)$. A quantidade e o posicionamento dos transdutores eletroacústicos é de suma importância no desempenho global de um sistema de controle ativo de ruído.

\subsection{Controle Ativo de Ruído de Transformadores}

As idéias básicas do controle ativo de ruído já são antigas, sendo a primeira patente do tipo atribuída a Lueg em 1933 [4], precedendo em vinte anos a primeira demonstração em laboratório de um sistema de controle ativo de ruído, feita por Olson e May [5]. Conover publicou o primeiro trabalho sobre controle de ruído de transformadores de grande porte que se tem notícia em 1956 ([6], apud [3]). Nesse artigo Conover discute as principais características para a aplicação do controle de ruído na redução do ruído de transformadores 


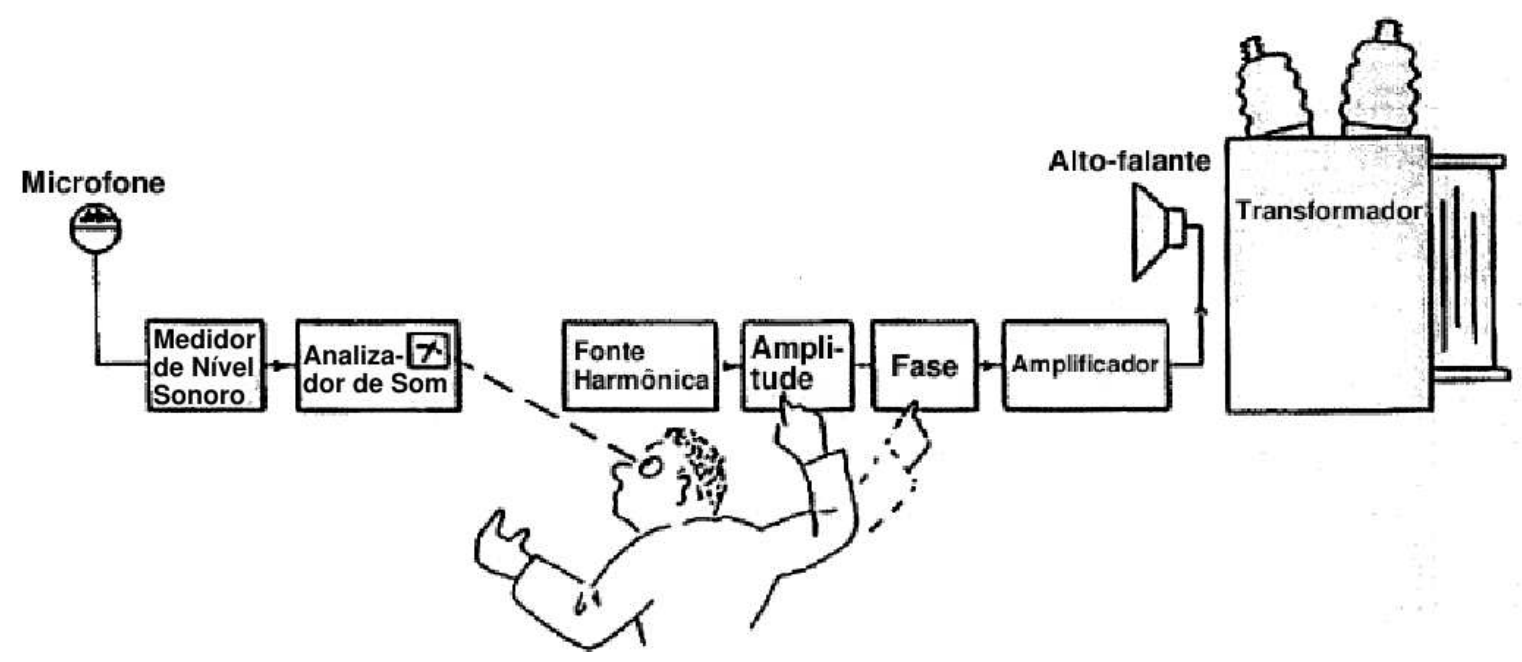

Figura 3: Sistema de controle ativo de ruído de transformadores com adaptação manual proposto por W. Conover em 1956. Baseado na referência [3].

de potência, sendo elas o fato de o ruído ser composto principalmente pelas harmônicas pares da freqüência de rede e o fato de ser possível extrair um sinal de referência da rede elétrica, sinal este altamente correlacionado com o ruído emitido pelo transformador. O sistema de controle usado por Conover é apresentado na figura 3 . Nele, a fonte harmônica é realizada pela retificação de onda completa e filtragem de um sinal extraído da rede. Conover desejava cancelar a pressão gerada pelo transformador em uma dada direção. Para isso ele realizava um controle manual da fase e amplitude do sinal de controle para compensar perturbações como vento e gradiente de temperatura. Conover discute ainda a necessidade de um sistema automático de controle e também a possibilidade do uso de mais de um alto-falante e um microfone de erro.

As pesquisas sobre controle ativo de ruído de transformadores não avançaram muito até a década de 1970, provavelmente por causa da inexistência de uma tecnologia adequada para realização do controle automático. O próximo passo dado na área foi a utilização de técnicas de processamento digital de sinais para a realização do controle automático, proposta por Kido [7, 8]. Nesses artigos, Kido descreve um sistema de controle adaptativo, apresentando resultados de testes de campo, em que conseguiu atenuar a pressão em uma superfície limitada. Ele também comenta sobre problemas de estabilidade do sistema de controle utilizado no experimento.

Em 1978 Ross publicou um artigo sobre um experimento de cancelamento ativo de ruído, realizado ainda usando um controlador analógico [9]. Nesse experimento ele desejava atenuar o campo sonoro gerado por dois transformadores de potência dentro de um 
escritório usando uma única fonte de controle posicionada próxima aos transformadores. Ross obteve atenuações de até $20 \mathrm{~dB}$ na freqüência fundamental do ruído em diversos pontos dentro do escritório, mas ele verificou que para as harmônicas superiores era possível controlar o ruído apenas em regiões localizadas do cômodo. Ele conclui seu trabalho propondo o uso de um maior número de fontes de controle.

Hesselmann publicou também em 1978 um artigo sobre o controle ativo de um transformador de pequeno porte por duas fontes de controle [10]. O transformador usado por ele apresentava emissão praticamente omnidirecional na freqüência fundamental do ruído. Hesselmann observou atenuações de mais de $30 \mathrm{~dB}$ numa grande área ao redor do transformador, mas comentou que se as dimensões do transformador forem grandes em comparação com o comprimento de onda emitido, então reduções globais do nível de ruído não devem ser esperadas. Ele também verificou que os níveis de pressão no campo próximo do transformador são maiores com o sistema de controle de ruído do que sem ele, enquanto que em campo distante o nível de pressão é reduzido quando o sistema de controle de ruído está ligado.

O artigo publicado por Berge, Petersen e Sørsdal em 1988 apresenta uma análise estatística das variações do nível de atenuação em função de variações nas condições do ambiente, transmissão do ruído do transformador e parâmetros de adaptação [11]. Para os testes foi usada apenas uma fonte de controle para realizar o cancelamento em apenas um microfone de erro, usando um sistema adaptativo de controle. Berge, Petersen e Sørsdal não conseguiram encontrar padrões consistentes em seus resultados, o que os levou a concluir que variações de clima ou horário de medição causavam grande variação nos resultados obtidos.

Angevine publicou diversos artigos sobre cancelamento de ruído de transformadores durante as décadas de 1980 e 1990. O melhor resultado apresentado por ele foi uma atenuação de até $30 \mathrm{~dB}$ em um azimute de $30^{\circ}$ na freqüência de $120 \mathrm{~Hz}$ [12, 13]. Este resultado foi obtido usando oito fontes de controle e com os microfones de erro posicionados a $30 \mathrm{~m}$ do transformador e os microfones de monitoramento posicionados a $60 \mathrm{~m}$ do transformador, ou seja, com todos os microfones já em campo distante円

Até meados da década de 1990 pouca atenção havia sido dada para o posicionamento dos transdutores eletroacústicos dos sistemas de controle de ruído de transformadores. Martin e Roure propuseram um método baseado na técnica da expansão de harmônicas esféricas (EHE) e de algoritmos genéticos (GA) para posicionar os transdutores ao redor

\footnotetext{
${ }^{1}$ Angevine não forneceu detalhes sobre o sistema de controle nas publicações a que se teve acesso.
} 
de um transformador, buscando atenuação global em volta do transformador [14, 15]. Eles apresentaram os resultados de um experimento realizado com um transformador de tamanho médio. Primeiramente, usaram o método EHE para definir 28 posições para as fontes de controle, baseado na pressão sonora medida em 210 pontos ao redor do transformador. Posteriormente usaram GA para escolher oito posições entre as 28 possíveis para as fontes de controle e para escolher dez posições entre as 210 posições de microfone. Esta configuração apresentou redução global de cerca de $15 \mathrm{~dB}$ na freqüência fundamental do ruído. Eles então escolheram dez novas posições para os microfones restringindo as possíveis posições fornecidas ao GA às 60 posições mais próximas do chão. Com essa configuração eles verificaram atenuações de 10 a $25 \mathrm{~dB}$ em todo o contorno do transformador para a freqüência fundamental do ruído, mas somente na região de até $1,5 \mathrm{~m}$ do chão, tendo as regiões mais elevadas nenhuma garantia de atenuação. Na segunda harmônica do ruído, a atenuação foi bastante irregular, apresentado reduções de até 30dB em algumas direções, mas ganhos de até 10dB em outras. Os resultados apresentados por Martin e Roure comprovam a importância do desenvolvimento de um método objetivo para o posicionamento dos transdutores de um sistema de controle ativo de ruído.

As pesquisas mais recentes de que se tem notícia sobre controle ativo de ruído de transformadores foram realizadas por Hansen et al. Eles publicaram artigos sobre algoritmos de estimação do caminho secundário [16, 17] e sobre estratégias de medição do sinal de erro em campo próximo [18]. Em sua tese de doutorado, Li trata dos problemas envolvidos com o sistema físico do controle ativo de ruído, discorrendo sobre o tipo de fonte de controle adequado e sobre as estratégias para a medição dos sinais de erro em campo próximo [19]. Li também utilizou algoritmos genéticos para definir o posicionamento ótimo dos transdutores para o controle ativo do ruído de um transformador de potência de grande porte. Em simulações observou-se uma atenuação global de $23 \mathrm{~dB}$, em média, usando para isso 80 fontes de controle e 96 sensores de erro. O autor constatou que a atenuação global aumenta conforme aumenta-se o número de fontes de controle e sensores de erro do sistema, mas o próprio autor admite que os sistemas de controle atualmente em uso não suportariam controlar o sistema com 80 fontes de controle e 96 sensores de erro por ele definido, e técnicas de controle distribuído talvez sejam necessárias.

\subsection{Motivação e Objetivos}

Esta dissertação foi motivada por um projeto de pesquisa e desenvolvimento financiado pela empresa AES Eletropaulo para o estudo de soluções não convencionais para a redução 
do nível de ruído emitido por um de seus transformadores de potência, instalado em uma subestação localizada em uma região predominantemente residencial da cidade de São Paulo. Este projeto teve duração de dois anos, mas o grupo de pesquisa para soluções acústicas foi criado um ano após o início do projeto.

A revisão bibliográfica feita sobre o tema "controle ativo de ruído de transformadores" mostrou que estudos constantes vêm sendo realizados nas últimas três décadas, mas que até o momento ainda não existem soluções comercialmente viáveis para a redução do ruído em subestações transformadoras, evidenciando a complexidade do tema.

O objetivo definido para esta dissertação é identificar as principais dificuldades para a aplicação bem sucedida do controle ativo de ruído no caso de transformadores de potência e estudar alternativas para a solução das dificuldades identificadas. Este trabalho deve fornecer informações valiosas para estudos futuros, em que serão procuradas soluções para as principais dificuldades identificadas.

\subsection{Discussão Inicial}

Levando-se em conta a pesquisa bibliográfica conduzida e as medições realizadas constata-se que a quantidade e o posicionamento dos transdutores eletroacústico têm influência crítica no desempenho de um sistema de controle ativo de ruído. Verifica-se que o nível de atenuação global aumenta conforme aumenta o número de transdutores do sistema (como pode ser visto na seção 4.3). O limite para a quantidade de transdutores é então a capacidade de processamento do sistema de controle.

Após definida a quantidade de transdutores a ser usada, o seu posicionamento ótimo em geral não é óbvio. Esse arranjo ótimo depende do campo sonoro gerado pela fonte primária, da região onde se deseja cancelamento e da faixa de freqüência em que o cancelamento é desejado, dentre muitos outros fatores. Portanto, faz-se necessário algum método para a otimização do posicionamento dos transdutores. Alguns métodos de otimização foram encontrados na pesquisa bibliográfica realizada, sendo os principais baseados na técnica de regressão múltipla, na ortogonalização de Gram-Schmidt, na expansão de harmônicas esféricas e em algoritmos genéticos. Algoritmos genéticos foi a técnica que apareceu com mais freqüência na literatura pesquisada e foi também a técnica utilizada neste trabalho (conforme descrito na seção 4.5), principalmente por causa da sua facilidade de implantação (o pacote Matlab possui uma ferramenta de otimização por algoritmos genéticos). Nesta dissertação apresenta-se uma nova maneira de realizar a oti- 
mização do posicionamento dos transdutores eletroacústicos do sistema ANC, que busca otimizar simultaneamente o posicionamento das fontes de controle e dos sensores de erro, e mostra-se mais eficiente que o método convencional, que otimiza o posicionamento das fontes de controle separadamente do posicionamento dos sensores de erro.

Para que qualquer um dos métodos de otimização mencionados acima forneça um bom resultado, é necessário que se conheça com boa precisão o campo sonoro gerado pela fonte de ruído, para se estimar via simulação acústica a melhor atenuação possível para cada arranjo de transdutores (como descrito na seção 4.2. É a partir desse dado que os diversos métodos procuram uma configuração de fontes secundárias que consiga reproduzir o campo sonoro primário. A maneira mais precisa para determinar o campo sonoro primário seria realizar uma medição em campo, o que é bastante difícil de fazer no caso de um transformador de potência por causa de suas dimensões físicas e também por restrições de segurança. Uma alternativa seria estimar o campo sonoro primário pelo método dos elementos de fronteira, que é um método que requer bastante tempo de processamento, ou alguma simplificação desse método, como o método de Usry (descrito na seção 4.4).

O desempenho do sistema ANC é bastante sensível ao posicionamento dos sensores de erro. Por um lado, quanto mais próximos os sensores estiverem da região onde se deseja atenuação, maior será a atenuação observada; mas por outro lado, quando mais distantes os sensores de erro estiverem das fontes de controle, mais difícil será estimar o caminho acústico entre os transdutores, e conseqüentemente mais instável será o sistema de controle. Uma alternativa para se conseguir uma atenuação elevada na região desejada com os sensores de erro distantes dessa região é o uso da técnica dos sensores virtuais, como explicado no capítulo 5. Nesta dissertação um novo método para a realização do sensor virtual é proposto e comparado com os demais métodos existentes na literatura. Verificase que o novo método proposto apresenta desempenho melhor que o dos demais métodos para a situação simulada na seção 5.5. Esta técnica se mostrou robusta em simulações de pequeno porte, mas sensível ao posicionamento dos transdutores para simulações mais realistas.

Os algoritmos convencionais de estimação do caminho secundário utilizam ruído branco aditivo para estimar a função de transferência entre os transdutores. Quando os transdutores estão posicionados muito distantes entre si, torna-se necessário o uso de um filtro muito longo para se poder estimar a função de transferência em toda a faixa de freqüência na qual o controlador atua, o que acaba fazendo com que a adaptação tenha de ser muito lenta. Outro membro do grupo de pesquisa buscou alternativas para o algoritmo de es- 
timação do caminho secundário. Ele propôs um novo método de estimação do caminho secundário, baseado em excitação tonal como ruído aditivo, que além de trabalhar com um filtro mais curto, também reduz o incômodo provocado pelo ruído aditivo usado pelos estimadores de caminho secundários usuais

Parte dos resultados apresentados nesta dissertação foram apresentados no " 5 o Congresso de Engenharia de Áudio", realizado de 21 a 23 de maio de 2007 na cidade de São Paulo [20].

\subsection{Organização}

Esta dissertação está organizada visando primeiramente a fornecer o conhecimento básico necessário para a compreensão do controle ativo de ruído, e posteriormente mostrar os resultados atingidos no decorrer da pesquisa de mestrado. O capítulo 2 apresenta as propriedades fundamentais de acústica necessárias para a compreensão do restante da dissertação. O capítulo 3 apresenta as propriedades fundamentais da filtragem adaptativa e os principais sistemas de controle utilizado em sistemas de controle ativo de ruído de transformadores. O capítulo 4 trata do sistema físico de um sistema de controle de ruído, descrevendo a técnica de simulação acústica, a modelagem da fonte primária e o algoritmo de otimização utilizados nesta dissertação. O capítulo 5 trata de sensores virtuais. Os dois métodos presentes na literatura e o novo método proposto nesta dissertação são descritos e uma comparação entre os três métodos e um estudo do método proposto são apresentados. O capítulo 6 apresenta medições realizadas em um transformador de potência, além de resultados de testes em campo com o sistema de controle ativo de ruído desenvolvido. Por fim, as conclusões e propostas de trabalhos futuros são apresentadas no capítulo 7. 


\section{FUNDAMENTOS DE ACÚSTICA}

\subsection{Introdução}

Os sistemas de controle de ruído podem ter atuação mecânica ou acústica. Quando a atuação é mecânica, a fonte de controle tenta atenuar mecanicamente a vibração da superfície vibrante da fonte de ruído, e conseqüentemente o nível sonoro gerado por essa fonte. Já quando a atuação é acústica, a fonte de controle tenta gerar um campo sonoro que reproduza o campo sonoro gerado pela fonte primária, mas em oposição de fase, gerando assim o fenômeno da interferência destrutiva de ondas. Esta dissertação se atém ao controle ativo de campos sonoros de amplitude moderada, para os quais os princípios da acústica linear ainda são válidos, em meio homogêneo e em freqüências dentro do espectro audível, com especial atenção às baixas freqüências (graves).

Os conceitos acústicos fundamentais para a compreensão de sistemas de controle ativo de ruído são expostos neste capítulo, sendo ele baseado principalmente no livro de Nelson e Elliott [21] sobre controle ativo de som. Inicia-se o capítulo descrevendo o fenômeno do deslocamento de onda acústica no meio fluido na seção 2.2 , formalizando-se matematicamente o conceito de propagação de onda com a derivação da equação de onda tridimensional e da equação de fontes pontuais esféricas. As grandezas intensidade e potência sonora são definidas na seção 2.3. Usando fontes pontuais esféricas como fonte de ruído e também como fonte de controle, analisam-se na seção 2.4 as condições sob as quais é possível obter supressão da potência sonora irradiada no campo livre, sendo descrita a supressão obtida com tanto uma quanto com várias fontes de controle. Por fim, na seção 2.5, é feito um breve resumo sobre a teoria da distribuição contínua de fontes, que deve ser levada em consideração quando as dimensões da fonte primária são da mesma ordem de grandeza ou maiores que o comprimento de onda por ela emitida. 


\subsection{Ondas Sonoras}

A propagação de uma variação de pressão ocorrida em um meio fluido é conhecida por onda acústica. Geralmente, é o movimento de uma superfície sólida, como um pistão, que é responsável pela radiação sonora. Na prática, estas superfícies costumam vibrar rapidamente para frente e para trás, ao redor de um ponto de equilíbrio, o conhecido movimento harmônico. Em especial, o movimento senoidal é de grande interesse para a acústica, já que qualquer movimento harmônico pode ser decomposto numa somatória de movimentos senoidais de diferentes freqüências. Para que uma superfície em movimento senoidal percorra um ciclo completo, é necessário um período de tempo $T$. A distância percorrida pela onda, que se propaga à velocidade do som $c$ neste intervalo de tempo, é $c T$ ou um comprimento de onda $\lambda$. Como a freqüência desse movimento é $f=1 / T$, então a freqüência e o comprimento de onda se relacionam por $c=f \lambda$. As freqüências audíveis pelo ouvido $(20 \mathrm{~Hz}$ a $20 \mathrm{kHz})$ têm comprimento de onda na faixa de $17 \mathrm{~m}$ a $17 \mathrm{~mm}$ no ar, o meio fluido de maior interesse na acústica. É o comprimento de onda relativamente grande das baixas freqüências que torna o controle ativo de ruído factível.

Uma formalização matemática da variação de pressão quando a onda sonora se propaga em campo aberto pode ser feita relacionando pressão, densidade do meio e velocidade das partículas do meio, com base nas leis de conservação de momento e de conservação de massa. Para o espaço aberto, qualquer posição é definida pelo vetor $\mathbf{x}=\left(x_{1} \overrightarrow{\boldsymbol{i}}, x_{2} \overrightarrow{\boldsymbol{j}}, x_{3} \overrightarrow{\boldsymbol{k}}\right)$. A velocidade das partículas 1 em um dado instante e em uma dada região de um fluido que preenche o espaço aberto é definida pelo vetor $\boldsymbol{v}=\left(v_{1} \overrightarrow{\boldsymbol{i}}, v_{2} \overrightarrow{\boldsymbol{j}}, v_{3} \overrightarrow{\boldsymbol{k}}\right)$. A pressão total em um dado ponto e em um dado instante é $p_{t}=p_{0}+p$, sendo $p_{0}$ a pressão atmosférica e $p$ a flutuação de pressão causada pela passagem de uma onda acústica $\left(p \ll p_{0}\right)$. A densidade do fluido em um dado instante e em um dado ponto é $\rho_{t}=\rho_{0}+\rho$, sendo $\rho_{0}$ a densidade nominal do fluido e $\rho$ o aumento da densidade do fluido causado pela compressão relativa à passagem da onda acústica $\left(\rho \ll \rho_{0}\right)$.

De acordo com a lei da Conservação de Momento, a força aplicada em cada direção de um elemento de volume do meio é equivalente à massa multiplicada pela aceleração desse elemento de volume. Na direção $\vec{i}$, como é mostrado na figura 4 , a lei da Conservação de Momento pode ser reescrita como

$$
\left[p_{t}(\mathbf{x})-p_{t}\left(\mathbf{x}+\Delta x_{1}\right)\right] S=\rho_{t} S d x \frac{d v_{1}}{d t} .
$$

\footnotetext{
${ }^{1}$ Esta é uma distinção muito importante a ser feita: $c$ é a velocidade com que a compressão acústica se propaga e $v$ é a velocidade com que as partículas do fluido se movimentam quando a região de compressão (onda acústica) passa por elas. Em geral, $v \ll c$.
} 


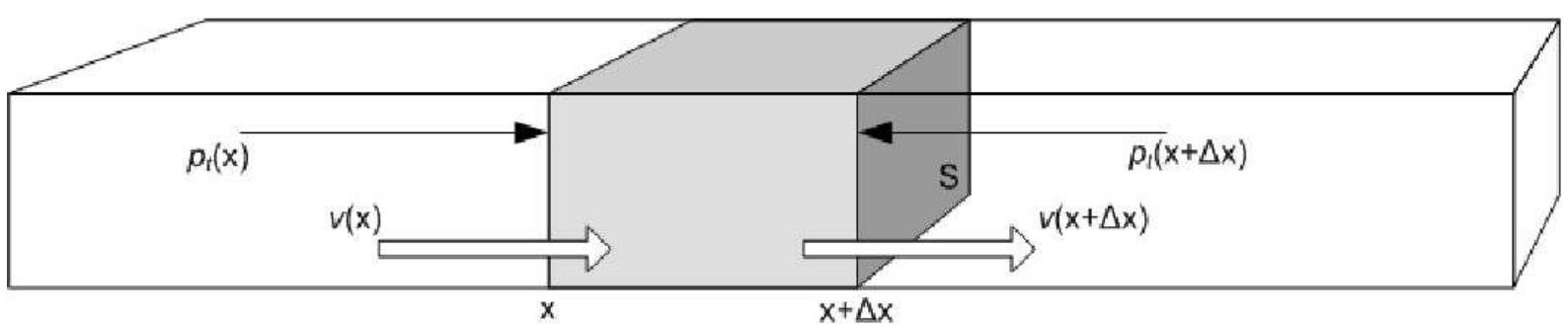

Figura 4: Volume de controle por onde passa uma onda acústica.

Como para cada direção a velocidade $v$ é função da posição $x$, a aceleração do fluido é dada por $\frac{d v}{d t}=\frac{\partial v}{\partial t}+\frac{\partial v}{\partial x} \frac{\partial x}{\partial t}=\frac{\partial v}{\partial t}+v \frac{\partial v}{\partial x}$. A partir deste fato, podemos reescrever a equação (2.1) da seguinte maneira.

$$
-\frac{\partial p_{t}}{\partial x_{1}}=\rho_{t}\left(\frac{\partial v_{1}}{\partial t}+v_{1} \frac{\partial v_{1}}{\partial x_{1}}\right)
$$

Como a velocidade da partícula $v_{1}$ é em geral muito pequena, o termo $v_{1} \frac{\partial v_{1}}{\partial x_{1}}$ será muito menor que o termo $\frac{\partial v_{1}}{\partial t}$, permitindo a aproximação $\frac{\partial v_{1}}{\partial t}+v_{1} \frac{\partial v_{1}}{\partial x_{1}} \approx \frac{\partial v_{1}}{\partial t}$. Como a pressão atmosférica $p_{0}$ praticamente não varia com a posição, $\frac{\partial p_{t}}{\partial x_{1}}=\frac{\partial\left(p_{0}+p\right)}{\partial x_{1}} \approx \frac{\partial p}{\partial x_{1}}$. Por último, como $\rho \ll \rho_{0}, \rho_{t} \approx \rho_{0}$. Estas simplificações resultam na equação conhecida como "Equação Linearizada da Conservação de Momento"

$$
-\frac{\partial p}{\partial x_{1}}=\rho_{0} \frac{\partial v_{1}}{\partial t}
$$

A mesma argumentação é válida para as demais direções do espaço, resultando nas equações

$$
\begin{aligned}
-\frac{\partial p}{\partial x_{2}} & =\rho_{0} \frac{\partial v_{2}}{\partial t} \\
-\frac{\partial p}{\partial x_{3}} & =\rho_{0} \frac{\partial v_{3}}{\partial t}
\end{aligned}
$$

As equações linearizadas da conservação de momento para cada direção do espaço podem ser escritas conjuntamente como uma equação vetorial

$$
-\nabla p=\rho_{0} \frac{\partial \boldsymbol{v}}{\partial t}
$$

onde $\nabla=\left(\frac{\partial}{\partial x_{1}} \overrightarrow{\boldsymbol{i}}+\frac{\partial}{\partial x_{2}} \overrightarrow{\boldsymbol{j}}+\frac{\partial}{\partial x_{3}} \overrightarrow{\boldsymbol{k}}\right)$ é o operador gradiente. Esta é a "Equação Linearizada da Conservação de Momento Tridimensional".

O fluido dentro de um volume também deve respeitar a lei da Conservação de Massa, a qual afirma que o fluxo de massa entrando no elemento de volume deve ser proporcional 
ao aumento de massa do volume. O aumento de massa no volume de controle será de $S \Delta x \frac{\partial \rho_{t}}{\partial t}$, enquanto que o fluxo de massa na direção $\overrightarrow{\boldsymbol{i}}$, por exemplo, será de

$$
S\left[\left(\rho_{t} v_{1}\right)_{\mathbf{x}+\Delta x_{1}}-\left(\rho_{t} v_{1}\right)_{\mathbf{x}}\right]=-S \Delta\left(\rho_{t} v_{1}\right) .
$$

A lei da Conservação de Massa resulta então na igualdade

$$
\frac{\partial\left(\rho_{t} v_{1}\right)}{\partial x_{1}}+\frac{\partial\left(\rho_{t} v_{2}\right)}{\partial x_{2}}+\frac{\partial\left(\rho_{t} v_{3}\right)}{\partial x_{3}}=-\frac{\partial \rho_{t}}{\partial t} .
$$

Algumas suposições podem ser feitas para simplificar a equação (2.8). Primeiro verifica-se que, para qualquer direção, $\rho_{t} v=\left(\rho_{0}+\rho\right) v$ e considerando que $\rho v$ é o produto de duas variáveis pequenas, este produto pode ser ignorado, $\log 0 \rho_{t} v \approx \rho_{0} v$. Como $\rho_{0}$ não varia com a posição, temos novamente que para qualquer direção, $\frac{\partial\left(\rho_{t} v\right)}{\partial x} \approx \rho_{0} \frac{\partial v}{\partial x}$. Por outro lado, como $\rho_{0}$ não varia com o tempo, temos que $\frac{\partial \rho_{t}}{\partial t}=\frac{\partial\left(\rho_{0}+\rho\right)}{\partial t} \approx \frac{\partial \rho}{\partial t}$. Estas simplificações resultam na equação conhecida como "Equação Linearizada da Conservação de Massa Tridimensional"

$$
\rho_{0}\left(\frac{\partial v_{1}}{\partial x_{1}}+\frac{\partial v_{2}}{\partial x_{2}}+\frac{\partial v_{3}}{\partial z_{3}}\right)=-\frac{\partial \rho}{\partial t}
$$

que pode ser escrita resumidamente usando-se a notação vetorial

$$
\rho_{0} \nabla \cdot \boldsymbol{v}=-\frac{\partial \rho}{\partial t}
$$

Calcula-se o divergente da equação 2.6 e a derivada temporal da equação (2.10). A combinação das duas equações resultantes fornece a equação de onda

$$
\nabla^{2} p-\frac{\partial^{2} \rho}{\partial t^{2}}=0
$$

A última suposição a ser feita é que as compressões acústicas no fluido em questão são adiabáticas, isto é, a variação de pressão ocorre tão rapidamente que não é possível a troca de calor entre elementos de volume vizinhos. Em compressões adiabáticas, $p=c^{2} \rho$. Logo a equação (2.11) pode ser reescrita da forma

$$
\nabla^{2} p-\frac{1}{c^{2}} \frac{\partial^{2} p}{\partial t^{2}}=0
$$

que é conhecida como a "Equação de Onda Tridimensional Linearizada". Esta equação descreve como as flutuações da pressão sonora devem se comportar com respeito ao espaço e ao tempo. Vale ressaltar que o processo de linearização usado foi de suma importância para se obter esta equação, sendo que para flutuações acústicas de grande amplitude esta equação não é mais válida. 


\subsubsection{Solução da Equação de Onda}

A solução mais simples para a equação de onda é encontrada quando se assume que a propagação da onda é esfericamente simétrica. Sob esta suposição, o operador $\nabla^{2} p$ pode ser escrito como

$$
\nabla^{2} p=\frac{1}{r^{2}} \frac{\partial}{\partial r}\left(r^{2} \frac{\partial p}{\partial r}\right)
$$

e a equação de onda fica

$$
\frac{\partial^{2} p}{\partial r^{2}}+\frac{2}{r} \frac{\partial p}{\partial r}-\frac{1}{c^{2}} \frac{\partial^{2} p}{\partial t^{2}}=0
$$

que tem como solução

$$
p(r, t)=\frac{f(t-r / c)}{r}
$$

$\mathrm{Ou}$

$$
p(r, t)=\frac{f(r-t c)}{r} .
$$

O termo $f$ representa ondas se distanciando da origem da coordenada esférica. Ambas as soluções poderiam conter um termo $g$ que representasse ondas se aproximando da origem, mas como esse tipo de ondas esféricas não é geralmente encontrado na prática, decidiu-se ignorá-lo neste texto.

Uma forma particular de representar a solução da equação de onda é dada pela representação complexa

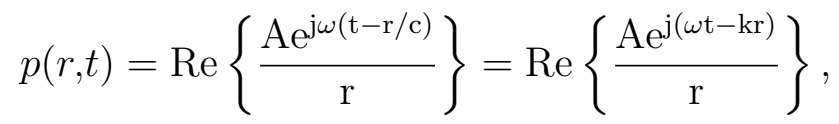

onde $\omega=2 \pi / T$ é a freqüência angular da flutuação harmônica de período $T, k=\omega / c$ é denominado o número de onda da flutuação harmônica e $A$ é um valor complexo que define a amplitude e a fase da onda.

É comum, quando se lida com uma única freqüência, definir a pressão complexa $p(r)$, dependente apenas do espaço, como:

$$
p(r)=\frac{A e^{-j k r}}{r} .
$$

\subsubsection{Fontes Pontuais de Radiação Esférica}

Ondas sonoras são sempre geradas em uma região definida do espaço (a fonte sonora) e se espalham por uma região sempre cada vez maior deste espaço. Se a fonte sonora tiver forma arbitrária, mas a sua maior dimensão $a$ for tal que $k a \ll 1$, a fonte se comportará 
como se fosse uma esfera de raio $r_{a} \rightarrow 0$, ou seja, uma fonte pontual. Neste caso, o som será irradiado igualmente em todas as direções (esfericamente simétrico) e a pressão sonora em um dado ponto do espaço irá depender apenas da distância $r$ entre este ponto e a fonte pontual.

Para gerar a onda acústica, uma fonte pontual deverá deslocar o meio ao seu redor. Define-se a velocidade de volume $Q(t)$ como a quantidade de volume do meio deslocado pela fonte pontual a cada instante. A velocidade de volume, também comumente chamada de intensidade da fonte, é equivalente à vazão do meio causada pela fonte pontual, tendo como unidade $\left[\mathrm{m}^{3} / \mathrm{s}\right]$.

É comum descrever a pressão sonora gerada por uma fonte pontual em função de sua velocidade de volume. Substituindo-se a equação (2.16) na equação linearizada da Conservação de Momento (2.6) tem-se

$$
\rho_{0} \frac{\partial \boldsymbol{v}}{\partial t}=-\frac{\partial p}{\partial r}=\left(\frac{1}{r^{2}} f(r-c t)-\frac{1}{r} f^{\prime}(r-c t)\right) .
$$

Assumindo que $f$ e $f^{\prime}$ sejam limitadas e fazendo $r \rightarrow 0$ (neste caso $\frac{1}{r^{2}} \gg \frac{1}{r}$ ), a equação 2.19 pode ser reescrita como

$$
\rho_{0} \frac{\partial \boldsymbol{v}}{\partial t}=\frac{1}{r^{2}} f(-c t)
$$

Multiplicando ambos os lados da equação pela área de uma esfera, tem-se

$$
\rho_{0} 4 \pi r^{2} \frac{\partial \boldsymbol{v}}{\partial t} \equiv \rho_{0} \dot{Q}(t)=4 \pi f(-c t)
$$

que equivale a

$$
f(z)=\frac{\rho_{0}}{4 \pi} \dot{Q}\left(-\frac{z}{c}\right) .
$$

Substituindo-se a equação 2.22 na equação 2.16), obtém-se

$$
p(r, t)=\frac{\rho_{0}}{4 \pi r} \dot{Q}\left(t-\frac{r}{c}\right) .
$$

Se a excitação dessa fonte for harmônica, ou seja, $Q(t)=q e^{j(\omega t)}$, a equação 2.23) pode ser reescrita da seguinte maneira:

$$
p(r, t)=\frac{j \omega \rho_{0}}{4 \pi r} q e^{j(\omega t-k r)} .
$$

É comum, quando se lida com uma única freqüência, suprimir o termo $e^{j \omega t}$, o que resulta na equação

$$
p(r)=\frac{j \omega \rho_{0}}{4 \pi r} q e^{-j k r} .
$$


Apenas por facilidade de notação, define-se a impedância de transferência acústica $Z$, tal que

$$
p(\mathbf{x})=q(\mathbf{y}) Z(\mathbf{x} \mid \mathbf{y}),
$$

em que $Z(\mathbf{x} \mid \mathbf{y})$ relaciona a pressão na posição $\mathbf{x}$ com a intensidade da fonte em $\mathbf{y}$. No caso de uma fonte pontual em campo livre, a impedância de transferência acústica assume o valor de

$$
Z(\mathbf{x} \mid \mathbf{y})=\frac{j \omega \rho_{0}}{4 \pi} \frac{e^{-j k r}}{r}
$$

onde $r=\|\mathbf{x}-\mathbf{y}\|_{2}$.

\subsection{Potência Sonora}

Quando uma onda se propaga de uma região para outra de um fluido, há uma transmissão de energia entre estas regiões. A taxa média com que a energia se propaga é a intensidade acústica, grandeza vetorial definida por

$$
\boldsymbol{I}=\frac{1}{T} \int_{-T / 2}^{T / 2} p(t) \boldsymbol{v}(t) d t,
$$

para propagações harmônicas, sendo $T$ o período da onda. Para uma propagação esfericamente simétrica, é possível expressar a intensidade acústica no sentido radial como

$$
I_{r}=\frac{1}{2} \operatorname{Re}\left\{\mathrm{p}^{*}(\mathrm{r}) \mathrm{v}_{\mathrm{r}}(\mathrm{r})\right\}=\frac{|\mathrm{p}(\mathrm{r})|^{2}}{2 \rho_{0} \mathrm{c}},
$$

onde $v_{r}(r)$ é a velocidade das partículas na direção radial. Nota-se que como a pressão acústica irradiada esfericamente apresenta atenuação proporcional a $1 / r$, a intensidade de uma onda esférica irá apresentar atenuação proporcional a $1 / r^{2}$.

A intensidade representa a taxa média de fluxo de energia que atravessa uma unidade de área na direção normal a essa superfície. Pode-se, a partir da intensidade acústica, definir a potência total emitida por uma fonte, integrando-se a intensidade que atravessa uma superfície que engloba a fonte sonora. Define-se a potência sonora por

$$
W=\int_{S} \boldsymbol{I} \cdot \boldsymbol{n} d S
$$

onde $\boldsymbol{n}$ é o vetor normal unitário que aponta para o exterior da superfície fechada $S$. Novamente no caso de uma propagação esfericamente simétrica, a potência sonora pode 
ser escrita por

$$
W=I_{r} S=\frac{|p|^{2}}{2 \rho_{0} c}\left(4 \pi r^{2}\right)=\frac{|A|^{2}}{2 \rho_{0} c r^{2}}\left(4 \pi r^{2}\right)=\frac{2 \pi|A|^{2}}{\rho_{0} c} .
$$

A potência sonora neste caso é, como esperado, um valor constante (independe da superfície de integração), o que significa que há uma taxa constante de potência sonora sendo irradiada pela fonte de radiação esférica no meio ao seu redor.

No caso de uma fonte pontual, substituindo-se a equação 2.25 na equação (2.31), verifica-se que

$$
W=\frac{4 \pi r^{2}}{2 \rho_{0} c}|p|^{2}=\frac{4 \pi r^{2}}{2 \rho_{0} c}\left|\frac{\omega \rho_{0} q}{4 \pi r}\right|^{2}=\frac{\omega^{2} \rho_{0}}{8 \pi c}|q|^{2} .
$$

De acordo com Nelson e Elliott [21, capítulo 9.11], a potência sonora irradiada por uma fonte pontual também pode ser calculada por

$$
W=\frac{1}{2} \operatorname{Re}\left\{p^{*} q\right\}=\frac{\omega^{2} \rho_{0}}{8 \pi c}|q|^{2},
$$

onde $p$ é a pressão sonora na posição da fonte pontual (vide explicação da fórmula (2.41)).

\subsection{Supressão de Potência Sonora Irradiada em Cam- po Livre}

Pode-se dizer que o caso mais simples de controle acústico ocorre ao atenuar-se o campo sonoro irradiado por uma fonte pontual (fonte primária) usando-se outra fonte pontual (fonte secundária). Este exemplo permite uma primeira abordagem ao tema do controle acústico. Uma configuração com duas fontes pontuais, mostrada na figura 5 , pode ser analisada como um dipolo, sendo a pressão sonora $p$ causada por esse dipolo em um ponto distando $r$ do seu centro dada por

$$
p(r)=\frac{j \omega \rho_{0}}{4 \pi}\left[q_{p} \frac{e^{-j k r_{p}}}{r_{p}}+q_{s} \frac{e^{-j k r_{s}}}{r_{s}}\right],
$$

em que $q_{p}$ é velocidade de volume da fonte primária e da mesma forma $q_{s}$ é velocidade de volume da fonte secundária.

Quando o ponto de observação se encontra em campo distante, algumas aproximações já bastante conhecidas podem ser feitas. Considerando que a fonte primária e a fonte secundária distem $d \ll r$ entre si, tem-se que $r_{p} \approx r_{s} \approx r$. Como para a fase mesmo pequenas diferenças de distância são importantes, as seguintes aproximações devem ser usadas: $r_{p}=r+d / 2 \cos \theta$ e $r_{s}=r-d / 2 \cos \theta$. A aplicação destas simplificações em (2.34) 


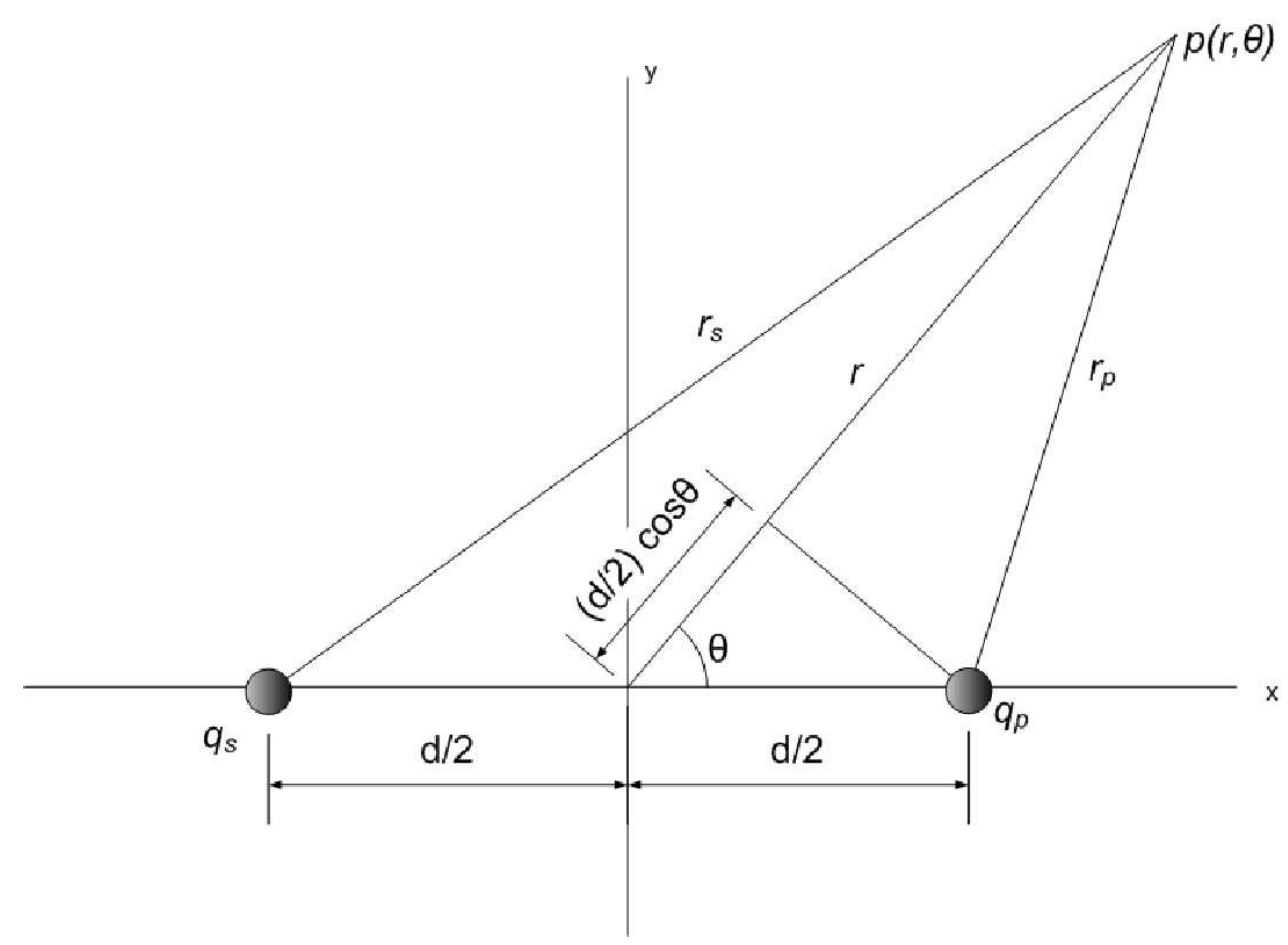

Figura 5: Dipolo constituído por uma fonte primária e uma fonte secundária separadas pela distância $d$.

resulta em

$$
p(r, \theta)=\frac{j \omega \rho_{0}}{4 \pi r}\left[q_{p} e^{-j k(r+d / 2 \cos \theta)}+q_{s} e^{-j k(r-d / 2 \cos \theta)}\right],
$$

que depende apenas da distância $r$ entre o dipolo e o ponto de observação e do ângulo $\theta$ formado entre o ponto de observação e o centro do dipolo.

Para se anular a pressão em um ponto em campo distante definido por $\left(r, \theta_{0}\right)$, é necessário que a velocidade de volume da fonte secundária seja

$$
q_{s}=-q_{p} e^{-j k d \cos \theta_{0}}
$$

O comportamento do campo sonoro nas demais direções, dado que em $\left(r, \theta_{0}\right)$ a pressão é nula, é obtido substituindo-se o novo valor de $q_{s}$ em 2.35 , que resulta em

$$
p(r, \theta)=p_{p}(r, \theta)\left[1-e^{-j k d\left(\cos \theta_{0}-\cos \theta\right)}\right],
$$

em que $p_{p}(r, \theta)$ é o campo sonoro gerado em $(r, \theta)$ pela fonte primária na ausência da fonte secundária. Usando a identidade $\left|1-e^{-j x}\right|^{2}=2(1-\cos x)$, pode-se comparar a energia sonora produzida apenas pela fonte primária com a energia sonora produzida pela fonte 

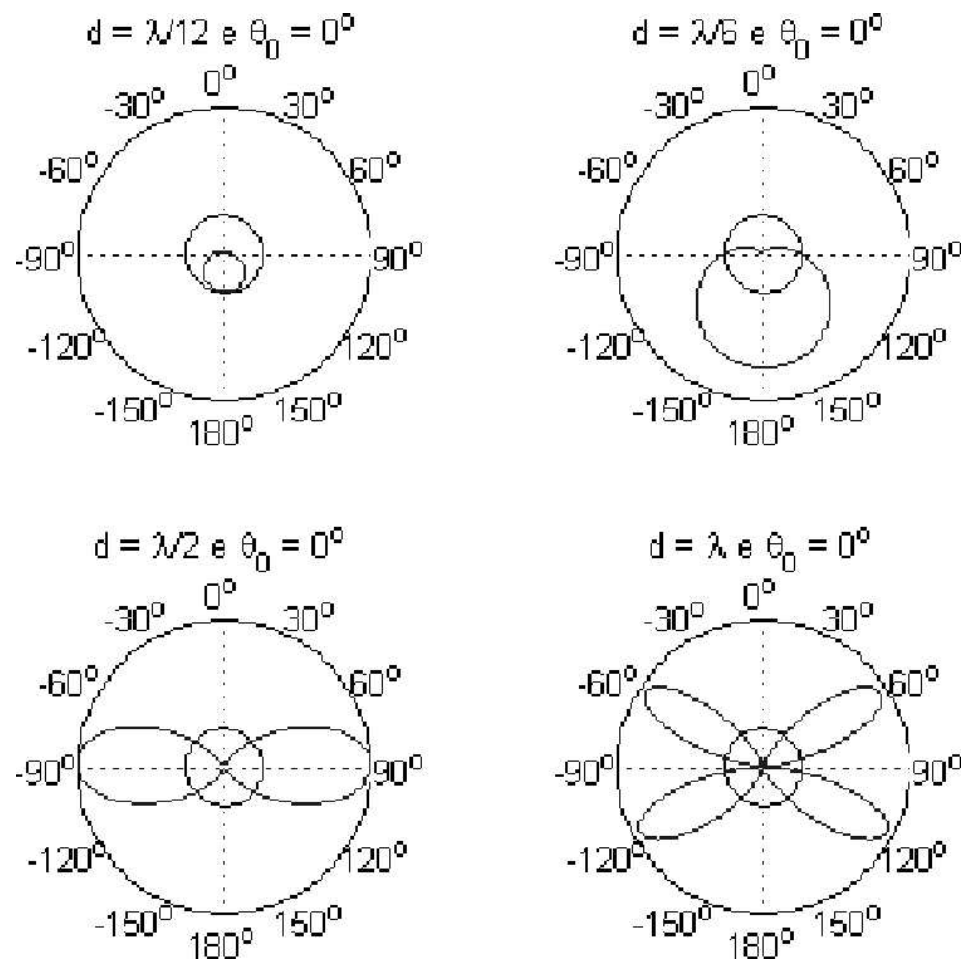

Figura 6: Gráfico polar da pressão sonora em campo distante da pressão resultante, quando a fonte secundária é ajustada para anular a pressão em $\theta_{0}=0^{\circ}$. $\mathrm{O}$ círculo mostra a pressão sonora em campo distante gerada apenas pela fonte primária.

primária e fonte secundária pela equação

$$
\frac{|p(r, \theta)|^{2}}{\left|p_{p}(r, \theta)\right|^{2}}=2\left\{1-\cos \left[k d\left(\cos \theta_{0}-\cos \theta\right)\right]\right\} \text {. }
$$

As figuras 6 e 7 mostram a influência da direção de cancelamento e a distância entre as fontes pontuais na atenuação sonora global. Verifica-se que quanto menor a distância entre as fontes, melhor será a atenuação obtida.

De acordo com a equação (2.38), a potência sonora pode até quadruplicar de valor para algumas direções diferentes da direção escolhida para anular-se a pressão, o que pode ser verificado nas figuras 6 e 7. Para que se verifique atenuação em qualquer direção $\theta$ independentemente da escolha de $\theta_{0}$, é necessário que o segundo membro da equação (2.38) seja sempre menor que um, ou que

$$
\left[1-\cos k d\left(\cos \theta_{0}-\cos \theta\right)\right]<1 / 2
$$

Essa desigualdade só será válida para $k d<\pi / 6$ ou $d<\lambda / 12$. Assim, para que haja atenuação global do campo sonoro gerado por uma fonte pontual, controlada por outra fonte pontual, estas duas fontes devem distar no máximo $d=\lambda / 12$ uma da outra. Este exemplo 

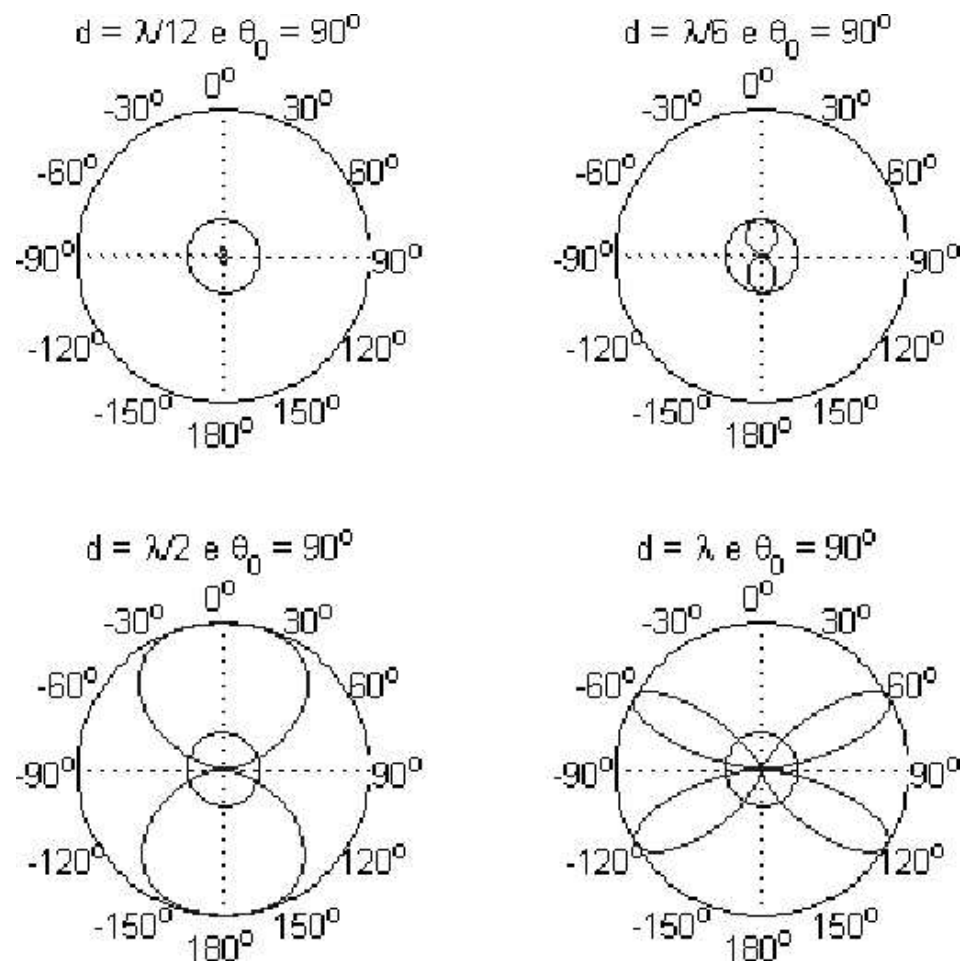

Figura 7: Gráfico polar da pressão sonora em campo distante da pressão resultante, quando a fonte secundária é ajustada para anular a pressão em $\theta_{0}=90^{\circ}$. $\mathrm{O}$ círculo mostra a pressão sonora em campo distante gerada apenas pela fonte primária.

mostra a necessidade de a fonte secundária estar sempre próxima da fonte primária, além de demonstrar por que esta técnica só é viável para baixas freqüências.

Uma alternativa a forçar que a pressão sonora seja nula em algum ponto do campo distante é minimizar a potência sonora total emitida pelo conjunto de fontes pontuais. Para a configuração de dipolo que vem sendo tratada até o momento, a potência total irradiada pelo dipolo pode ser escrita como

$$
W=\frac{1}{2} \operatorname{Re}\left\{\left(\mathrm{p}_{\mathrm{pp}}+\mathrm{p}_{\mathrm{ps}}\right)^{*} \mathrm{q}_{\mathrm{p}}\right\}+\frac{1}{2} \operatorname{Re}\left\{\left(\mathrm{p}_{\mathrm{ps}}+\mathrm{p}_{\mathrm{ss}}\right)^{*} \mathrm{q}_{\mathrm{s}}\right\},
$$

onde $p_{p p}$ é a pressão na posição da fonte primária por causa da fonte primária e $p_{s p}$ é a pressão na posição da fonte secundária por causa da fonte primária; e similarmente $p_{p s}$ é a pressão na posição da fonte primária e $p_{s s}$ na posição da fonte secundária por causa da fonte secundária. Usando-se a equação (2.24), a equação 2.40 pode ser reescrita, simplificando-se cada um de seus termos como a seguir:

$$
\frac{1}{2} \operatorname{Re}\left\{\mathrm{p}^{*} \mathrm{q}\right\}=\frac{1}{2} \operatorname{Re}\left\{\left(\frac{\mathrm{j} \omega \rho_{0}}{4 \pi \mathrm{r}} \mathrm{qe} \mathrm{e}^{-\mathrm{jkr}}\right) \mathrm{q}^{*}\right\}=\frac{\omega^{2} \rho_{0}}{8 \pi \mathrm{c}}|\mathrm{q}|^{2} \operatorname{Re}\left\{\frac{\mathrm{je}}{\mathrm{kr}}\right\} .
$$



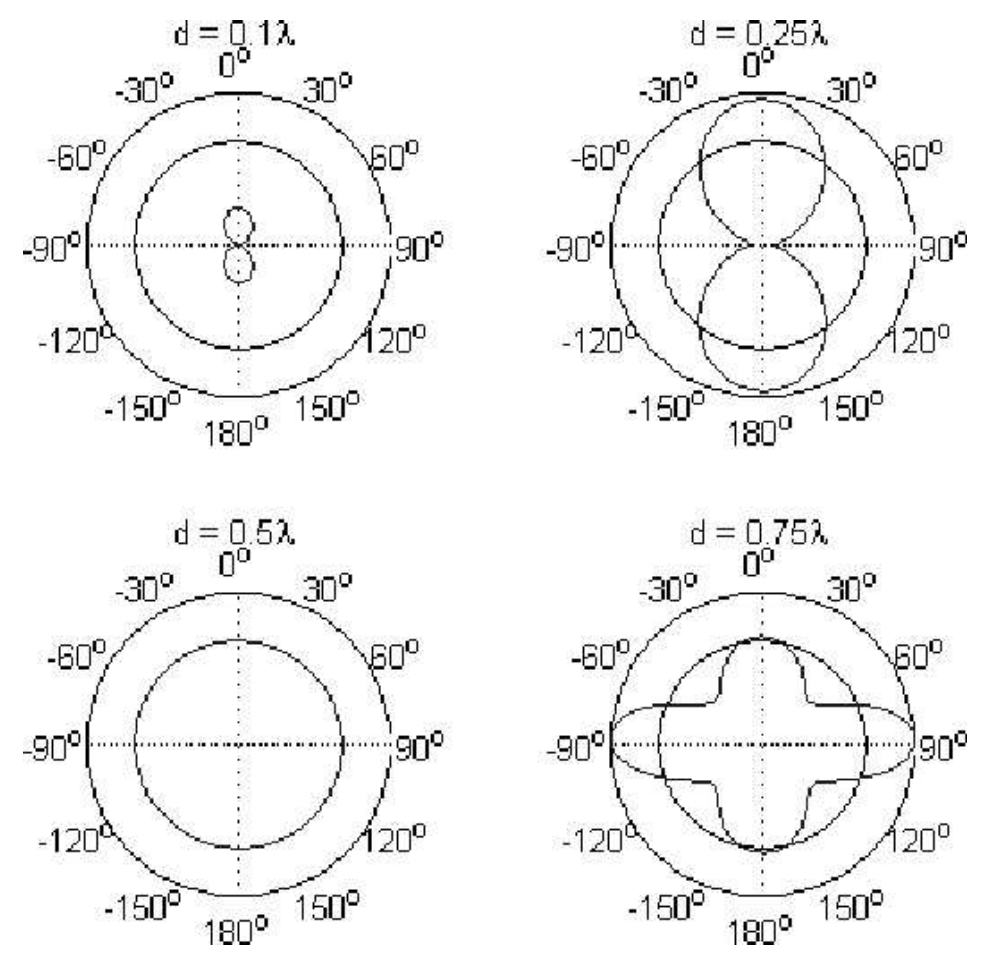

Figura 8: Gráfico polar da pressão sonora em campo distante da pressão resultante, quando a fonte secundária é ajustada para reduzir a potência sonora emitida. O círculo mostra a pressão sonora em campo distante gerada apenas pela fonte primária.

O termo complexo dentro das chaves pode ser reescrito como

$$
\frac{j e^{-j k r}}{k r}=\frac{\sin k r}{k r}+j \frac{\cos k r}{k r}
$$

lembrando que $\lim _{k r \rightarrow 0} \frac{\sin k r}{k r}=1$. Usando as abreviações $Z_{0}=\frac{\omega^{2} \rho_{0}}{4 \pi c}$ e $\operatorname{sinc} \nu=\frac{\sin \nu}{\nu}$, a equação 2.40 pode então ser reescrita como

$$
W=\frac{1}{2} Z_{0}\left\{\left|q_{p}\right|^{2}+q_{s}^{*} q_{p} \operatorname{sinc} k d+q_{p}^{*} q_{s} \operatorname{sinc} k d+\left|q_{s}\right|^{2}\right\},
$$

que pode ter sua forma reduzida para

$$
W=A\left|q_{s}\right|^{2}+q_{s}^{*} b+b^{*} q_{s}+c
$$

onde $A=Z_{0} / 2, b=Z_{0} / 2 q_{p}$ sinc $k d$ e $c=Z_{0} / 2\left|q_{p}\right|^{2}$. Este último termo é claramente a potência emitida somente pela fonte primária, denominada $W_{p p}$. A forma da equação 2.44 é conhecida como forma quadrática e apresenta uma solução conhecida para o valor de $q_{s}$ que minimiza $W$. A mínima potência emitida por um dipolo será $W=c-b^{*} A^{-1} b$, quando a velocidade de volume ótima for $q_{s 0}=-A^{-1} b$. Substituindo estes valores, obtém- 
se

$$
\begin{gathered}
q_{s 0}=-q_{p} \operatorname{sinc} k d, \\
W_{0}=W_{p p}\left[1-\operatorname{sinc}^{2} k d\right] .
\end{gathered}
$$

A figura 8 mostra a influência da distância entre as fontes pontuais na atenuação sonora global.

Em contraste com o valor ótimo de $q_{s}$ em 2.36, o valor ótimo de $q_{s 0}$ em 2.45) será sempre um valor real, sendo que a fonte secundária está sempre $180^{\circ}$ fora de fase em relação à fonte primária, e somente sua amplitude diminui conforme $d$ aumenta. De (2.46) verifica-se que a atenuação tende assintoticamente para zero conforme $d$ aumenta, sendo que uma redução considerável na potência emitida pelo dipolo só será obtida quando a distância entre as fontes obedecer $d<\lambda / 2$.

\subsubsection{Múltiplos Sensores de Erro}

A seção anterior mostrou que existe uma atenuação global ótima da potência sonora emitida por uma fonte pontual controlada por outra fonte pontual. Para monitorar a potência sonora emitida, seria necessário monitorar a pressão sonora em todos os pontos de uma superfície no campo distante que englobasse as duas fontes pontuais, já que a potência sonora é calculada por meio de uma integral de superfície de acordo com a equação 2.30 .

Na prática, fica-se restrito a um número finito de "sensores de erro" para se estimar a potência sonora total emitida. Pode-se então definir a posição de $L$ "sensores de erro" para os quais se deseja reduzir a pressão sonora, mantendo a configuração de uma fonte primária e uma fonte secundária. Especifica-se o vetor $\boldsymbol{p}$ com a pressão sonora em cada uma das $L$ posições. Considera-se que todos os sensores de erro distem $r$ do centro do dipolo, que todos os sensores e as duas fontes estejam em um mesmo plano e que cada sensor forme um ângulo $\theta_{i}$ com o centro do dipolo, de tal forma que

$$
\boldsymbol{p}^{T}=\left[\begin{array}{llll}
p\left(r, \theta_{1}\right) & p\left(r, \theta_{2}\right) & \cdots & p\left(r, \theta_{L}\right)
\end{array}\right] .
$$

A pressão sonora total nestes pontos é a superposição das pressões causadas pelos campos primário e secundário,

$$
\boldsymbol{p}=\boldsymbol{z}_{p} q_{p}+\boldsymbol{z}_{s} q_{s}
$$


onde $\boldsymbol{z}_{p}$ e $\boldsymbol{z}_{s}$ são vetores de impedância de transferência acústica, definidos por

$$
\begin{aligned}
\boldsymbol{z}_{p}^{T} & =\frac{j \omega \rho_{0}}{4 \pi}\left[\begin{array}{llll}
\frac{e^{-j k r_{p 1}}}{r_{p 1}} & \frac{e^{-j k r_{p 2}}}{r_{p 2}} & \ldots & \frac{e^{-j k r_{p L}}}{r_{p L}}
\end{array}\right], \\
\boldsymbol{z}_{s}^{T} & =\frac{j \omega \rho_{0}}{4 \pi}\left[\begin{array}{llll}
\frac{e^{-j k r_{s 1}}}{r_{s 1}} & \frac{e^{-j k r_{s 2}}}{r_{s 2}} & \cdots & \frac{e^{-j k r_{s L}}}{r_{s L}}
\end{array}\right],
\end{aligned}
$$

sendo $r_{p i}$ a distância entre a fonte primária e os $L$ sensores de erro e $r_{s j}$ a distância entre a fonte secundária e os mesmos $L$ sensores de erro.

Define-se como função de mérito $J=\sum_{i}\left|p_{i}\right|^{2}=\boldsymbol{p}^{H} \boldsymbol{p}$, ou seja, a função a ser minimizada é a somatória da pressão ao quadrado em todos os sensores de erro. Encontra-se o mínimo desta função fazendo-se $\frac{\partial J}{\partial q_{s}^{*}}=0$. Verifica-se que a velocidade de volume da fonte secundária que minimiza a somatória da pressão acústica ao quadrado em todos os sensores de erro pode ser escrita como

$$
q_{s 0}=-\frac{\boldsymbol{z}_{s}^{H} \boldsymbol{z}_{p}}{\boldsymbol{z}_{s}^{H} \boldsymbol{z}_{s}} q_{p} \approx-\frac{q_{p}}{L} \sum_{i=1}^{L} e^{-j k d \cos \theta_{i}}
$$

usando as aproximações usuais para campo distante.

Nelson e Elliott mostram que resultados próximos do resultado ótimo calculado na seção anterior podem ser obtidos com relativamente poucos sensores de erro (quatro, por exemplo), mostrando que o uso de múltiplos sensores de erro é uma boa estratégia para redução do campo sonoro distante [21, capítulo 8.5].

\subsubsection{Múltiplas Fontes Secundárias}

Uma idéia comum é tentar reproduzir o campo distante produzido por uma fonte primária usando um conjunto compacto de fontes secundárias corretamente excitadas. Se isso for possível, pode-se excitar o conjunto de fontes secundárias com o sinal de excitação ótimo com sinal invertido, gerando então cancelamento do campo sonoro distante. Kempton investigou esta idéia, tentando cancelar o campo produzido por uma fonte primária pontual com um multipolo pontual $\left.\right|^{2}$ distante $d$ da fonte primária [22]. Ele avaliou o nível de atenuação em campo distante em função do número $M$ de fontes presentes no multipolo como sendo

$$
20 \log \left(\frac{M !}{(k d)^{M} \cos ^{M} \theta}\right),
$$

\footnotetext{
${ }^{2}$ Um multipolo pontual é um grupo de fontes pontuais dispostas ao redor do ponto y, sendo que a região ocupada por estas fontes pontuais é muito pequena em comparação ao comprimento de onda irradiado.
} 
onde $\theta$ é o ângulo formando pela linha que liga o ponto de observação à fonte primária e a linha que liga o multipolo pontual à fonte primária. Verifica-se que quanto maior o número de fontes no multipolo, maior sua capacidade de emular o campo distante de uma fonte primária. Seu trabalho também mostra que para distâncias pequenas entre a fonte primária e o grupo de fontes secundárias, uma boa reprodução do campo sonoro já é possível com poucos elementos gerando o campo secundário.

Conclui-se ser possível obter um cancelamento cada vez melhor em campo distante para uma fonte compacta usando-se distribuições de controle (fontes secundárias e microfones de erro) cada vez mais sofisticadas. O uso de um número maior de fontes secundárias implica a necessidade de um maior número de microfones de erro. Pode-se então tentar minimizar a soma das pressões ao quadrado nestes diversos sensores, controlando a velocidade de volume das diversas fontes secundárias.

Representa-se a pressão gerada pela fonte primária nos $L$ microfones de erro por

$$
\boldsymbol{p}_{p}^{T}=\left[\begin{array}{llll}
p_{p}\left(\mathbf{x}_{1}\right) & p_{p}\left(\mathbf{x}_{2}\right) & \cdots & p_{p}\left(\mathbf{x}_{L}\right)
\end{array}\right]
$$

e a pressão gerada pelas fontes secundárias nos mesmos L microfones de erro por

$$
\boldsymbol{p}_{s}^{T}=\left[\begin{array}{llll}
p_{s}\left(\mathbf{x}_{1}\right) & p_{s}\left(\mathbf{x}_{2}\right) & \cdots & p_{s}\left(\mathbf{x}_{L}\right)
\end{array}\right]
$$

Assumindo-se que $M$ fontes secundárias sejam usadas, define-se o vetor de velocidade de volume como

$$
\boldsymbol{q}_{s}^{T}=\left[\begin{array}{llll}
q_{s}\left(\mathbf{y}_{1}\right) & q_{s}\left(\mathbf{y}_{2}\right) & \cdots & q_{s}\left(\mathbf{y}_{M}\right)
\end{array}\right]
$$

Finalmente assume-se que as pressões produzidas pelas fontes secundárias sejam relacionadas às velocidades de volume das fontes por meio da matriz de impedância acústica $Z$, tal que

$$
\boldsymbol{p}_{s}=\boldsymbol{Z} \boldsymbol{q}_{s}
$$

onde a matriz $\boldsymbol{Z}$ é definida por

$$
\boldsymbol{Z}=\left[\begin{array}{cccc}
Z\left(\mathbf{x}_{1} \mid \mathbf{y}_{1}\right) & Z\left(\mathbf{x}_{1} \mid \mathbf{y}_{2}\right) & \cdots & Z\left(\mathbf{x}_{1} \mid \mathbf{y}_{M}\right) \\
Z\left(\mathbf{x}_{2} \mid \mathbf{y}_{1}\right) & Z\left(\mathbf{x}_{2} \mid \mathbf{y}_{2}\right) & & \vdots \\
\vdots & & \ddots & \\
Z\left(\mathbf{x}_{L} \mid \mathbf{y}_{1}\right) & \cdots & & Z\left(\mathbf{x}_{L} \mid \mathbf{y}_{M}\right)
\end{array}\right]
$$

sendo $Z(\mathbf{x} \mid \mathbf{y})=\frac{j \omega \rho_{0}}{4 \pi} \frac{e^{-j k r}}{r}$ e $r=\|\mathbf{x}-\mathbf{y}\|_{2}$, no caso de fontes e sensores pontuais.

Usando o princípio da superposição, pode-se escrever o vetor da pressão total nos $L$ 
sensores de erro como

$$
\boldsymbol{p}=\boldsymbol{p}_{p}+\boldsymbol{p}_{s}=\boldsymbol{p}_{p}+\boldsymbol{Z} \boldsymbol{q}_{s}
$$

Ao se minimizar o somatório da pressão ao quadrado de um número $L$ de sensores de erro maior do que o número $M$ de fontes secundárias, obtém-se uma atenuação local menor do que se $L=M$, mas em compensação consegue-se uma atenuação mais homogênea no campo sonoro. Assim como ocorreu na seção 2.4.1, define-se a função custo como

$$
J_{p}=\sum_{l=1}^{L}\left|p\left(\mathbf{x}_{l}\right)\right|^{2}=\boldsymbol{p}^{H} \boldsymbol{p} .
$$

Por ser uma função quadrática, esta função é minimizada pelo vetor de intensidade das fontes secundárias ótimo

$$
\boldsymbol{q}_{s 0}=\boldsymbol{Z}^{+} \boldsymbol{p}_{p}
$$

onde $\boldsymbol{Z}^{+}$é a pseudo-inversa de $\boldsymbol{Z}[23$, apêndice A]. No caso usual em que o número de microfones é maior do que o de fontes secundárias $(L \geq M)$, e em que o posto de $\boldsymbol{Z}$ é $M$, tem-se (compare com 2.51)

$$
\boldsymbol{Z}^{+}=\left(\boldsymbol{Z}^{H} \boldsymbol{Z}\right)^{-1} \boldsymbol{Z}^{H}
$$

Em resumo, uma das abordagens para o controle da radiação em campo distante é introduzir um número de fontes secundárias excitadas de forma a minimizar a pressão em um conjunto de sensores de erro. O posicionamento das fontes secundárias e dos sensores de erro influirá no desempenho do sistema, logo muito cuidado é necessário para planejar onde estes elementos devem ser posicionados. Em geral, é necessário realizar simulações previamente à montagem do sistema, procurando otimizar o posicionamento dos transdutores. Algumas simulações são discutidas no capítulo 4

\subsection{Distribuição Contínua de Fontes}

Até o momento nesta discussão sobre a atenuação sonora em campo livre, lidouse apenas com fontes pontuais como fontes primárias e fontes de controle. Mas se a fonte de ruído tiver dimensões comparáveis ao comprimento de onda de interesse, esta fonte não-compacta não pode mais ser aproximada por uma fonte pontual. Passa a ser necessário tratar esta fonte como se ela fosse uma distribuição de fontes contínuas, ou seja, a fonte não-compacta pode ser discretizada em diversos elementos de volume, cada um deles possuindo uma não-homogeneidade que pulsa introduzindo uma variação de volume $q_{\mathrm{vol}}(\mathbf{x}, t)$ no seu interior. A amplitude desta variação de volume pode variar de elemento 
para elemento, e quando estes elementos forem infinitesimalmente pequenos, esta variação deve ser contínua no espaço. Sob estas condições, Nelson e Elliott mostram que a equação de Conservação de Massa (2.10) deve ser modificada como a seguir:

$$
\frac{\partial \rho(\mathbf{x}, t)}{\partial t}+\rho_{0} \nabla \boldsymbol{v}(\mathbf{x}, t)=\rho_{0} q_{\mathrm{vol}}(\mathbf{x}, t)
$$

levando agora em conta a variação local de volume [21, capítulo 9].

Da mesma maneira, a equação da Conservação de Momento 2.1 também deve ser alterada como a seguir:

$$
\rho_{0} \frac{\partial \boldsymbol{v}(\mathbf{x}, t)}{\partial t}+\nabla p(\mathbf{x}, t)=f_{\mathrm{vol}}(\mathbf{x}, t)
$$

já que esta variação de volume interno irá aplicar uma força variável $f_{\text {vol }}(\mathbf{x}, t)$ nos elementos de volume.

Assumindo novamente compressões adiabáticas no fluido dentro dos elementos de volume, e calculando o divergente da equação da Conservação de Momento e a derivada temporal da equação de Conservação de Massa, deriva-se a equação de Onda Não-Homogênea

$$
\left(\nabla^{2}-\frac{1}{c^{2}} \frac{\partial^{2}}{\partial t^{2}}\right) p(\mathbf{x}, t)=\nabla \cdot f_{\mathrm{vol}}(\mathbf{x}, t)-\rho_{0} \frac{\partial q_{\mathrm{vol}}(\mathbf{x}, t)}{\partial t} .
$$

Os termos do lado direito podem ser interpretados como fontes sonoras. No caso de flutuação harmônicas de volume, pode-se escrever a equação de Helmholtz não-homogênea

$$
\left(\nabla^{2}+k^{2}\right) p(\mathbf{x})=\nabla \cdot f_{\mathrm{vol}}(\mathbf{x})-j \omega \rho_{0} q_{\mathrm{vol}}(\mathbf{x})
$$

\subsubsection{A Solução da Equação de Onda Não-Homogênea}

A solução para esta equação é obtida usando-se a função de Green $G(\mathbf{x} \mid \mathbf{y})$, que caracteriza a dependência espacial da pressão sonora $p$ num ponto $\mathbf{x}$ com uma fonte pontual harmônica em $\mathbf{y}$ como $p(\mathbf{x})=j \omega \rho_{0} G(\mathbf{x} \mid \mathbf{y})$. De acordo com Pierce ([24], apud [21]), a função de Green é recíproca, isto é, $G(\mathbf{x} \mid \mathbf{y})=G(\mathbf{y} \mid \mathbf{x})$ e por definição obedece à equação

$$
\left(\nabla^{2}+k^{2}\right) G(\mathbf{x} \mid \mathbf{y})=-\delta(\mathbf{x}-\mathbf{y})
$$

onde $\delta(\mathbf{x})$ é a função delta de Dirac, que possui a seguinte propriedade

$$
\int_{V} f(\mathbf{x}) \delta(\mathbf{x}-\mathbf{y})=\left\{\begin{array}{ll}
f(\mathbf{y}), & \mathbf{y} \text { dentro de } \mathrm{V} \\
0, & \mathbf{y} \text { fora de } \mathrm{V}
\end{array} .\right.
$$




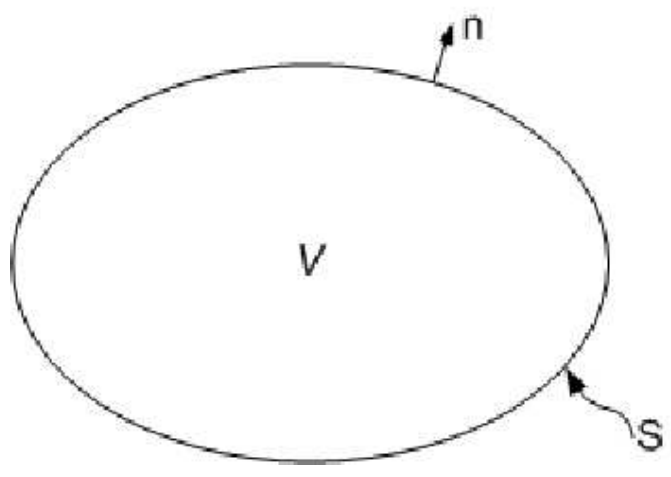

(a)

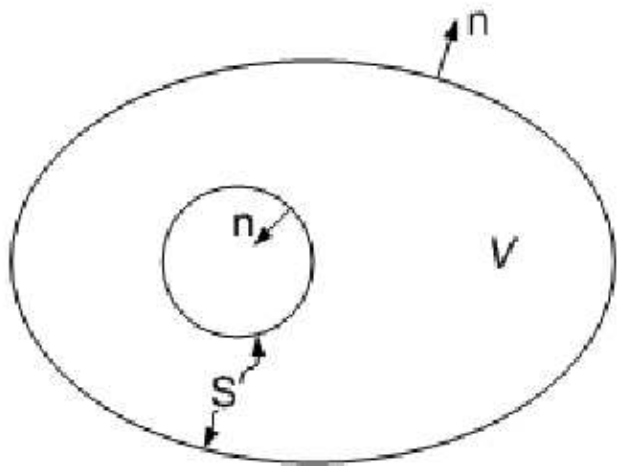

(b)

Figura 9: (a) Representação bidimensional de um volume $V$ e sua superfície limite $S$. (b) Uma outra possível situação de um volume $V$ com superfície limite $S$ composta. Pode-se considerar que a superfície limite exterior esteja no infinito.

Usando a abreviação $Q(y)=j \omega \rho_{0} q_{\mathrm{vol}}(\mathbf{y})-\nabla f_{\mathrm{vol}}(\mathbf{y})$, busca-se a solução da equação

$$
\left(\nabla^{2}+k^{2}\right) p(\mathbf{y})=-Q_{\mathrm{vol}}(\mathbf{y})
$$

Usa-se a equação (2.66) para auxiliar a solução deste problema. Multiplicando-se a equação 2.67) pela função de Green e subtraindo-se deste resultado a equação 2.66 multiplicada por $p(\mathbf{y})$, obtém-se

$$
G(\mathbf{y} \mid \mathbf{x}) \nabla^{2} p(\mathbf{y})-p(\mathbf{y}) \nabla^{2} G(\mathbf{y} \mid \mathbf{x})=-Q_{\mathrm{vol}}(\mathbf{y}) G(\mathbf{y} \mid \mathbf{x})+p(\mathbf{y}) \delta(\mathbf{y}-\mathbf{x}) .
$$

Integrando-se os dois lados da equação no volume $\mathrm{V}$, que se define como um volume que englobe todos os pontos de interesse, verifica-se que

$$
\begin{array}{r}
\int_{V} G(\mathbf{y} \mid x) \nabla^{2} p(\mathbf{y})-p(\mathbf{y}) \nabla^{2} G(\mathbf{y} \mid \mathbf{x}) d V+\int_{V} Q_{\mathrm{vol}}(\mathbf{y}) G(\mathbf{y} \mid \mathbf{x}) d V= \\
=\left\{\begin{array}{ll}
p(\mathbf{x}), & \mathbf{x} \text { dentro de } \mathrm{V} \\
0, & \mathbf{x} \text { fora de } \mathrm{V}
\end{array} .\right.
\end{array}
$$

É importante notar que este volume é delimitado pela superfície limite $S$, mas esta superfície limite não é necessariamente um único elemento de área, como é mostrado na figura 9 .

Usando o teorema de Green, a pressão nos pontos $\mathbf{x}$ dentro do volume V é reescrita como

$$
p(\mathbf{x})=\int_{V} Q_{\mathrm{vol}}(\mathbf{y}) G(\mathbf{y} \mid \mathbf{x}) d V+\int_{S}[G(\mathbf{y} \mid \mathbf{x}) \nabla p(\mathbf{y})-p(\mathbf{y}) \nabla G(\mathbf{y} \mid \mathbf{x})] \cdot \mathbf{n} d S
$$


também conhecida como equação de Helmholtz não-homogênea. Com esta equação é possível calcular a pressão em um ponto x no interior do volume $V$ de superfície limite $S$, desde que sejam conhecidas a distribuição de fontes $Q_{\text {vol }}(\mathbf{y})$ presente no interior do volume $V$, os valores $p(\mathbf{y})$ e $\nabla p(\mathbf{y})$ na superfície $S$ e a função de Green $G(\mathbf{x} \mid \mathbf{y})$. A escolha da função de Green pode ser feita com relativa liberdade, já que a única restrição na sua escolha é que $G(\mathbf{x} \mid \mathbf{y})$ deve satisfazer a equação 2.66). Logo, a função de Green poderia ser escolhida de forma a satisfazer $\nabla G(\mathbf{x} \mid \mathbf{y})=0$, simplificando a equação (2.70).

\subsubsection{A Solução da Equação de Green para o Espaço Livre}

Se a fonte sonora se encontra no espaço livre, ou seja, um espaço somente com superfície externa localizada no infinito, pode-se aplicar a condição de Sommerfeld, que argumenta que quando a distância radial de um ponto em campo aberto a uma fonte harmônica se aproxima de infinito, então apenas ondas na direção da fonte para o ponto poderão existir. Considerando-se que no campo aberto a superfície limite tem distância da fonte harmônica $r \rightarrow \infty$, então a integral de superfície da equação 2.70 não pode estar gerando pressão no interior do volume e portanto é nula. A solução para a equação de onda não-homogênea neste caso se resume a

$$
p(\mathbf{x})=\int_{V} Q_{\mathrm{vol}}(\mathbf{y}) G(\mathbf{y} \mid \mathbf{x}) d V
$$

De acordo com Morse e Ingard ([25], apud [21]), a equação de Green para o espaço aberto é dada por

$$
g(\mathbf{x} \mid \mathbf{y})=\frac{e^{-j k\|\mathbf{x}-\mathbf{y}\|_{2}}}{4 \pi\|\mathbf{x}-\mathbf{y}\|_{2}}
$$

Se a fonte sonora estiver associada a uma variação de volume tal que

$$
Q_{\mathrm{vol}}(\mathbf{y})=j \omega \rho_{0} q \delta\left(\mathbf{y}-\mathbf{y}_{1}\right)
$$

ou seja, se existir apenas uma fonte pontual em $\mathbf{y}_{1}$, então a solução da equação (2.71) será

$$
p(\mathbf{x})=\frac{j \omega \rho_{0} q e^{-j k\left\|\mathbf{x}-\mathbf{y}_{1}\right\|_{2}}}{4 \pi\left\|\mathbf{x}-\mathbf{y}_{1}\right\|_{2}},
$$

a já conhecida equação da pressão sonora para uma fonte pontual em campo livre.

Apesar de a equação 2.70 parecer ter resolução bastante complicada, ela é muito importante, já que ela fornece a pressão num ponto $\mathbf{x}$ de um volume, considerando a existência de fontes sonoras dentro do volume de interesse (primeiro termo do lado direito da equação) ou considerando ondas provenientes da fronteira deste volume (segundo termo 
do lado direito da equação). Esta equação é a base do método numérico de Elementos Finitos, método bastante poderoso para resolução de problemas de radiação acústica. Para a resolução de problemas de irradiação em campo aberto com este método é necessário fornecer um modelo da superfície da fonte de ruído, que será considerado como a superfície limite interna do volume $V$, e as condições de contorno dessa superfície, como rigidez, massa e o mais importante, velocidade ou aceleração da superfície nos diversos elementos de fronteira, de onde provém o nome do método. 


\section{SISTEMAS DE CONTROLE ATIVO DE RUÍDO}

\subsection{Introdução}

Em 1956 Conover já havia constatado que os sistemas de controle ativo de ruído de transformadores necessitavam de ajustes constantes para corrigir as variações do ruído ocorridas por causa de variações de tensão da rede ou das condições meteorológicas. Conover sinalizou a necessidade de um sistema de controle automático da amplitude e da fase do "anti-ruído".

Um sistema de controle automático deve ser um sistema (não necessariamente linear) cuja função de transferência se altera com o tempo buscando compensar as variações ocorridas no ruído a ser cancelado. A precisão desse sistema de controle é de suma importância no desempenho global de um sistema ANC. Como um exemplo simples, um sistema acústico constituído por uma única fonte primária irradiando em uma única freqüência e uma única fonte secundária usada para controlar o ruído precisa que o erro de fase não seja maior que $\pm 6^{\circ}$ e que a variação de amplitude não seja maior que $\pm 0,6 \mathrm{~dB}$ para que se atinjam reduções do nível sonoro em torno de $20 \mathrm{~dB}$ em um dado ponto, como mostra a figura 10. Este simples exemplo mostra o nível de precisão necessário para o algoritmo de controle em aplicações de ANC. Outra constatação importante, feita a partir da figura 10, é que o erro de fase deve ser menor do que $\pm 90^{\circ}$ para que possa haver atenuação.

O uso de um filtro digital adaptativo como elemento de controle do sistema ANC, proposto inicialmente por Kido [7, 8], pode fornecer a precisão que os sistemas ANC requerem. Os filtros digitais adaptativos podem ser realizados com relativa facilidade, e ajustam automaticamente seus coeficientes com o objetivo de minimizar, por exemplo, a potência de um sinal de erro, podendo com isso compensar variações que porventura ocorram na função de transferência do sistema ANC. Filtros adaptativos podem ser realizados de diversas formas [26], sendo o filtro FIR com adaptação LMS a forma mais comumente 


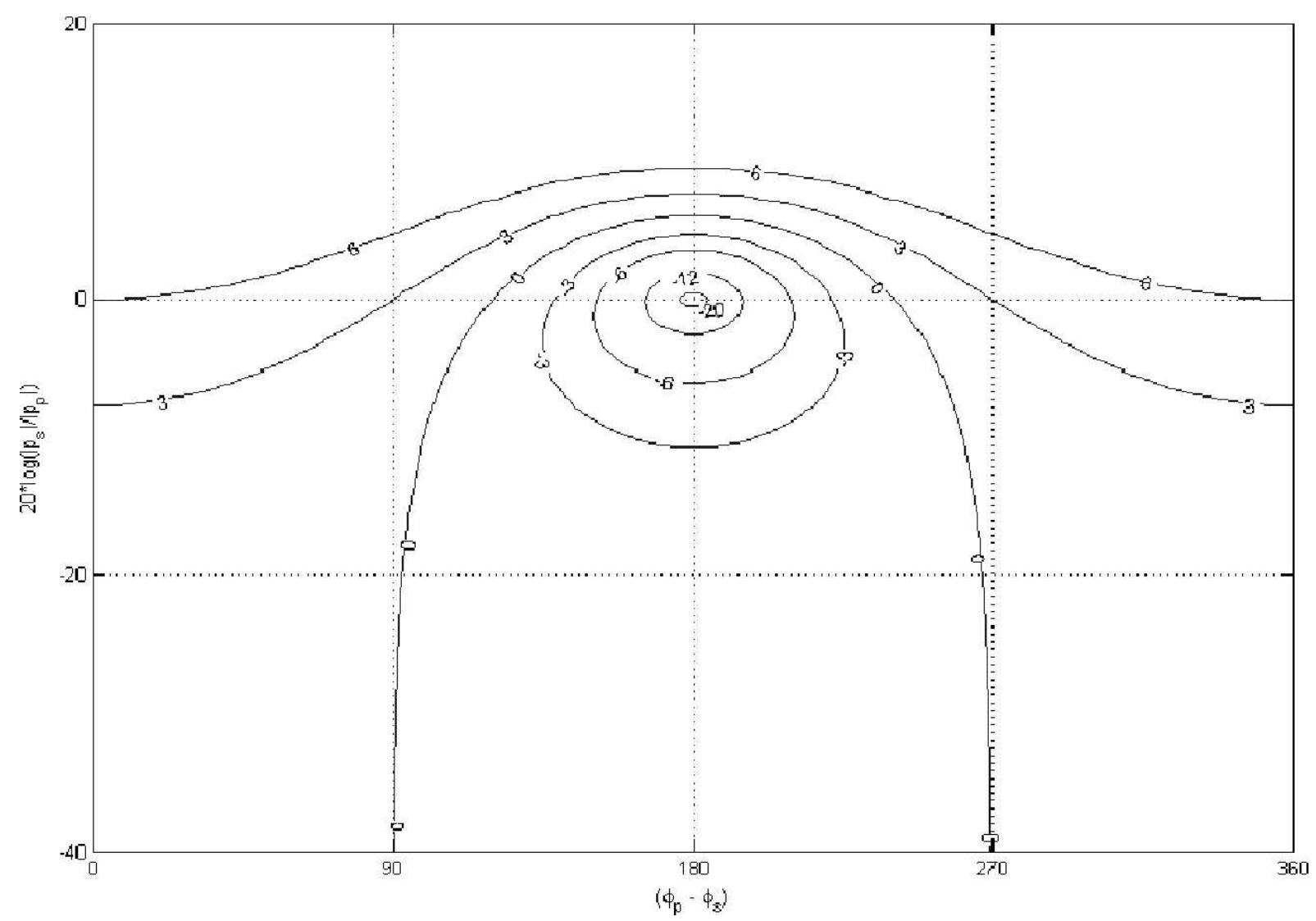

Figura 10: Nível de atenuação (em dB) da amplitude do ruído primário em um ponto em função da diferença de amplitude e de fase entre o campo sonoro primário e o campo sonoro secundário.

usada em aplicações de ANC, que são descritas neste capítulo.

Este capítulo apresenta uma revisão da técnica de controle ativo de ruído, enfocando as características mais importantes para o controle de transformadores de potência. Primeiramente descreve-se o filtro FIR na seção 3.2.1. Como o sistema ANC deve ser adaptativo para acompanhar variações no ruído ou no caminho acústico, é feita uma introdução à teoria de filtragem ótima na seção 3.2.2.1 e à teoria da filtragem adaptativa na seção 3.2.2.2. O ruído emitido pelos transformadores é bastante correlacionado com o sinal da rede elétrica, por isso descreve-se o esquema de controle com referência, ou direto na seção 3.3.1. A presença do caminho acústico secundário entre a fonte de controle e o sensor de erro pode causar instabilidade no sistema de controle, e por isso seu efeito deve ser compensado para permitir a convergência do controle adaptativo, o que é feito comumente com o uso do controle tipo FxLMS, descrito na seção 3.3.2. A técnica de estimação do caminho secundário comumente utilizada é apresentada na seção 3.3.3. Por fim, como o campo acústico dos transformadores de potência é um campo relativamente complexo, são necessárias múltiplas fontes de controle para tentar reproduzir esse campo e múltiplos 
sensores de erro para tentar estimar o campo resultante. Portanto, o algoritmo MELMS, usado para o controle de sistemas ANC multicanal, é descrito na seção 3.3 .4 e a técnica de estimação de múltiplos caminhos secundários é descrita na seção 3.3 .5 .

É importante lembrar que a escolha correta do sistema de controle e de seus parâmetros garante convergência, rastreabilidade e atenuação adequada para o sistema, mas os níveis globais de atenuação obtidos não estão relacionados somente ao algoritmo de controle usado. O posicionamento das fontes de controle e sensores de erro ao redor da fonte primária é crítico para o desempenho do sistema e será discutido no capítulo seguinte.

\subsection{Filtros Adaptativos}

Um filtro digital adaptativo é um sistema composto por um filtro digital cujos coeficientes podem variar no tempo e por um algoritmo adaptativo que se baseia em um sinal de referência e em um sinal de erro (cuja potência média deseja-se minimizar) para calcular os valores dos coeficientes do filtro a cada nova amostra. Os filtros adaptativos podem ser realizados de diversas formas [27, 26], mas a forma mais comumente usada em aplicações de ANC é o filtro de resposta ao impulso finita (em inglês: finite impulse response, FIR) com adaptação que minimiza o erro quadrático médio (em inglês: least mean-square, LMS), ou a sua variante LMS filtrado (em inglês: filtered-x LMS, FxLMS) que tenta compensar o efeito do caminho acústico secundário no sistema de controle. Filtros adaptativos também podem ser usados para controlar sistemas multivariáveis (múltiplos sinais de controle e múltiplos sinais de erro), usando-se para isto uma nova variante da adaptação LMS.

\subsubsection{Filtros FIR}

O filtro FIR é um sistema linear e invariante no tempo cuja resposta impulsiva é nula após um número finito de amostras. A saída desse filtro depende apenas das últimas $N$ amostras do sinal de entrada, de tal modo que

$$
y(n)=\sum_{i=0}^{N-1} w_{i} x(n-i) .
$$

A equação 3.1 pode ser reescrita num formato vetorial como

$$
y(n)=\boldsymbol{w}^{T} \boldsymbol{x}(n),
$$


onde $\boldsymbol{w}$ e $\boldsymbol{x}$ são definidos por

$$
\begin{gathered}
\boldsymbol{w}^{T}=\left[\begin{array}{llll}
w_{0} & w_{1} & \cdots & w_{N-1}
\end{array}\right], \\
\boldsymbol{x}^{T}=\left[\begin{array}{llll}
x(n) & x(n-1) & \cdots & x(n-N+1)
\end{array}\right] .
\end{gathered}
$$

Como os pólos dos filtros FIR são sempre nulos, esta configuração de filtro é sempre estável para coeficientes limitados. Esta configuração de filtros geralmente requer um número elevado de coeficientes para reproduzir a função de transferência de sistemas físicos mais complexos, principalmente aqueles que apresentem ressonâncias. Para problemas de controle de ruído tonal, como é o caso dos transformadores de potência, deseja-se que o filtro adaptativo reproduza a função de transferência do sistema de forma o mais fidedigna possível próximo das harmônicas de interesse, sendo as reprodução das demais faixas de freqüência de menor interesse. O uso de filtros adaptativos FIR se mostra bastante eficaz nestes casos.

\subsubsection{Algoritmo de Adaptação}

Os algoritmos de adaptação comumente usados são baseados na teoria do filtro ótimo de Wiener, substituindo-se os valores estatísticos das variáveis de entrada por valores instantâneos, como será mostrado a seguir.

\subsubsection{Filtro Ótimo de Wiener}

A filtragem ótima de Wiener (com número de coeficientes pré-definido) será explicada por meio de um exemplo. $W(z)$ é um filtro FIR com $N$ coeficientes que recebe na sua entrada o sinal de referência $x(n)$ e fornece na sua saída o sinal $y(n)$. Este sinal de saída é somado ao sinal desejado $d(n)$, resultando no sinal de erro $e(n)$, como mostrado na figura 11. Assume-se que o sinal de referência é, em algum nível, correlacionado com o sinal desejado e que ambos tenham média estatística nula $(E[x(n)]=E[d(n)]=0)$. Na literatura em geral, a saída do filtro é subtraída do sinal desejado, mas aqui os dois sinais são somados, já que nos sistemas ANC o sinal das fontes de controle se soma (por superposição) ao ruído primário.

Usando a equação (3.2), o sinal de erro pode ser escrito como

$$
e(n)=d(n)+\boldsymbol{w}^{T} \boldsymbol{x}(n)
$$

Deseja-se agora encontrar os coeficientes de $W(z)$ que minimizam a potência do sinal de 


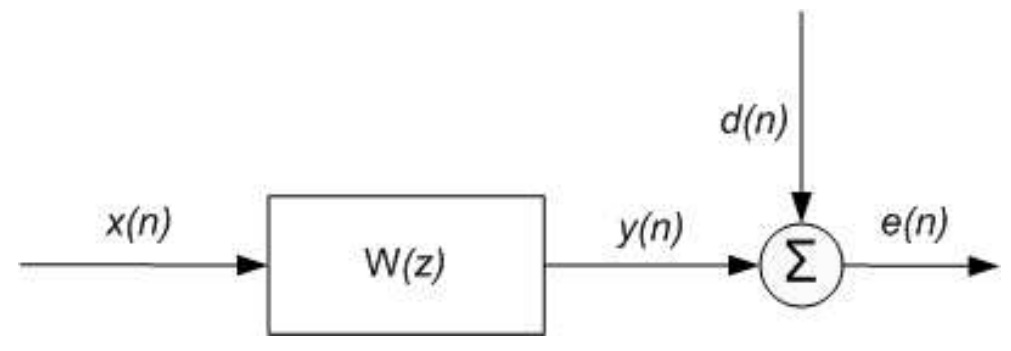

Figura 11: Esquema de um problema generalizado de estimação.

erro, dada por $J=E\left[e^{2}(n)\right]$. Usando a equação (3.5) a potência do sinal de erro pode ser reescrita como

$$
\begin{aligned}
J & =E\left[\left(d(n)+\boldsymbol{w}^{T} \boldsymbol{x}(n)\right)^{2}\right] \\
& =E\left[\left(d(n)+\boldsymbol{w}^{T} \boldsymbol{x}(n)\right)\left(d(n)+\boldsymbol{x}^{T}(n) \boldsymbol{w}\right)\right] .
\end{aligned}
$$

Assumindo que os processos $\{d(n)\}$ e $\{x(n)\}$ sejam estacionários e que o valor ótimo de $\boldsymbol{w}$ não varia no tempo, esta equação pode ser reescrita como

$$
J=E\left[d^{2}(n)\right]+\boldsymbol{w}^{T} E[\boldsymbol{x}(n) d(n)]+E[\boldsymbol{x}(n) d(n)]^{T} \boldsymbol{w}+\boldsymbol{w}^{T} E\left[\boldsymbol{x}(n) \boldsymbol{x}^{T}(n)\right] \boldsymbol{w}
$$

Os valores estatísticos presentes na equação (3.7) são conhecidos como a correlação cruzada $E[\boldsymbol{x}(n) d(n)]=\boldsymbol{R}_{X d}$, a autocorrelação $E\left[\boldsymbol{x}(n) \boldsymbol{x}(n)^{T}\right]=\boldsymbol{R}_{X}$ e a variância do sinal desejado $E\left[d^{2}(n)\right]=\sigma_{d}^{2}$. Verifica-se que a equação (3.7) é uma função quadrática de $\boldsymbol{w}$. Nelson e Elliott [21, Apêndice A.5] mostram que se $\boldsymbol{R}_{X}$ for uma matriz positiva definida, a equação (3.7) possui um único mínimo global, sendo o vetor de coeficientes ótimos que minimiza esta equação dado por

$$
\boldsymbol{w}_{0}=-\boldsymbol{R}_{X}^{-1} \boldsymbol{R}_{X d}
$$

O mínimo valor da potência de erro será então

$$
J_{\min }=\sigma_{d}^{2}-\boldsymbol{R}_{X d} \boldsymbol{R}_{X}^{-1} \boldsymbol{R}_{X d}
$$

\subsubsection{Algoritmo LMS}

O projeto de um filtro ótimo de Wiener requer o conhecimento prévio dos valores de autocorrelação do sinal de referência e da relação cruzada do sinal de referência com o sinal desejado. Isto é inviável na grande maioria dos projetos de filtro. Outra dificuldade desta técnica é a necessidade de inversão de matrizes, que é uma operação que requer grande carga computacional nos processadores digitais.

Como já foi mencionado, a equação (3.7) é uma função quadrática de $\boldsymbol{w}$ que apresenta 
um único mínimo global. Pode-se então usar métodos iterativos, como o algoritmo do gradiente, que a partir de uma estimativa inicial de $\boldsymbol{w}$, procuram a cada iteração calcular um novo valor de $\boldsymbol{w}$ que reduza o valor de $J$. O algoritmo LMS usa o método do gradiente estocástico para realizar estas iterações. Pelo método do gradiente determinístico,

$$
\boldsymbol{w}(n+1)=\boldsymbol{w}(n)-\left.\mu \frac{\partial J}{\partial \boldsymbol{w}}\right|_{w=w(n)} .
$$

Da equação (3.7), verifica-se que

$$
\frac{\partial J}{\partial \boldsymbol{w}}=\boldsymbol{R}_{X d}+\boldsymbol{R}_{X} \boldsymbol{w}
$$

resultando na recursão

$$
\boldsymbol{w}(n+1)=\boldsymbol{w}(n)-\mu\left(\boldsymbol{R}_{X d}+\boldsymbol{R}_{X} \boldsymbol{w}(n)\right),
$$

onde $\boldsymbol{w}(0)$ é um vetor inicial aleatório. Já que em geral não se dispõe dos valores estatísticos do sinal de referência e do sinal a ser cancelado, esses valores estatísticos são substituídos por valores instantâneos, ou seja, $\boldsymbol{R}_{X d}=\boldsymbol{x}(n) d(n)$ e $\boldsymbol{R}_{X}=\boldsymbol{x}(n) \boldsymbol{x}(n)^{T}$. A equação 3.12 pode ser reescrita como

$$
\begin{aligned}
\boldsymbol{w}(n+1) & =\boldsymbol{w}(n)-\mu\left(\boldsymbol{x}(n) d(n)+\boldsymbol{x}(n) \boldsymbol{x}^{T}(n) \boldsymbol{w}(n)\right) \\
& =\boldsymbol{w}(n)-\mu \boldsymbol{x}(n)\left(d(n)+\boldsymbol{w}^{T}(n) \boldsymbol{x}(n)\right) .
\end{aligned}
$$

O termo $d(n)+\boldsymbol{w}^{T}(n) \boldsymbol{x}(n)$ na equação 3.13$)$ é igual ao próprio sinal de erro, de acordo com a equação (3.5). A equação (3.13) pode então ser reescrita como

$$
\boldsymbol{w}(n+1)=\boldsymbol{w}(n)-\boldsymbol{\mu} \boldsymbol{x}(n) e(n)
$$

O valor $\mu$ é conhecido como o passo de adaptação. A escolha do passo de adaptação é muito importante, pois o valor escolhido influencia diretamente a velocidade de adaptação e a estabilidade do sistema. Sayed [27] realizou uma análise da estabilidade do filtro adaptativo LMS e demonstrou que para garantir a convergência na média quadrática, o valor de $\mu$ deve satisfazer

$$
0<\mu<\frac{2}{3 M E\left[x^{2}(n)\right]},
$$

onde $M$ é o número de coeficientes do filtro adaptativo e $E\left[x^{2}(n)\right]$ a variância do sinal de referência. Na prática, usam-se valores pequenos para $\mu$ para assegurar convergência e robustez ao ruído, apesar de a convergência neste caso ser lenta. Um valor de $\mu$ próximo da metade do limite de convergência garantiria uma convergência rápida, mas deixaria o algoritmo muito suscetível ao ruído, fazendo com que os valores dos coeficientes oscilassem 
muito em torno dos valores ótimos dos coeficientes (para valores de passo de adaptação acima da metade do limite de convergência, a velocidade de convergência tende a diminuir, dependendo da estatística do sinal de entrada).

\subsection{Técnicas de Controle Adaptativo}

Kuo e Morgan fazem uma análise de todas as técnicas de controle aplicadas ao controle ativo de ruído [28]. Nesta seção, são resumidos os tópicos desse trabalho importantes para o controle do ruído de transformadores de potência. As figuras 12 a 15 são baseadas em figuras do artigo de Kuo e Morgan [28].

O ANC pode ser baseado em duas técnicas de controle:

Controle Direto Um sinal de referência correlacionado com o ruído é capturado sem sofrer influência das fontes secundárias.

Controle Realimentado O controlador tenta cancelar o ruído no sensor de erro sem o auxílio de um sinal de referência [5].

Controle Híbrido O controlador combina as características de um controlador direto com as de um realimentado. O controlador direto atenua o ruído primário correlacionado com o ruído de referência, enquanto o controlador realimentado atua nas freqüências do sinal de erro que não são amostradas pelo sensor de referência. É indicado para situações em que a fonte de ruído a ser controlada está localizada em um ambiente com ruído de fundo elevado.

Controladores diretos são normalmente empregados em situações em que é possível obter um sinal antecipado e de boa correlação com o ruído emitido. Já os sistemas realimentados são indicados para os casos em que o sistema acústico não permite a detecção prévia de um sinal correlacionado ou quando se pretende controlar um grande número de fontes de ruído descorrelacionadas, que caso fossem controladas de forma direta iriam requerer o uso de muitos sensores de referência. Para o controle de ruído de transformadores é comum usar-se controladores diretos, com a referência extraída diretamente da rede elétrica ou de acelerômetros presos ao tanque do transformador. 


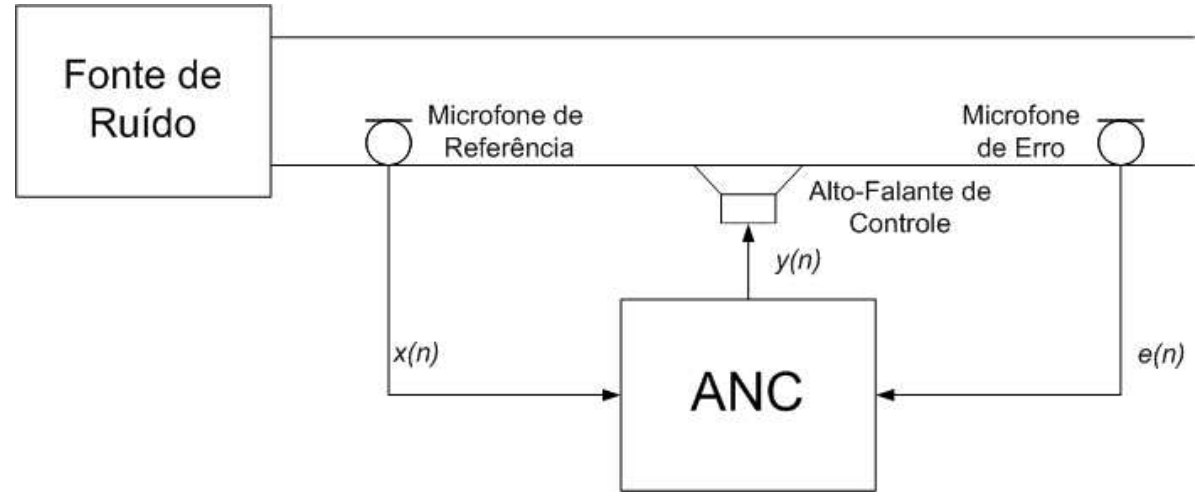

Figura 12: Controle direto com um canal aplicado em um duto.

\subsubsection{Controle Direto}

Nesta seção considera-se um sistema de controle direto com um sensor de referência, uma fonte secundária e um sensor de erro. Esta configuração pode ser exemplificada pelo controle simples de ruído em um duto, como mostrado na figura 12 . O sinal de referência é processado pelo sistema ANC, gerando o sinal que alimentará a fonte secundária. O sensor de erro é usado para monitorar o desempenho do sistema ANC. O objetivo deste sistema é minimizar o ruído medido pelo sensor de erro. Apesar de exemplificado para o controle de um duto, essa técnica pode ser aplicada a uma grande variedade de problemas de acústica e vibração.

O sistema ANC mostrado na figura 13 é descrito como um sistema de controle adaptativo, em que um filtro adaptativo $W(z)$ é usado para estimar o caminho acústico $P(z)$ entre o sensor de referência e o sensor de erro (onde se deseja que a atenuação ocorra). Se a planta for dinâmica, então o filtro adaptativo tem a função de rastrear variações na dinâmica da planta. O objetivo do filtro adaptativo $W(z)$ é minimizar o erro residual $e(n)$.

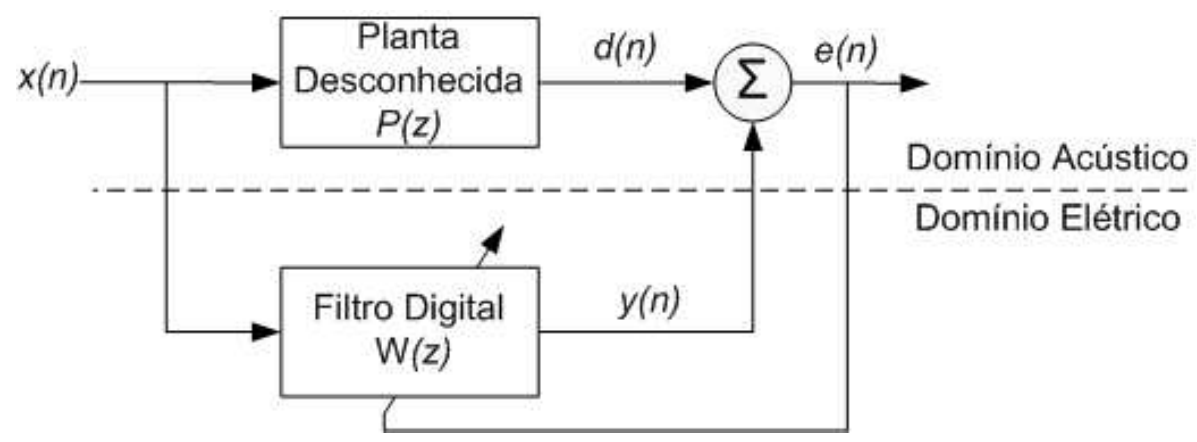

Figura 13: Identificação do sistema ANC. 


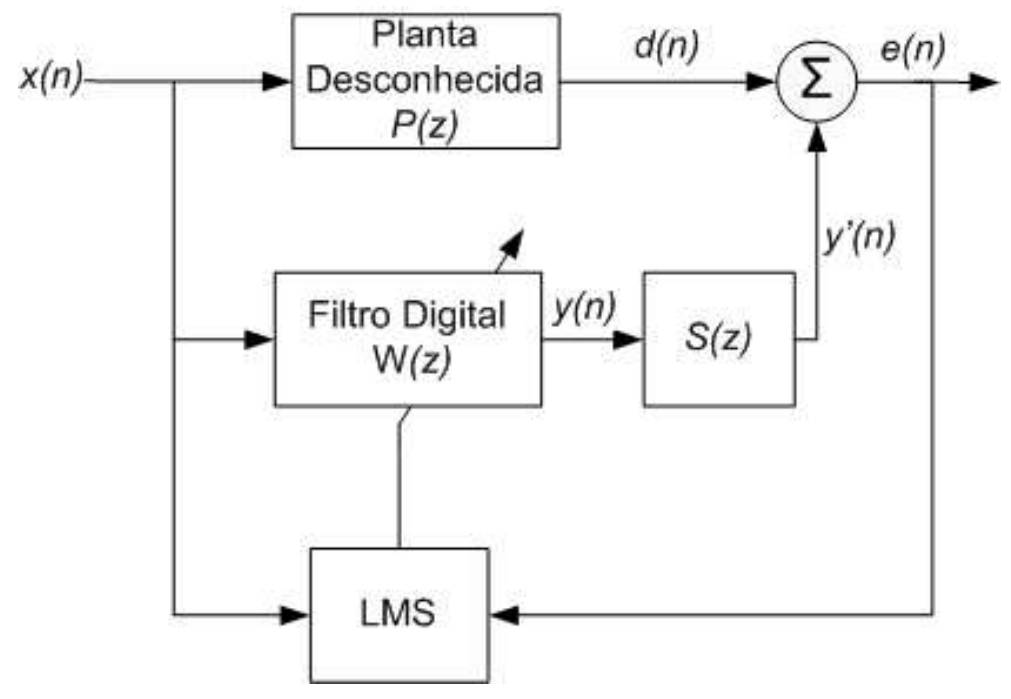

Figura 14: Diagrama de blocos simplificado do sistema ANC.

Como ilustrado na figura 12, após o sinal de referência ser capturado pelo sensor de referência, o controlador precisará de certo tempo para calcular a saída ótima para a fonte secundária. Se este atraso elétrico for maior que o atraso acústico entre o sensor de referência e a fonte secundária, o desempenho do sistema ficará comprometido, porque a resposta ótima do controlador teria de ser não-causal. No entanto, mesmo que a condição de causalidade não seja atendida, o controlador poderá ainda controlar ruídos harmônicos, ou seja, periódicos.

Uma complicação adicional é o fato de o somatório da figura 13 representar uma superposição acústica no espaço entre a fonte secundária e o sensor de erro, no qual o ruído primário é combinado com o sinal emitido pela fonte secundária. Logo, é necessário considerar o caminho acústico secundário $S(z)$ entre a excitação $y(n)$ da fonte secundária e o erro $e(n)$, que em um sistema digital inclui o conversor digital-analógico, o filtro de reconstrução, o amplificador, o alto-falante, o caminho secundário entre o alto-falante e o microfone, o microfone de erro, o pré-amplificador, o filtro anti-recobrimento e o conversor analógico-digital. A figura 14 apresenta o diagrama de blocos de um sistema ANC já considerando a influência do caminho secundário. Verifica-se que a transformada- $z$ do sinal de erro é

$$
E(z)=[P(z)+S(z) W(z)] X(z)
$$

Se for assumido que após a convergência do filtro adaptativo o sinal de erro é anulado, tem-se então que $E(z)=0$. Isso requer que $W(z)$ realize a função de transferência ótima

$$
W_{o}(z)=-\frac{P(z)}{S(z)} .
$$




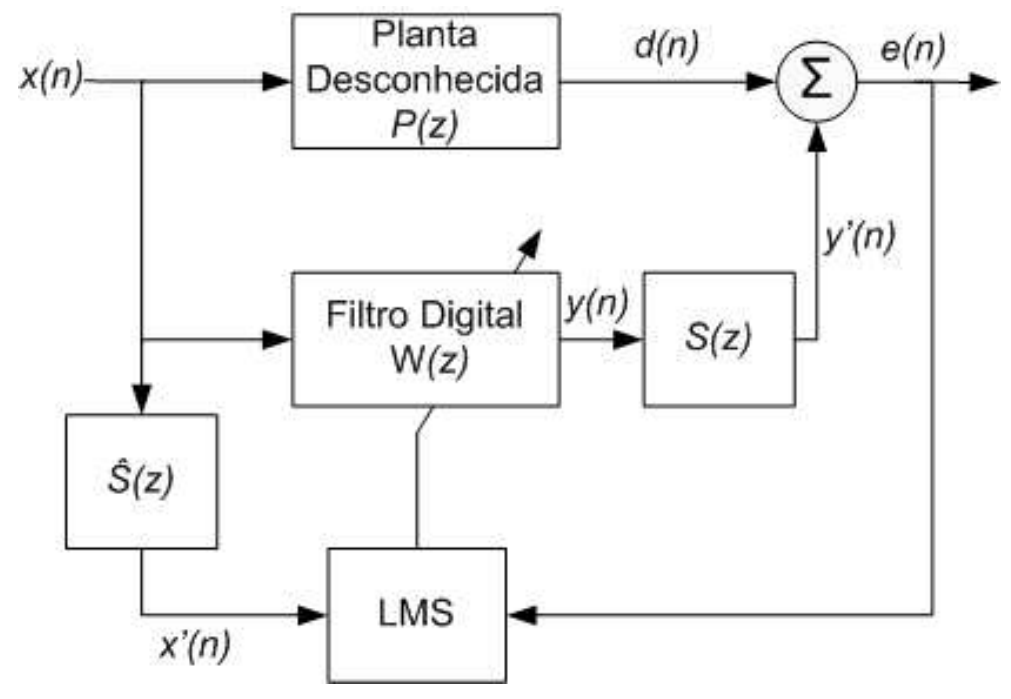

Figura 15: Diagrama de blocos do sistema ANC usando o algoritmo FxLMS.

Ou seja, o filtro adaptativo $W(z)$ tem de simultaneamente modelar $P(z)$ e o inverso de $S(z)$. Com isso, o desempenho do sistema ANC depende fortemente da função de transferência do caminho acústico.

\subsubsection{Controle FxLMS}

A influência do caminho acústico secundário em um controlador usando o algoritmo de adaptação LMS pode gerar instabilidade no sistema ANC [27, 26]. Como ondas sonoras se propagam com velocidade relativamente baixa, verifica-se um atraso significativo entre o sinal que sai do alto-falante e o que é medido no microfone, especialmente em sistemas ANC aplicados em campo aberto. Além disso, normalmente ocorrem reflexões do som por superfícies como o chão, que por menores que sejam, alteram a forma de onda recebida nos microfones. Uma possível solução para este problema seria colocar um filtro inverso $1 / S(z)$ em série com $S(z)$ para remover o seu efeito. Mas esta função de transferência pode eventualmente não ter inversa, ou ter uma inversa de difícil reprodução, inviabilizando a solução. A abordagem mais comumente usada em sistemas ANC é colocar um filtro $\hat{S}(z)$, cuja função de transferência é uma estimativa da função de transferência de $S(z)$, entre o sinal de referência e a entrada da adaptação do algoritmo LMS. Esta configuração é conhecida por "Filtered- $x$ LMS" (FxLMS). A figura 15 mostra o diagrama de blocos de um sistema FxLMS. Os detalhes sobre a construção e a análise do algoritmo FxLMS podem ser encontrados no livro de Kuo e Morgan [29] ou nos trabalhos de Bermudez et al. [30, 31]. 


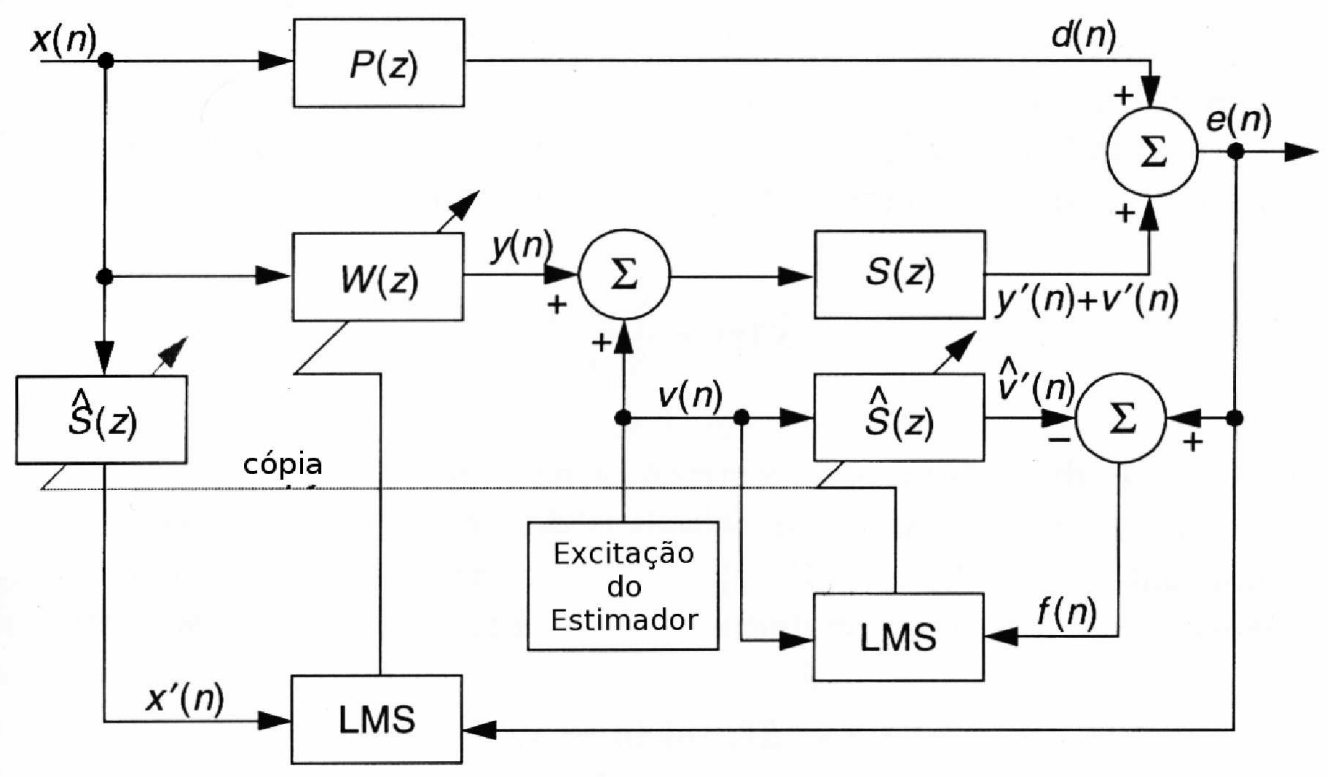

Figura 16: Diagrama de blocos do sistema FxLMS, com filtro de estimação do caminho secundário.

A função de transferência de $S(z)$ pode ser estimada de diversas maneiras, com o sistema de controle em funcionamento ou não. Uma boa estimativa de $S(z)$ é necessária, senão o controle diverge depois de um intervalo de tempo relativamente curto. Alguns dos métodos para estimar esta função de transferência com o controle desligado foram discutidos por Masiero [32. Para estimação de $S(z)$ com o sistema ANC em funcionamento, soma-se um sinal conhecido (e de preferência descorrelacionado com o sinal de controle) ao sinal de controle e usa-se um filtro LMS para estimar $S(z)$, como exemplificado na figura 16 .

\subsubsection{Estimativa do Caminho Secundário}

Cabe aqui um comentário sobre a estimação do caminho secundário. A idéia principal é usar um filtro adaptativo LMS em configuração de identificação de sistemas: insere-se um sinal $v(t)$ conhecido no caminho secundário $S(z)$ e ao mesmo tempo filtra-se este sinal pelo filtro $\hat{S}(z)$. O sinal de erro fornecido ao estimador $f(n)$ é a diferença entre o sinal de erro $e(n)$ e o sinal $v(t)$ filtrado pelo estimador $\hat{S}(z)$. Minimizar a energia de $f(n)$ implica que o modelo $\hat{S}(z)$ seja o mais similar possível ao caminho secundário $S(z)$. Se $v(t)$ for um ruído de banda larga, $\hat{S}(z)$ irá tentar reproduzir o caminho secundário em todo espectro, sendo necessário o uso de um filtro FIR longo (o que acaba fazendo com que a adaptação tenha de ser muito lenta). Já se $v(t)$ for um tom com freqüência $\omega_{0}$, o modelo irá emular o 
caminho acústico unicamente nesta freqüência, ou seja, irá estimar somente $S\left(\omega_{0}\right)$, sendo necessário para isso um filtro bem mais curto que no caso anterior.

Tradicionalmente utiliza-se ruído branco, por causa de seu espectro igualmente rico em todas as freqüências, como sinal de excitação para o estimador do caminho secundário. Isso garante uma estimação correta de $S(z)$, desde que o ruído inserido tenha potência suficiente e o filtro adaptativo para estimação de $S(z)$ tenha ordem suficientemente alta. Em aplicações de cancelamento de ruído em áreas abertas - por exemplo, o controle ativo de ruído de transformadores - as distâncias envolvidas resultam em um caminho secundário com grande atraso, e portanto a estimação do caminho secundário requer um filtro com centenas de coeficientes, mesmo para taxas de amostragem reduzidas. Nesses cenários, estimadores com excitação persistente exigem recursos computacionais extremamente altos. Uma vez que o ruído a ser cancelado é tonal, a solução ideal seria estimar o caminho secundário somente nas freqüências em que se deseja cancelamento, deixando o algoritmo de adaptação interpolar o caminho secundário nas demais freqüências em função dos valores estimados nas freqüências de interesse.

Uma contribuição de outro membro deste grupo foi desenvolver um estimador de caminho secundário que utiliza excitação senoidal ao invés de ruído branco. Como para controle de ruído em transformadores a estimação do caminho secundário é mais importante em $120 \mathrm{~Hz}$, propõe-se como sinal de excitação um par de senóides vizinhas a essa freqüência (por exemplo, em $100 \mathrm{~Hz}$ e $140 \mathrm{~Hz}$ ). Isso permite que S(z) seja estimada em $100 \mathrm{~Hz}$ e $140 \mathrm{~Hz}$, e assumindo que $S(z)$ não sofra variações bruscas (o que é coerente, já que o caminho acústico não irá apresentar ressonâncias), o valor de $S(z)$ em $120 \mathrm{~Hz}$ será automaticamente interpolado com boa precisão. Essa restrição permite o uso de filtros curtos para $S(z)$, aliviando os requisitos de processamento por pelo menos um fator 10, e melhorando as características de convergência do filtro de estimação.

Para melhorar a robustez do sistema, foram inseridos filtros de banda estreita (notch) em posições estratégicas do sistema de controle. Para melhorar a robustez do estimador foram usados filtros notch para cada harmônica de $120 \mathrm{~Hz}$ ligados na entrada de erro do estimador do caminho secundário. A idéia é minimizar a interferência da fonte primária na convergência do filtro estimador. Esses filtros são extremamente estreitos, e são projetados em tempo real, a partir de uma estimativa da freqüência da rede. O sinal de erro do filtro LMS de controle também é filtrado, mas por um filtro de pico em 120Hz. A função deste filtro é rejeitar o sinal $v(t)$ do estimador de caminho secundário e também rejeitar ruídos fora de banda, como o dos carros passando nas redondezas, permitindo melhor convergência para o sistema de controle. 
Outra consideração a ser feita é sobre a potência do sinal de excitação usado pelo estimador de $S(z)$. Esta potência deve ser minimizada, pois efetivamente as senóides inseridas no sinal de controle são ruído adicional. Por outro lado, a potência do sinal deve ser alta o suficiente (quanto mais distantes os sensores de erro estiverem das fontes de controle, maior deverá ser esta potência) para permitir uma estimação eficaz de $S(z)$, sob o risco de tornar o algoritmo instável. Para isso, o sistema calcula a potência média do erro $P_{e}$ e ajusta a potência do ruído de estimação medido pelo microfone $P_{v}$ para que a razão $P_{e} / P_{v}$ seja constante. Assim, o sucesso do cancelador de ruído permite a diminuição da potência de $v^{\prime}(n)$ sem comprometer a estabilidade do sistema.

A idéia de usar senóides como sinal de excitação também tem uma razão psicoacústica, baseada no efeio do mascaramento. O efeito do mascaramento ocorre quando a percepção pela audição humana de um ruído (tonal ou de banda estreita) em uma dada faixa de freqüência é reduzida pela presença de um outro ruído (também tonal ou de banda estreina) em outra faixa de freqüência. Assim, se a amplitude do sinal de excitação for mantida abaixo do limiar de mascaramento do tom em $120 \mathrm{~Hz}$, este sinal de excitação não será percebido pelas pessoas na proximidade do sistema ANC.

\subsubsection{Controle Ativo Multicanal}

O campo sonoro gerado por um transformador de potência é consideravelmente mais complicado do que o campo sonoro em um duto ou o gerado por uma fonte pontual. Como discutido na seção 2.4.2, conforme o campo primário torna-se mais complexo, o número de fontes primárias necessárias para reproduzir esse campo aumenta. O uso de múltiplas fontes secundárias permite então que uma maior redução do campo acústico seja alcançada. O uso de múltiplos sensores de erro para uma melhor amostragem espacial do campo sonoro resultante também é recomendado. Usa-se então o somatório das pressões quadráticas,

$$
J_{p}=\sum_{l=1}^{L}\left|p_{l}\right|^{2},
$$

medidas em cada sensor de erro, como uma estimativa para a potência acústica irradiada, e o sistema de controle deve definir a intensidade de cada uma das fontes secundárias para reduzir o somatório 3.18 .

O sistema ANC multicanal ilustrado na figura 17 é uma generalização para múltiplas fontes secundárias e múltiplos sensores de erro do algoritmo FxLMS, denominado "Multiple Error LMS" ou MELMS. O controlador gera $M$ sinais para alimentar as fontes 


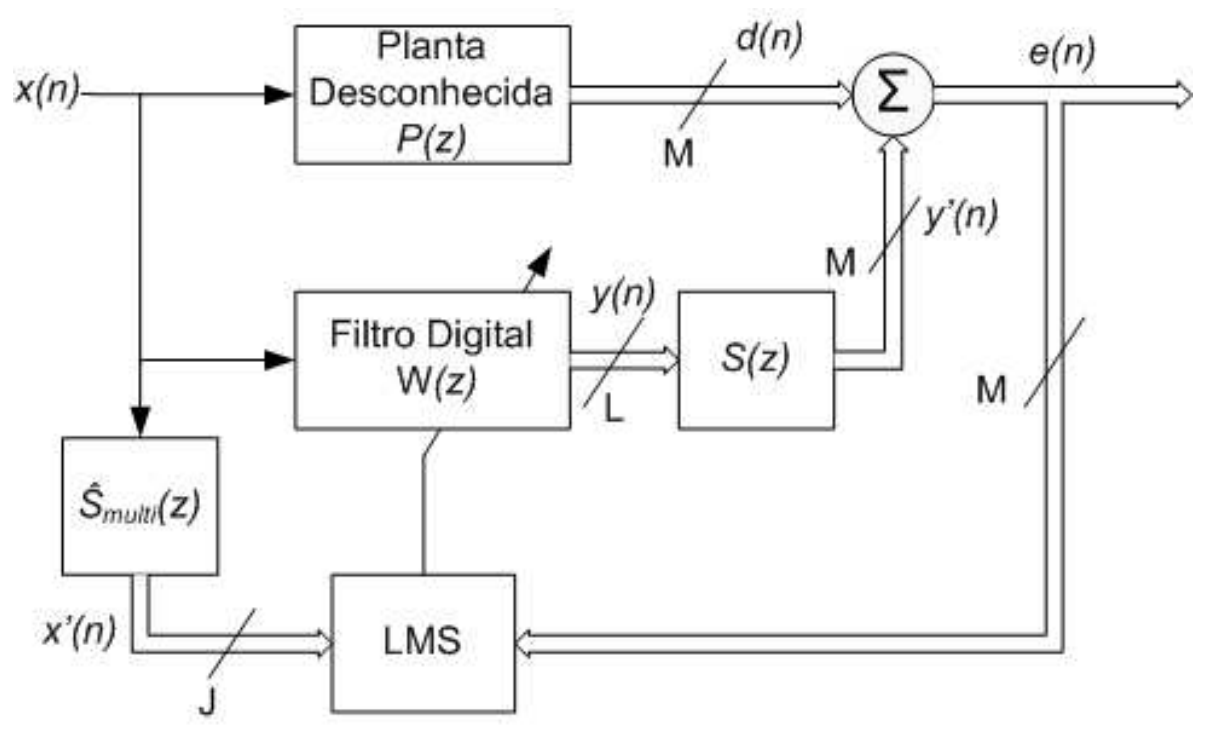

Figura 17: Diagrama de blocos do sistema ANC usando o algoritmo FxLMS multicanal.

secundárias e $L$ sensores de erro são usados para medir o ruído residual. Os $J=M \times L$ caminhos acústicos entre as $M$ fontes secundárias e os $L$ sensores de erro devem ser emulados pelo banco de filtros $\hat{S}_{\text {multi }}$, e o algoritmo de adaptação LMS deve ser generalizado para levar em conta os $J$ sinais de referência filtrados e os $L$ sinais de erro. Este algoritmo pode ser generalizado para trabalhar com múltiplos sinais de referência, mas para o controle ativo do ruído de transformadores um único sinal de referência extraído da rede elétrica é suficiente, já que este sinal será correlacionado com o ruído gerado por magnetostricção em qualquer parte do transformador.

Como se considera que tanto o caminho acústico $S$ como o filtro adaptativo $W$ variam muito lentamente com o tempo, ambos podem ser considerados sistemas lineares e invariantes no tempo, e por isso suas posições em um diagrama de blocos podem ser

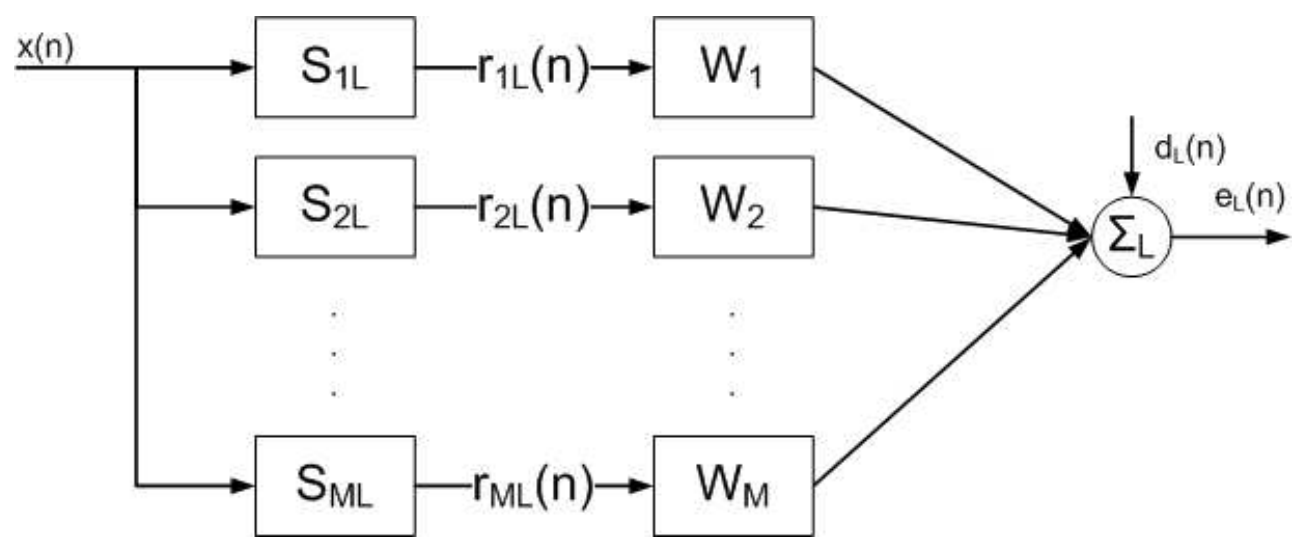

Figura 18: Diagrama de blocos do l-ésimo sinal de erro de um sistema ANC multicanal. 
invertidas. Por causa dessa inversão, os filtros $W_{m}$ e o algoritmo de adaptação LMS estarão recebendo os mesmos sinais de referência filtrados, compensando assim a influência dos caminhos acústicos $S_{m l}$ na convergência dos filtros adaptativos. A figura 18 mostra o diagrama de bloco equivalente para cada um dos $L$ sensores de erro, já com as posições dos filtros $W_{m}$ e dos caminhos acústicos $S_{m l}$ invertidas. Verifica-se que a n-ésima amostra do l-ésimo sinal de erro pode ser dada por

$$
e_{l}(n)=d_{l}(n)+\sum_{m=1}^{M} \sum_{g=0}^{G-1} h_{m}(g) r_{l m}(n-g),
$$

onde $h_{m}(g)$ é o g-ésimo coeficiente do m-ésimo filtro $W_{m}$.

Definindo os vetores

$$
\begin{gathered}
\boldsymbol{h}^{T}(g)=\left[\begin{array}{llll}
h_{1}(g) & h_{2}(g) & \cdots & h_{M}(g)
\end{array}\right] \\
\boldsymbol{r}_{l}^{T}(n)=\left[\begin{array}{llll}
r_{l 1}(n) & r_{l 2}(n) & \cdots & r_{l M}(n)
\end{array}\right],
\end{gathered}
$$

a equação 3.19 pode ser reescrita como

$$
e_{l}(n)=d_{l}(n)+\sum_{g=0}^{G-1} \boldsymbol{h}^{T}(g) \boldsymbol{r}_{l}(n-g),
$$

que ainda apresenta um somatório. Definindo-se agora os novos vetores

$$
\begin{array}{r}
\boldsymbol{e}^{T}(n)=\left[\begin{array}{llll}
e_{1}(n) & e_{2}(n) & \cdots & e_{L}(n)
\end{array}\right], \\
\boldsymbol{d}^{T}(n)=\left[\begin{array}{llll}
d_{1}(n) & d_{2}(n) & \cdots & d_{L}(n)
\end{array}\right], \\
\boldsymbol{w}^{T}=\left[\begin{array}{llll}
\boldsymbol{h}^{T}(0) & \boldsymbol{h}^{T}(1) & \cdots & \boldsymbol{h}^{T}(G-1)
\end{array}\right],
\end{array}
$$

e a matriz de referências

$$
\boldsymbol{R}(n)=\left[\begin{array}{cccc}
\boldsymbol{r}_{1}^{T}(n) & \boldsymbol{r}_{1}^{T}(n-1) & \cdots & \boldsymbol{r}_{1}^{T}(n-G+1) \\
\boldsymbol{r}_{2}^{T}(n) & \boldsymbol{r}_{2}^{T}(n-1) & \cdots & \boldsymbol{r}_{2}^{T}(n-G+1) \\
\vdots & \vdots & \ddots & \vdots \\
\boldsymbol{r}_{L}^{T}(n) & \boldsymbol{r}_{L}^{T}(n-1) & \cdots & \boldsymbol{r}_{L}^{T}(n-G+1)
\end{array}\right]
$$

a equação (3.19) pode ser finalmente escrita em uma forma vetorial como a seguir:

$$
\boldsymbol{e}(n)=\boldsymbol{d}(n)+\boldsymbol{R}(n) \boldsymbol{w}
$$

Repetindo a análise já feita na seção 3.2.2.1, pode-se encontrar o vetor de pesos composto ótimo que minimiza $J=E\left[\boldsymbol{e}^{T}(n) \boldsymbol{e}(n)\right]$. Expandindo-se a função de mérito 
tem-se

$$
J=E\left[\boldsymbol{d}^{T}(n) \boldsymbol{d}(n)\right]+E\left[\boldsymbol{d}^{T}(n) \boldsymbol{R}(n)\right] \boldsymbol{w}+\boldsymbol{w}^{T} E\left[\boldsymbol{R}(n)^{T}(n) \boldsymbol{d}\right]+\boldsymbol{w}^{T} E\left[\boldsymbol{R}^{T}(n) \boldsymbol{R}(n)\right] \boldsymbol{w},
$$

que é uma função quadrática e que apresenta um único mínimo global para

$$
\boldsymbol{w}_{0}=-E\left[\boldsymbol{R}^{T}(n) \boldsymbol{R}(n)\right]^{-1} E\left[\boldsymbol{R}^{T}(n) \boldsymbol{d}\right]
$$

que corresponde a um valor mínimo da função de mérito

$$
J_{0}=E\left[\boldsymbol{d}^{T}(n) \boldsymbol{d}(n)\right]-E\left[\boldsymbol{R}^{T}(n) \boldsymbol{d}\right]^{T} E\left[\boldsymbol{R}^{T}(n) \boldsymbol{R}(n)\right]^{-1} E\left[\boldsymbol{R}^{T}(n) \boldsymbol{d}\right] .
$$

O sistema de controle descrito acima pode ser realizado substituindo-se os filtros $W$ da figura 18 por filtros adaptativos, cuja atualização leva em conta todos os sinais de erro e de referência na busca de um mínimo global. Como argumentado na seção 3.2.2.2. os valores estatísticos do sinal necessários para o projeto do filtro ótimo em geral não estão disponíveis, e a inversão de matrizes é uma operação que consome grande carga computacional. Para evitar o cálculo da matriz inversa, utiliza-se o método iterativo do gradiente, como no algoritmo LMS. A partir da equação (3.28) calcula-se a derivada da superfície de erro como sendo

$$
\frac{\partial J}{\partial \boldsymbol{w}}=2 E\left[\boldsymbol{R}^{T}(n) \boldsymbol{d}+\boldsymbol{R}^{T}(n) \boldsymbol{R}(n) \boldsymbol{w}\right]=2 E\left[\boldsymbol{R}^{T}(n) \boldsymbol{e}(n)\right]
$$

Como o cálculo da esperança estatística também não é uma operação viável na prática, usam-se os valores instantâneos de cada sinal de erro e do sinal de referência para atualizar os coeficientes do filtro adaptativo. A iteração resultante, usada no algoritmo Multiple Error LMS será

$$
\boldsymbol{w}(n+1)=\boldsymbol{w}(n)-\mu \boldsymbol{R}^{T}(n) \boldsymbol{e}(n),
$$

onde $\mu$, como no algoritmo LMS convencional, deve ser um valor pequeno, para evitar que o controlador divirja.

Note que este método é apenas uma generalização do algoritmo FxLMS de controle para um sistema multicanal. O sinal de referência aqui deve ser filtrado por $J=M \times L$ filtros, cada um emulando o caminho acústico entre um par alto-falante microfone. É necessário então que o sistema de estimação do caminho secundário estime estes $J$ caminhos secundários. Elliott, Stother e Nelson descrevem esse algoritmo e concluem que o algoritmo converge para valores próximos aos valores ótimos da equação (3.29) e que o algoritmo é robusto a erros na identificação dos caminhos secundários [33], comportamento similar ao apresentado pelo algoritmo FxLMS monocanal. 


\subsubsection{Estimação do Caminho Secundário Multicanal}

Do mesmo modo que no algoritmo FxLMS, o algoritmo MELMS também requer a estimação dos caminhos secundários. No sistema desenvolvido pelo grupo, antes de o sistema de controle entrar em funcionamento, o sistema realiza uma primeira estimação dos caminhos secundários sem a presença dos sinais de controle. Esta estimação de múltiplos caminhos secundários é realizada para uma fonte de controle por vez. O sinal $v(t)$ é fornecido a uma fonte de controle e é captado pelos $L$ microfones de erro, sendo usado para adaptar estes $L$ estimadores. Após um intervalo de tempo definido pelo usuário, o sistema fixa os valores dos $L$ caminhos secundários recém-estimados. O sistema então se mantém 100ms sem excitação, para que o som emitido pelo último alto-falante se dissipe, e após este intervalo passa a excitar uma nova fonte de controle, estimando novos $L$ caminhos secundários. Após realizar a primeira estimação de todos os caminhos secundários, o sistema de controle propriamente dito entra em funcionamento, utilizando os modelos de caminho secundário estimados nesta primeira etapa, sendo que o sistema de estimação continua funcionando, atualizando a cada intervalo os caminhos secundários de cada uma das fontes de controle. 


\section{PROJETO DO SISTEMA FÍSICO}

\subsection{Introdução}

O princípio acústico em que todo sistema de controle ativo de ruído se baseia é o mesmo: o princípio físico da superposição. Wright publicou uma série de artigos descrevendo um sistema de controle ativo de ruído ambiental por meio do uso de uma parede de alto-falantes, que geram um campo secundário que tenta cancelar um ruído em campo aberto por meio da superposição de ondas [34, 35, 36, 37, 38, 39, 40, 41].

O princípio da superposição é válido para qualquer sistema linear, e a propagação de uma onda acústica de amplitude não excessivamente elevada pode ser considerado um processo linear. Em sistemas ANC, a mais provável causa de não-linearidades está presente nos alto-falantes de bobina móvel usados como fonte de controle. Em geral, com o uso de alto-falantes adequadamente projetados, a não-linearidade presente será pequena e poderá ser ignorada sem causar grandes perdas ao sistema.

O sistema de Olson e May propunha que um microfone de erro ficasse posicionado próximo a uma fonte secundária [5]. Essa arquitetura produz atenuação apenas em uma região próxima aos transdutores, deixando o campo distante praticamente inalterado. Isso permite a atenuação de baixas freqüências ao redor da cabeça de um passageiro, mas não é viável para a atenuação de uma fonte de ruído de grande porte. Para este segundo caso, é necessário posicionar-se adequadamente um arranjo de fonte secundárias, de tal forma que ele reproduza da forma mais fiel possível o campo sonoro gerado pela fonte primária. Para se controlar o ruído em toda uma região de interesse, é necessário posicionar adequadamente um arranjo de sensores de erro que possa estimar a forma do campo sonoro gerado pela fonte de ruído, e assim definir como as fontes secundárias devem ser excitadas.

Verifica-se então que o projeto da disposição física do sistema de controle de ruído, que consiste na determinação da quantidade de fontes de controle e sensores de erro a serem usados e no seu respectivo posicionamento, tem grande impacto no nível de redução 
sonora que pode ser alcançado por um sistema ANC. Segundo Snyder, é o projeto físico do sistema ANC que define o nível máximo de atenuação global que pode ser obtido com um sistema ANC [42]. Por esta razão, grande importância deve ser dada ao correto posicionamento dos transdutores.

O posicionamento ótimo dos transdutores em geral não é obvio. Ele irá depender do campo sonoro gerado pela fonte primária, da região onde se deseja cancelamento e da faixa de freqüência em que se deseja cancelamento, entre muitos outros fatores. Infelizmente, os maus posicionamentos para os transdutores em geral também não são óbvios e não podem ser facilmente evitados. Logo faz-se necessário algum método para a otimização do posicionamento dos transdutores.

Muitos artigos foram publicados na última década tratando deste tema. Snyder e Hansen propuseram o uso da técnica de regressão múltipla para a otimização do projeto de um sistema de controle [43]. Esta técnica é uma generalização da técnica de estimação por mínimos quadrados, e para um grupo de fontes secundárias e sensores de erro, fornece a intensidade das fontes secundárias que produz a melhor atenuação do ruído nos sensores de erro. Mas esta técnica não permite escolher o melhor arranjo de transdutores dentre um conjunto de possíveis posições de transdutores, sendo apenas uma etapa auxiliar para um rotina de busca, como os algoritmos genéticos.

Asano, Suzuki e Swanson propuseram um método baseado na ortogonalização de Gram-Schmidt para não somente determinar o posicionamento como também a quantidade necessária de fontes de controle para redução de ruído em um ambiente reverberante [44]. Esta técnica se mostra bastante interessante, já que consegue definir não somente as posições mas também a quantidade ótima de fontes secundárias. Mas esta técnica não leva em consideração a posição ou quantidade de sensores de erro, sendo necessária uma generalização deste algoritmo para também levar em consideração a influência dos sensores de erro.

Martin e Roure utilizaram a técnica da expansão de harmônicas esféricas (EHE) e algoritmos genéticos para posicionar os transdutores ao redor de um transformador em campo aberto, buscando atenuação global em volta do transformador [14, 15]. A técnica EHE fornece um conjunto de fontes pontuais que melhor reproduz o campo sonoro gerado por uma fonte qualquer de ruído. Para isso é necessário fornecer um grande número de valores medidos da pressão sonora ao redor da fonte de ruído, o que inviabilizou a utilização deste método nesta dissertação.

Os algoritmos genéticos foram usados por Martin e Roure para selecionar um pequeno 
conjunto de fontes dentre aquelas fornecidos pela EHE e um pequeno conjunto de sensores dentre as posições usadas para medir a pressão sonora ao redor da fonte de ruído. Baek e Elliott também usaram algoritmos genéticos para otimizar o posicionamento de fontes de controle, mas para o controle de ruído em um ambiente reverberante (uma sala) [45]. Os algoritmo genéticos se mostram um método bastante robusto para a otimização do posicionamento de transdutores em sistemas ANC e por esta razão decidiu-se por usar algoritmos genéticos nesta dissertação para otimizar o posicionamento dos transdutores de um sistema ANC para controle do ruído de transformadores de potência. Como rotina de otimização foi usado o "GADS Toolbox" do Matlab 2006b.

Para realizar a otimização do posicionamento dos transdutores, é necessário fornecer ao algoritmo de otimização uma medição ou estimativa do campo de ruído primário em todas as possíveis posições de sensores de erro. A qualidade do resultado da otimização é diretamente influenciada pela qualidade das medições ou estimativas fornecidas ao algoritmo. Por isso é importante investir em uma determinação precisa do campo acústico. Realizar uma medição precisa do campo sonoro emitido por um transformador de grande porte é uma tarefa bastante cara, e por esta razão buscaram-se formas alternativas de estimação do campo sonoro que precisassem de menos medidas, para se chegar a um método mais barato.

Neste capítulo descrevem-se todas as etapas realizadas na tentativa de desenvolver um sistema de otimização do posicionamento dos transdutores usados em sistemas de controle ativo de ruído. Primeiramente descreve-se na seção 4.2 uma técnica de simulação acústica baseada em fontes pontuais situadas em campo aberto, podendo ela também simular o efeito do solo reflexivo (seção 4.2.1). A influência da quantidade de transdutores é exemplificada por simulações apresentadas na seção 4.3. Também se faz necessário estimar a pressão sonora primária em cada possível posição dos sensores de erro. O método de Usry, que estima o nível de pressão sonora em qualquer ponto exterior a uma fonte de ruído com base em medidas de vibração das paredes dessa fonte de ruído, é descrito na seção 4.4 .

Para a otimização propriamente dita da disposição dos transdutores apresenta-se a técnica dos algoritmos genéticos na seção 4.5.1. Diferentes métricas são testadas para o algoritmo genético (seção 4.5.2.1), assim como diferentes construções para os seus cromossomos (seção 4.5.2.2). Verificou-se que mesmo sendo o algoritmo genético um método de busca exaustiva, a qualidade da resposta obtida com esta técnica piora significativamente com o aumento do número de possíveis posições para os transdutores. É portanto indicado, previamente ao uso desta técnica de otimização, definir um grupo pequeno de 
possíveis posições dos transdutores, como feito por Martin e Roure ao aplicarem a técnica da expansão de harmônicas esféricas.

\subsection{Modelagem do Sistema Acústico}

O projeto da distribuição física dos transdutores é feito sempre buscando minimizar algum tipo de medida da perturbação que se deseja atenuar. Em geral, para problemas em campo aberto, o que se deseja minimizar é a potência emitida pelo conjunto de fonte primária (de ruído) e fontes secundárias (de controle), que é estimada como a somatória do quadrado da pressão sonora medida nos sensores de erro, como já discutido anteriormente no capítulo 2 .

Os algoritmos de otimização comentados anteriormente buscam então minimizar a potência sonora estimada. Para isto, o algoritmo deve realizar dois cálculos distintos: 1) calcular a máxima atenuação possível para um dado arranjo de transdutores e 2) calcular o arranjo de transdutores ótimo. O primeiro cálculo é relativamente fácil de se realizar, como já foi descrito na seção 2.4. O segundo cálculo é um pouco mais complexo, pois envolve algum tipo de busca coordenada, e é comentado na seção 4.5.1.

Para determinar a máxima atenuação possível para um dado arranjo de transdutores, é necessário saber o valor da pressão gerada tanto pela fonte primária quanto pelas fontes secundárias em cada um dos sensores de erro. O valor da pressão primária pode ser medido in situ, pode ser estimado a partir de medições de vibração na superfície da fonte primária ou pode ser simulado com base em um modelo matemático da fonte primária. Na seção 4.4 será discutido como o campo primário foi estimado neste projeto. Também é importante definir o campo sonoro que será gerado por cada uma das fontes secundárias. Como sons em baixa freqüência são geralmente irradiados de forma omnidirecional por alto-falantes, as fontes de controle podem ser simuladas como fontes pontuais de irradiação esférica, como foi descrito na seção 2.2 .2 .

Outro fator importante é o meio onde o sistema se encontra. As simulações deste capítulo foram todas feitas considerando um meio homogêneo, sendo ele campo aberto ou semi-aberto. Para as simulações com campo semi-aberto, definiu-se que o limite do espaço (o solo) era acusticamente duro, que é uma condição bastante próxima da verificada na prática, já que o solo ao redor de transformadores é comumente composto de brita, material bastante reflexivo.

No problema de redução de ruído em transformadores, geralmente não é necessário 
redução da pressão sonora em todo o entorno do transformador, mas somente em um ângulo sólido onde se encontra uma residência ou um grupo delas. Neste caso, em vez de se procurar o arranjo de transdutores que reduz a potência total emitida pelo conjunto de fontes, define-se uma superfície de controle (discretizada por um grupo de sensores de pressão), e procura-se pelo arranjo de transdutores que minimize a energia acústica estimada nesta superfície. Wright e Vuksanovic mostram que a maior atenuação neste caso é obtida quando os sensores de erro são posicionados exatamente na superfície de controle definida [35]. Mas nem sempre isto é possível, já que muitas vezes deseja-se atenuar uma região distante da fonte primária, mas limitações físicas como o comprimento do cabo por exemplo, não permitem que se posicionem os microfones nesta mesma região.

O cálculo da máxima atenuação possível na superfície de controle, dado o valor da pressão primária nos sensores de erro e na superfície de controle $\left(\boldsymbol{p}_{p}\right)$, e a posição das fontes secundárias e sensores de erro, pode ser realizado calculando-se o valor ótimo da velocidade de volume para cada fonte secundária que minimiza a somatória do quadrado da pressão nos sensores de erro, exatamente como descrito na seção 2.4.2. De posse do vetor velocidade de volume ótimo $\boldsymbol{q}_{0}$, pode-se calcular a pressão resultante na superfície de erro por

$$
\boldsymbol{p}_{r}=\boldsymbol{p}_{p}+\boldsymbol{Z} \boldsymbol{q}_{0}
$$

sendo $\boldsymbol{Z}$ a matriz de transferência entre as fontes secundárias e a os pontos que discretizam a superfície de erro. A estimativa da atenuação da energia acústica obtida na superfície de controle que se deseja maximizar é dada por

$$
\Delta=-10 \log \left(\frac{\boldsymbol{p}_{r}^{H} \boldsymbol{p}_{r}}{\boldsymbol{p}_{p}^{H} \boldsymbol{p}_{p}}\right) .
$$

Os algoritmos de otimização em geral calculam o valor de $\Delta$ para diversos arranjos de transdutores, verificando qual deles fornece a maior atenuação na superfície desejada.

\subsubsection{Efeito do Solo}

Ao se propagar por um meio que não um espaço aberto homogêneo, a onda sonora poderá sofrer influências dos obstáculos presentes na sua direção de propagação ou da não-homogeneidade do próprio meio de propagação. Simulações com um transformador localizado em campo aberto podem ser ditas irreais, uma vez que um transformador estará sempre posicionado próximo ao solo. Por essa razão, é conveniente realizar as simulações em campo semi-aberto. 


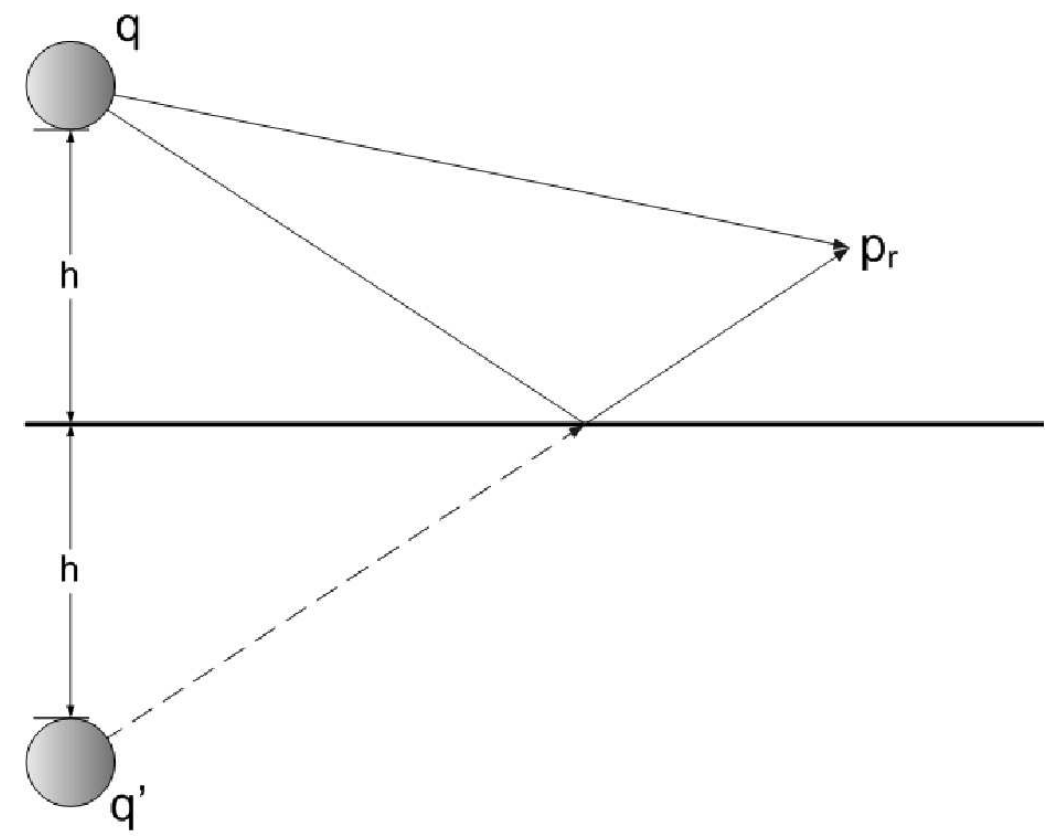

Figura 19: Diagrama mostrando onda direta e onda refletida da fonte $q$ que atingem o ponto $p_{r}$. Mostra-se que a onda refletida pode ser interpretada como uma onda direta proveniente da fonte-imagem $q^{\prime}$.

Quando uma frente de onda plana bate em uma parede infinita de superfície perfeitamente lisa ocorre o fenômeno da reflexão. Segundo a lei da reflexão, neste caso a onda será refletida com o mesmo ângulo que o ângulo entre a onda incidente e o vetor normal à parede, podendo a amplitude da onda refletida ser reduzida por um fator $|\alpha|$ e sua fase alterada por um fator $\gamma$, que pode ser representado pelo coeficiente de reflexão $\alpha=|\alpha| e^{j \gamma}$. Uma superfície é dita reflexiva ou acusticamente dura quando $|\alpha|=1$, e dita absorsiva ou acusticamente mole quando $\alpha=0$. A energia que não é transmitida ou refletida pela barreira é absorvida por ela. A onda sonora resultante dentro da barreira é chamada de onda transmitida, e sua amplitude será atenuada em relação à onda incidente pelo fator de transmissão $|\tau|=1-|\alpha|$.

Sendo $x, y, z$ um sistema de coordenadas cartesianas, define-se o semi-espaço

$$
S=\left\{S \in \mathbb{R}^{3} \mid-\infty<x<\infty ;-\infty<y<\infty ; 0<z<\infty\right\}
$$

Uma onda refletida pela superfície limítrofe desse espaço, o solo, pode ser calculada pelo método das imagens, com base na acústica geométrica. $\mathrm{O}$ método das imagens considera que o raio proveniente de uma fonte $q \in S$ que é refletido pelo solo e atinge o ponto $p_{r}$ é equivalente a um raio direto entre a fonte-imagem $q^{\prime}$ e o mesmo ponto $p_{r}$. No caso em que o solo é definido por $\partial S=(x, y, 0)$, a imagem de uma fonte pontual $q$ posicionada 
em $Q=(x, y, z)$ será uma fonte pontual $q^{\prime}$ com velocidade de volume atenuada pelo coeficiente de reflexão do solo $\alpha$ e localizada em $Q^{\prime}=(x, y,-z)$, como mostrado na figura 19.

O cálculo do vetor velocidade de volume ótimo deve ser alterado, para levar em conta a influência da reflexão no solo. Se os valores de pressão primária $\boldsymbol{p}_{p}^{\prime}$ usados na simulação tiverem sido medidos, assume-se que eles já contenham a influência do solo (e qualquer outro obstáculo) do local da medição; mas se os valores de pressão forem simulados, essa simulação deve considerar o efeito do solo, gerando uma imagem da fonte primária a partir do modelo de fonte primária construído.

A velocidade de volume das fontes-imagem é dada por $q^{\prime}=\alpha q$, logo a pressão total gerada pelas fontes secundárias e suas imagens nos sensores de erro pode ser escrita como

$$
\boldsymbol{p}_{s}^{\prime}=\boldsymbol{Z} \boldsymbol{q}+\boldsymbol{Z}^{\prime} \alpha \boldsymbol{q}=\left(\boldsymbol{Z}+\alpha \boldsymbol{Z}^{\prime}\right) \boldsymbol{q},
$$

sendo $\boldsymbol{Z}^{\prime}$ a matriz de transferência entre as fontes-imagem e os sensores de erro. $\boldsymbol{Z}^{\prime}$ irá diferir de $\boldsymbol{Z}$ porque a distância entre as fontes-imagem e os sensores de erro será diferente da distância entre as fontes secundárias e os sensores de erro.

A pressão resultante nos sensores de erro será então

$$
\boldsymbol{p}_{r}=\boldsymbol{p}_{p}^{\prime}+\left(\boldsymbol{Z}+\alpha \boldsymbol{Z}^{\prime}\right) \boldsymbol{q}
$$

Seguindo o mesmo raciocínio desenvolvido na seção 2.4.1, o vetor velocidade de volume ótimo que irá fornecer a maior atenuação nos sensores de erro considerando a influência da reflexão do solo será dado por

$$
\boldsymbol{q}=-(\boldsymbol{Z}+\alpha \boldsymbol{Z})^{+} \boldsymbol{p}_{p}^{\prime}
$$

\subsection{Influência da Quantidade de Transdutores}

Com base na simulação acústica descrita na seção anterior, é possível agora realizar algumas simulações simples, apenas para de uma forma intuitiva verificar como o sistema ANC se comporta para diversas combinações de número de fontes secundárias e número de sensores de erro.

A fonte primária foi modelada por um grupo de oito fontes pontuais, com velocidade de volume aleatória, distribuídas nos vértices de um cubo de $2 \mathrm{~m}$ de lado (doravante chamado octopolo) com sua base centrada na origem. Até três fontes pontuais distribuídas próximas 
a esse cubo foram utilizadas como fontes secundárias e até quatro sensores omnidirecionais foram usados como sensores de erro.

Primeiramente verifica-se a influência da quantidade de sensores de erro para uma configuração com apenas uma fonte de controle posicionada em $(x, y, z)=(1,2 ; 0 ; 0,7)$. Verifica-se com um sensor de erro a inserção de um ponto com pressão sonora nula no espaço, exatamente na posição desse sensor, como é mostrado na figura 20. Com dois sensores de erro, a atenuação obtida já não é tão grande quanto a obtida com apenas um sensor, mas o ângulo sólido em que ocorre atenuação é substancialmente maior, como mostra a figura 21. Conforme aumenta o número de sensores de erro, observa-se um aumento no ângulo sólido em que ocorre atenuação, como se verifica nas figuras 22 e 23. Mantendo quatro sensores de erro fixos, varia-se agora o número de fontes secundárias usadas. Verifica-se que a atenuação aumenta quanto maior o número de fontes secundárias, como é mostrado nas figuras 23,24 e 25.

No entanto, quando os números de fontes secundárias e de sensores de erro se igualam, o sistema se torna um sistema determinado, com uma única solução, que é a imposição de pressão nula nas posições dos microfones. A imposição de nulos pode acarretar em ganho do nível sonoro em posições entre os microfones. Diante deste fato, Martin e Roure propõem como regra prática usar sempre ao menos um sensor de erro a mais que o número de fontes secundárias [15].

A figura 26 exemplifica o comportamento de um sistema subdeterminado, com um sensor de erro e três fontes secundárias. Esse sistema apresenta um resultado semelhante ao obtido pelo sistema com apenas uma única fonte secundária.

Verifica-se então desta simulação muito simples a necessidade do uso de múltiplas fontes secundárias e múltiplos sensores de erro quando se deseja atenuar um campo sonoro mais complexo. O posicionamento dos transdutores é chave para que a atenuação ocorra na direção desejada.

\subsection{Modelagem do Campo Sonoro Primário}

Para qualquer método de otimização que se queira utilizar para estimar o melhor posicionamento de transdutores para sistemas ANC, é necessário conhecer o campo sonoro primário gerado pela fonte de ruído. É a partir deste dado que os diversos métodos procuram uma configuração de fontes secundárias que consiga reproduzir o campo sonoro primário, ao menos para uma região de interesse do espaço. 

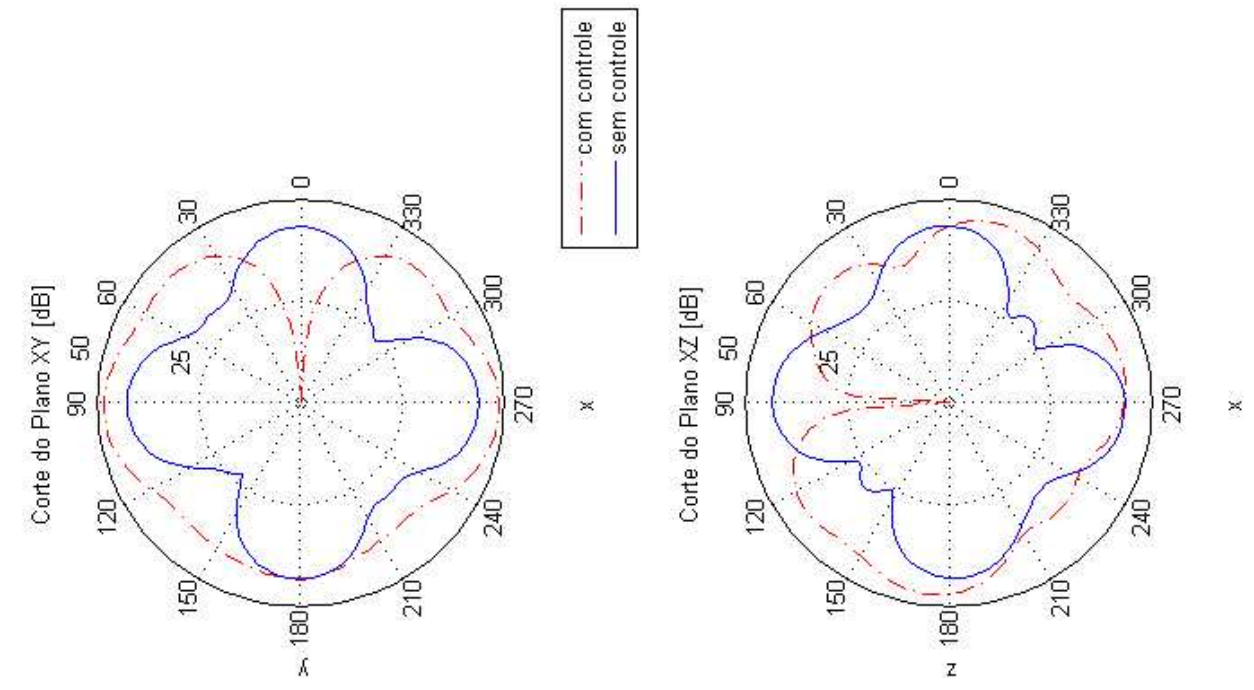

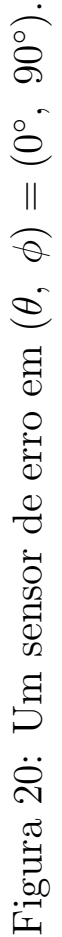

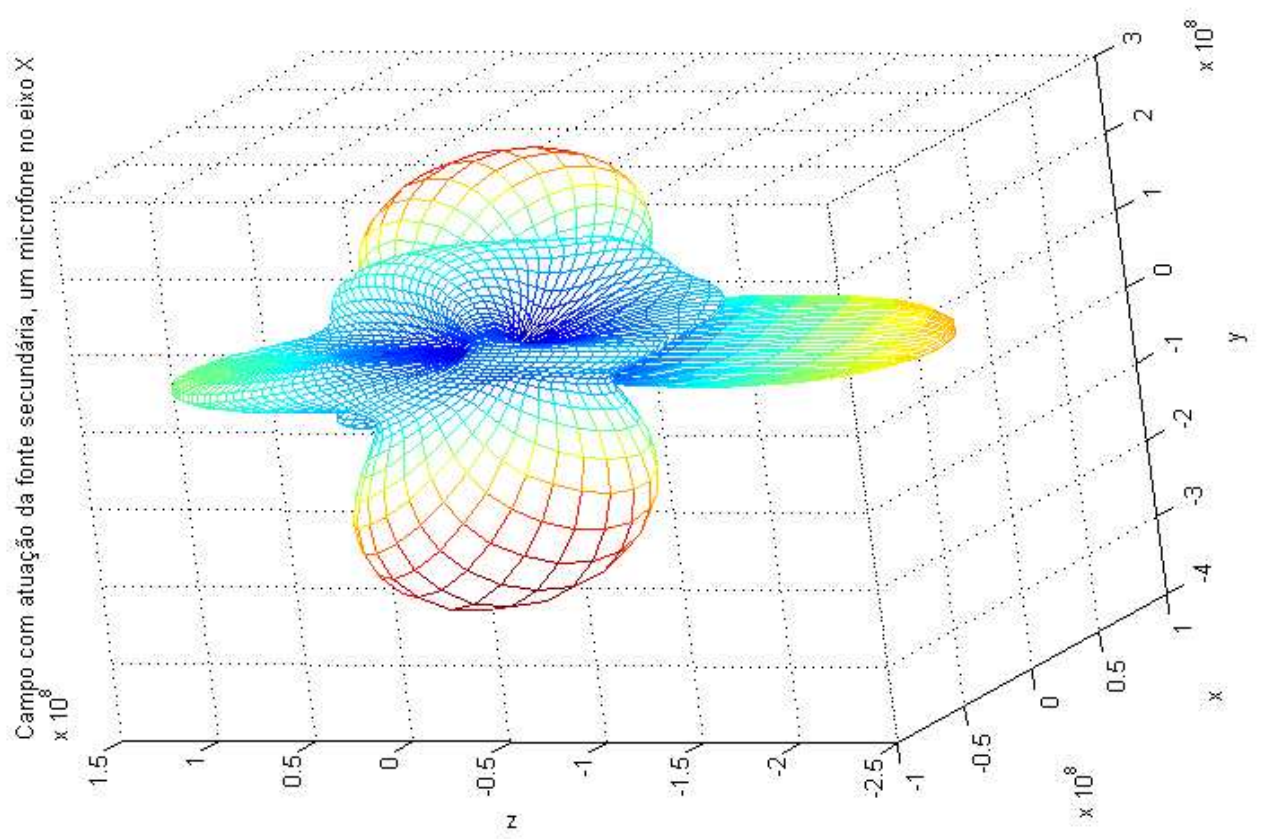



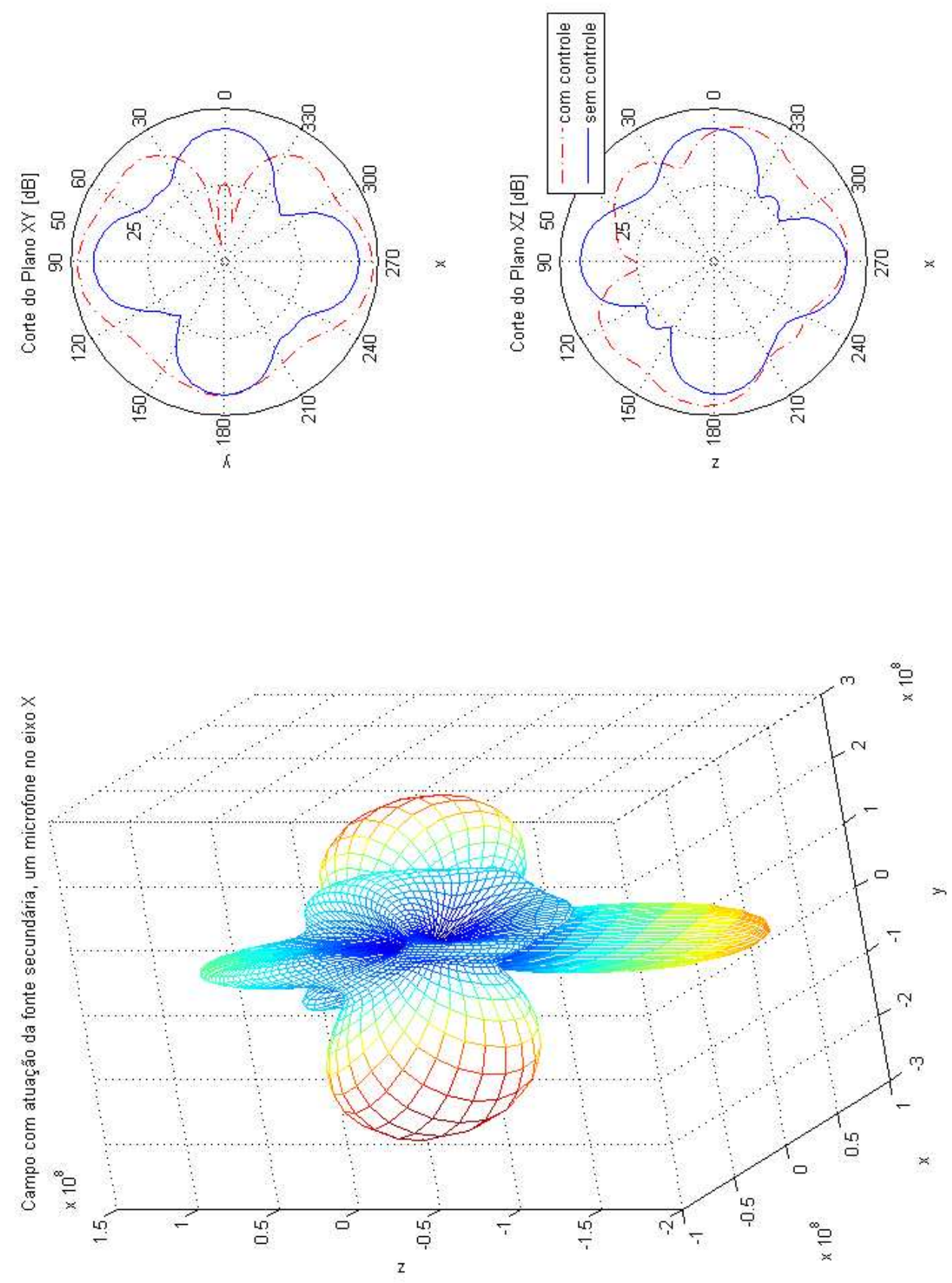

$\dot{0}$
0
8
0
0
0
0
8
8
0
0
1
11
0
0
0
8
0
0
0
0
0
0
0
0
0
0
0
0
0
0
0
$\ddot{1}$
0
0
0
0
01
01 

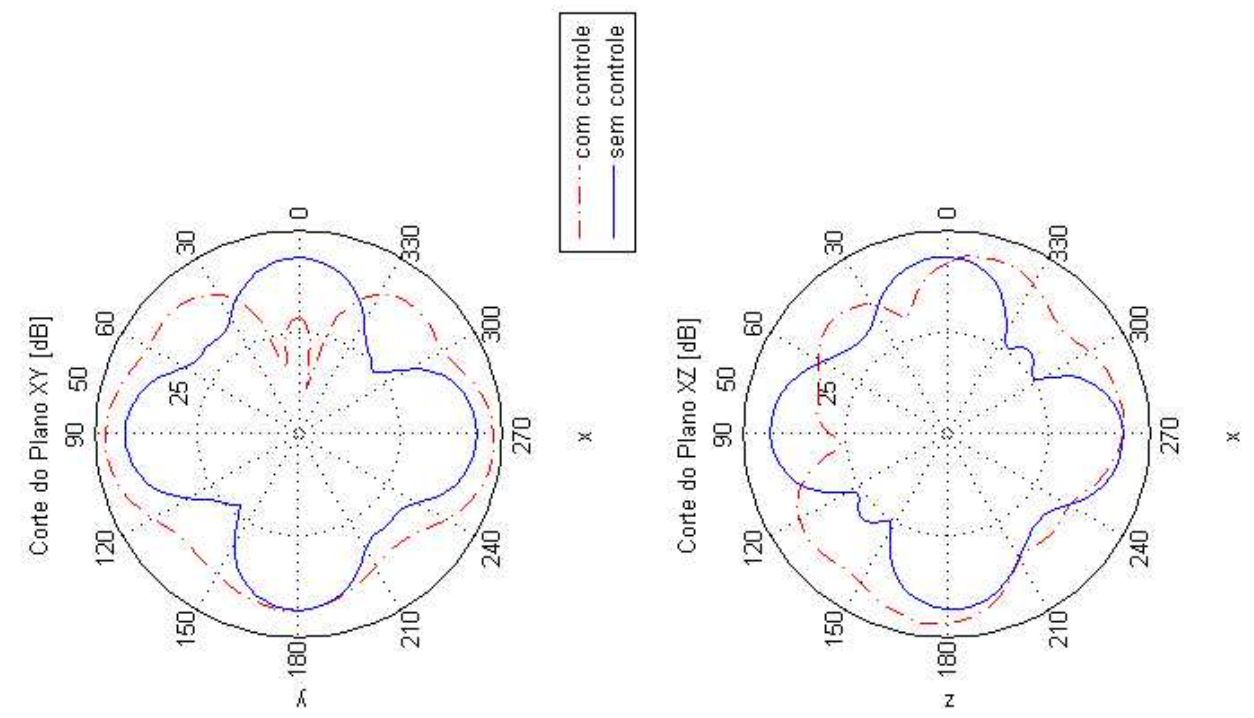

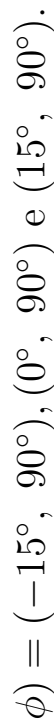

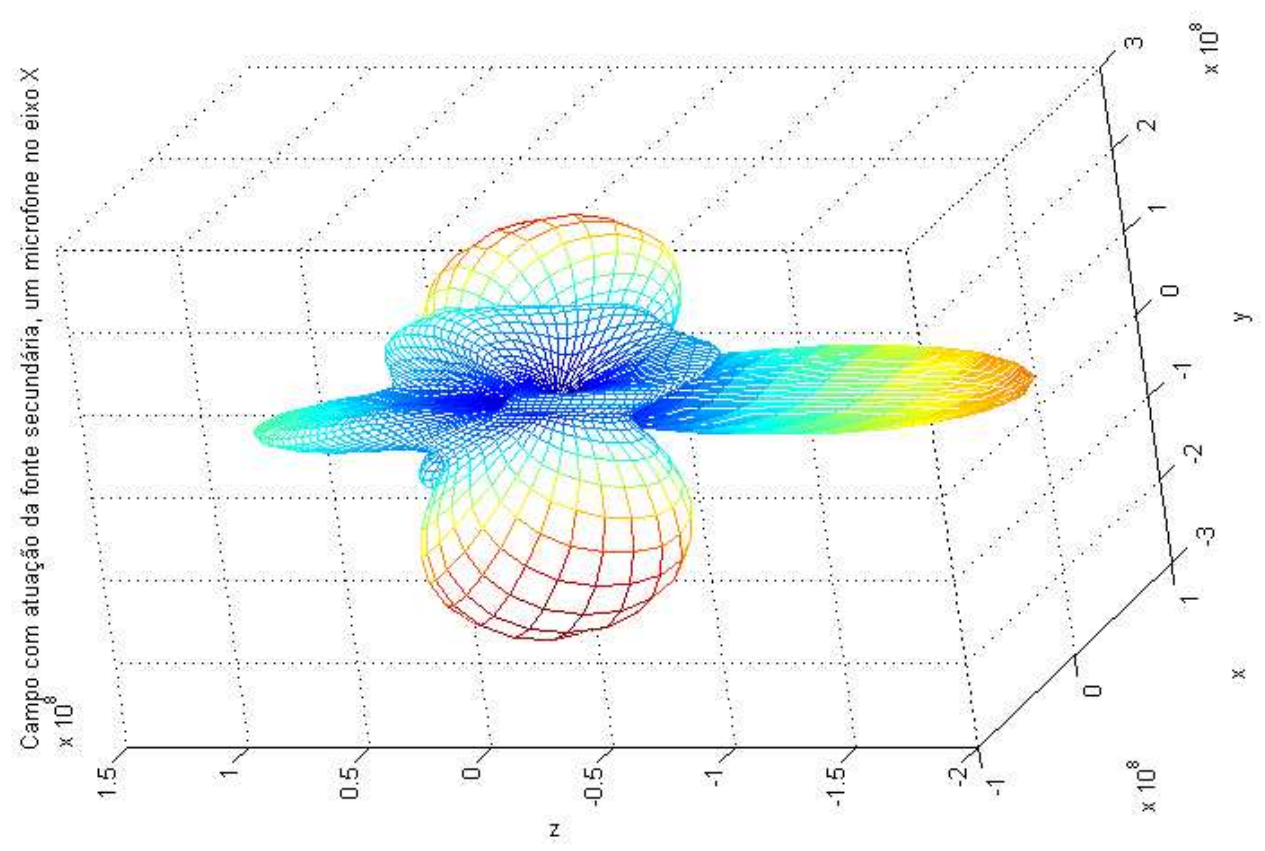

ब

풍 

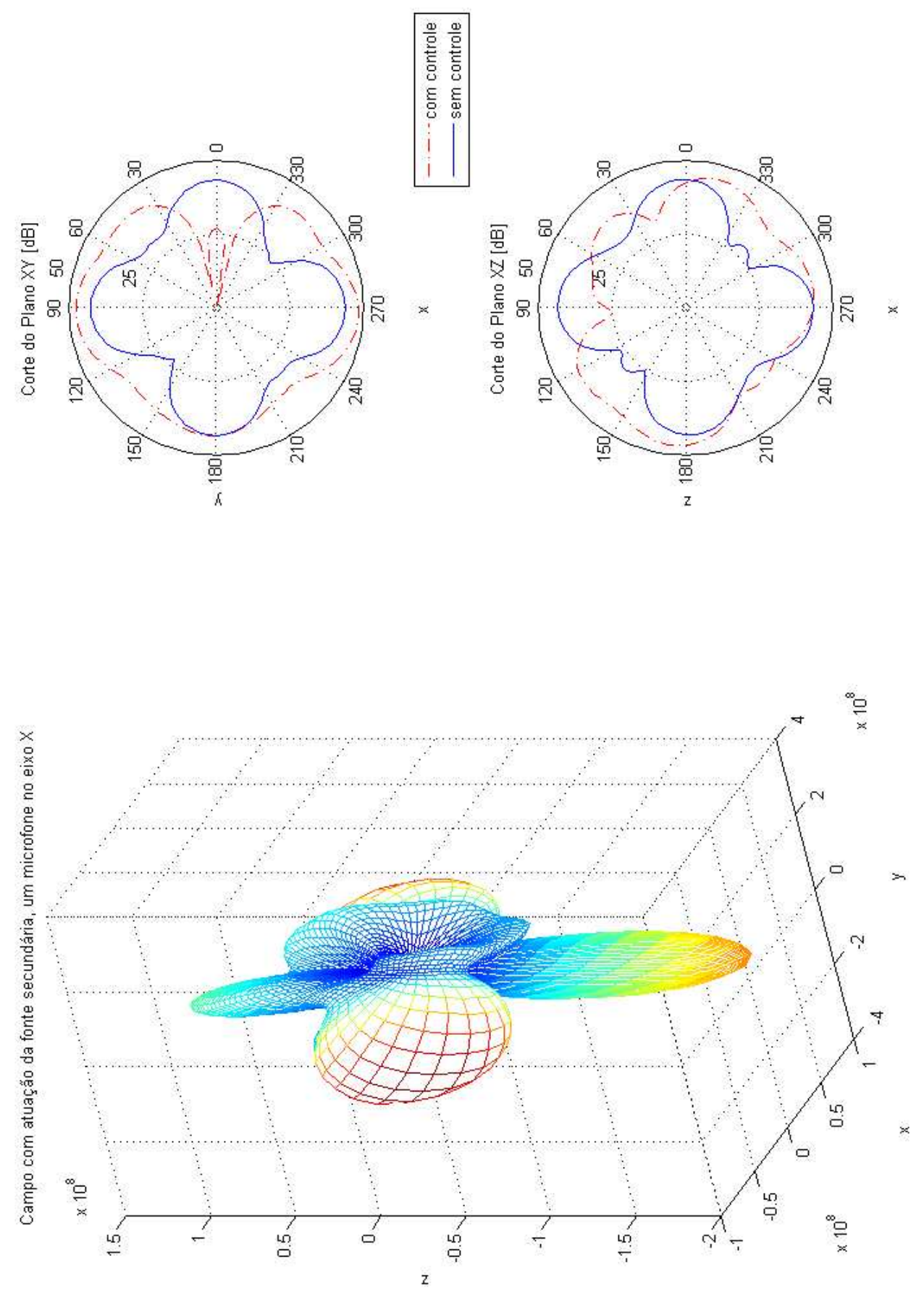

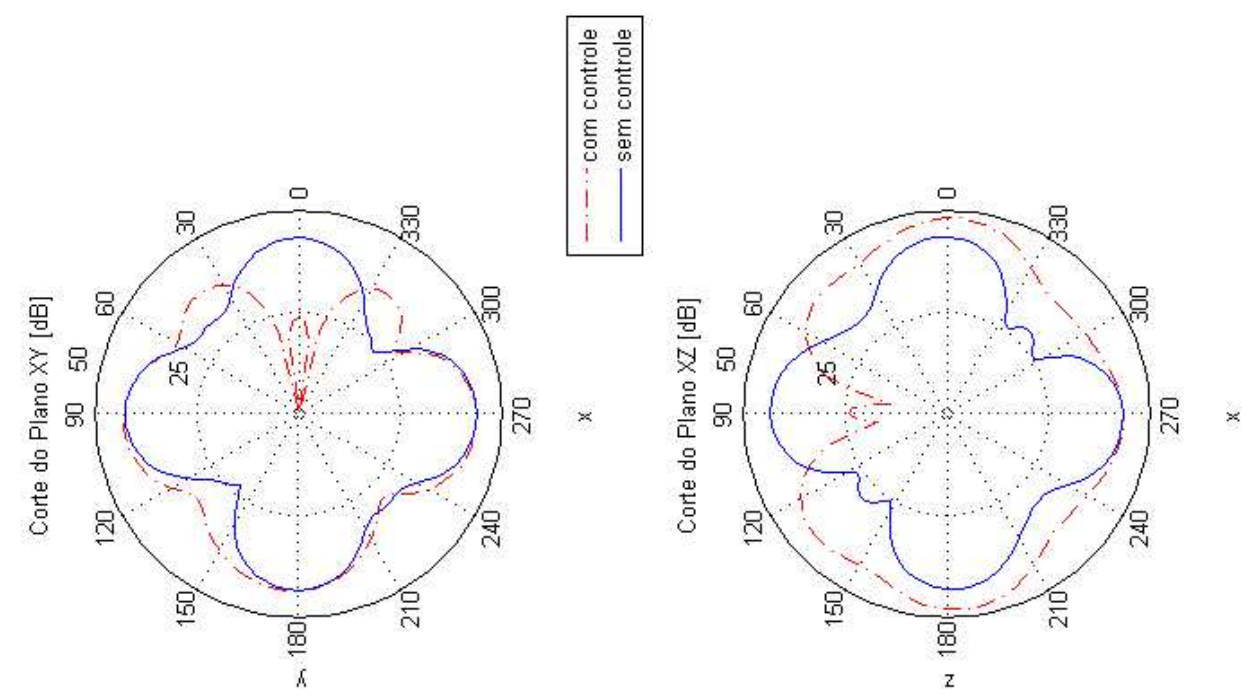

$\dot{\sigma}$

$\dot{0}$

$\ddot{\sim}$

$\stackrel{-}{\stackrel{\Xi}{0}}$

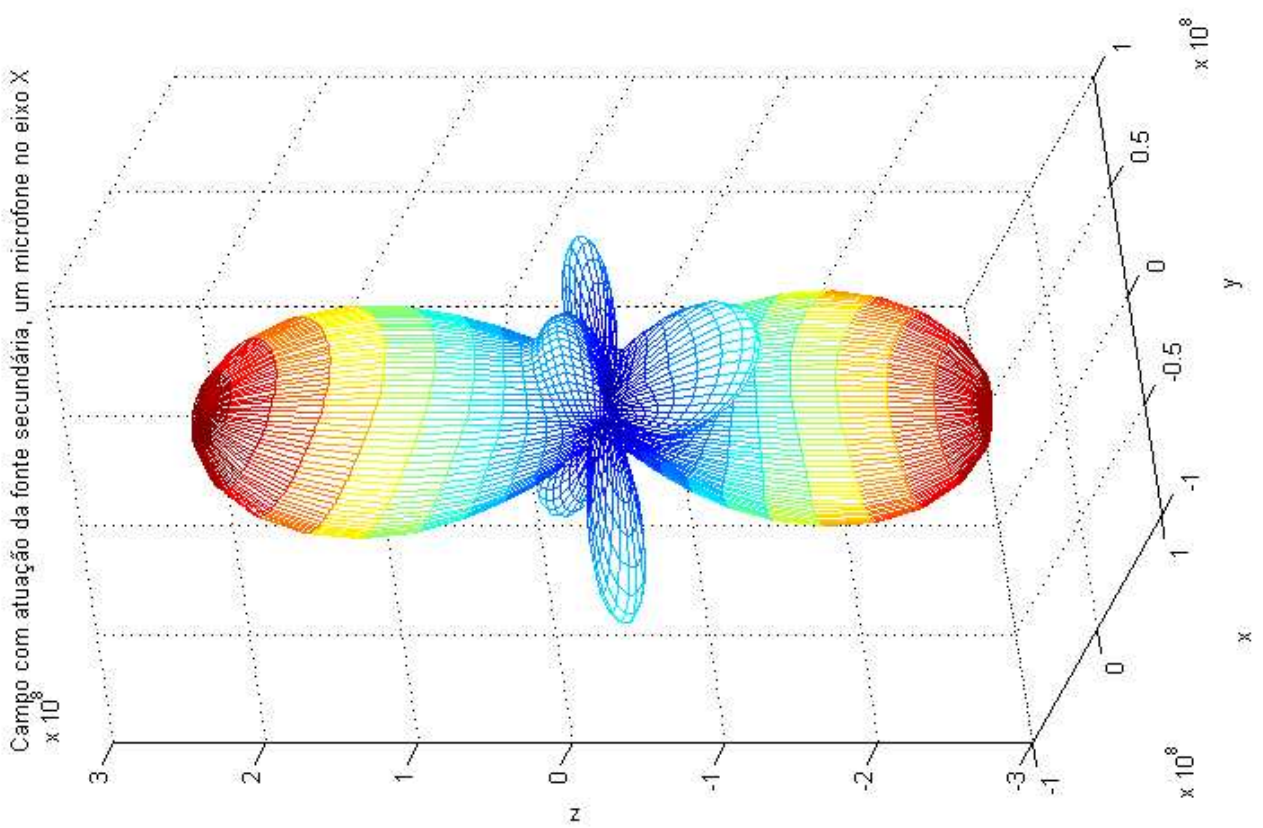

i

$\stackrel{-1}{-1}$

(1)

si

8

है

की

葛

כ

矛

$\stackrel{\widetilde{\Xi}}{\Xi}$

뭉

ค)

๘ี

$\stackrel{80}{=}$

$\frac{\pi}{2}$

क

ठี

0
0
0
0
$\Xi$
0
0
0
0
0
0
0
0
0

$0^{2}$

$\ddot{\mathrm{H}}$

$\underset{\Xi}{\widetilde{\Xi}}$ 

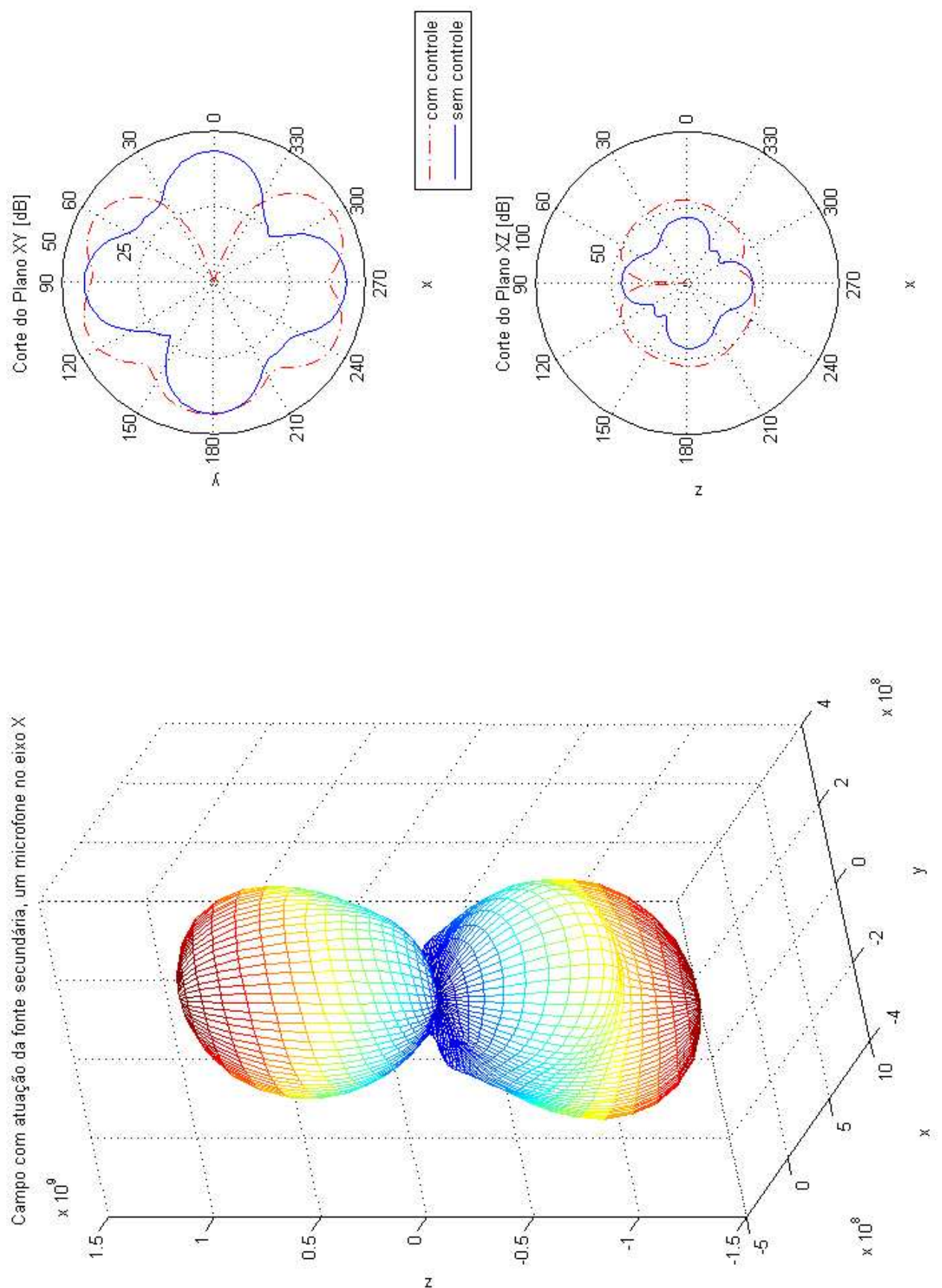

o

$\ddot{\sigma}$

iิ

$\subsetneq$

ก

0

$\ddot{\mathrm{i}}$

Е

$\dot{0}$

ㅂ.

$\stackrel{\sim}{-}$

$\frac{1}{x}$

रे

8

్ㅜㅇ

. .

.

胥

致

s

ฮี

ค่

ఈ

$\pi$

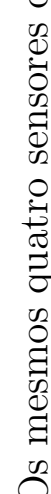

요

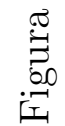



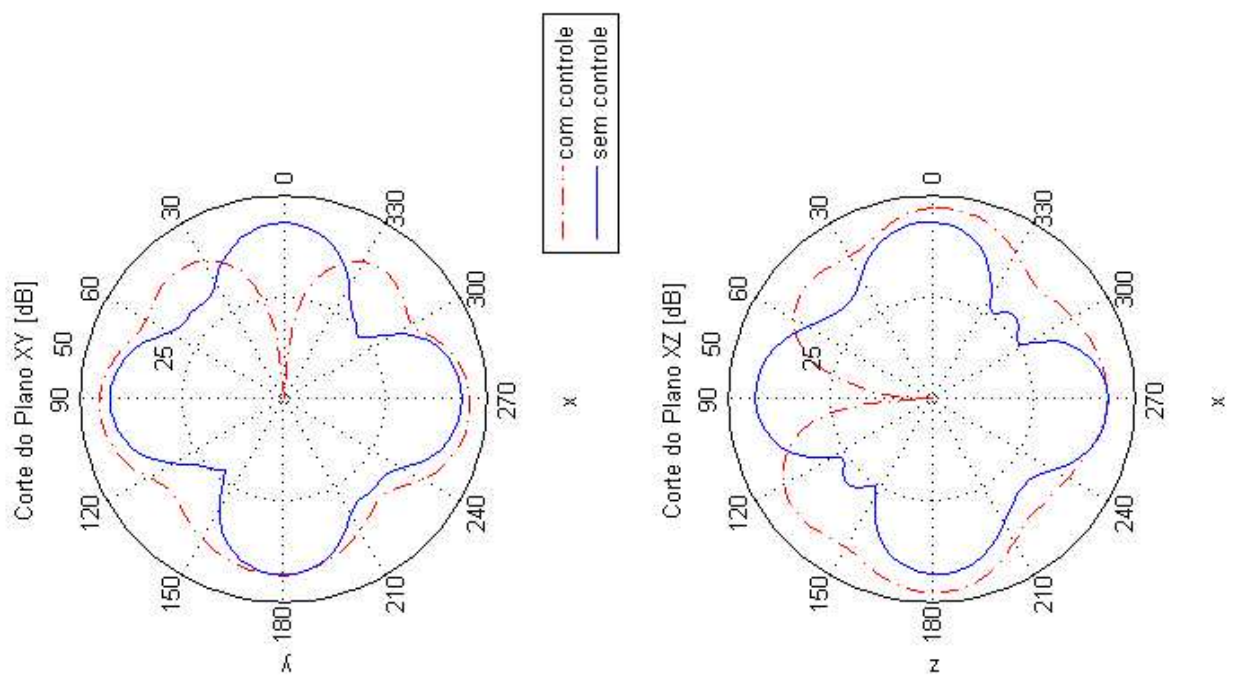

ஓं

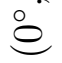

$\frac{11}{\theta}$

e

망

๑ี

ष

ठี

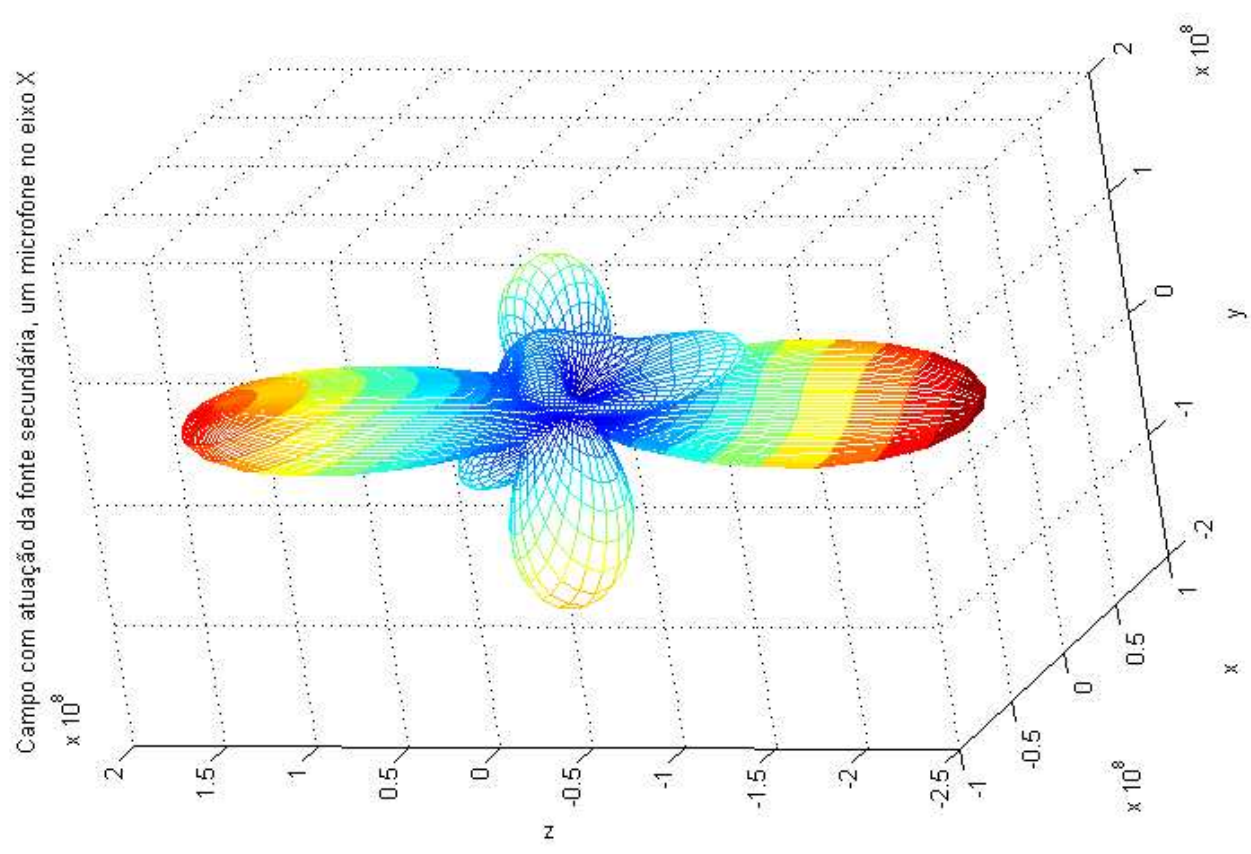


A maneira mais precisa de se determinar o campo sonoro primário produzido por um transformador seria realizar uma medição em campo, o que é bastante difícil de se fazer no caso de um transformador de potência por causa de suas dimensões físicas e também por restrições de segurança, já que estas medições precisariam ser feitas com o transformador em funcionamento, o que envolve altos níveis de tensão elétrica em suas buchas.

O campo sonoro pode ser estimado pelo método dos elementos de fronteira (BEM, do inglês Boundary Element Method), no qual é necessário fornecer as condições de fronteira do problema. Para simular o campo acústico gerado por um transformador em campo aberto, a fronteira a ser definida seriam as próprias paredes do transformador, que devem ser subdivididas em diversos elementos de área (ou elementos de fronteira), e a condição de fronteira a ser fornecida é a velocidade (ou aceleração) destes diversos elementos de fronteira. Apesar de ser uma técnica bastante poderosa para prever o campo acústico de uma fonte, esta técnica consome muito tempo com o correto modelamento da fonte e requer valores exatos de aceleração para cada elemento de área considerado.

Usry et al. propõem um método simplificado para a estimação do campo acústico produzido por transformadores de potência [46], baseado na equação de Helmholtz descrita na seção 2.5 e nas equações de Pierce para a difração em quinas [47]. Este método considera cada elemento de área como se fosse um pistão em uma parede infinita e calcula a pressão gerada em um dado ponto pela onda direta vinda deste "pistão", a onda refletida no solo e as ondas difratadas nas quinas do transformador. Somando-se o efeito de cada elemento de área no ponto desejado, obtém-se a estimativa da pressão gerada pela fonte primária no ponto de observação.

A razão para se implementar este método foi o fato de medições de vibração da parede do tanque do transformador terem sido feitas por outros componentes deste grupo de pesquisa, que trabalharam em soluções de controle da vibração do mesmo transformador de potência. O nível de vibração foi medido em cerca de trezentos pontos distribuídos pela superfície do transformador. Esta técnica se mostrou bastante atrativa por duas razões: 1) porque permite que o nível de pressão sonora gerado pela fonte primária seja estimado em qualquer ponto desejado ao redor da fonte primária, permitindo uma maior flexibilidade na escolha dos pontos de sensores de erro e de controle usados nos algoritmos de otimização do posicionamento dos transdutores do sistema ANC, e 2) porque os níveis de vibração da parede do tanque do transformador já estavam disponíveis, enquanto que a medição detalhada dos níveis de pressão sonora ao redor da fonte primária iria consumir muito tempo e recursos financeiros. 


\subsubsection{O Método de Usry}

O campo acústico gerado por um transformador de potência pode ser previsto baseado em medições de vibração da parede do tanque de um transformador. Para se estimar o ruído do transformador em campo distante, isto é, a distâncias grandes se comparadas com as dimensões do transformador, Usry et al. alegam que é suficiente idealizar o transformador como um paralelepípedo [46]. A segunda idealização proposta por eles é considerar o solo como acusticamente duro (perfeitamente reflexivo). Usa-se para isto o método das imagens para inserir a influência do solo no modelo. Por fim, cada harmônica do espectro do ruído do transformador é tratada independentemente.

Usry et al. iniciam sua análise pela equação de Helmholtz

$$
p(\mathbf{x})=\int_{V} Q_{\mathrm{vol}}(\mathbf{y}) G(\mathbf{y} \mid \mathbf{x}) d V+\int_{S^{\prime}}[G(\mathbf{y} \mid \mathbf{x}) \nabla p(\mathbf{y})-p(\mathbf{y}) \nabla G(\mathbf{y} \mid \mathbf{x})] \cdot \mathbf{n} d S^{\prime} .
$$

Define-se como volume de integração o volume $V$ limitado por uma superfície interna e uma superfície externa, sendo que a superfície interna $S$ é a própria parede do transformador e a superfície externa tende ao infinito. Considera-se que dentro deste volume não existam fontes de volume $\left(Q_{\mathrm{vol}}(\mathbf{y})=0\right)$, então a equação acima se reduz a

$$
p(\mathbf{x})=\int_{S}[G(\mathbf{y} \mid \mathbf{x}) \nabla p(\mathbf{y})-p(\mathbf{y}) \nabla G(\mathbf{y} \mid \mathbf{x})] \cdot \mathbf{n} d S .
$$

Como já comentado na seção 2.5.1, a função de Green pode, em princípio, assumir qualquer valor, desde que satisfazendo a função 2.66). Sendo $S$ uma superfície fechada, a função de Green ${ }^{1} G(\mathbf{y} \mid \mathbf{x})=2 g(\mathbf{y} \mid \mathbf{x})$ garante que $\nabla G(\mathbf{y} \mid \mathbf{x}) \cdot \mathbf{n}=0$ em todos os pontos da superfície $S$ [21, capítulo 9.9]. A equação 4.7) pode então ser reescrita como

$$
p(\mathbf{x})=\int_{S} G(\mathbf{y} \mid \mathbf{x}) \nabla p(\mathbf{y}) \cdot \mathbf{n} d S
$$

O gradiente da pressão sonora na superfície $S$ é $\nabla p(\mathbf{x})=-j \omega \rho_{0} \boldsymbol{v}(\mathbf{x})$. E como para excitações harmônicas a aceleração das partículas é $\boldsymbol{a}(\mathbf{x})=j \omega \boldsymbol{v}(\mathbf{x})$, então $\nabla p(\mathbf{x})=$ $-\rho_{0} \boldsymbol{a}(\mathbf{x})$. A aceleração das partículas está orientada na direção contrária ao vetor normal da superfície, $\operatorname{logo} \boldsymbol{a} \cdot \mathbf{n}=-a_{n}$. Assim, a equação (4.8) pode ser escrita como

$$
p(\mathbf{x})=\rho_{0} \int_{S} G(\mathbf{y} \mid \mathbf{x}) a_{n}(\mathbf{y}) d S .
$$

Quando uma onda plana incide sobre uma barreira finita, além da reflexão, comentada na seção 4.2.1, em sua quina ocorrerá um espalhamento da energia sonora, que pode ser

\footnotetext{
${ }^{1} g(\mathbf{y} \mid \mathbf{x})$ é a equação de Green para o espaço livre, como definida na seção 2.5 .2
} 


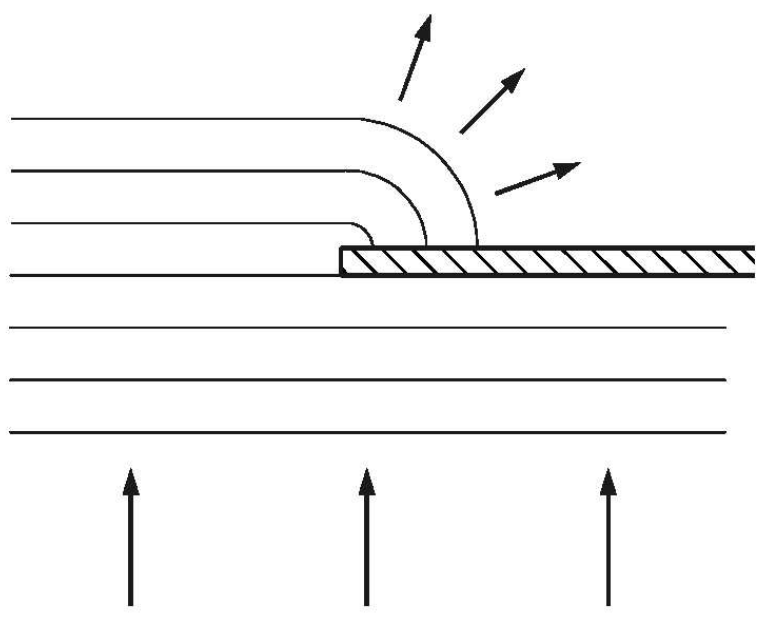

Figura 27: Efeito de difração de canto que ocorre quando uma onda plana incide em uma barreira finita.

descrito como um fenômeno de difração ou espalhamento de onda, como mostrado na figura 27. É interessante notar que o fenômeno da difração de cantos só ocorre para ondas com comprimento de onda maior que a ordem de grandeza das dimensões da superfície. Logo, ondas de alta freqüência terão muito pouco energia espalhada, enquanto ondas de baixa freqüência terão um quantidade considerável de energia espalhada.

Para inserir a influência da difração do som nas quinas do transformador, a função de Green deve ter um novo termo para quantificar este efeito. Como a função de Green exata que representa este efeito é muito difícil de ser calculada, Usry et al. propõem uma aproximação baseada no trabalho de Pierce sobre difração sonora por cunhas [47].

O fenômeno da difração de canto pode ser analisado sob a ótica da teoria geométrica da difração, que diz que a energia de um raio incidente em uma quina ou canto de uma dada superfície é distribuída em um grupo de raios difratados, cuja energia é determinada pela geometria e propriedades acústicas da quina ou canto. Considerando a superfície do transformador como uma concatenação de cunhas de ângulo reto (formadas pela interseção de dois lados adjacentes), uma aproximação para a equação de Green da componente difratada pode ser obtida considerando cada face da superfície $S$ como um lado de quatro possíveis cunhas de ângulo reto, o que pode ser escrito como

$$
G(\mathbf{x} \mid \mathbf{y})=g_{\text {dir }}(\mathbf{x} \mid \mathbf{y})+\sum_{n} g_{\text {diff }}(\mathbf{x} \mid \mathbf{y})
$$

onde $\mathbf{x}$ é a posição da fonte e $\mathbf{y}$ a posição do observador. O termo $g_{\text {dir }}$ se refere à onda 


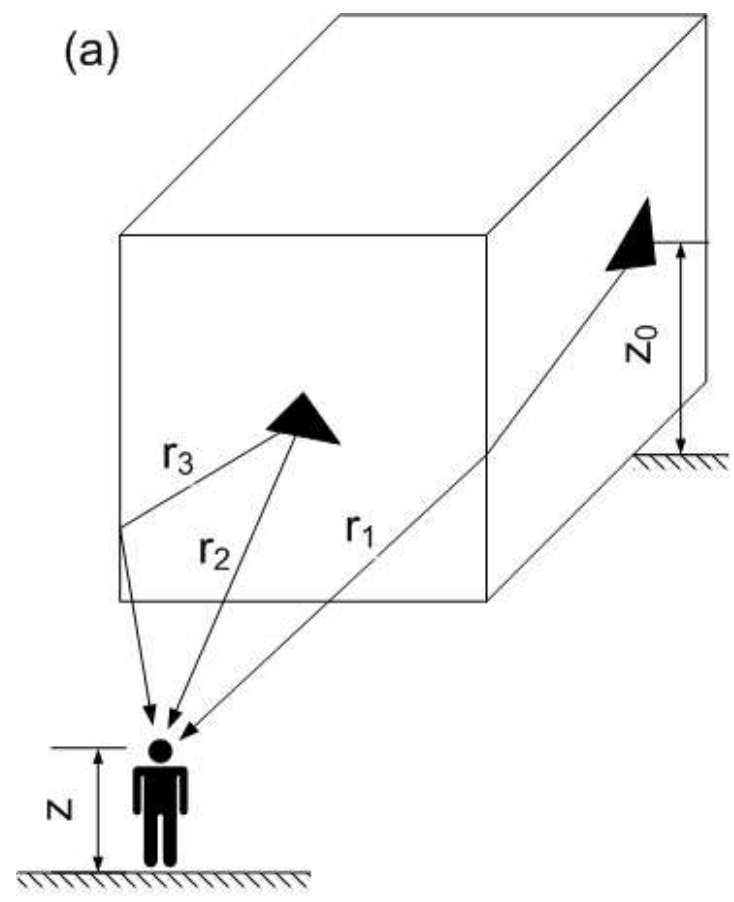

(b)

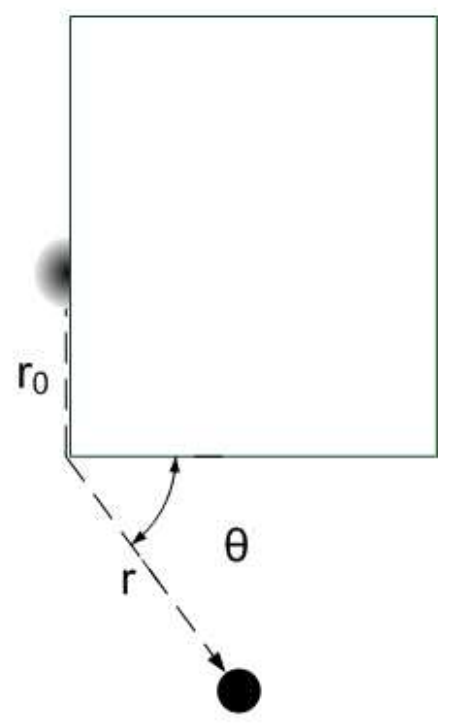

Figura 28: A superfície do transformador pode ser modelada por um paralelepípedo (a) dividido em diversos pequenos elementos de área. O raio $r_{2}$ representa um raio direto entre fonte e receptor. $r_{1}$ e $r_{3}$ são dois exemplos de raios difratados. A figura (b) mostra a vista de cima do paralelepípedo com os parâmetros geométricos necessários para o cálculo de $g_{\text {diff. }}$.

direta, e é dado pela equação de Green no campo livre

$$
g_{\text {dir }}=2 \frac{e^{-j k r}}{4 \pi r}
$$

onde $r$ é a distância entre $\mathbf{x}$ e $\mathbf{y}$. Este termo só deve ser computado se a fonte for visível pelo observador, ou seja, desde que não haja nenhuma barreira entre fonte e observador.

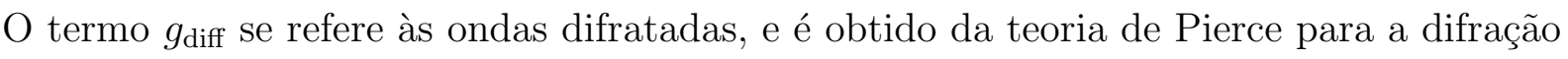
em cunhas de ângulo reto, dado por

$$
g_{\text {diff }}=\frac{e^{j k L+\pi / 4}}{L \sqrt{2}}\left[A_{D}\left(X_{+}\right)+A_{D}\left(X_{-}\right)\right]
$$

onde $L=\sqrt{\left(r+r_{0}\right)^{2}+\left(z-z_{0}\right)^{2}}$ é o comprimento do menor caminho que liga o observador, o canto difrator e a fonte (elemento de fronteira); sendo $r$ a distância entre o observador e o canto difrator, $r_{0}$ a distância entre o canto difrator e a fonte, $z_{0}$ a altura da fonte, $z$ a altura do observador e $\theta$ o ângulo entre a superfície visível pelo observador e a reta $r$, como é mostrado na figura 28.

A função $A_{D}(\mathbf{x})$ é relacionada às funções auxiliares de Fresnel [48], chamadas de 
$f(\mathbf{x})$ e $g(\mathbf{x})$, da seguinte maneira:

$$
A_{D}(X)=\operatorname{sinal}(X)[f(|X|)-j g(|X|)]
$$

Os argumentos $X_{+}$e $X_{-}$são dados por

$$
X_{ \pm}=\Gamma M\left(\theta \pm \frac{3 \pi}{2}\right)
$$

onde

$$
\begin{gathered}
M(\phi)=-\sqrt{3}\left[\frac{1}{2}+\cos \left(\frac{2 \phi}{3}\right)\right], \\
\Gamma=\sqrt{\frac{k r r_{0}}{\pi L}} .
\end{gathered}
$$

Para cada arranjo de fonte e receptor tal que seja possível traçar um segmento de raio entre a fonte e uma quina da superfície $S$ e um outro segmento do ponto onde o segmento de raio anterior incide na quina até o receptor, deve-se adicionar um termo $g_{\text {diff }}$ à equação 4.10.

Pierce também formaliza em seu artigo a difração por duas quinas [47], mas em seu método, Usry desconsidera este efeito. Por causa disso, é possível verificar descontinuidades nas fronteiras onde uma superfície deixa de ser visível ou uma nova superfície passa a ser visível.

\subsubsection{Programação do Método de Usry}

Uma rotina em Matlab foi desenvolvida para calcular o nível de ruído emitido por um transformador baseado nas medidas de vibração de sua parede. O primeiro passo é fornecer os limites da superfície que irá representar o transformador. Esta superfície deve então ser dividida em um número finito de elementos, os elementos de fronteira, sendo que cada um destes elementos deve ter um valor de aceleração relacionado. Para este tipo de simulação é necessário que as dimensões do elemento de fronteira sejam menores que metade do comprimento de onda em análise. Não foi possível realizar medições de vibração na superfície superior do transformador por questões de segurança, mas como o núcleo não possui nenhum vínculo mecânico com esta superfície e o óleo do interior também não encosta nesta superfície, conclui-se que a superfície superior apresenta vibração muito menor que as demais superfícies, e portanto pode ser desconsiderada.

Para cada ponto onde se deseja estimar a pressão sonora deve-se calcular a função de 
Green deste ponto a todos os elementos de fronteira, substituindo-se a equação 4.8 pelo somatório

$$
p(\mathbf{x})=\frac{\rho_{0}}{4 \pi} \sum_{m=1}^{N} a_{n}\left(\mathbf{y}_{m}\right) d S_{m}\left[\sum_{l=1}^{M_{m}} G_{l}\left(\mathbf{x} \mid \mathbf{y}_{m}\right)\right],
$$

onde $d S_{m}$ é a área de cada elemento de fronteira, $N$ é o número de elementos de fronteira considerados e $M_{m}$ é o número de termos da função de Green a serem considerados para cada configuração fonte-receptor. Note que o fator $4 \pi$ presente em todas as formas da equação de Green foi colocado em evidência.

Como para uma cunha de ângulo reto $X_{+}=X_{-}$, então o termo $g_{\text {diff }}$ pode ser reescrito como

$$
g_{\text {diff }}=2 \operatorname{sinal}(X) \frac{e^{j k L+\pi / 4}}{L \sqrt{2}}[f(|X|)-j g(|X|)]
$$

com

$$
X=X_{V}=-\sqrt{\frac{3 k r r_{0}}{\pi L}}\left[\frac{1}{2}+\cos \left(\frac{2 \theta}{3}\right)\right]
$$

para quando a fonte é visível para o receptor, e

$$
X=X_{S}=\sqrt{\frac{3 k r r_{0}}{\pi L}}\left[\cos \left(\frac{2 \theta}{3}\right)-\frac{1}{2}\right]
$$

para quando o receptor estiver na sombra de uma quina difratora. Para os dois casos o ângulo $\theta$ é medido como mostrado na figura 28 .

Para cada configuração fonte-receptor é necessário calcular os parâmetros geométricos presentes nas equações 4.19) e 4.20). A rotina de cálculo de pressão sonora pelo método de Usry foi programada da seguinte forma:

- Para o receptor posicionado em um ponto exterior à superfície definida do transformador, testa-se se cada uma das paredes é visível para o receptor.

- Se a parede é visível, calcula-se $g_{\text {dir }}$ e as quatro possíveis $g_{\text {diff }}$ (de acordo com a equação (4.19) ) e posteriormente $p(\mathbf{x})$ para cada um dos elementos de área da parede.

- Se a parede não for visível, calcula-se apenas um $g_{\text {diff }}$ (de acordo com a equação 4.20) e posteriormente $p(\mathbf{x})$ para cada um dos elementos de área da parede.

- Ao fim soma-se a influência de todos elementos de superfície no receptor.

Os parâmetros geométricos são calculados a cada nova iteração usando ferramentas de álgebra vetorial, sendo $\boldsymbol{a} \cdot \boldsymbol{b}$ o produto escalar e $\boldsymbol{a} \times \boldsymbol{b}$ o produto vetorial dos vetores $\boldsymbol{a}$ e $\boldsymbol{b}$ e $\|\boldsymbol{a}\|_{2}$ a norma euclidiana do vetor $\boldsymbol{a}$. A distância $R$ entre fonte e receptor é calculada 


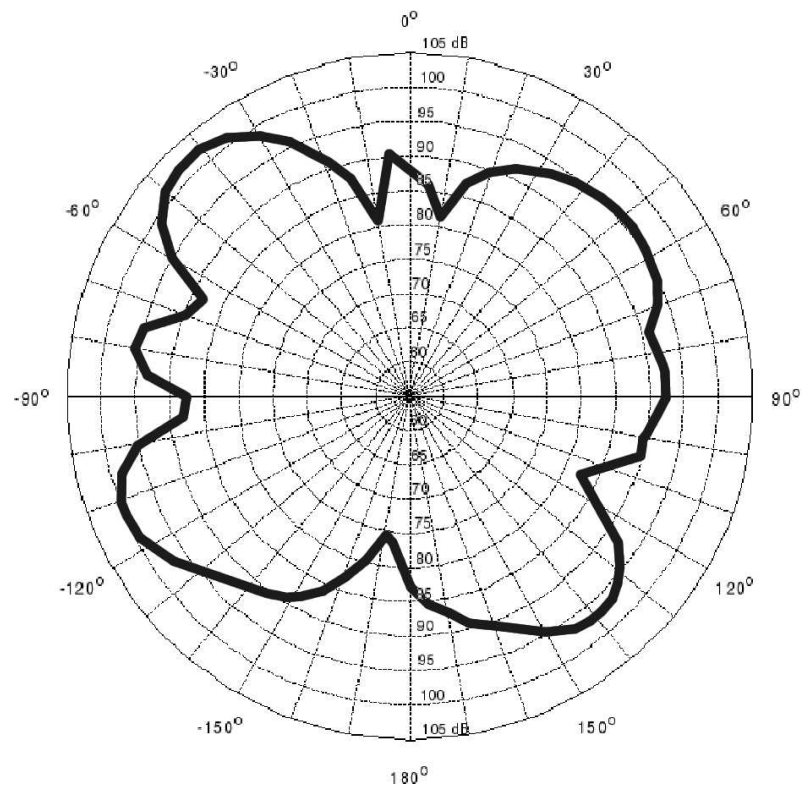

Figura 29: Nível sonoro estimado a 10m do Transformador (1m de altura), previsto pelo método de Usry.

por

$$
R=\|x-y\|_{2} .
$$

Para a componente difratada, é necessário fornecer, além da posição da fonte e do receptor, as arestas $\boldsymbol{q}(n)$ da parede onde se encontra a fonte (fornecidas em ordem antihorária). Calculam-se então os vetores unitários $\boldsymbol{n}_{q}(n)$ que ligam seqüencialmente as arestas da superfície. Sendo ainda $\boldsymbol{e}$ o ponto central de cada elemento de fronteira, $\boldsymbol{p}$ o ponto onde o receptor se encontra e $\boldsymbol{n}_{S}$ o vetor unitário normal à parede em questão, calculam-se os parâmetros geométricos da seguinte maneira:

$$
\begin{aligned}
r_{0} & =\left\|(\boldsymbol{e}-\boldsymbol{q}(n)) \times \boldsymbol{n}_{q}(n)\right\|_{2} \\
r & =\left\|(\boldsymbol{p}-\boldsymbol{q}(n)) \times \boldsymbol{n}_{q}(n)\right\|_{2} \\
d & =(\boldsymbol{p}-\boldsymbol{q}(n)) \cdot \boldsymbol{n}_{S} \\
\theta & =\arccos \left(\frac{d}{r}\right) \\
\Delta z & =\left\|(\boldsymbol{e}-\boldsymbol{p}) \cdot \boldsymbol{n}_{q}(n)\right\|_{2}
\end{aligned}
$$

Os requisitos computacionais deste método são bastante elevados, o cálculo da pressão em uma centena de pontos pode ser uma tarefa demorada. A figura 29 mostra o resultado de uma simulação realizada com o método de Usry para o transformador irradiando 
em $120 \mathrm{~Hz}$, baseado nas medidas de vibração da parede realizadas no transformador de potência de interesse.

\subsubsection{Discussão}

Os níveis de ruído estimados com este método não apresentaram boa correlação com os níveis medidos em campo. A tabela 1 mostra os níveis sonoros medidos em $120 \mathrm{~Hz}$ entre o transformador e o prédio vizinho, distando a superfície de medição cerca de $6 \mathrm{~m}$ do transformador e $1,5 \mathrm{~m}$ do muro de $5 \mathrm{~m}$ de altura que divide o terreno da subestação com o terreno do condomínio vizinho. As medições foram feitas em quatro cotas igualmente espaçadas na vertical e oito pontos igualmente espaçados na horizontal. A cota A é a mais baixa, a $1,5 \mathrm{~m}$ do chão e a cota $\mathrm{D}$ é a mais alta a $6 \mathrm{~m}$ do chão. O ponto 1 é o mais à esquerda e o ponto 8 o mais à direita de um observador voltado para o transformador. A tabela 2 mostra os níveis sonoros estimados pelo método de Usry para os mesmos pontos da tabela 1. Por meio de uma simples comparação ponto a ponto é possível constatar que as estimativas não são boas. Em especial, na coluna 8 da tabela 1, os valores medidos apresentam uma redução significativa se comparados com os demais pontos da tabeld $2^{2}$, mas nem mesmo uma tendência de redução pode ser verificada na coluna 8 da tabela 2 .

Tabela 1: Nível de Pressão Sonora medido em campo.

\begin{tabular}{ccccccccc} 
& 1 & 2 & 3 & 4 & 5 & 6 & 7 & 8 \\
\hline $\mathrm{D}$ & 61,3 & 66,5 & 63,5 & 71,5 & 63,0 & 60,0 & 49,2 & 55,8 \\
$\mathrm{C}$ & 63,5 & 64,0 & 59,6 & 66,6 & 62,7 & 70,0 & 66,7 & 54,0 \\
$\mathrm{~B}$ & 64,2 & 65,1 & 63,0 & 65,8 & 62,8 & 67,5 & 62,2 & 54,1 \\
$\mathrm{~A}$ & 60,8 & 65,1 & 56,1 & 64,3 & 66,1 & 68,7 & 63,0 & 62,5 \\
\hline
\end{tabular}

Tabela 2: Nível de Pressão Sonora estimado pelo método de Usry.

\begin{tabular}{ccccccccc} 
& 1 & 2 & 3 & 4 & 5 & 6 & 7 & 8 \\
\hline D & 66,6 & 66,8 & 67,1 & 68,6 & 69,1 & 71,1 & 70,5 & 69,5 \\
C & 62,5 & 48,0 & 59,4 & 65,2 & 65,9 & 63,9 & 61,3 & 62,4 \\
B & 56,0 & 56,2 & 66,1 & 70,1 & 69,6 & 63,4 & 58,5 & 61,0 \\
A & 59,3 & 65,9 & 70,5 & 73,5 & 73,8 & 71,6 & 69,5 & 66,0 \\
\hline
\end{tabular}

\footnotetext{
${ }^{2}$ Acredita-se que este efeito ocorra por causa da atuação dos radiadores térmicos como barreiras acústicas, como será comentado na seção 6.2 .
} 
Vale ressaltar que uma possível influência do muro no campo sonoro gerado pelo transformador não pôde ser considerada pelo método de Usry. Para levar este efeito em consideração, seria necessário realizar uma simulação pelo método dos elementos de fronteira, inserindo-se também o muro no modelo acústico.

\subsection{Otimização do Posicionamento}

Os resultados de simulação do campo acústico do transformador apresentados na seção anterior não foram satisfatórios, de modo que algoritmos para posicionamento ótimo dos transdutores não terão dados de entrada bons o suficiente para poderem ser usados com proveito. No entanto, em paralelo ao estudo sobre simulação do campo acústico foi também estudado o problema de escolha ótima das posições dos transdutores, e as conclusões obtidas são descritas nesta seção.

Determinar a pressão acústica primária em um dado ponto e a máxima atenuação que um arranjo de fontes de controle pode gerar em um arranjo de sensores de erro são etapas importantes, mas ainda não fornecem a resposta que realmente se busca, que é o posicionamento de transdutores que fornece a melhor atenuação possível numa dada superfície de controle. Não existe até o momento uma fórmula fechada que forneça o número ideal de transdutores a ser usado e suas respectivas posições. Normalmente, usam-se rotinas de busca numérica para tentar determinar a disposição ótima das fontes de controle e dos sensores de erro. Estas rotinas tentam minimizar uma função de mérito (normalmente uma estimativa da potência acústica emitida pelas fontes) movendo os transdutores no espaço. Podem existir soluções que são mínimos locais e que podem atrapalhar certas rotinas de busca (como busca baseada no gradiente da superfície de erro) na tentativa de achar o mínimo global do problema. O algoritmo genético aparece como uma solução para este efeito.

A qualidade da busca realizada pelo algoritmo genético está relacionada à quantidade de possíveis posições de transdutores fornecidas. Deve-se, portanto, evitar fornecer uma quantidade muito grande de possíveis posições de transdutores. Sabe-se, da seção 2.4, que as fontes de controle devem ser posicionadas o mais próximo possível da fonte primária. Com isso em mente, é possível reduzir o grupo de posições possíveis para as fontes de controle.

Várias simulações foram feitas com o intuito de testar o funcionamento do algoritmo genético para a otimização da disposição de transdutores para sistemas ANC, que são 
mostradas adiante.

\subsubsection{Algoritmos Genéticos}

Algoritmos genéticos (do inglês: Genetic Algorithm, GA) são procedimentos de otimização global estocástica para encontrar um máximo (ou mínimo) global de uma função multivariável. O GA requer que as variáveis do problema sejam codificadas como uma seqüência alfanumérica finita (o cromossomo), em que cada caractere é chamado de gene. O GA é iniciado a partir de uma população inicial aleatória, com a função custo calculada para cada cromossomo. Uma próxima geração é então gerada a partir desta primeira. Um número de indivíduos da geração anterior é escolhido, tendo os indivíduos com melhor função custo maior probabilidade de serem selecionados. Após esta seleção, as operações genéticas mutação, recombinação e reprodução são aplicadas para tentar extrair as "boas propriedades" compartilhadas por dois cromossomos que serão então combinados. Estes processos são repetidos a cada nova geração, até que um máximo (ou mínimo) global tenha sido atingido ou as condições de parada do algoritmo tenham sido atingidas.

Seguindo o modelo proposto por Baek [45], a posição das fontes secundárias e dos sensores de erros são codificadas em formato binário, no qual cada posição possível é representada por um elemento de uma seqüência binária. Cada gene terá valor "0" ou "1", indicando, respectivamente, a ausência ou presença de um transdutor. Por exemplo, a seqüência ‘00001111' significa que as últimas quatro posições, de oito possíveis, estão em uso.

A operação de recombinação produzirá um novo par de cromossomos ao combinar dois cromossomos-pais. Esta operação geralmente escolhe um bloco de tamanho aleatório e troca os genes desses blocos entre os dois cromossomos-pais, gerando os cromossomosfilhos. Como o objetivo é achar a melhor posição de um número fixo de transdutores, é necessário sempre manter o número de uns ("1") da seqüência. No exemplo de recombinação dos cromossomos A = '000111' e B = '111000', qualquer novo par de cromossomos não terá três uns. Se a recombinação ocorrer a partir do quarto elemento, o cromossomo A se tornará ‘000000' e o cromossomo B se tornará '111111'. Para que isto não ocorra, o algoritmo de recombinação não pode trocar os blocos a esmo, mas deve trocar um número par aleatório de genes que difiram nos dois cromossomos, mantendo assim o número de uns constante.

A operação de mutação também tem um papel importante em um GA. A mutação é a alteração aleatória de um gene do cromossomo, geralmente com uma pequena probabi- 
lidade de ocorrer. Na codificação binária, isso simplesmente significa trocar um "0" por um "1" ou vice-versa. A mutação ajuda a evitar que o GA convirja para um mínimo local no espaço de buscas. Para manter o número de uns constante no cromossomo, a mutação de um gene do cromossomo deve ser acompanhada da mutação de um outro gene de valor diferente do valor do primeiro gene.

Os cromossomos que não sofrem recombinação ou mutação irão então se reproduzir normalmente. O modelo elitista foi adotado, em que os melhores cromossomos de cada geração sobrevivem na geração seguinte, substituindo os piores cromossomos desta nova geração. A classificação dos cromossomos é feita usando como função custo a atenuação provocada pela posição dos transdutores que ele representa. Logo, os cromossomos que apresentarem a maior atenuação na superfície de controle definida sobreviverão.

\subsubsection{Simulações}

Diversas simulações foram feitas para se verificar o funcionamento do Algoritmo Genético e a influência que alguns parâmetros do algoritmo exercem sobre o resultado final. Como fonte primária de ruído usou-se o mesmo octopolo descrito na seção 4.3 , sendo o ruído um tom em $120 \mathrm{~Hz}$. Foram definidas 21 possíveis posições para as fontes de controle, dispostas em três grupos de sete fontes pontuais (como é mostrado na figura 30) e 65 possíveis posições para os sensores de erro, equiespaçadamente dispostos num setor de esfera com dez metros de raio. Se todos estes transdutores forem usados para tentar reduzir a potência sonora numa superfície de controle esférica a $30 \mathrm{~m}$ do octopolo, o resultado seria o exposto na figura 31. Neste exemplo considera-se que o conjunto de transdutores esteja num campo aberto e verifica-se que mesmo com um número bastante elevado de sensores de erro distribuídos ao redor da fonte primária, não foi possível atenuar

a potência sonora em toda a superfície de controle. É interessante notar que realizando esta mesma simulação, agora considerando um solo totalmente reflexivo em $z=0$, a região de atenuação aumenta, como mostrado na figura 32 .

\subsubsection{Influência da Função de Mérito}

Usou-se o algoritmo genético para escolher cinco fontes de controle e seis sensores de erro (otimizados conjuntamente, como é comentado na próxima seção) dentre as posições possíveis definidas acima, tal que seja atingida a máxima atenuação possível na região de controle. As posições das fontes de controle e dos sensores de erro foram variadas conjuntamente e para todas as simulações levou-se em consideração a presença de solo 


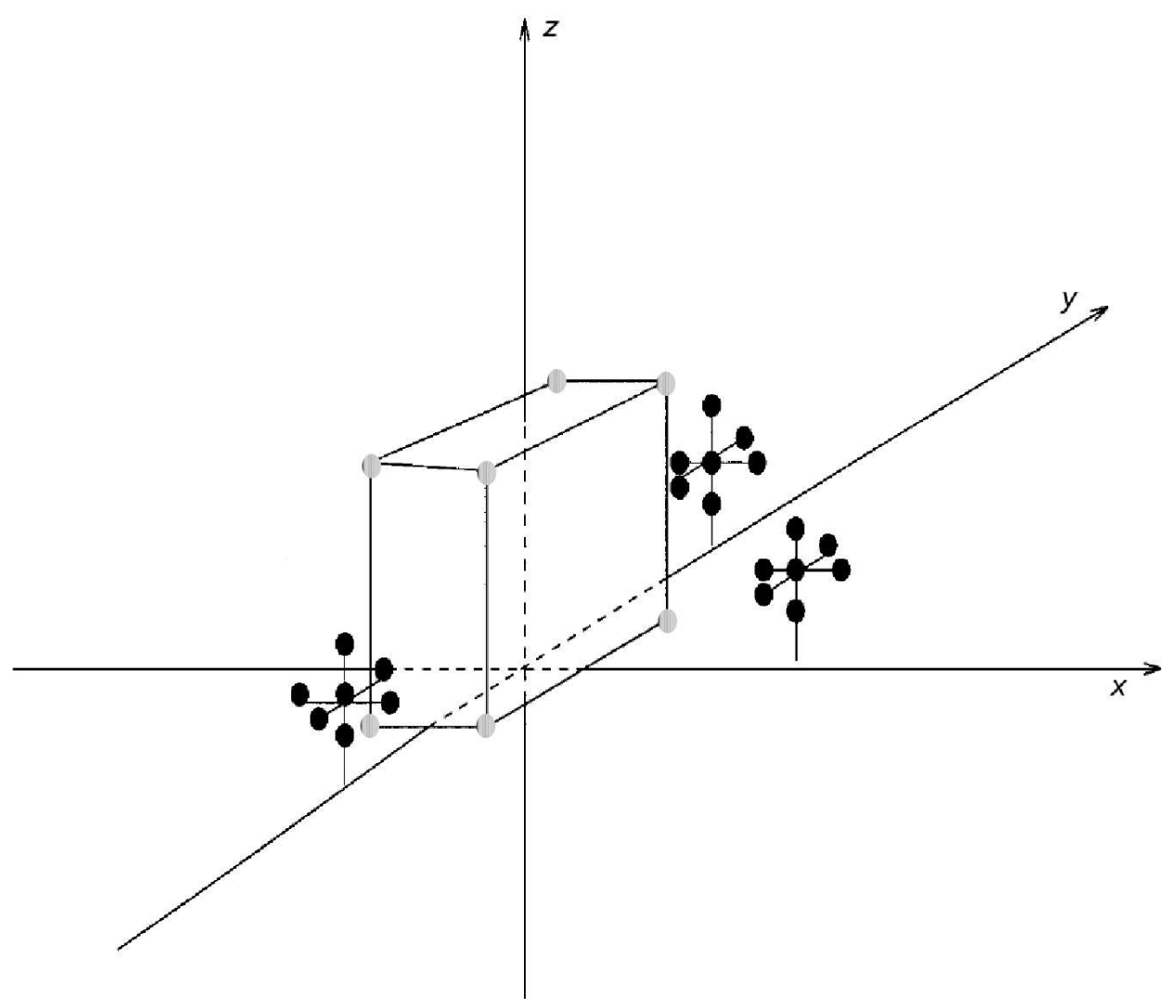

Figura 30: Disposição das possíveis posições de fontes de controle ao redor do octopolo em preto e fontes do octopolo em cinza. Baseada na referência [15].

totalmente reflexivo em $\mathrm{z}=0$. Todas as simulações foram iniciadas com a mesma semente para o algoritmo de geração de números aleatórios. Com este objetivo, foram definidas três funções de mérito, descritas a seguir, que têm seus resultados exibidos nas figuras 33 . 34 e 35.

A primeira função de mérito usada é a razão entre a energia sonora total na superfície de controle sem controle e com controle. A estimativa da energia sonora total na superfície de controle é feita somando-se a energia sonora em cada sensor usado para representar a superfície de controle. A função de mérito pode ser escrita como

$$
J=10 \log \left(\frac{\boldsymbol{p}_{r}^{*} \boldsymbol{p}_{r}}{\boldsymbol{p}_{p}^{*} \boldsymbol{p}_{p}}\right) .
$$

A segunda função de mérito usada foi maximizar a mínima atenuação (ou minimizar o máximo ganho). Isso é calculado verificando qual dos sensores usados para representar a superfície de erro apresenta menor atenuação (ou maior ganho) e usando esse valor como 
(a)
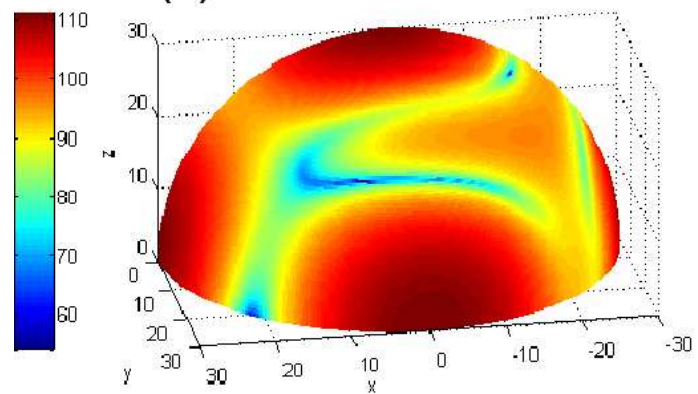

(c)

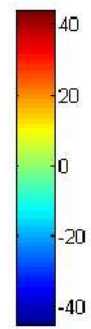

(b)

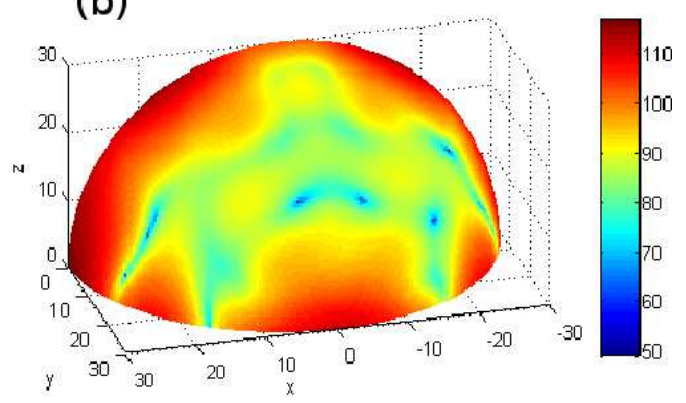

(d)

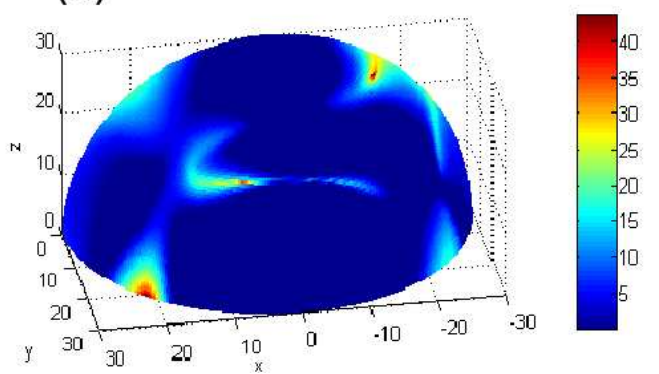

Figura 31: Pressão sonora na superfície de controle, com transdutores em campo aberto. (a) Campo sonoro primário, em dB. (b) Campo sonoro resultante, em dB. (c) Ganho do nível de pressão do campo resultante em relação ao campo primário. (d) Regiões onde ocorreu ganho de pressão (toda a área atenuada é representada pela cor azul escuro.

o valor da função de mérito, descrita por

$$
J=\max _{i}\left[10 \log \left(\frac{p_{r}^{*}(i) p_{r}(i)}{p_{p}^{*}(i) p_{p}(i)}\right)\right] .
$$

Por fim, a terceira função de mérito usada foi a média das atenuações. Enquanto a primeira função de mérito calcula a potência média para a superfície de erro com e sem controle e posteriormente define a atenuação pela razão dessas duas potências médias, a terceira função de mérito primeiro define a atenuação de cada ponto da superfície de controle e depois calcula a média da atenuação em todos estes pontos, como é descrito pela equação

$$
J=\frac{1}{N} \sum_{i=1}^{N} 10 \log \left(\frac{p_{r}^{*}(i) p_{r}(i)}{p_{p}^{*}(i) p_{p}(i)}\right) .
$$

Apesar de as figuras acima serem o resultado de apenas uma simulação de um algoritmo aleatório, elas possuem algumas características que foram observadas em diversas outras simulações feitas, que não são exibidas aqui para preservar a brevidade desta dissertação.

Fica óbvio que a métrica 2 não é adequada, pois, apesar de apresentar o menor 

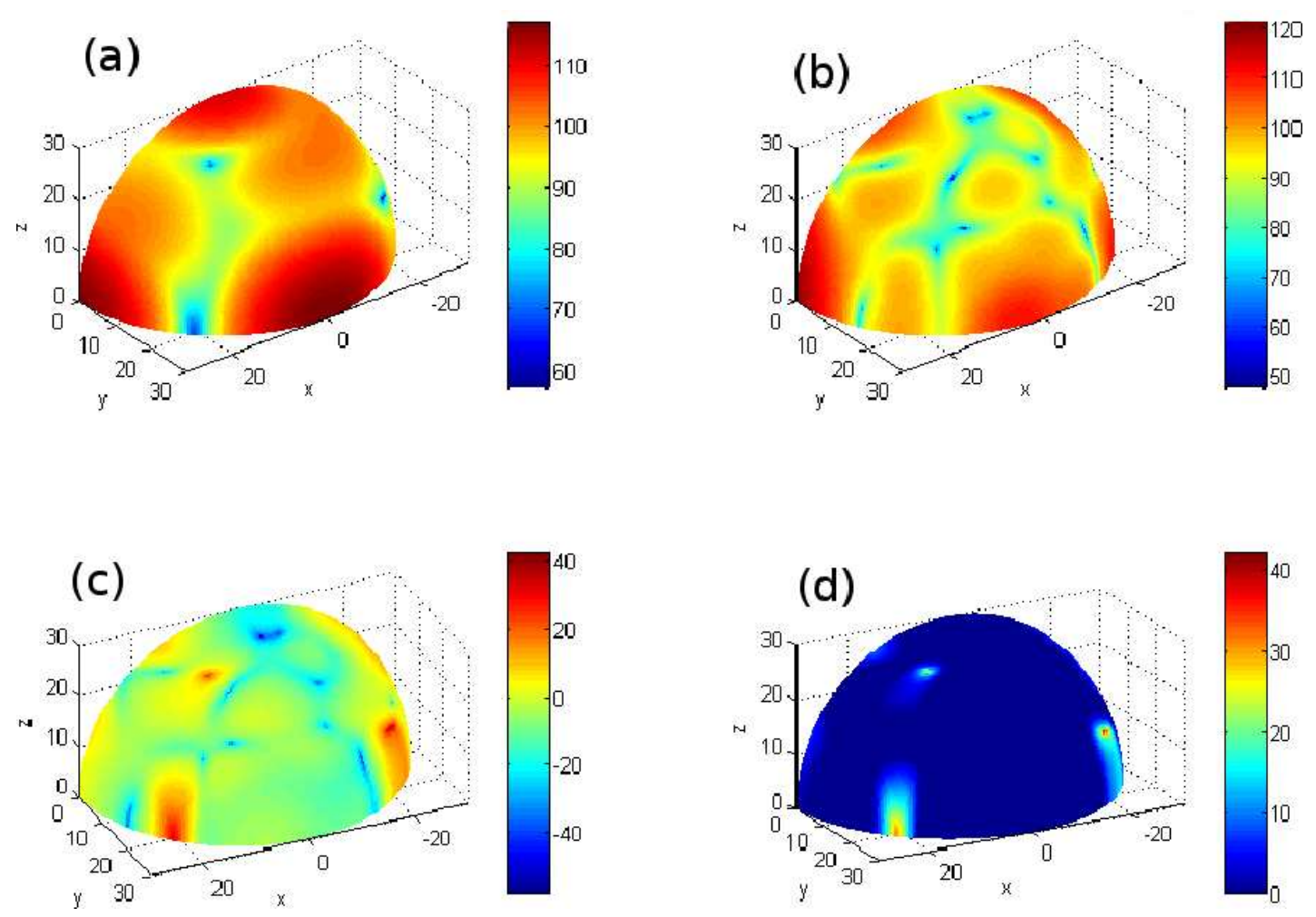

Figura 32: Pressão sonora na superfície de controle, com a presença de chão reflexivo. (a) Campo sonoro primário, em dB. (b) Campo sonoro resultante, em dB. (c) Ganho do nível de pressão do campo resultante em relação ao campo primário. (d) Regiões onde ocorreu ganho de pressão (toda a área atenuada é representada pela cor azul escuro.

ganho na superfície de erro (10dB enquanto nas outras era de cerca de $20 \mathrm{~dB}$ ), ela faz apenas uma análise pontual da superfície de erro e acaba fornecendo uma superfície de erro com uma região muito reduzida onde a potência sonora é efetivamente atenuada. Comparando a métrica 1 com a métrica 3, verifica-se que a última apresenta uma região consideravelmente maior onde a potência sonora é efetivamente atenuada. Isto porque a métrica 1 busca reduzir a potência sonora total na superfície de controle, o que pode ser realizado atenuando-se muito uma pequena região da superfície de controle. Já a métrica 3, por ser uma média da atenuação em todos os pontos da superfície de controle, busca justamente aumentar a atenuação (minimizar o ganho) em todos os pontos da superfície de controle, fornecendo uma redução mais global da potência sonora na superfície de controle.

\subsubsection{Influência da Ordem da Otimização}

Diferente do que foi feito na seção anterior, Snyder e Vokalek sugerem que o posicionamento dos alto-falantes e dos microfones seja feito separadamente. De fato, de acordo 


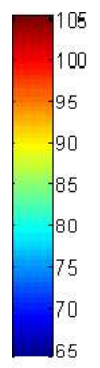

(a)

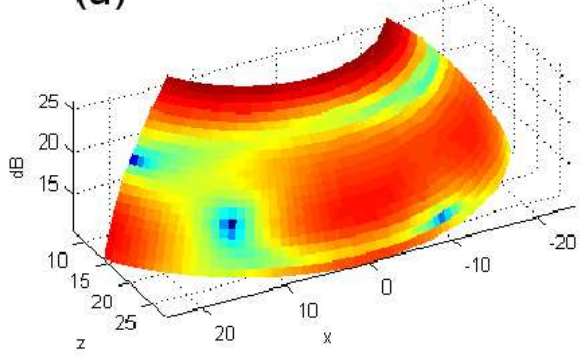

(c)

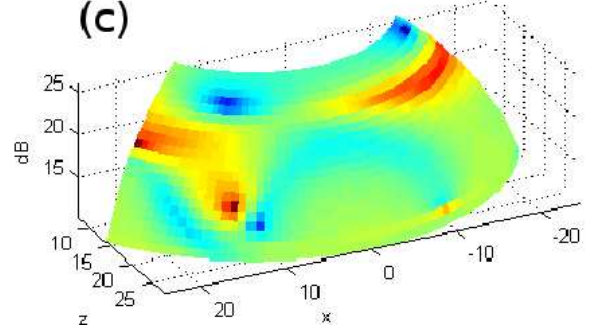

(b)
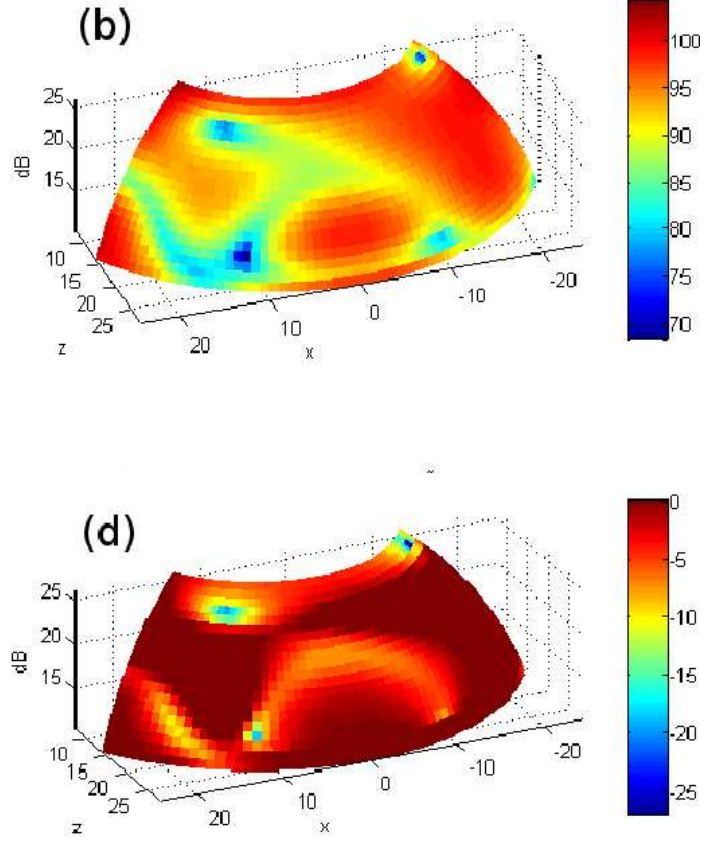

Figura 33: Pressão sonora na superfície de controle, com a posição dos transdutores definida pela métrica 1. (a) Campo sonoro primário, em dB. (b) Campo sonoro resultante, em dB. (c) Ganho do nível de pressão do campo resultante em relação ao campo primário.

(d) Regiões onde ocorreu redução de pressão (toda a área com ganho é representada pela cor vermelho escuro.
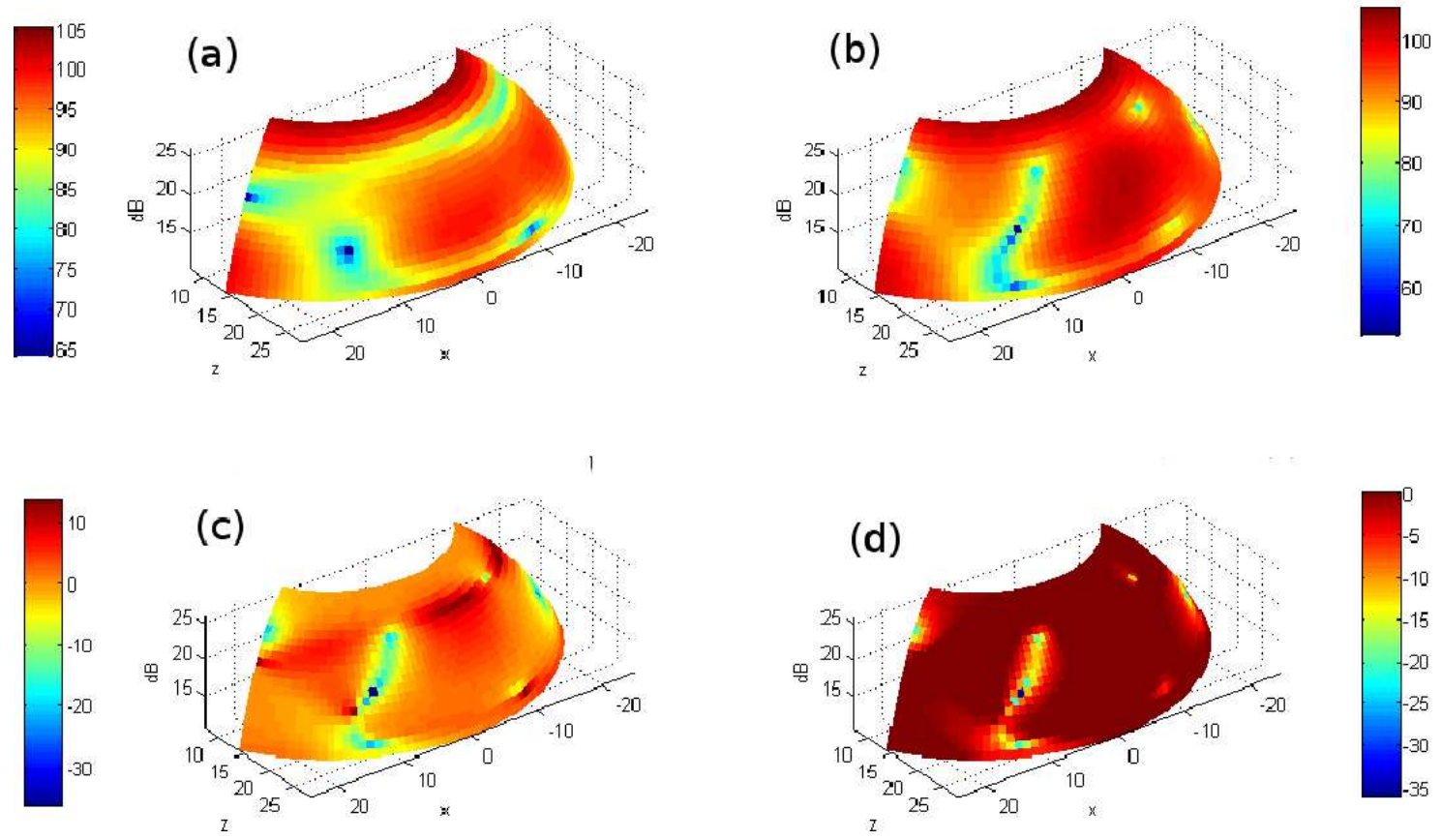

Figura 34: Pressão sonora na superfície de controle, com a posição dos transdutores definida pela métrica 2. (a) Campo sonoro primário, em dB. (b) Campo sonoro resultante, em dB. (c) Ganho do nível de pressão do campo resultante em relação ao campo primário. (d) Regiões onde ocorreu redução de pressão (toda a área com ganho é representada pela cor vermelho escuro. 

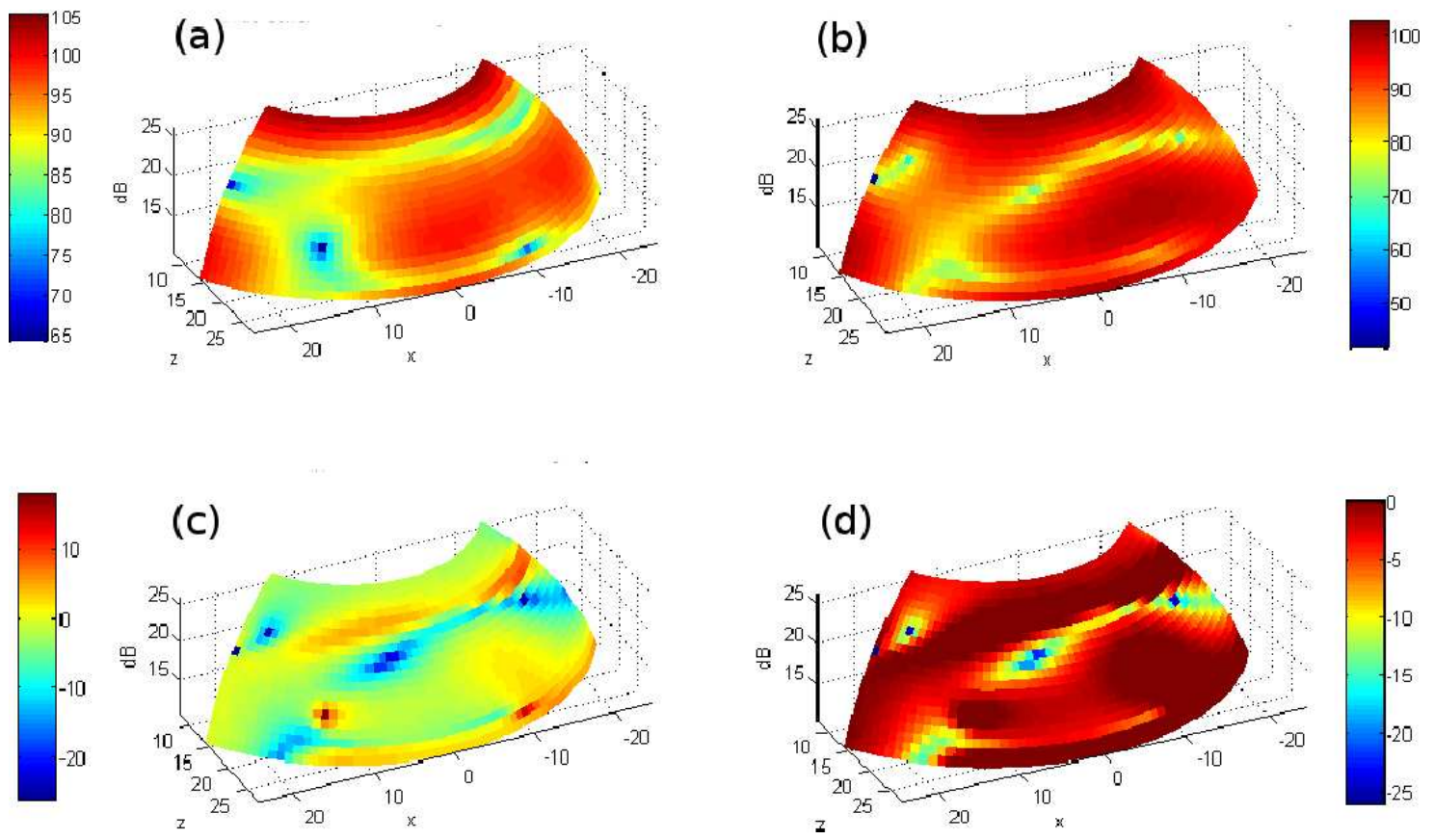

Figura 35: Pressão sonora na superfície de controle, com a posição dos transdutores definida pela métrica 3. (a) Campo sonoro primário, em dB. (b) Campo sonoro resultante, em dB. (c) Ganho do nível de pressão do campo resultante em relação ao campo primário. (d) Regiões onde ocorreu redução de pressão (toda a área com ganho é representada pela cor vermelho escuro.

com esses autores, "o arranjo das fontes de controle irá definir um limite superior no nível de atenuação global possível de se atingir com um sistema ANC ótimo, e o posicionamento dos sensores de erro irá determinar quão próximo deste limite superior de atenuação o sistema ANC poderá chegar. A otimização do posicionamento destes dois grupos de transdutores deverá ser feita separadamente: primeiramente as fontes de controle, depois os sensores de erro" [42].

Pode-se supor que após encontrar uma posição adequada para as fontes de controle, e posteriormente encontrar uma posição adequada para os sensores de erro referente a esta posição de fontes de controle, é possível que exista uma posição de fontes de controle que melhore a atenuação global, mantendo-se agora fixa a posição dos sensores de erro, já que originalmente a posição das fontes de controle foi definida sem levar em conta a posição dos sensores de erro. É possível usar este mesmo argumento para a definição de uma nova posição dos sensores de erro para a nova posição das fontes de controle, levando a um ciclo de otimização, que só pararia quando a posição ótima das fontes de controle e dos sensores de erro fosse atingida.

Mas em sua afirmação, Snyder e Vokalek não levam em consideração as quantidades de fontes de controle ou sensores de erro. Seria possível existir uma dada posição ótima 
de fontes de controle, para a qual fosse necessário um número enorme de sensores de erro para atingir um dado nível de atenuação, enquanto que uma configuração de fontes de controle aparentemente pior que a ótima poderia atingir este mesmo nível de atenuação com um número bem menor de sensores de erro.

Os dois exemplos acima justificam realizar uma rotina de otimização conjunta, que busque otimizar a disposição das fontes de controle e dos sensores de erro ao mesmo tempo. Neste caso, o algoritmo de otimização já iria procurar automaticamente o melhor arranjo de fontes de controle para a quantidade de sensores de erro disponíveis. Um novo tipo de cromossomo deve ser gerado para a otimização conjunta. Ele será a concatenação de dois cromossomos, um relacionado à posição das fontes de controle, e outro relacionado à posição dos sensores de erro. Apesar de aumentar o número de combinações possíveis dentro do algoritmo genético, esta abordagem pode ser vantajosa, já que requer apenas uma realização do algoritmo, enquanto a otimização por ciclos proposta por Snyder e Vokalek pode consumir um tempo muito grande até fornecer uma resposta adequada, ou eventualmente divergir.

As simulações apresentadas a seguir mostram que com apenas uma realização da otimização conjunta já se obtém um resultado melhor do que o resultado obtido com a otimização apenas das fontes de controle seguida da otimização apenas dos sensores de erro (otimização por etapas). As simulações foram feitas usando-se a terceira métrica exposta na seção anterior. Pode-se comparar então a figura 35, que foi gerada por otimização conjunta, com a figura 36, que foi gerada após um ciclo da otimização por etapas. Verificase que a região atenuada na figura 36 é menor que a região atenuada na figura 35.

Se agora um novo ciclo for realizado, atualizando a posição das fontes de controle para a posição de sensores de erro previamente definida, e posteriormente se definir uma nova posição para os sensores de erro mantendo-se fixa a última posição de fontes de controle encontrada (como é mostrado na figura 37), verifica-se que a superfície de atenuação obtida agora se assemelha bastante à mostrada na figura 35. A posição das fontes de controle que se obteve nesta etapa é praticamente a mesma obtida na otimização conjunta realizada na seção anterior. Para se chegar a este resultado, foram necessárias quatro execuções do algoritmo genético, enquanto que na otimização conjunta apenas uma realização foi suficiente para chegar a uma resposta similar. O tempo necessário para uma realização da otimização conjunta é praticamente igual ao tempo necessário para a realização de um ciclo da otimização por etapał 3 , caracterizando a eficácia da abordagem conjunta.

\footnotetext{
${ }^{3}$ Nestes exemplos, cada realização do algoritmo genético durou cerca de 10 minutos, rodando o Matlab 2006a em um PC com processador AMD Athlon XP3000 2,1GHz e 512MB de memória RAM.
} 

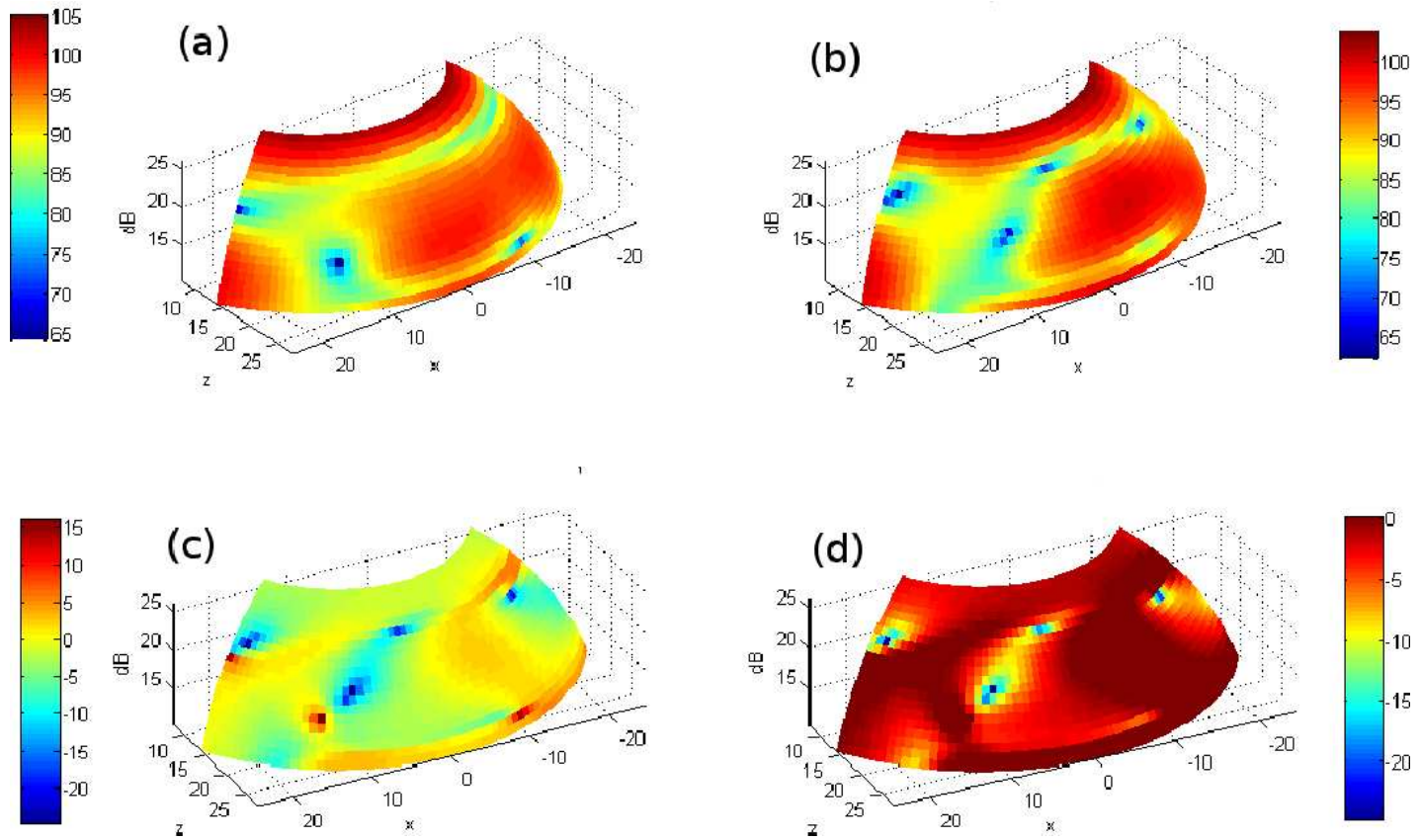

Figura 36: Pressão sonora na superfície de controle otimizando primeiramente a posição das fontes de controle e posteriormente a posição dos sensores de erro. (a) Campo sonoro primário, em dB. (b) Campo sonoro resultante, em dB. (c) Ganho do nível de pressão do campo resultante em relação ao campo primário. (d) Regiões onde ocorreu redução de pressão (toda a área com ganho é representada pela cor vermelho escuro.

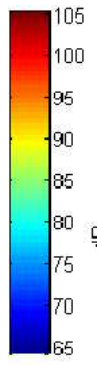

(a)

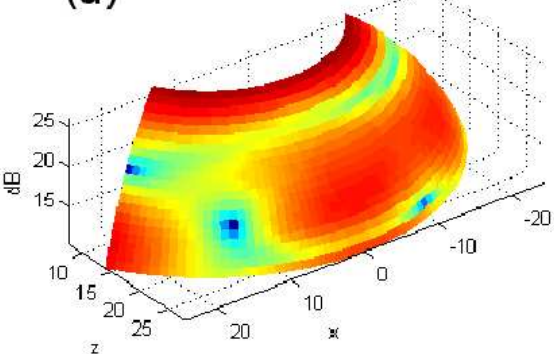

(c)
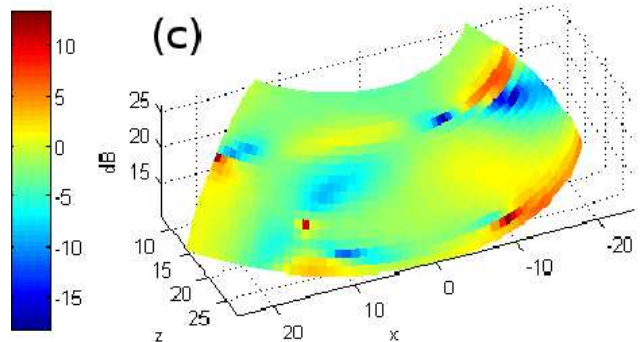

(b)
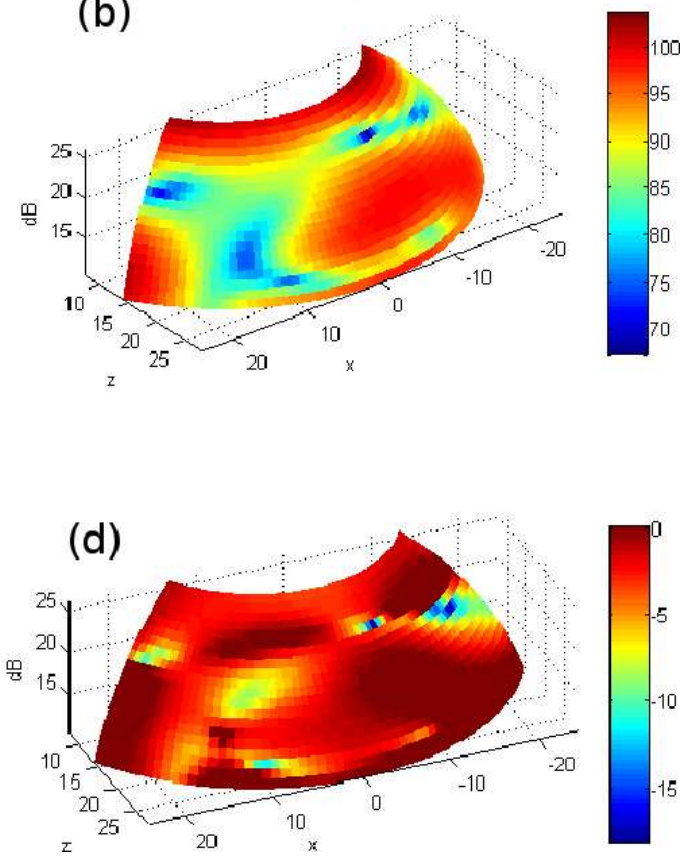

Figura 37: Pressão sonora na superfície de controle obtida após dois ciclos de otimização da posição dos transdutores. (a) Campo sonoro primário, em dB. (b) Campo sonoro resultante, em dB. (c) Ganho do nível de pressão do campo resultante em relação ao campo primário. (d) Regiões onde ocorreu redução de pressão (toda a área com ganho é representada pela cor vermelho escuro. 


\subsection{Conclusão}

Neste capítulo foram apresentados alguns insumos necessários para a otimização do posicionamento dos transdutores eletroacústicos de um sistema de controle ativo de ruído via simulação.

A influência da quantidade de transdutores foi mostrada de forma prática por uma simulação simples, na qual foi possível verificar que o aumento do número de sensores de erro permite aumentar a área de atenuação, para isso diminuindo o nível de atenuação presente em cada sensor de erro. A maior quantidade de fontes de controle permite que elas reproduzam de forma mais fiel o campo sonoro primário, e com isso o nível de atenuação aumenta conforme o número de fontes de controle aumenta, até o limite da quantidade de fontes de controle inferior à quantidade de sensores de erro. Acima deste limite, o nível de pressão nos sensores de erro será mínimo, mas na região entre os sensores o nível de pressão sonora irá aumentar.

Apresentou-se o método convencional de modelagem do sistema acústico em campo aberto (ou semi-aberto) usando fontes pontuais esféricas e sensores omnidirecionais. É com base neste modelo que os algoritmos de otimização podem variar a posição dos transdutores e verificar qual arranjo de transdutores fornece a maior atenuação na região desejada.

Para a modelagem do campo primário, foi apresentado o método proposto por Usry et al., que tenta estimar a pressão sonora em um ponto distante de um transformador com base em medidas de vibração da parede de seu tanque. Este método foi escolhido porque sua implantação é relativamente simples e porque havia medidas de vibração da parede do tanque de um transformador disponíveis. Os resultados obtidos com este método não foram satisfatórios. Uma das possíveis razões para as discrepâncias dos níveis estimados com os níveis medidos pode ser a demasiada simplificação do modelo acústico utilizado nas simulações, que não considerou, por exemplo, a presença de um muro a cerca de $10 \mathrm{~m}$ do transformador.

Por fim, tratou-se da otimização do posicionamento dos transdutores do sistema ANC com o método dos algoritmos genéticos, que se utiliza dos modelos acústicos expostos acima para buscar o arranjo de transdutores que fornece a maior atenuação do campo primário na região de interesse. Ele faz isso testando diversas combinações de posicionamento e gerando variações das melhores combinações. Verifica-se na literatura que é comum otimizar-se primeiramente o posicionamento das fontes de controle, e depois o 
posicionamento dos sensores de erro com base na posição de fontes de controle previamente escolhida. Esta dissertação propõe a otimização conjunta da posição das fontes de controle e dos sensores de erro, já que é sabido que na otimização de problemas multivariáveis em geral a definição de uma variável anteriormente às demais pode enviesar a escolha das outras variáveis. Verificou-se que este método converge, em apenas uma iteração, para um resultado similar ao que o método convencional converge após diversas iterações. Verificou-se que a função de mérito minimizada pelos algoritmos genéticos também influencia o resultado final, sendo recomendado o uso de uma função de mérito que procure maximizar a média das atenuações obtidas em cada sensor de controle. 


\section{SENSORES VIRTUAIS}

\subsection{Introdução}

Como mencionado na seção 1.3 . muita pesquisa já foi realizada na área do controle ativo de ruído, mas a maioria desses trabalhos teve como objetivo o "controle global" do ruído, ou seja, buscavam atenuar algum parâmetro global como a potência sonora total irradiada. O controle global tipicamente requer um grande número de fontes de controle e sensores de erro, o que acarreta uma convergência muito lenta (ou a não-convergência) e baixa estabilidade do sistema de controle e, o mais importante, nem sempre produz o nível de atenuação necessário para a situação [49]. Em muitas situações não é necessário (ou mesmo possível) o controle global, como no caso de grandes fontes de ruído em campo aberto. Nesse caso, o controle local acaba sendo a única alternativa.

O controle local, como o próprio nome sugere, gera uma região de atenuação próxima ao sensor de erro e, para que tenha aplicação prática, é essencial que esta região de atenuação se localize próxima às pessoas expostas ao ruído. Os sistemas tradicionais de controle local apresentam maior atenuação na posição onde os sensores de erro estão localizados, que nem sempre é a posição onde a atenuação é desejada, já que algumas limitações do sistema de controle, como por exemplo a estimação do caminho secundário, impedem que os sensores de erro sejam posicionados exatamente onde a atenuação é desejada.

Para que o controle local seja viável, faz-se necessária alguma técnica para estimar a potência do ruído em uma posição remota onde se deseja atenuação a partir das medidas de sensores colocados em posições viáveis. Garcia-Bonito apresentou a idéia do microfone virtual [50] (chamado neste trabalho de "sensor virtual por função de transferência" ou SVFT), que permite obter atenuação em uma região distante do sensor de erro. Para isso, o sistema de controle deve incorporar a função de transferência entre a posição onde o sensor de erro está localizado e a posição onde se deseja máxima atenuação. Uma outra estratégia para a realização de um sensor virtual, proposto por Kestell e Cazzolato [51] 
(chamado neste trabalho de "sensor virtual por extrapolação" ou SVE), utiliza dois ou mais sensores de erro para estimar o nível de ruído na região onde a máxima atenuação é desejada, dando para isso diferentes pesos para cada um dos sensores de erro. As duas técnicas se mostraram efetivas em simulações, mas até o momento os resultados práticos ainda não são muito animadores, principalmente por causa de variações no posicionamento dos transdutores.

Esta dissertação propõe estratégia diferente das anteriores para a realização de um sensor virtual (chamada de "sensor virtual por janelamento das fontes secundárias" ou JFS). Nesta estratégia, pesos são dados às fontes secundárias baseados na função de transferência entre as fontes secundárias e os sensores de erro, na função de transferência entre as fontes secundárias e os sensores virtuais e no campo sonoro primário nos sensores de erro. Esta técnica se mostrou robusta em simulações de pequeno porte, como será melhor explicado nas seções 5.6 e 5.7.

Neste capítulo, as três estratégias de realização de sensores virtuais acima mencionadas serão descritas nas seções 5.2 a 5.4 e posteriormente comparadas entre si na seção 5.5 . A robustez do método proposto nesta dissertação será analisada quanto à variação de fase primária, variação de posicionamento das fontes secundárias e variação do posicionamento dos sensores de erro na seção 5.6. Por fim, algumas simulações com uma fonte primária mais complexa e um maior número de fontes de controle e sensores de erro são apresentadas na seção 5.7 .

\subsection{Sensor Virtual por Função de Transferência}

O método de sensores virtuais proposto pelo grupo de pesquisa da Universidade de Southampton baseia-se na hipótese de que para baixas freqüências, a variação espacial da pressão em um campo sonoro reverberante é pequena o suficiente para assumir-se que a pressão primária no sensor de erro $p_{p}(\mathbf{s})$ e a pressão primária no sensor virtual $p_{p}(\mathbf{v})$ seja aproximadamente a mesma (ver figura 38 ).

Como definido na seção 2.4 para excitação em uma única freqüência, escrevem-se a pressão resultante no sensor de erro como

$$
p_{r}(\mathbf{s})=p_{p}(\mathbf{s})+Z_{\mathbf{S}} \cdot q
$$

e a pressão resultante no sensor virtual como

$$
p_{r}(\mathbf{v})=p_{p}(\mathbf{v})+Z_{\boldsymbol{V}} \cdot q .
$$




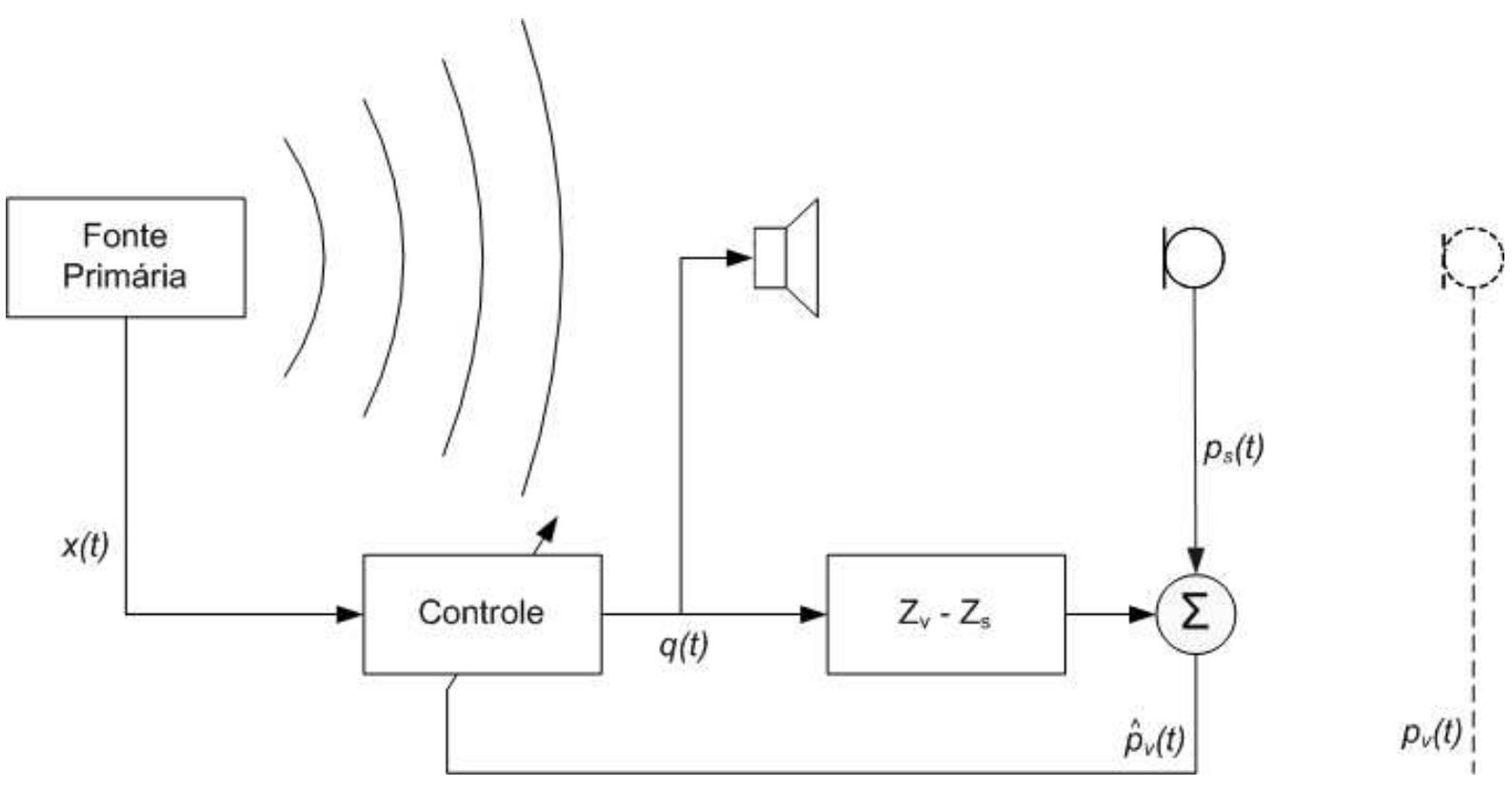

Figura 38: Diagrama de bloco de um sistema ANC monocanal com sensor virtual.

Mesmo assumindo que a variação da pressão primária seja pequena, a função de transferência entre a fonte secundária e o sensor de erro $Z_{\boldsymbol{S}}$ e entre a fonte secundária e o sensor virtual $Z_{\boldsymbol{V}}$ podem ser substancialmente diferentes por causa da influência do campo próximo da fonte secundária. Sob estas hipóteses, a pressão no sensor virtual pode ser estimada a partir da pressão medida no sensor de erro, com uma correção baseada na diferença nas funções de transferência, como é mostrado na figura 38. Esse diagrama equivale à seguinte equação:

$$
\hat{p}_{r}(\mathbf{v})=p_{r}(\mathbf{s})+\left[Z_{\boldsymbol{S}}-Z_{\boldsymbol{V}}\right] \cdot q
$$

A pressão estimada no sensor virtual pode então ser atenuada pela fonte secundária apenas com medições feitas no sensor de erro. Este sistema irá gerar uma região de atenuação próxima à posição do sensor virtual.

Em seu trabalho, Garcia-Bonito conclui que esse sistema consegue projetar a região de atenuação em uma região à frente do sensor de erro [50], mas o sistema é bastante sensível a erros na estimação das funções de transferência $Z_{\boldsymbol{S}}$ e $Z_{\boldsymbol{V}}$, especialmente para altas freqüências. Ele também verificou que a presença de uma esfera acusticamente dura próxima ao sensor virtual melhora o desempenho do sistema, porque essa esfera torna o campo difuso à sua volta mais uniforme. 


\subsection{Sensor Virtual por Extrapolação}

O método de sensores virtuais proposto pelo grupo de pesquisa da Universidade de Adelaide baseia-se na extrapolação linear e polinomial para calcular o nível de ruído ou a densidade de energia acústica do ruído a partir da pressão sonora medida em dois ou mais sensores de erro posicionados entre a fonte primária de ruído e a região onde a atenuação é desejada (onde se localiza o sensor virtual).

Usando dois sensores de erro (microfone virtual de primeira ordem), Cazzolato mostra que é possível estimar a pressão sonora em uma dada posição da seguinte maneira:

$$
p(\mathbf{v})=\frac{p_{2}-p_{1}}{h} x+p_{2}
$$

onde $p_{1}$ é a pressão medida no sensor de erro mais distante do sensor virtual, $p_{2}$ é a pressão medida no sensor de erro mais próximo ao sensor virtual, $h$ é a distância entre os dois sensores de erro reais e $x$ é a distância entre o sensor virtual e o sensor de erro mais próximo dele [49]. A equação (5.4) pode ser reescrita como

$$
p(\mathbf{v})=\boldsymbol{w} \boldsymbol{p}
$$

onde

$$
\begin{gathered}
\boldsymbol{w}=\left[\begin{array}{cc}
-x / h & x / h+1
\end{array}\right], \\
\boldsymbol{p}^{T}=\left[\begin{array}{ll}
p_{1} & p_{2}
\end{array}\right],
\end{gathered}
$$

evidenciando os pesos dados a cada sensor de erro.

Se um terceiro sensor de erro for inserido no meio dos dois usados previamente (microfone virtual de segunda ordem), será possível estimar a taxa de variação do gradiente de pressão sonora, permitindo uma estimativa mais exata da pressão no sensor virtual [49]. Neste caso, a estimativa da pressão sonora no sensor virtual será dada por

$$
p(\mathbf{v})=\left(\frac{p_{1}-2 p_{2}+p_{3}}{h^{2}}\right) \frac{x^{2}}{2}+\left(\frac{p_{1}-4 p_{2}+3 p_{3}}{2 h}\right) x+p_{3} .
$$

Novamente, $p_{1}$ é a pressão medida no sensor de erro mais distante do sensor virtual, $p_{2}$ é a pressão medida no sensor de erro intermediário, $p_{3}$ é a pressão medida no sensor de erro mais próximo ao sensor virtual, $h$ é a distância entre os sensores de erro reais e $x$ é a distância entre o sensor virtual e o sensor de erro mais próximo [49]. A equação (5.8) também pode ser reescrita evidenciando os pesos de cada sensor de erro da seguinte 
maneira:

$$
p(\mathbf{v})=\boldsymbol{w} \boldsymbol{p}
$$

onde

$$
\begin{gathered}
\boldsymbol{w}=\left[\begin{array}{ccc}
\frac{x(x+h)}{2 h^{2}} & \frac{x(x+2 h)}{-h^{2}} & \frac{(x+2 h)(x+h)}{2 h^{2}}
\end{array}\right] \\
\boldsymbol{p}^{T}=\left[\begin{array}{lll}
p_{1} & p_{2} & p_{3}
\end{array}\right]
\end{gathered}
$$

Cazzolato demonstrou que os sistemas ANC com o sensor virtual apresentam melhor desempenho que os sistemas ANC convencionais, com distância entre sensores de erro e ponto de observação equivalentes [49]. Ele também verificou que o método SVE é bastante sensível a variações espaciais do campo sonoro primário, especialmente em altas freqüências, o que condiz com o fato de a extrapolação polinomial não ser um método de extrapolação muito confiável. Para controlar a sensibilidade verificada no método SVE, Cazzolato utiliza o algoritmo LMS para estimar os pesos dados aos sensores de erro [49]. Nesse trabalho, ele coloca microfones nas posições dos sensores de erro e também coloca um microfone na posição onde se deseja atenuação, e usa o algoritmo LMS para definir os pesos dos sensores de erro de tal forma que a estimativa do ruído na posição do sensor virtual seja a melhor possível. Uma vez que o sistema tenha convergido, os pesos são fixados e o microfone remoto retirado.

Em sua tese de doutorado, Munn realizou uma comparação entre simulações em campo aberto dos métodos SVFT e SVE [52]. Ela verificou que o método SVE apresenta melhores resultados que o método da função de transferência na situação de campo aberto. A explicação para isso está no fato de a suposição de que a pressão primária é aproximadamente a mesma tanto no sensor de erro quanto no sensor virtual tornar-se cada vez menos válida conforme a distância entre o sensor real e o virtual deixa de ser muito menor que o comprimento de onda (ou conforme a freqüência aumenta). Na seção 5.5 esta comparação é estendida para contemplar também o método JFS.

\subsection{Sensores Virtuais por Janelamento das Fontes Secundárias}

A idéia de aplicar uma janela aos pesos calculados para cada uma das fontes de controle, podendo desta forma modelar a região de atenuação na superfície de controle (onde se localizam os sensores virtuais), é equivalente à filtragem espacial comumente realizada em matrizes de antenas ou de microfones para alterar sua diretividade [26], por 
exemplo. Assim, ao se multiplicar o vetor intensidade das fontes de controle por uma matriz de pesos, estará sendo realizada uma filtragem espacial no campo acústico gerado por estas fontes sonoras.

A importância da matriz de pesos é que o sistema de controle funciona tentando minimizar a potência sonora nos sensores de erro, e não na superfície de controle, existindo então a possibilidade, se os transdutores estiverem mal posicionados, de reduzir a potência sonora nos sensores de erro, mas de aumentá-la na superfície de controle, que é onde realmente se deseja atenuação. A matriz de pesos, desde que corretamente calculada, pode corrigir esta distorção, reduzindo a potência sonora no local desejado.

A matriz de pesos pode ser calculada de forma ótima da seguinte maneira: Sendo $\boldsymbol{p}_{p}(\mathbf{s})$ o vetor pressão primária nos sensores de erro e $\boldsymbol{Z}_{\boldsymbol{S}}$ a matriz de transferência entre as fontes de controle e os sensores de erro, sabemos que o vetor velocidade de volume ótimo que reduz a pressão nos sensores de erro é

$$
\boldsymbol{q}_{0}=-\left(\boldsymbol{Z}_{\boldsymbol{S}}\right)^{+} \boldsymbol{p}_{p}(\mathbf{s})
$$

Agora, se $\boldsymbol{p}_{p}(\mathbf{v})$ for o vetor pressão primária nos pontos da superfície de controle onde se "localizam" os sensores virtuais e $\boldsymbol{Z}_{\boldsymbol{V}}$ a matriz de transferência entre as fontes de controle e estes sensores virtuais, o vetor velocidade de volume ótimo que fornece a melhor atenuação nos sensores virtuais é

$$
\boldsymbol{q}_{0}^{\prime}=-\left(\boldsymbol{Z}_{\boldsymbol{V}}\right)^{+} \boldsymbol{p}_{p}(\mathbf{v})
$$

Logo, como o sistema de controle fornece $\boldsymbol{q}_{0}$, mas deseja-se $\boldsymbol{q}_{0}^{\prime}$, pode-se definir uma matriz de pesos diagonal $\boldsymbol{W}$, tal que

$$
\boldsymbol{q}_{0}^{\prime}=\boldsymbol{W} \boldsymbol{q}_{0}
$$

\subsection{Comparação entre os Métodos de Sensores Vir- tuais}

Nesta seção, os métodos SVFT, SVE e JFS serão comparados em uma simulação baseada em funções de transferência teoricamente calculadas em um campo aberto, sem a incorporação de erros à simulação. Este trabalho não realiza uma comparação prática entre os métodos.

O ambiente em campo aberto é modelado como nas simulações realizadas por Munn [52]. A fonte primária é modelada como uma única fonte pontual esférica e a fonte secundária também é modelada como uma única fonte pontual esférica distante 4,5m da 


\section{Fonte Primária} de Ruído

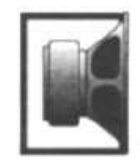

Região de Observação (distância entre sensores de $25 \mathrm{~mm}$ )

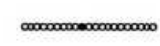

Fonte Secundária de Ruído

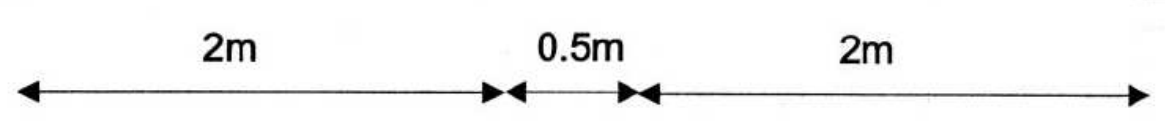

Figura 39: Diagrama do sistema modelado para a comparação dos métodos de sensores virtuais. Baseado na referência [51].

fonte primária. Os sensores de erro são posicionados entre as duas fontes, assim como a posição do sensor virtual, como é mostrado na figura 39. As comparações foram realizadas em duas freqüências de excitação, sendo elas $200 \mathrm{~Hz}$ e $400 \mathrm{~Hz}$.

\subsection{1 $200 \mathrm{~Hz}$}

As figuras 40 a 42 mostram os resultados obtidos ao se controlar um ruído de $200 \mathrm{~Hz}$ em campo aberto com os três métodos de sensores virtuais descritos neste capítulo. A linha vertical à direita mostra a posição onde a atenuação é desejada (é a posição do sensor virtual) e as três linhas verticais à esquerda mostram a posição dos sensores de erro. Para o método SVE, as três posições de sensores de erro são utilizadas (a distância $h$ entre eles é de $25 \mathrm{~mm}$ ). Já para os métodos SVFT e JFS apenas um sensor de erro é necessário, e o sensor mais próximo da região de atenuação desejada é utilizado (terceira linha vertical da esquerda para a direita).

Com uma distância de separação entre o sensor virtual e o sensor de erro mais próximo igual a $h$, verifica-se que o método SVFT apresenta uma atenuação elevada em um ponto intermediário entre o sensor de erro e o sensor virtual, mas na posição onde se deseja atenuação seu desempenho (atenuação de 20dB) é bem pior que o dos outros dois métodos, que neste caso apresentaram desempenho praticamente idêntico, como é mostrado na figura 40. Vale ressaltar que exatamente no ponto onde se localiza o sensor virtual o método SVE produz uma atenuação de $56 \mathrm{~dB}$, enquanto o método JFS anula o nível de pressão sonora neste ponto.

A figura 41 mostra os resultados da comparação quando a distância de separação entre o sensor virtual e o sensor de erro mais próximo aumenta de $h$ para $4 h$. Neste caso o 


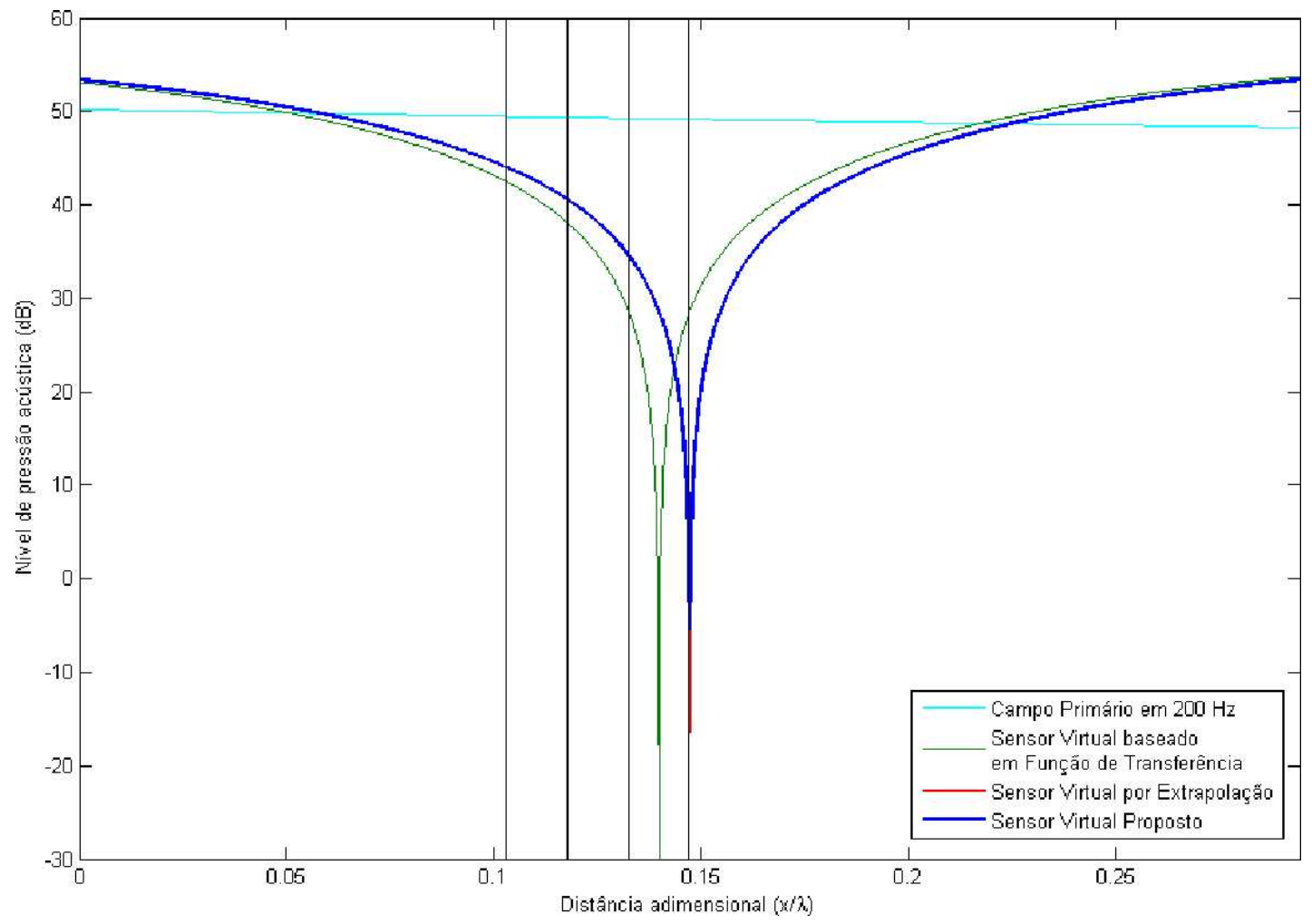

Figura 40: Comparação entre as estratégias de sensores virtuais, para uma distância de separação de 1 h em $200 \mathrm{~Hz}$.

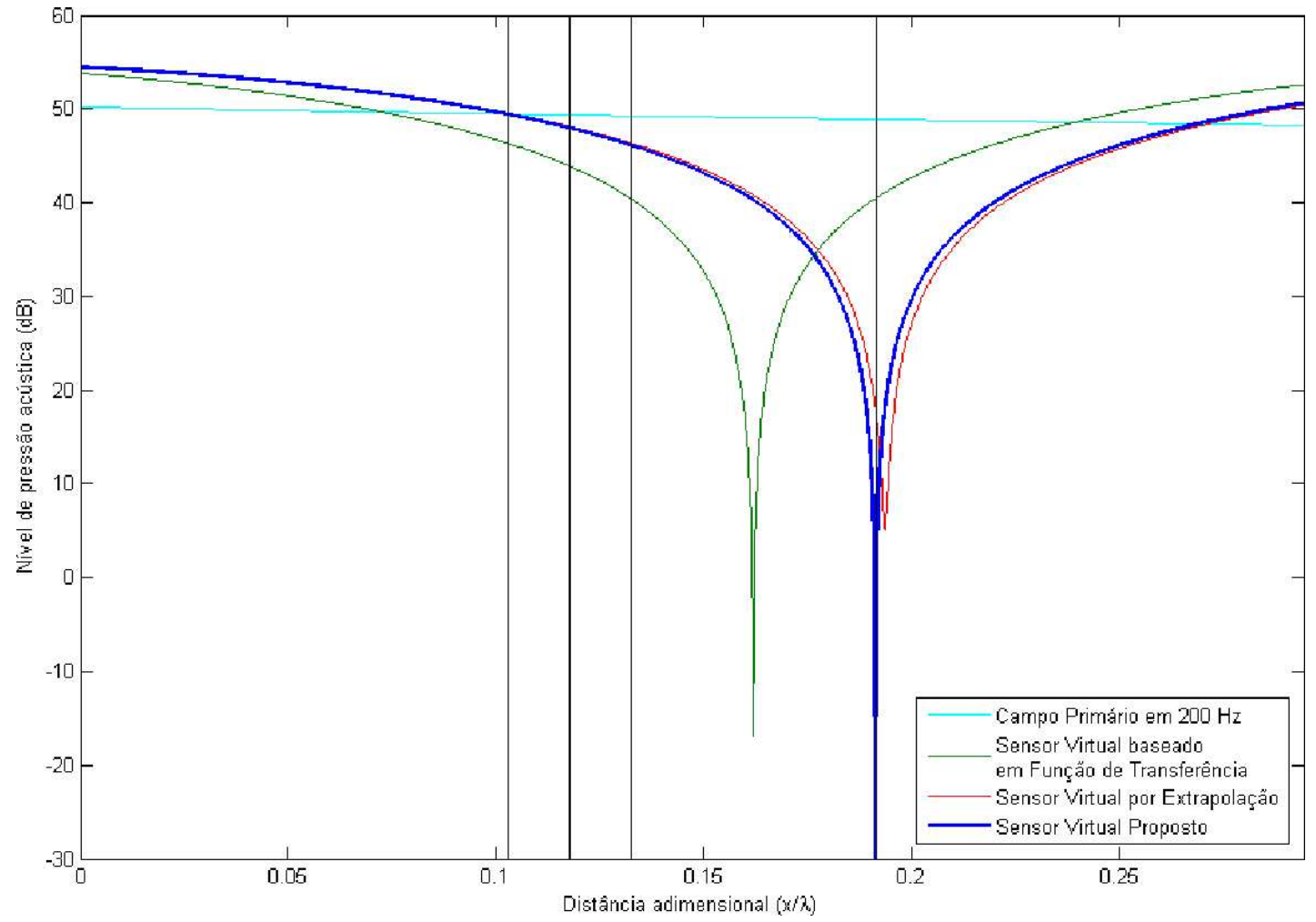

Figura 41: Comparação entre as estratégias de sensores virtuais, para uma distância de separação de $4 \mathrm{~h}$ em $200 \mathrm{~Hz}$. 


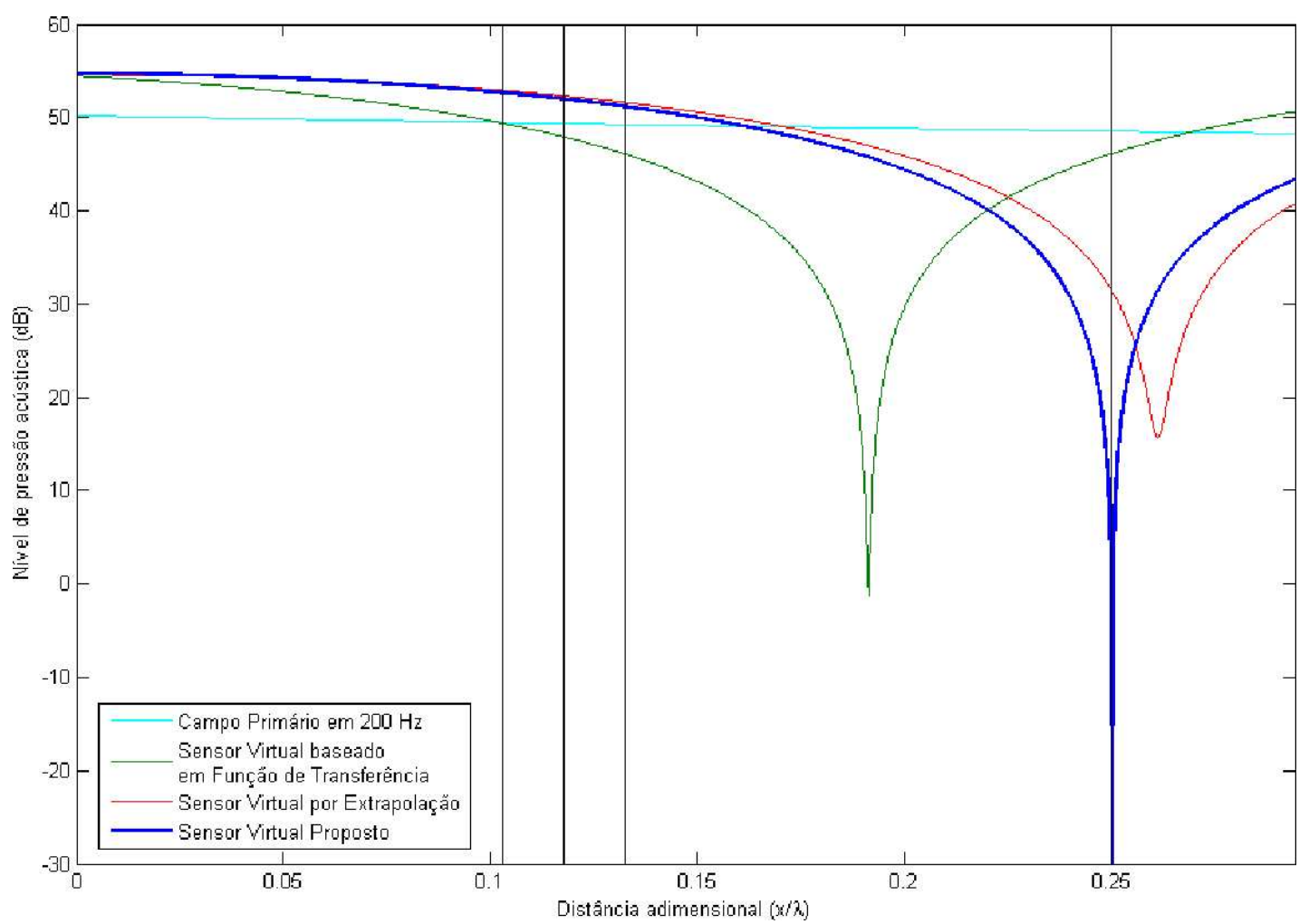

Figura 42: Comparação entre as estratégias de sensores virtuais, para uma distância de separação de $8 \mathrm{~h}$ em $200 \mathrm{~Hz}$.

método SVFT continua apresentando o pior desempenho, e já é possível notar um melhor desempenho do método JFS em comparação com o método SVE. Enquanto o método SVFT apresenta atenuação de 8dB na posição do sensor virtual, o método SVE apresenta atenuação de 30dB; por sua vez, o método JFS consegue efetivamente anular o nível de pressão sonora na posição do sensor virtual.

Quando a distância de separação aumenta para 8h, fica evidente a superioridade do método JFS, que sempre consegue anular o nível de pressão sonora na posição de interesse, enquanto o método SVE apresenta atenuação de $17 \mathrm{~dB}$ e o método SVFT apresenta atenuação de apenas $2 \mathrm{~dB}$, como é mostrado na figura 42.

\section{$5.5 .2 \quad 400 \mathrm{~Hz}$}

As figuras 43 a 45 mostram os resultados obtidos ao se controlar um ruído de $400 \mathrm{~Hz}$ em campo aberto com os três métodos de sensores virtuais expostos neste capítulo. A modelagem da simulação e a forma de apresentação dos resultados é a mesma da seção 5.5.1.

Com uma distância de separação entre o sensor virtual e o sensor de erro mais próximo 


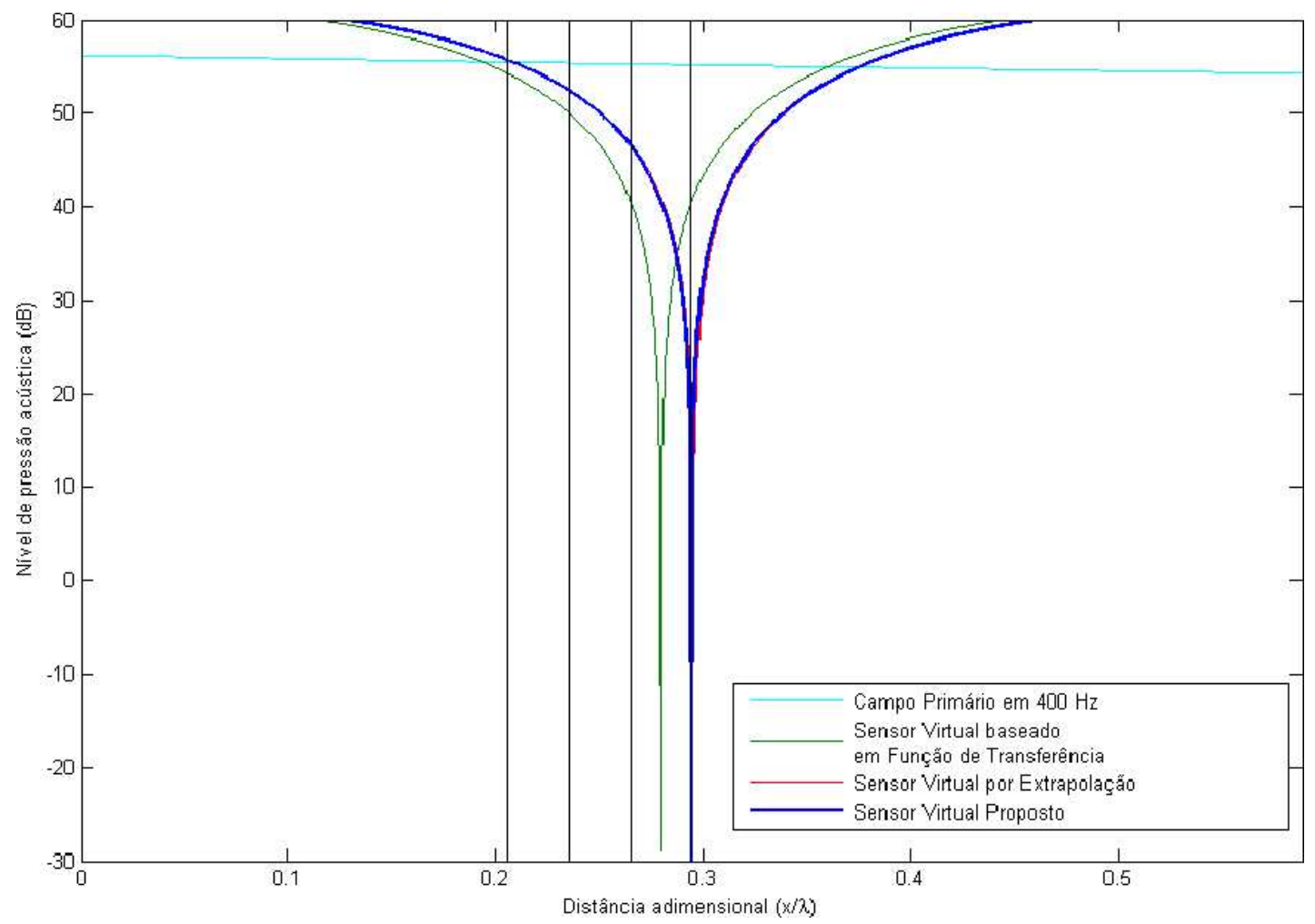

Figura 43: Comparação entre as estratégias de sensores virtuais, para uma distância de separação de $1 \mathrm{~h}$ em $400 \mathrm{~Hz}$.

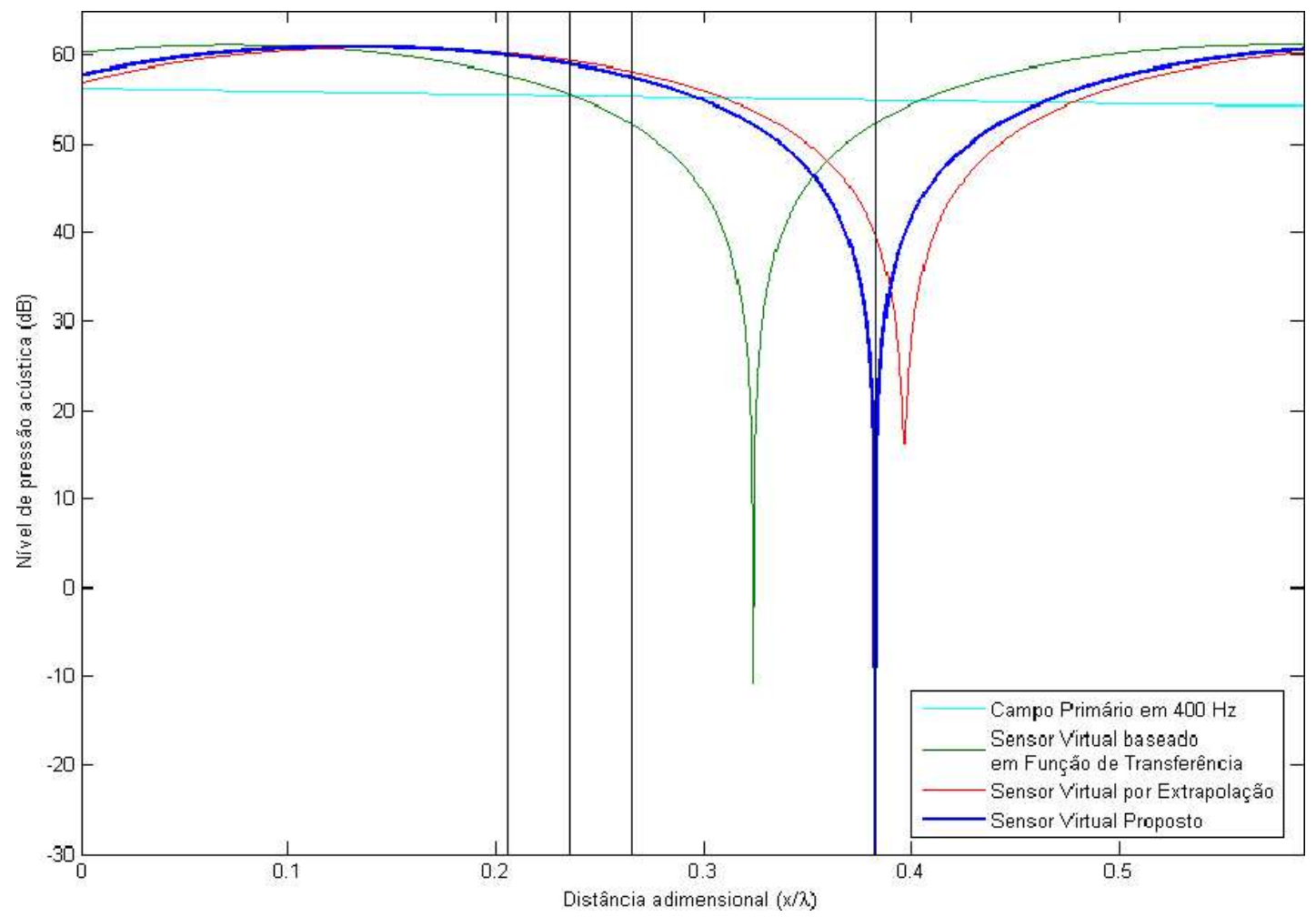

Figura 44: Comparação entre as estratégias de sensores virtuais, para uma distância de separação de $4 \mathrm{~h}$ em $400 \mathrm{~Hz}$. 


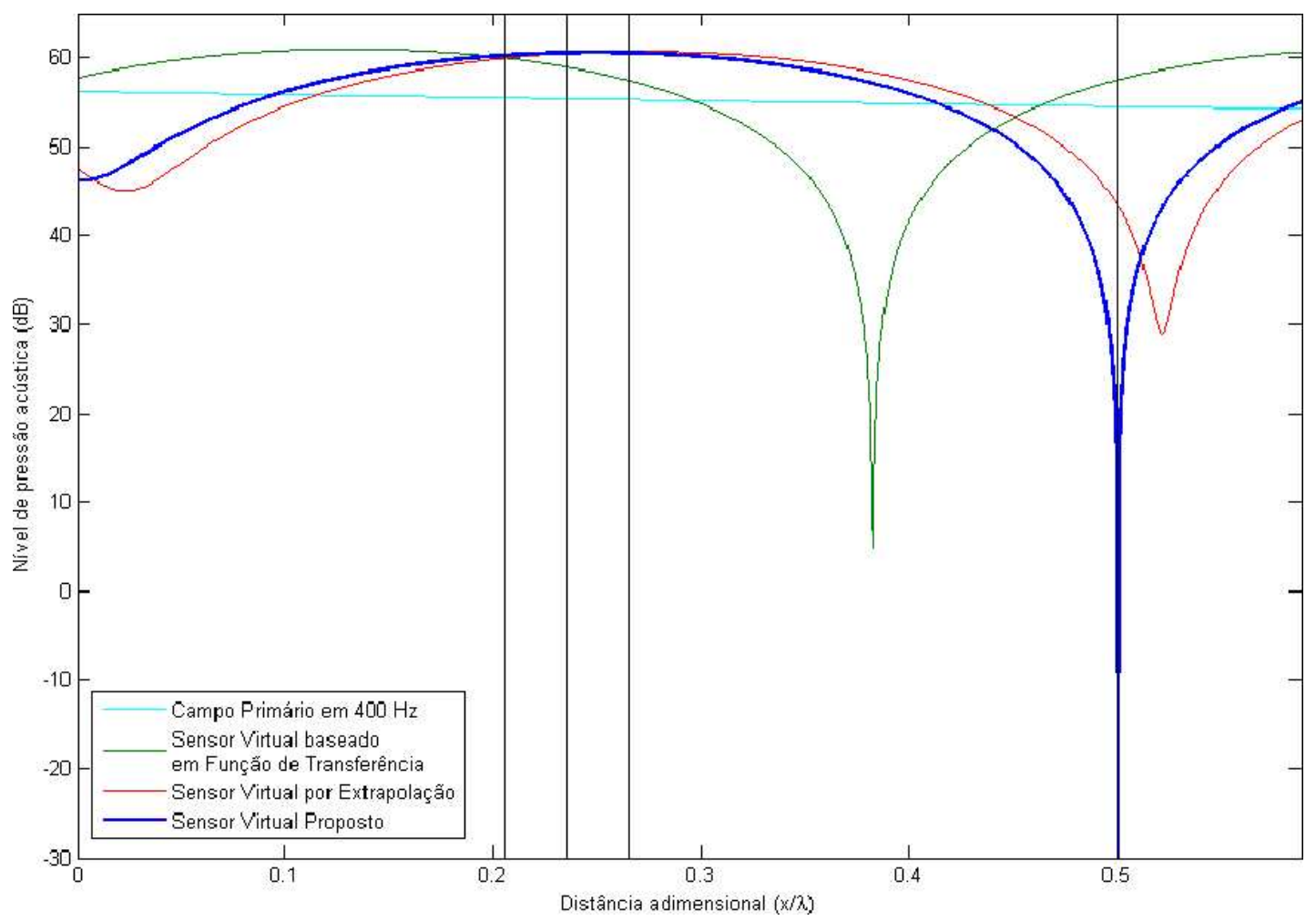

Figura 45: Comparação entre as estratégias de sensores virtuais, para uma distância de separação de $8 \mathrm{~h}$ em $400 \mathrm{~Hz}$.

igual a $h$, verifica-se o mesmo comportamento verificado quando a freqüência do ruído era 200Hz, com o método SVFT apresentando atenuação de 14dB, o método SVE apresentando atenuação de $38 \mathrm{~dB}$ e o método JFS anulando o nível de pressão sonora na posição do sensor virtual, como é mostrado na figura 43.

A figura 44 mostra os resultados da comparação quando a distância de separação entre o sensor virtual e o sensor de erro mais próximo aumenta de $h$ para $4 h$ e a figura 45 quando essa distância aumenta para 8h. Essas figuras indicam que os níveis de atenuação obtidos com os métodos SVFT e SVE diminuem conforme a distância de separação aumenta, enquanto o método JFS consegue sempre anular o nível de pressão sonora na posição do sensor virtual, independentemente da distância de separação ou da freqüência do ruído.

\subsubsection{Discussão}

Como Munn já havia discutido em sua dissertação [52], o método SVFT não apresenta bons resultados em simulações em campo aberto, por causa da hipótese assumida de que a pressão primária no sensor de erro e no sensor virtual sejam praticamente iguais. Quanto mais distantes estiverem estes sensores, ou quanto maior for a freqüência de interesse, 
menos esta hipótese será válida. Ela também notou que o desempenho do método SVE também piora com o aumento da distância de separação ou da freqüência, mas não tão acentuadamente quanto o método SVFT.

O método JFS apresentado nesta dissertação consegue anular o nível de pressão sonora para qualquer posição do sensor virtual e qualquer freqüência sob as condições desse modelo. Para conseguir tal desempenho, é necessário conhecer com precisão a função de transferência entre a fonte secundária e o sensor de erro e a fonte secundária e o sensor virtual, além da pressão primária no sensor de erro, uma quantidade de parâmetros bem maior que a quantidade de parâmetros necessários para o cálculo dos pesos no método SVE, além de serem parâmetros consideravelmente mais complexos de se obterem.

\subsection{Robustez do método JFS}

O método JFS conseguiu atenuação perfeita nos exemplos acima, mas isto não significa que seu desempenho real seja melhor do que o dos outros métodos. Para verificar melhor o potencial do método JFS, foi feita uma análise da robustez do método JFS quanto a variações de fase e posicionamento dos transdutores do sistema de controle. Para estas simulações foram usadas duas fontes pontuais esféricas como fontes primárias, duas fontes pontuais esféricas como fontes secundárias, três sensores de erro e três sensores virtuais, posicionados como é mostrado na figura 46. As fontes primárias estão a $0,1 \lambda$ da origem.

\subsubsection{Robustez quanto à Variação de Fase da Fonte Primária}

A definição da janela de pesos a ser aplicada nas fontes secundárias depende, entre outros fatores, das características do campo primário. Nesta simulação, a janela de pesos é calculada para uma dada defasagem entre as fontes primárias (tendo ambas a mesma velocidade de volume), e verifica-se o desempenho do método com a defasagem entre as fontes primárias.

As figuras 47 e 48 mostram como o nível de pressão sonora na região de observação (segmento de arco com raio de $5 \lambda$ variando de $\theta=-15^{\circ}$ a $\theta=15^{\circ}$ ) varia conforme a defasagem entre as fontes primárias varia de 0 a $2 \pi$. A grade verde mostra o nível de pressão sonora causado pelas fontes primárias na região de observação. A grade preta mostra o nível de pressão sonora verificado na região de observação com o controle de ruído minimizando o nível de pressão sonora nos sensores de erro. A superfície cor de 


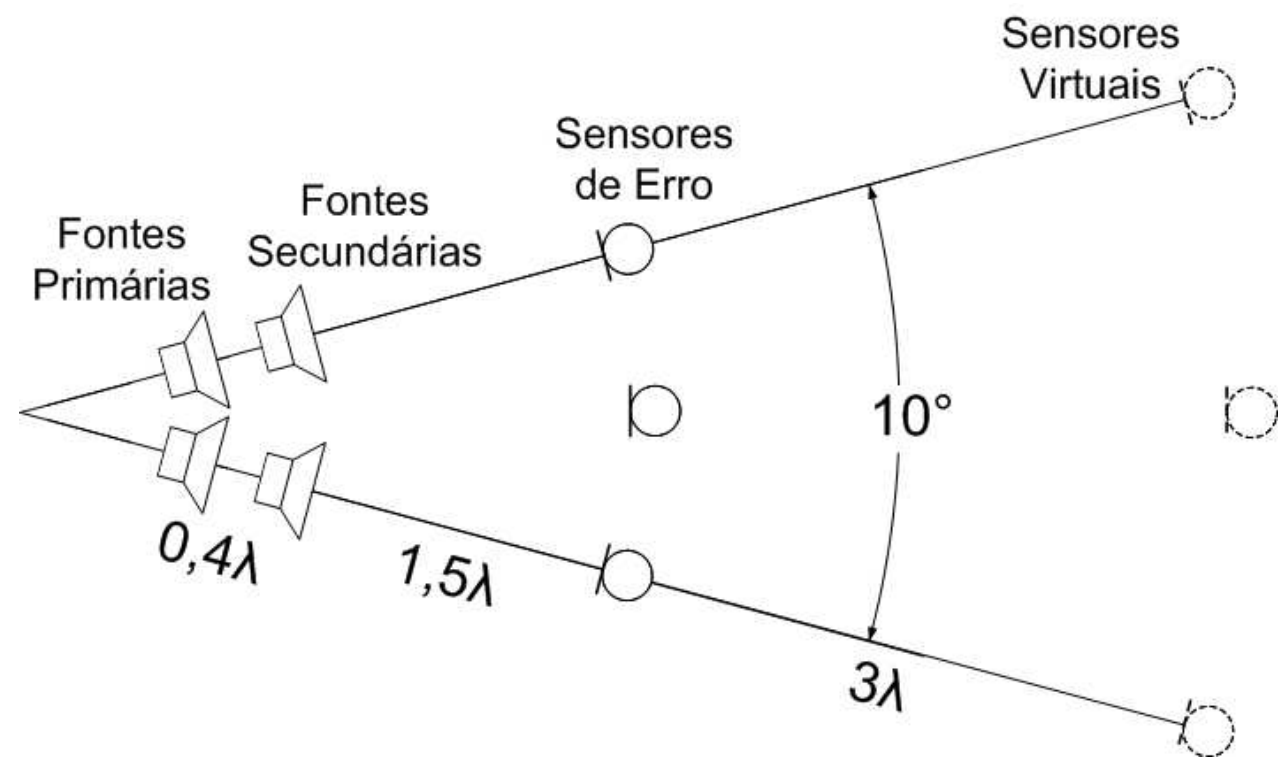

Figura 46: Disposição dos transdutores no sistema modelado para o estudo da robustez do método JFS.

cobre mostra o nível de pressão sonora verificado na região de observação com o método JFS minimizando o nível da pressão sonora nos sensores virtuais.

Na figura 47, a janela de pesos foi calculada para uma defasagem entre as fontes primárias de $\psi=0$. Já na figura 48, a janela de pesos foi calculada para uma defasagem entre as fontes primárias de $\psi=\pi / 2$. Em ambas as figuras observa-se um vale no meio do gráfico, que ocorre quando as fontes estão com fase invertida, resultando em pressão primária nula na direção $\theta=0^{\circ}$. Com exceção desse caso singular, o nível de pressão sonora obtido com o método JFS é sempre menor que o nível de pressão obtido com controle convencional e sempre consideravelmente menor que o nível de pressão primária. Na região entre os sensores virtuais, a atenuação obtida com o método JFS é sempre maior que 40dB (com exceção do ponto de singularidade) nas duas figuras, indicando a insensibilidade deste método ao erro na estimação de fase do campo primário.

Este método deixaria de funcionar bem se a defasagem entre as fontes primárias estivesse muito próxima de $\psi=\pi$. Nesta situação, o campo primário presente nos sensores de erro é praticamente nulo, ficando o cálculo da janela de pesos comprometido por causa da divisão de um número pequeno por um outro número pequeno. Por outro lado, como o nível do campo primário nesta situação já é baixo, o uso de controle de ruído é desnecessário. 


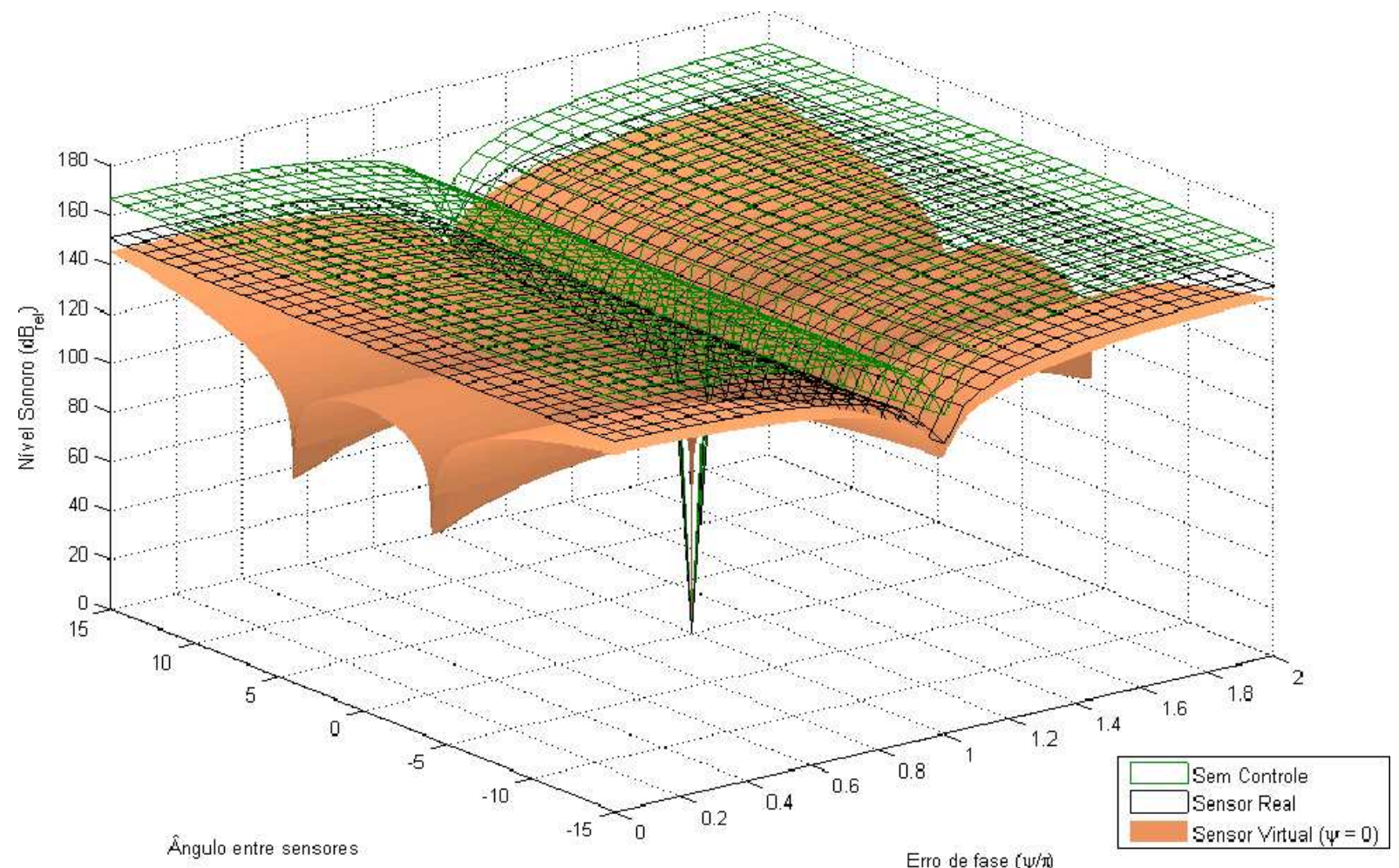

Figura 47: Variação do nível de pressão sonora na região de controle em função do erro de estimação da fase da fonte primária. Janela de pesos calculada para $\psi=0^{\circ}$.

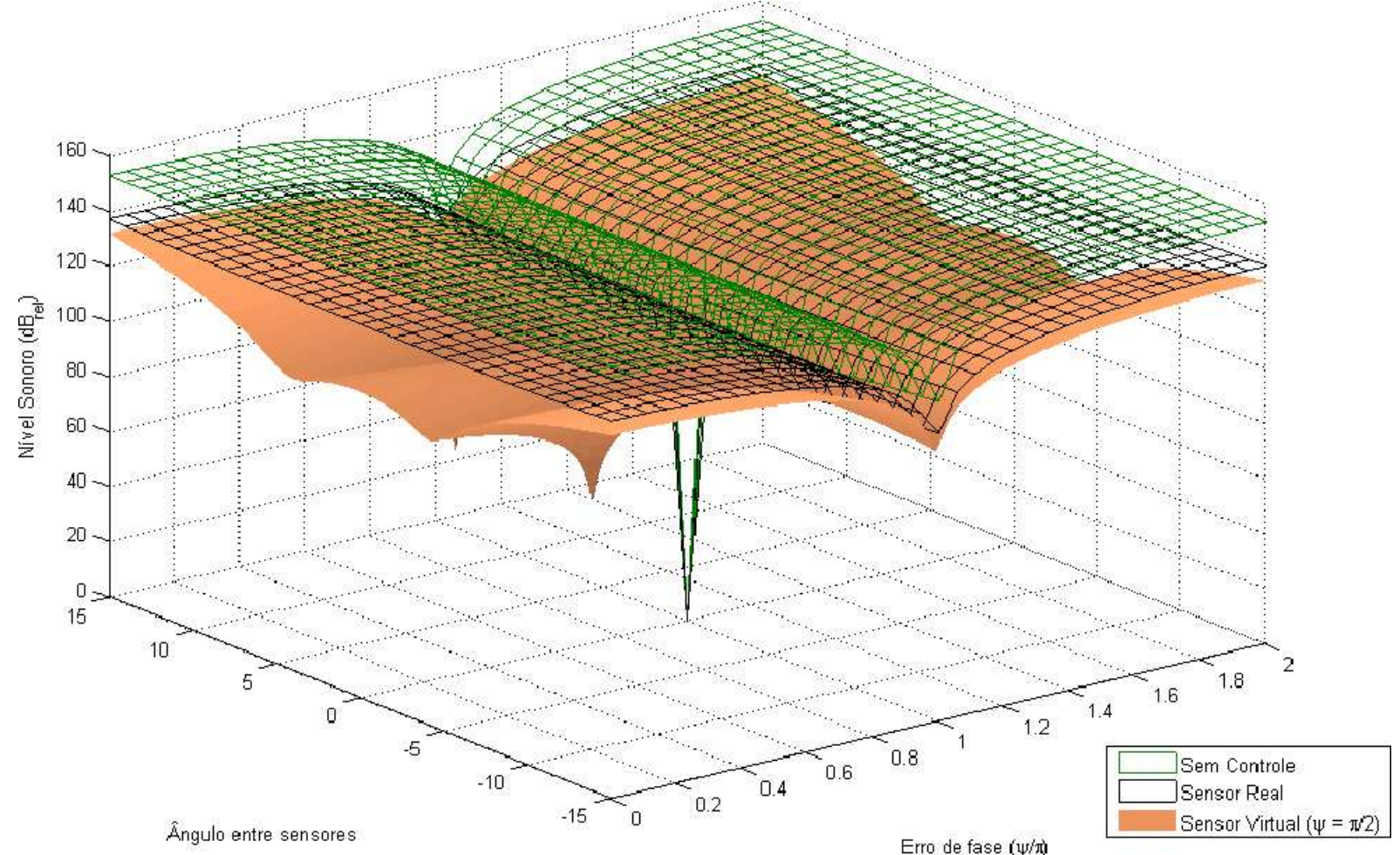

Figura 48: Variação do nível de pressão sonora na região de controle em função do erro de estimação da fase da fonte primária. Janela de pesos calculada para $\psi=90^{\circ}$. 


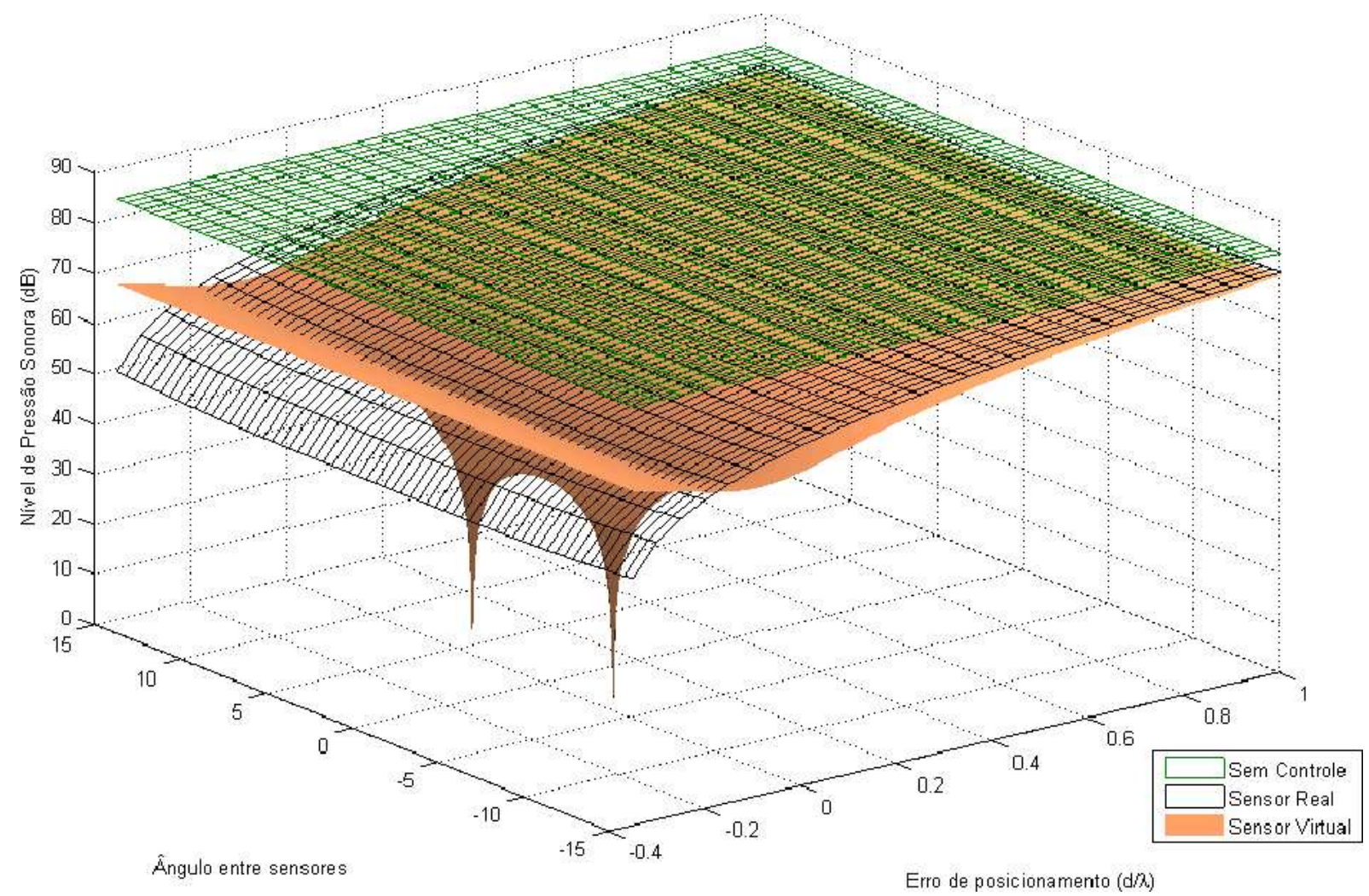

Figura 49: Variação do nível de pressão sonora na região de controle em função do erro de estimação da posição das fontes secundárias. A variação do erro é mostrada em unidades adimensionais.

\subsubsection{Robustez quanto ao Posicionamento da Fonte Secundária}

A definição da janela de pesos a ser aplicada nas fontes secundárias depende, além das características do campo primário, também da função de transferência entre fontes secundárias e sensores de erro e sensores virtuais. Nesta simulação, a janela de pesos é calculada para uma dada posição de fontes primárias, e verifica-se o desempenho do método com a variação do seu posicionamento.

A figura 49 mostra agora como varia o nível de pressão sonora na mesma região de observação das figuras anteriores quando a distância das fontes secundárias à referência varia (o ângulo entre as duas fontes secundárias se mantém inalterado). As superfícies presentes nessa figura são as mesmas descritas para as duas figuras anteriores.

Quando as fontes secundárias estiverem mais próximas da fonte primária do que projetado, o nível de pressão sonora observado com o controle convencional é menor que o obtido com o método JFS, caso contrário, o nível de pressão sonora observado com o método JFS será menor que o observado com o controle convencional, com essa diferença tendendo a se anular quanto mais as fontes secundárias se distanciam do da fonte 


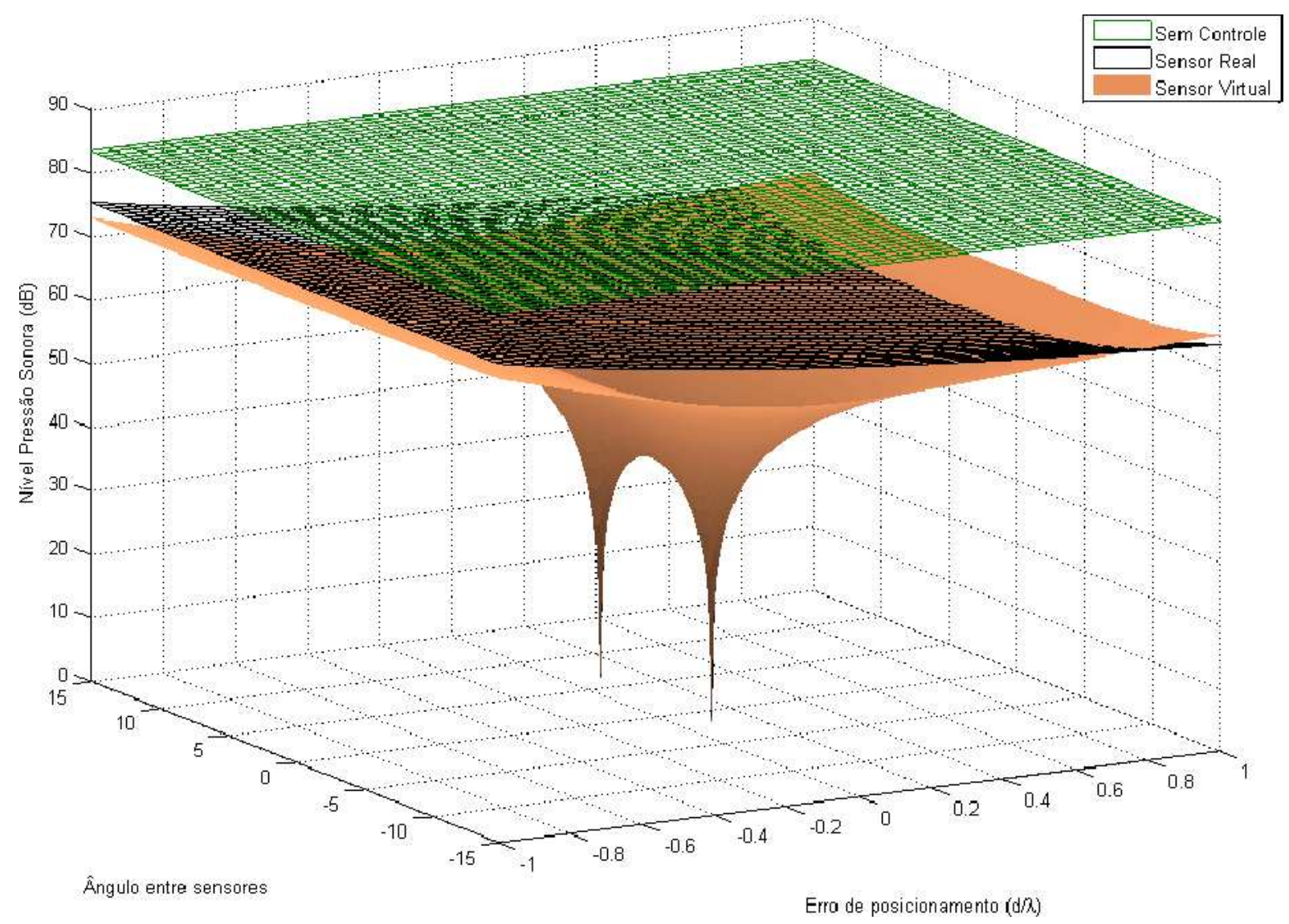

Figura 50: Variação do nível de pressão sonora na região de controle em função do erro de estimação da posição dos sensores de erro. A variação do erro é mostrada em unidades adimensionais.

primária. A região de interesse é quando o erro de posicionamento das fontes secundárias é de até $\pm 0,1 \lambda$. Nesse caso, verifica-se na região entre os sensores virtuais com o método JFS uma atenuação pelo menos $20 \mathrm{~dB}$ maior que a obtida com o controle convencional.

\subsubsection{Robustez quanto ao Posicionamento do Sensor de Erro}

Como a definição da janela de pesos a ser aplicada nas fontes secundárias depende das características do campo primário e da função de transferência entre fontes secundárias e sensores de erro, verfica-se nesta simulação a influência da correta definição do posicionamento dos sensores de erro no desempenho do sistema JFS.

A figura 50 mostra como varia o nível de pressão sonora na mesma região de observação das figuras anteriores quando a distância dos sensores de erro à referência varia (os ângulos entre três sensores de erro se mantêm inalterados). As superfícies presentes nessa figura são as mesmas descritas para as três figuras anteriores. 
Verifica-se que na região entre os sensores virtuais, o método JFS apresenta níveis de pressão sonora pelo menos $20 \mathrm{~dB}$ mais baixos que os níveis obtidos com o sistema de controle de ruído convencional se o erro da posição dos sensores de erro estiver entre $\pm 0,2 \lambda$. Conforme o erro de posicionamento aumenta e os sensores de erro passam a ficar mais próximos dos sensores virtuais, o sistema de controle convencional consegue impor na região de observação níveis de pressão sonora menores que os observados com o método JFS. Este fato explica-se porque o sistema de controle convencional sempre minimiza o nível de pressão sonora nos sensores de erro, não importando onde eles estejam. Sendo assim, o nível de pressão sonora imposto pelo controle convencional na região de observação fica cada vez menor, quanto mais próximos da região de observação estiverem os sensores de erro.

\subsubsection{Discussão}

Verifica-se que o método JFS, na configuração analisada nesta seção, é robusto ao erro de estimativa de fase do campo primário, mas sensível ao erro na estimação da posição das fontes secundárias e dos sensores de erro. Ainda assim, quando o erro da estimação do posicionamento for pequeno, menor que $0,1 \lambda$, o desempenho do método JFS será consideravelmente melhor que o desempenho do sistema de controle de ruído convencional.

Da mesma forma que Munn aborda a possibilidade de se otimizar os pesos do método SVE [52] baseado no algoritmo de adaptação LMS (descrito na seção 3.2.2.2), os pesos do método JFS também poderiam ser otimizados por meio do algoritmo LMS, lembrando que diferentemente do método SVE, onde os pesos são reais, no método JFS os pesos obtidos pelo algoritmo LMS devem ser complexos.

\subsection{Outras Simulações com o método JFS}

Quando a superfície de controle a ser atenuada é pequena, a melhoria obtida na atenuação desta superfície é bastante elevada, como pode ser visto na figura 51. Aqui usou-se o mesmo octopolo apresentado na seção 4.3 como fonte primária, cinco fontes pontuais como fontes de controle (uma em cada vértice de um quadrado de $(1 \times 1) \mathrm{m}^{2}$ e uma no centro deste quadrado) a $5 \mathrm{~cm}$ de uma das faces do octopolo e cinco sensores de erro, dispostos da mesma forma que as fontes secundárias a $10 \mathrm{~m}$ do octopolo. A pressão na superfície de controle foi amostrada por cinco sensores virtuais, a partir dos quais a 

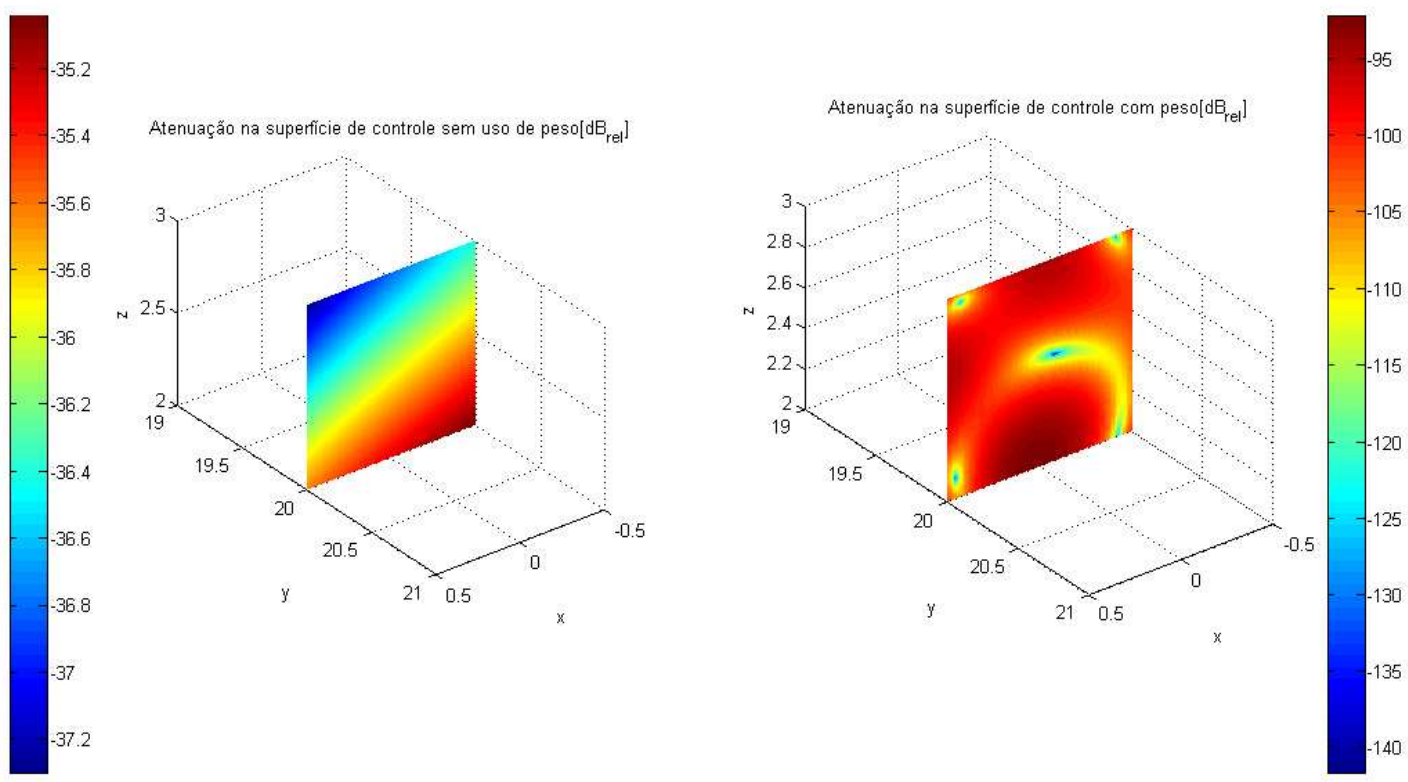

Figura 51: Efeito do uso de pesos na atenuação na superfície de controle a $20 \mathrm{~m}$ da fonte primária.
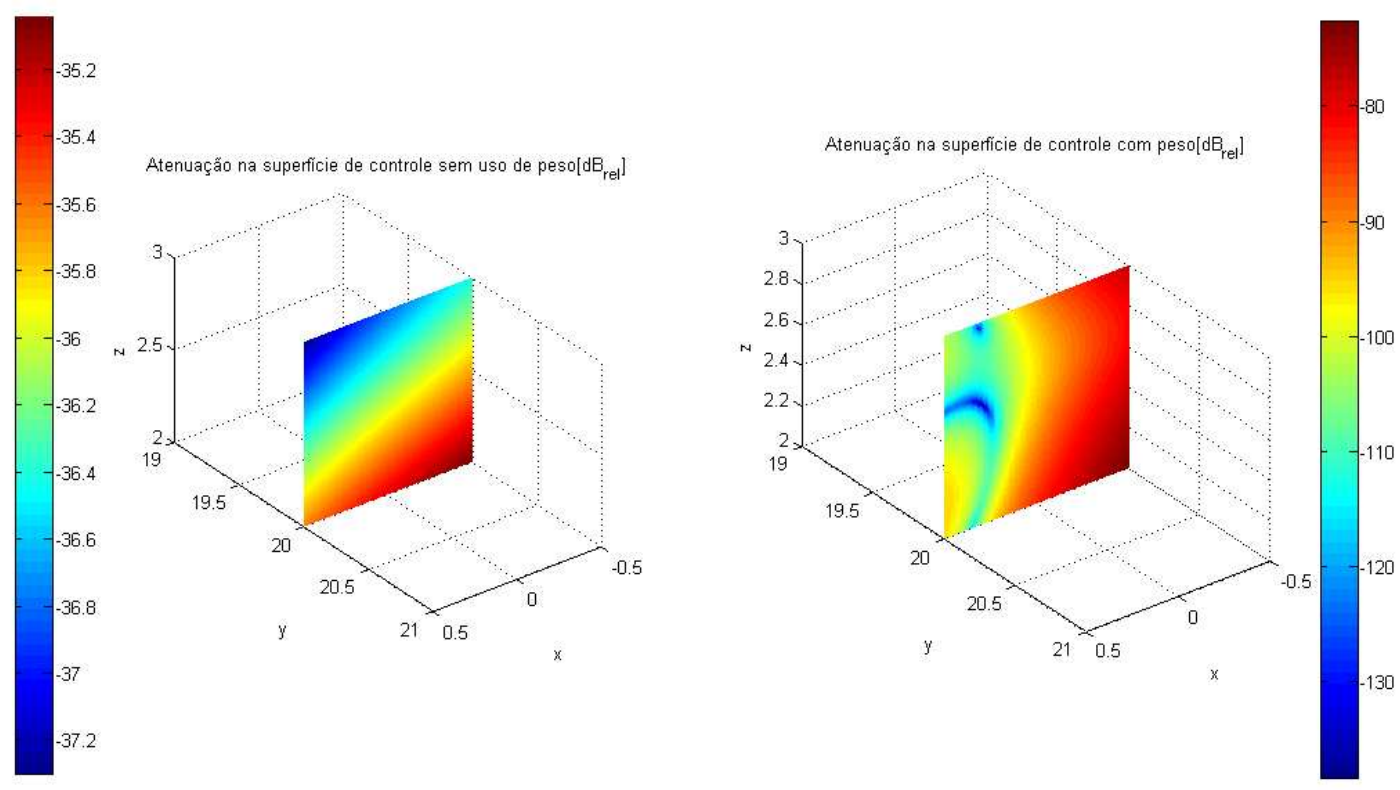

Figura 52: Atenuação resultante na superfície de controle para uma janela de pesos calculada para uma posição de sensores virtuais deslocada de $0,5 \mathrm{~m}$ na direção $x$ da posição correta da superfície de controle. 

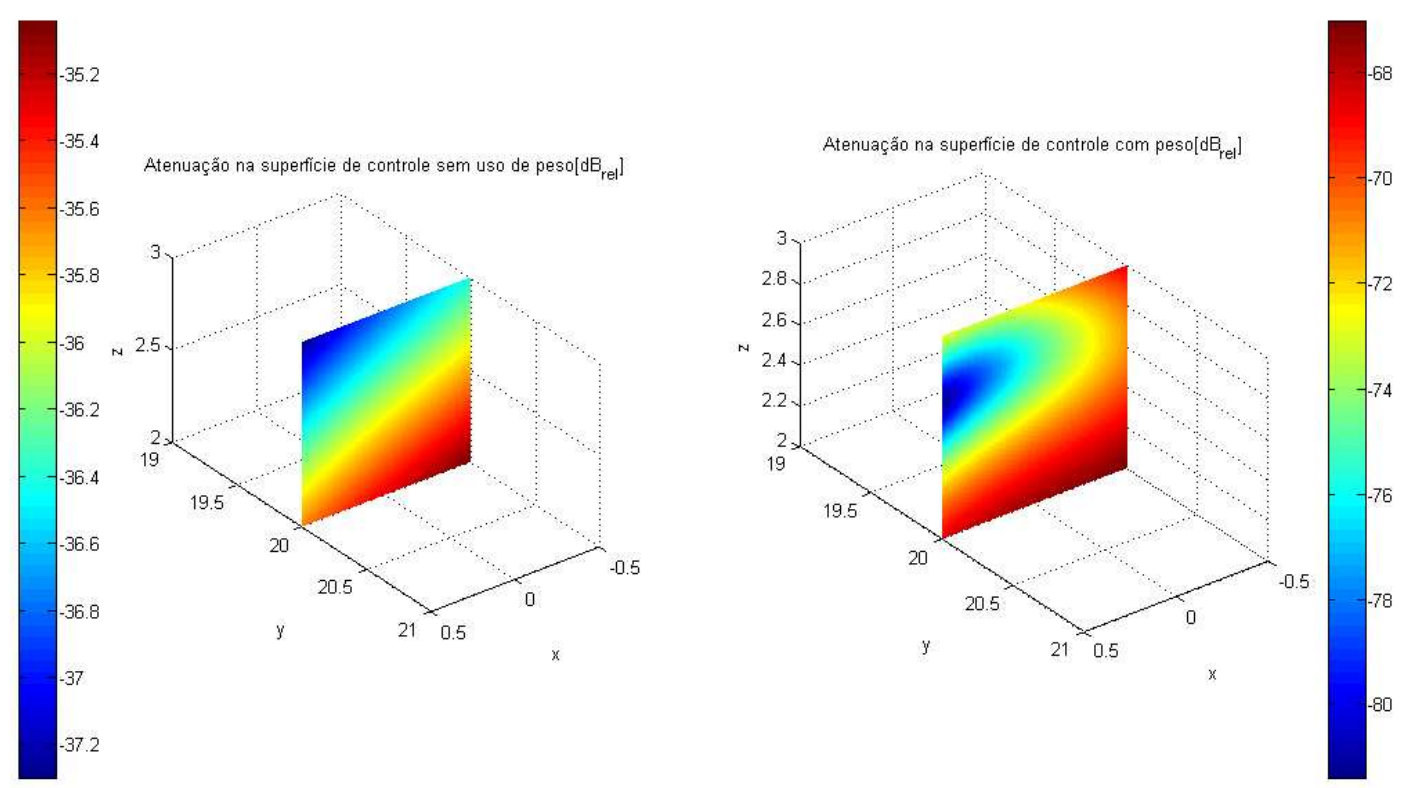

Figura 53: Atenuação resultante na superfície de controle para a janela de pesos calculada para uma posição de sensores virtuais $2 \mathrm{~m}$ mais próxima da fonte primárias que a posição efetiva da superfície de controle.
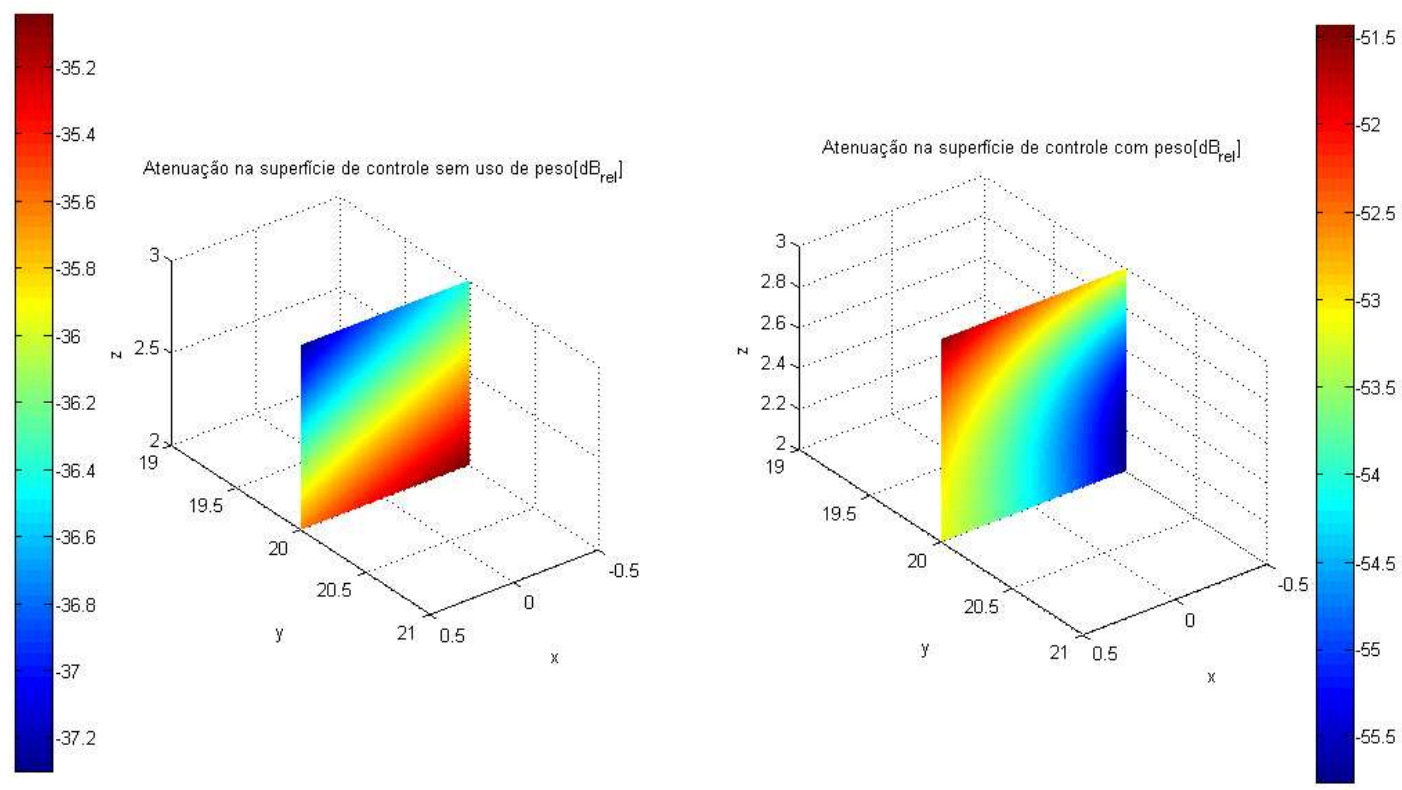

Figura 54: Atenuação resultante na superfície de controle para a janela de pesos calculada para uma posição de sensores virtuais $2 \mathrm{~m}$ mais distante da fonte primárias que a posição efetiva da superfície de controle. 

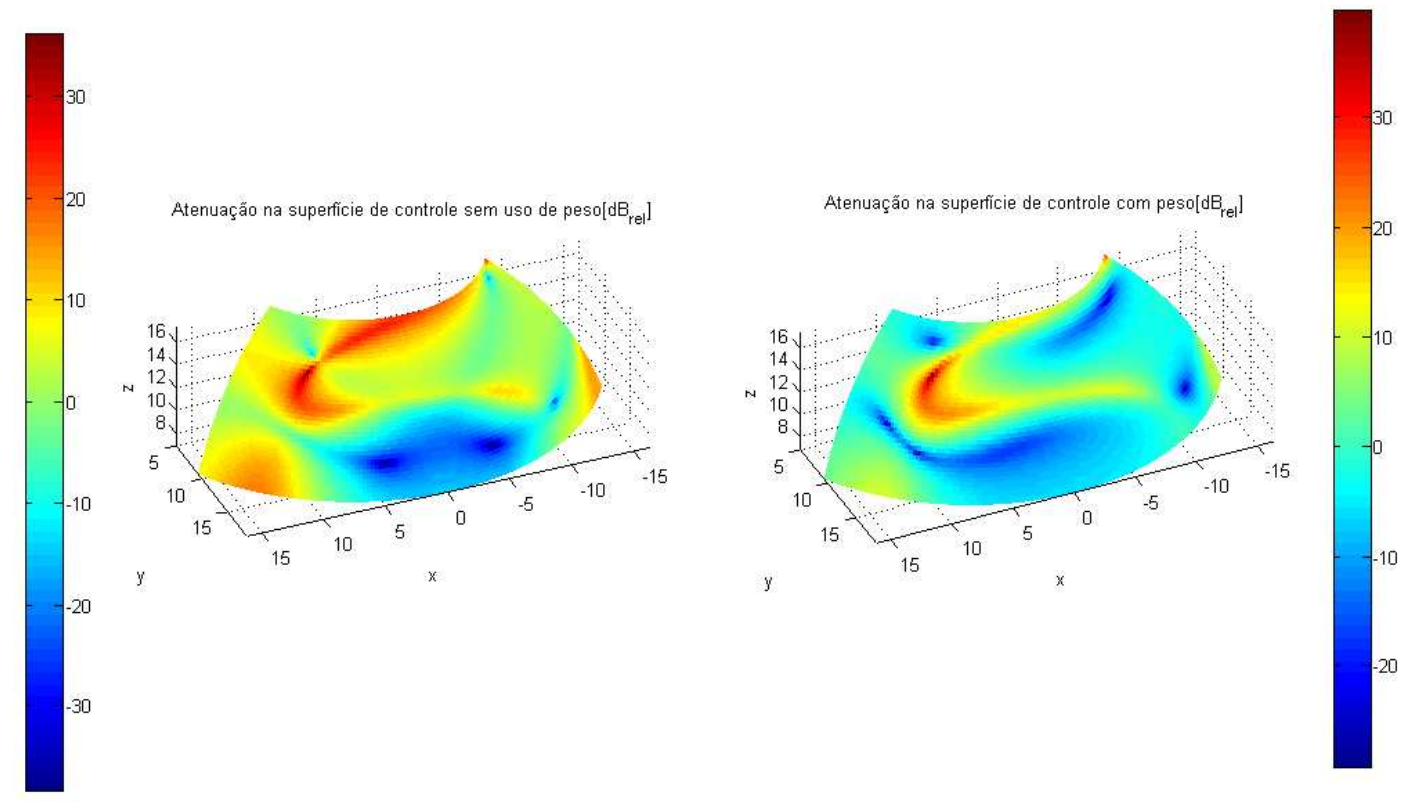

Figura 55: Atenuação resultante em uma superfície de controle grande em comparação com o tamanho da fonte primária.

janela de pesos foi calculada. Verifica-se para esta situação uma melhoria média de $60 \mathrm{~dB}$ no nível de atenuação desta superfície de controle de $1 \mathrm{~m}^{2}$.

É interessante investigar a sensibilidade desta matriz de pesos. Se posicionarmos os sensores virtuais deslocados de $0,5 \mathrm{~m}$ na direção $x$ da posição correta da superfície de controle, verifica-se uma redução na atenuação na região da superfície de controle que não está coberta pelos sensores virtuais, mas ainda assim, a atenuação nesta situação é consideravelmente melhor do que a atenuação obtida sem o uso de pesos, como mostra a figura 52 . Se agora os sensores virtuais tiverem sido estimados $2 \mathrm{~m}$ antes da posição correta da superfície de controle, verifica-se novamente que apesar de a atenuação ser menor do que a ótima mostrada na figura 51, ela continua sendo melhor do que a situação sem o uso de pesos, como mostra a figura 53. O mesmo vale se estimarmos a posição dos sensores virtuais $2 \mathrm{~m}$ à frente da superfície de onde a superfície de controle realmente está, como mostra a figura 54 .

Vale ressaltar que estas simulações foram feitas usando uma superfície de controle relativamente pequena. Quando se tenta utilizar esta técnica para atenuar superfícies de controle maiores, como um setor de esfera com $120^{\circ} \times 40^{\circ}$, quando há uma melhora, esta melhora é bastante singela, como mostra a figura 55, que foi obtida usando a mesma configuração de fonte primária, fontes secundárias e sensores de erro, mas agora utilizando-se 33 
sensores virtuais distribuídos uniformemente pela superfície de controle. Acredita-se que a razão do baixo desempenho do método neste caso é a quantidade e posicionamento das fontes secundárias, que em pequeno número não conseguem reproduzir o campo acústico primário em toda a área de interesse.

\subsection{Conclusão}

Neste capítulo foram apresentados dois métodos para a realização de sensores virtuais existentes na literatura, são eles: o "método dos sensores virtuais por função de transferência" e o "método dos sensores virtuais por extrapolação". Um novo método para a realização de sensores virtuais foi proposto, sendo este método chamado de "sensor virtual por janelamento das fontes secundárias".

Realizou-se uma comparação do desempenho dos três métodos por meio de simulação em campo aberto. Verifica-se que nesta situação, o método SVFT apresenta o pior desempenho. Quando a distância entre o sensor real e o sensor virtual é pequena, os métodos SVE e JFS apresentam desempenho semelhante, mas quando esta distância aumenta, o desempenho do método SVE passa a deteriorar, enquanto o método JFS continua conseguindo anular o nível de pressão sonora na posição do sensor virtual.

Verificou-se a robustez do método JFS a erros de estimação durante o cálculo da janela de pesos. O método se mostra robusto a erros de estimativa de fase do campo primário, mas sensível ao erro na estimação da posição das fontes secundárias e dos sensores de erro.

Por fim foram apresentadas algumas simulações do desempenho do método JFS com uma fonte primária mais complexa e um maior número de fontes de controle e sensores de erro. Verificou-se que o método apresenta bom desempenho quando a região onde se deseja atenuação é pequena. Para atenuação numa grande área, o desempenho não foi satisfatório. Acredita-se que o uso de um maior número de fontes secundárias poderia melhorar o desempenho do sistema neste caso. 


\section{MEDIÇÕES EM CAMPO}

\subsection{Introdução}

A grandeza física mais importante na propagação acústica é a variação de pressão sonora $p$, que indica a variação na pressão atmosférica causada por uma onda sonora. A unidade mais comum em que $p$ é expresso é o Pascal $\left([\mathrm{Pa}]=\left[\mathrm{N} / \mathrm{m}^{2}\right]\right)$. Normalmente, a pressão atmosférica $\left(p_{0} \approx 10^{5} \mathrm{~Pa}\right)$ tem valor muito superior à pressão acústica. A audição humana detecta variações de pressão da ordem de $20 \mu \mathrm{Pa}$ até $20 \mathrm{~Pa}$. Em razão da grande excursão dos valores de pressão e por a audição humana ter característica logarítmica, em vez da pressão sonora a grandeza mais utilizada na prática é o nível de pressão sonora

$$
L_{p}=20 \log \left(\frac{\tilde{p}}{\tilde{p}_{\text {ref }}}\right),
$$

expresso em decibéis $[\mathrm{dB}]$. Esta é uma medida logarítmica, que compara o valor eficaz da pressão sonora $\tilde{p}=\sqrt{\frac{1}{T} \int_{0}^{T} p^{2}(t) d t}$ com a pressão de referência $\tilde{p}_{r e f}=20 \mu \mathrm{Pa}$. O valor eficaz da pressão de referência é o limiar de audição, que corresponde à menor pressão eficaz de um tom em $1 \mathrm{kHz}$ ainda audível pelo ouvido humano.

O ouvido humano não é igualmente sensível em todo o espectro de audição, sendo mais sensível nas freqüências próximas a $4 \mathrm{kHz}$, como é mostrado na figura 56. Para tentar simular a curva de audibilidade do ouvido humano, foi definido um grupo de filtros de compensação, sendo a ponderação A ou simplesmente "dB(A)" a mais usada. Quando estes filtros são usados, o equipamento de medição deve primeiramente filtrar o sinal por um desses filtros, para depois calcular o nível de sinal.

Os valores máximos de ruído aceitável são definidos por legislações ambientais específicas de cada país. No Brasil, quando o transformador se encontra em operação em uma área habitada, estes limites são especificados pela norma NBR 10151: Avaliação do Ruído em Áreas Habitadas Visando o Conforto da Comunidade. No caso 


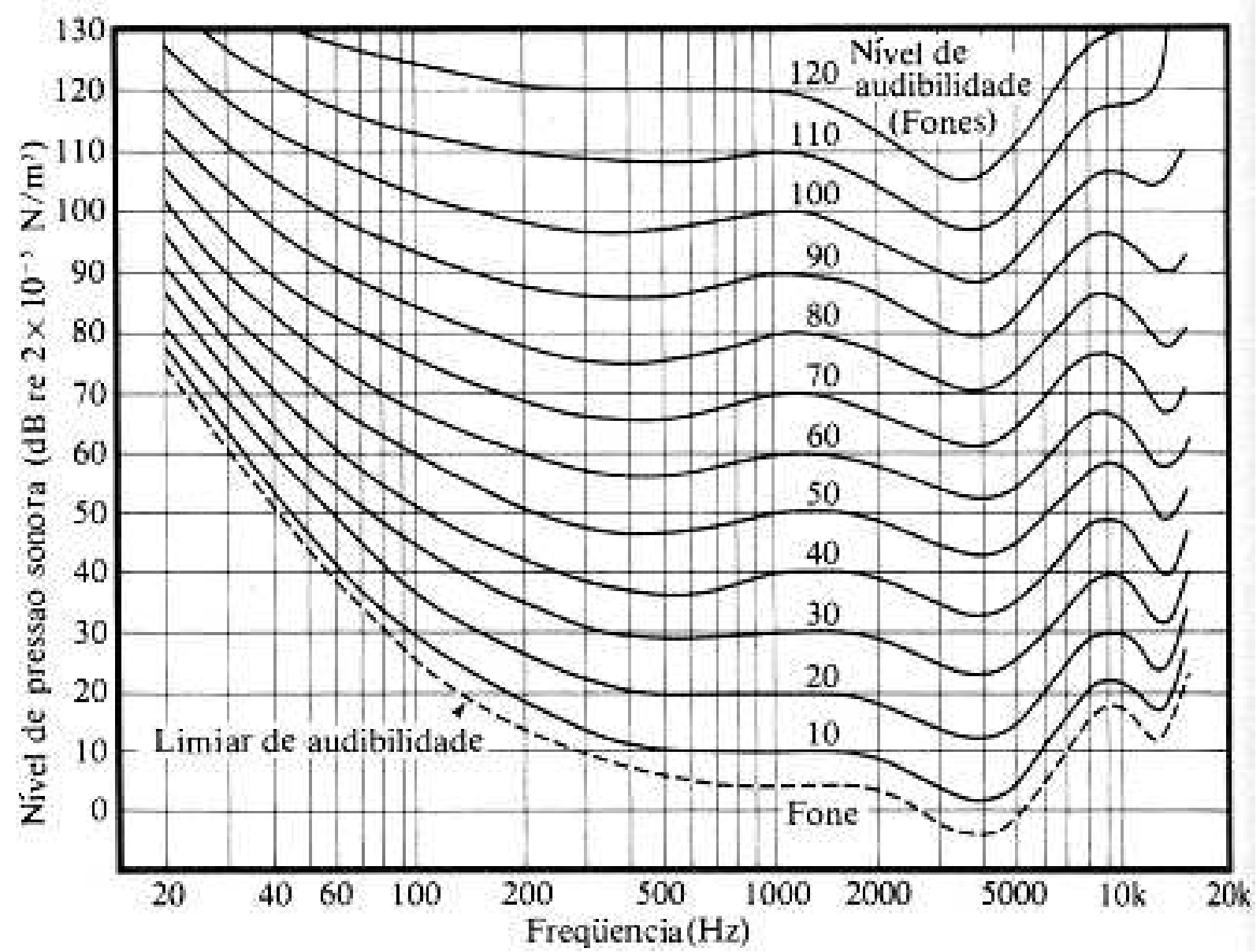

Figura 56: Curvas de mesmo nível de audibilidade para tons puros, também conhecidas por curvas de Fletcher-Munson.

específico do estado de São Paulo, a CETESB estabelece, pela Norma L11.032: Determinação de Nível de Ruído em Ambientes Internos e Externos de Áreas Habitadas, os níveis admissíveis de ruído. Os limites destas duas normas estão detalhados na tabela 3 ,

Neste capítulo são apresentados os resultados de diversas medições realizadas em laboratório e em uma subestação transformadora de distribuição (STD). Primeiramente apresenta-se uma análise do ruído emitido pelos transformadores da STD na seção 6.2. Em seguida, na seção 6.3 , descreve-se o equipamento que foi adquirido para os testes em laboratório e em campo. Os resultados dos testes realizados com o sistema ANC em laboratório são apresentados na seção 6.4. Testes de compatibilidade magnética realizados com o equipamento em uma STD são descritos na seção 6.5. Por fim, a seção6.6 apresenta resultados de testes realizados no campo com o sistema de controle de ruído.

O processo de aquisição dos equipamentos do sistema ANC pela empresa financiadora 
Tabela 3: Níveis de Ruído para ambientes externos definidos pela legislação nacional e pela legislação estadual - em dB(A)

NBR 10151 (revisão junho/2000)

\begin{tabular}{lcc}
\hline \multicolumn{1}{c}{ Tipos de áreas } & Diurno & Noturno \\
\hline Áreas de sítios e fazendas & 40 & 35 \\
Área estritamente residencial urbana, hospitais e escolas & 50 & 45 \\
Área mista, predominantemente residencial & 55 & 50 \\
Área mista, com vocação comercial e administrativa & 60 & 55 \\
Área mista, com vocação recreacional & 65 & 55 \\
Área predominantemente industrial & 70 & 60 \\
\hline
\end{tabular}

Norma L11.032 CETESB

\begin{tabular}{lccc}
\hline \multicolumn{1}{c}{ Tipos de áreas } & Diurno & Vespertino & Noturno \\
\hline Estritamente residencial & 50 & 45 & 40 \\
Predominantemente residencial & 55 & 50 & 45 \\
Diversificada (residência, comércio e indústria) & 60 & 55 & 50 \\
Predominantemente industrial & 65 & 60 & 55 \\
Estritamente industrial & 70 & 70 & 70 \\
\hline
\end{tabular}

do projeto foi um processo bastante moroso, tendo sido completado com quase três meses de atraso. Somando-se a isso a dificuldade de acesso à STD e o prazo restrito para a realização do projeto, não foi possível realizar na STD todos os testes desejados, sendo os testes não realizados propostos como trabalho futuro.

\subsection{Análise do Ruído de Transformadores}

Uma série de medições foi realizada em uma subestação, com o objetivo de identificar as características do ruído irradiado pelos transformadores nela instalados, bem como medir os níveis sonoros no prédio de apartamentos vizinho à subestação. Esta subestação possui dois transformadores em operação, sendo o localizado mais próximo aos edifícios denominado T2 e o outro T1. Ambos os transformadores possuem núcleo imerso em óleo e possuem bombas hidráulicas para forçar o fluxo do óleo em seus interiores.

Como o ruído emitido por um transformador não é o mesmo em todo seu entorno, não se pode simplesmente realizar uma medição em um ponto de seu entorno e considerá-la o valor de nível do ruído da unidade. O procedimento adotado foi o de se medir níveis de ruído em seis pontos igualmente espaçados ao redor do transformador T2, como mostra a 


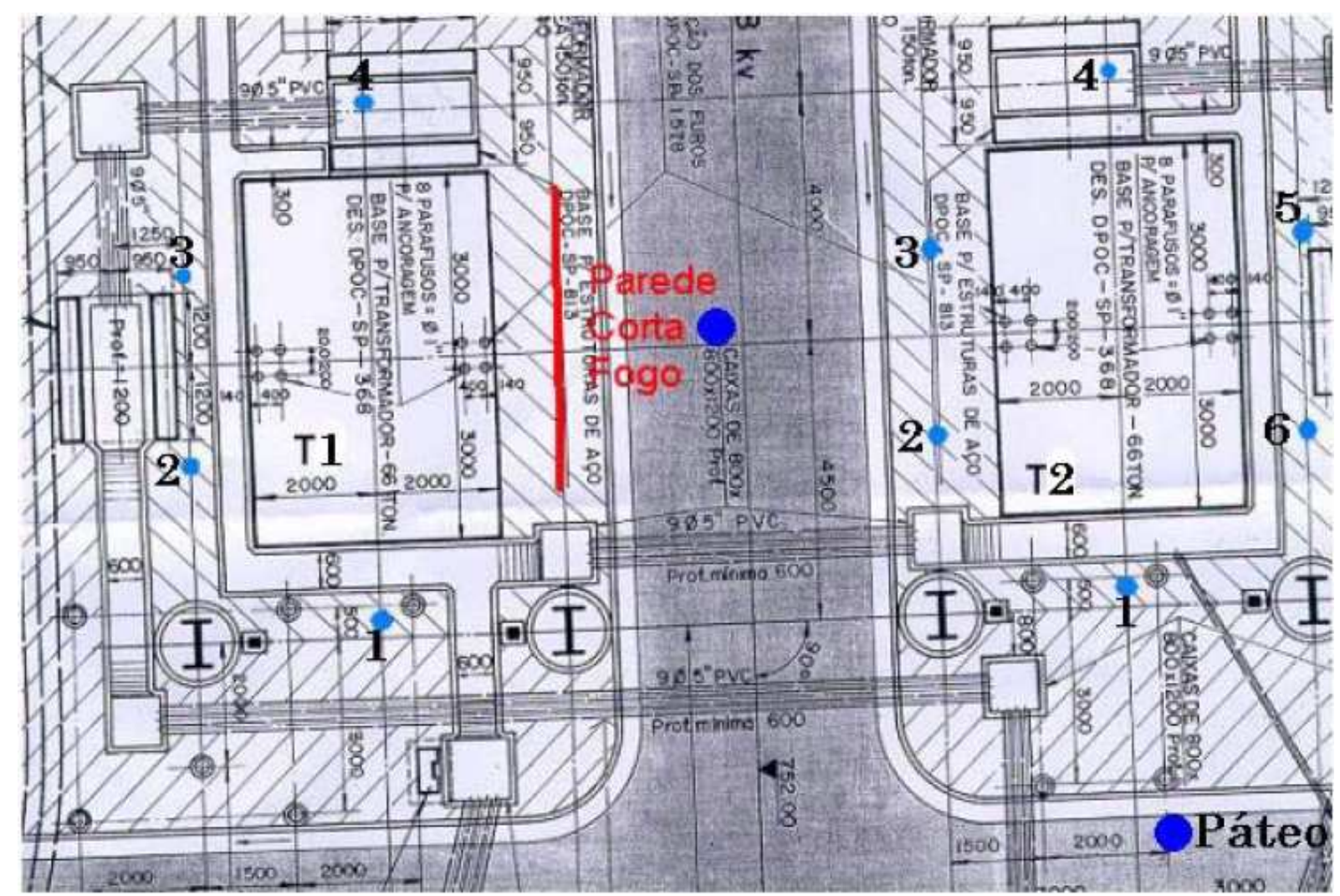

Figura 57: Pontos de medição de ruído ao redor dos transformadores.

figura 57, e em um ponto na janela de um apartamento no nono andar do prédio vizinho à subestação. As medições de níveis de ruído foram feitas com um analisador sonoro de banda estreita da marca Neutrik AG, devidamente calibrado.

Observa-se na tabela 4 que o nível sonoro máximo em todos os pontos encontra-se em $120 \mathrm{~Hz}$. Os segundos níveis sonoros máximos ocorrem quase sempre em $240 \mathrm{~Hz}$, porém há pontos em que estes ocorrem em $360 \mathrm{~Hz}$ ou $480 \mathrm{~Hz}$. A última linha da tabela apresenta as diferenças entre os máximos e os segundos máximos em cada ponto, onde se observa que as diferenças encontram-se na maioria dos pontos acima de 10dB. Observa-se ainda que os níveis sonoros máximos variam ponto a ponto. O máximo nível de pressão verificado foi $79,4 \mathrm{~dB}$ no ponto 4 do transformador T2 com sua bomba hidráulica desligada.

A tabela 5 apresenta os níveis sonoros do lado de fora da janela no nono andar do prédio vizinho à subestação com apenas o transformador T1 ligado, apenas o transformador T2 ligado e ambos ligados. As medidas correspondem às freqüências predominantes do espectro sonoro obtidas via FFT. Similarmente às medições próximas aos transformadores, os níveis sonoros máximos no prédio continuam ocorrendo em $120 \mathrm{~Hz}$, com diferenças entre os máximos e os segundos máximos em torno de 9dB. Observa-se que com o T1 
Tabela 4: Níveis sonoros nos pontos de medição no entorno do transformador T2 (bomba desligada e ligada) nas freqüências predominantes do espectro sonoro em bandas estreitas obtidos via FFT. $\Delta$ mostra a diferença entre a primeira e a segunda harmônica mais fortes para cada posição.

\begin{tabular}{ccccccccc}
\hline T2 & \multicolumn{1}{c}{ Bomba Desligada } & \multicolumn{6}{c}{ Bomba Ligada } \\
\hline Ponto & 1 & 4 & 1 & 2 & 3 & 4 & 5 & 6 \\
\hline Freq. (Hz) & \multicolumn{2}{c}{$L_{p}(\mathrm{~dB})$} & & \multicolumn{6}{c}{$L_{p}(\mathrm{~dB})$} \\
\hline 120 & 72,5 & 79,4 & 67,9 & 75,1 & 73,8 & 78,6 & 77,0 & 76,5 \\
240 & 60,5 & 63,8 & 64,4 & - & - & - & - & 62,7 \\
360 & - & 61,2 & - & 55,2 & 60,1 & 59,5 & 62,3 & 64,1 \\
480 & 48,3 & 56,0 & 53,6 & 58,2 & 54,8 & 52,6 & 66,8 & 55,7 \\
600 & 46,6 & 53,6 & 47,5 & 48,1 & - & - & 59,1 & 59,5 \\
720 & - & 56,6 & - & - & 53,5 & - & 53,3 & 51,1 \\
840 & 38,8 & 47,0 & - & 43,0 & 48,6 & 41,1 & 46,0 & 49,2 \\
\hline$\Delta(\mathrm{dB})$ & 12,0 & 15,6 & 3,5 & 16,9 & 13,7 & 19,1 & 10,2 & 12,4 \\
\hline
\end{tabular}

Tabela 5: Níveis sonoros do lado de fora da janela no nono andar do prédio vizinho à subestação com apenas o transformador T1 ligado, apenas o transformador T2 ligado e ambos ligados nas freqüências predominantes do espectro sonoro em bandas estreitas obtidos via FFT.

\begin{tabular}{cccc}
\hline $9^{\circ}$ Andar & T1 & T2 & T1 e T2 \\
\hline Freq. (Hz) & \multicolumn{3}{c}{$L_{p}(\mathrm{~dB})$} \\
\hline 120 & 57,9 & 58,5 & 58,2 \\
240 & - & 49,7 & 49,2 \\
360 & 41,6 & 47,8 & 46,6 \\
480 & 47,3 & - & - \\
600 & - & 48,7 & 43,5 \\
720 & - & 37,8 & 33,3 \\
840 & 27,4 & 30,1 & - \\
\hline$\Delta(\mathrm{dB})$ & 8,8 & 10,6 & 9,0 \\
\hline
\end{tabular}


Tabela 6: Níveis de pressão sonora em pontos próximos ao radiador.

\begin{tabular}{llc}
\hline & Posição do Ponto & $L_{p}(\mathrm{~dB})$ \\
\hline 1 & Ponto interno esquerda & 83,3 \\
2 & Ponto externo esquerda & 61,0 \\
3 & Ponto externo direita & 63,8 \\
4 & Ponto interno direita & 81,8 \\
5 & Ponto intermediário & 76,1 \\
\hline
\end{tabular}
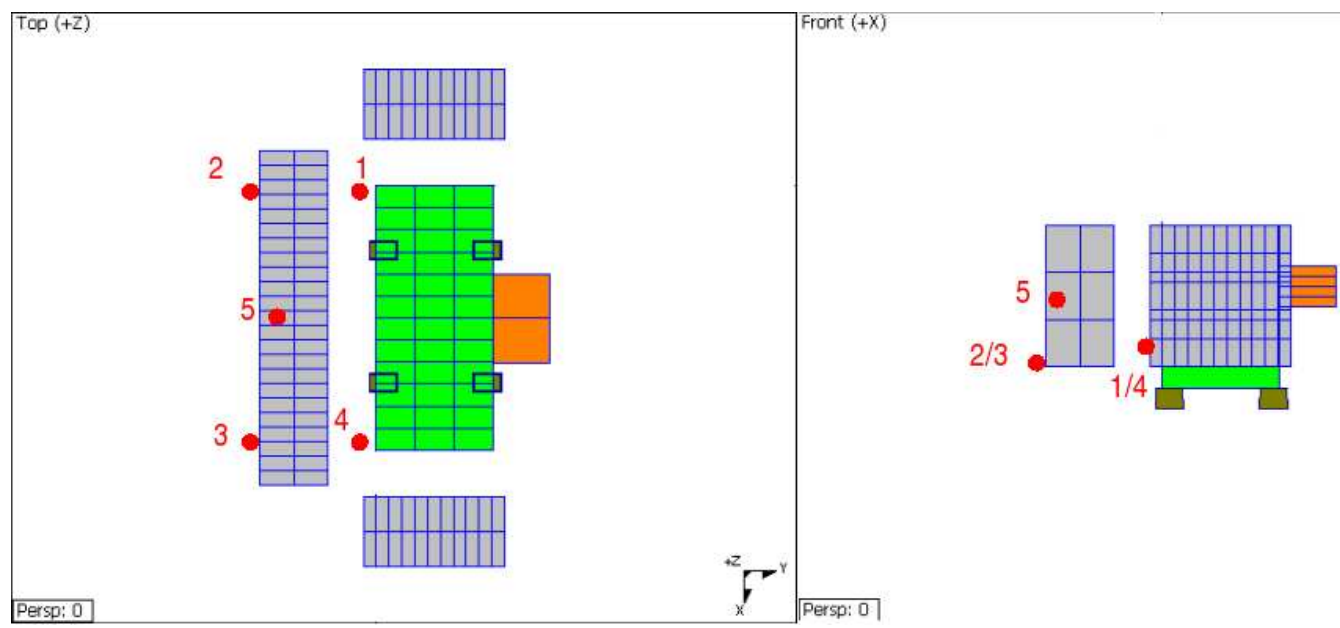

Figura 58: Pontos de medição próximos ao radiador traseiro.

ligado, T2 ligado e T1 e T2 ligados, os níveis sonoros ficam praticamente inalterados e em torno de $58 \mathrm{~dB}$, que está bastante acima da faixa estabelecida pela norma Norma L11.032 no horário da medição (noturno).

A análise dos espectros em bandas de $1 / 3$ oitava dos níveis equivalentes medidos nos pontos 1 e 4 do transformador T2 com a bomba ligada comparativamente com a bomba desligada mostra que o efeito da bomba ligada parece ser o aumento dos níveis sonoros nas bandas acima de $3,15 \mathrm{kHz}$. Respectivamente, nos pontos 1 e 4, os níveis equivalentes totais medidos foram de 59,0 e 67,3dB(A) com a bomba desligada e de 59,4 e 65,6dB(A) com a bomba ligada. Tanto com a bomba ligada como desligada, os níveis equivalentes totais são praticamente os mesmos, confirmando que a influência do sistema de refrigeração no ruído gerado pelos transformadores não é importante.

Novas medições foram feitas para verificar a função acústica que os radiadores de calor exercem. A pressão acústica foi medida em cinco posições, sendo duas entre o radiador e o tanque, uma no meio do radiador e duas posteriores ao radiador, como mostra a figura 
Apesar de medições de vibração terem mostrado que as placas do radiador vibram com amplitude comparável à amplitude de vibração da parede do tanque do transformador, a pressão sonora na região externa do radiador é menor que na região interna, como é mostrado na tabela 6. Logo os radiadores não atuam como fonte de ruído, mas sim como uma barreira acústica. A provável explicação para este fenômeno deve ser a geometria dos radiadores, que faz com que eles não se acoplem acusticamente muito bem com o ar.

\subsection{Descrição dos Equipamentos}

Os equipamentos utilizados para o sistema de controle ativo de ruído foram adquiridos pela Eletropaulo AES, empresa financiadora deste projeto. Para o sistema de controle, comprou-se a placa EZ-ANC da empresa Causal Systems, desenvolvida especialmente para aplicações ANC. Esta placa possui seis saídas para fontes de controle e seis entradas, sendo uma entrada para o sinal de referência e cinco entradas para sensores de erro. A placa EZ-ANC possui o algoritmo FxLMS programado para o controle, sendo que a estimação do caminho secundário pode ser feita com ruído branco ou com o próprio sinal de controle, um método proprietário dessa empresa. O usuário pode alterar todos os parâmetros do controle adaptativo via comunicação serial com um micro-computador. Pode-se alterar, entre outros parâmetros, o número de coeficientes, a taxa de convergência do filtro adaptativo, o ganho dos sinais de entrada e a taxa de amostragem dos conversores A/D e D/A. A placa EZ-ANC também permite que o sinal de referência seja filtrado digitalmente por um filtro FIR fornecido pelo usuário. Outro membro do grupo desenvolveu uma placa DSP para controle ativo de ruído. Por causa de atrasos no processo de compra dos componentes dessa placa, houve muito pouco tempo hábil para a realização de testes com ela e por essa razão quase todos os experimentos apresentados a seguir foram feitos com a placa EZ-ANC.

As caixas acústicas adquiridas são de fibra de vidro. Utilizou-se este material por que as caixas acústicas terão de ficar expostas ao tempo, e precisam ser à prova de água. Os alto-falantes tiveram uma camada de silicone aplicada a seus cones para elevar sua resistência à água. As caixas acústicas foram dimensionadas para apresentarem boa resposta na faixa média de freqüência, faixa em que a maior parte da energia do ruído do transformador se concentra. Para alimentar os alto-falantes foram comprados três amplificadores de potência Z300 da StudioR. 


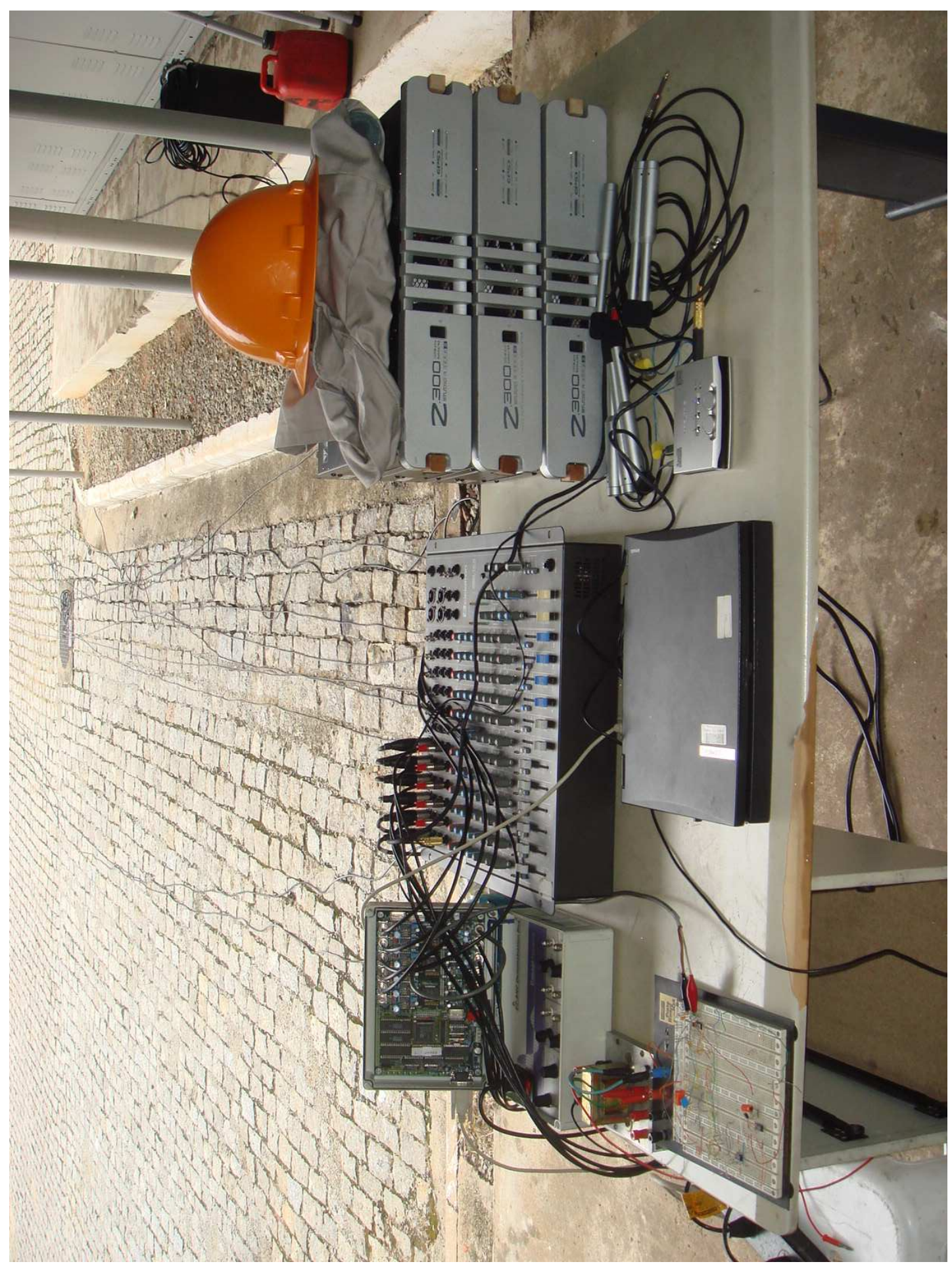

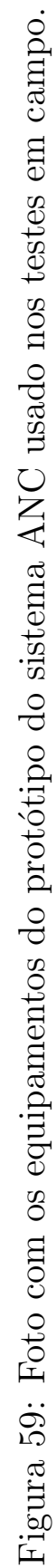



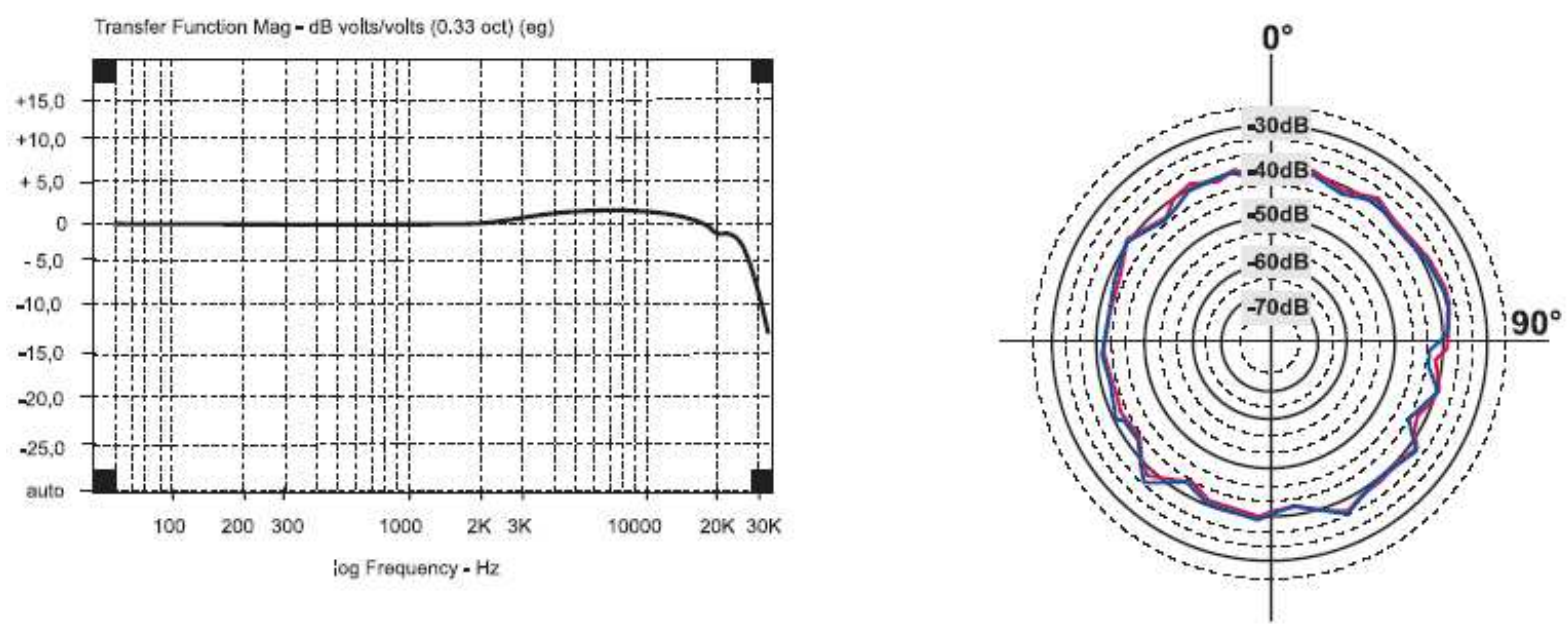

Figura 60: Resposta em freqüência e diretividade do microfone ECM8000.

Foram adquiridos microfones de medição ECM8000 da Behringer, com característica omnidirecional e resposta em freqüência plana na faixa espectral de interesse, como mostra a figura 60, fornecida pelo próprio fabricante. Para ficarem expostos ao tempo, estes microfones irão precisar de alguma forma de proteção, como uma caixa metálica, por exemplo. Para a alimentação "Phanton Power" e pré-amplificação dos sinais do microfone, adquiriu-se uma mesa mixadora CSM $16 \mathrm{R}$ da Ciclotron.

A figura 59 mostra todos os equipamentos adquiridos sendo usado em um teste realizado na STD.

\subsubsection{Gerador de Referência}

Como a placa EZ-ANC funciona com um algoritmo de controle direto, é necessário fornecer à placa um sinal de referência com a freqüência exata que se deseja atenuar na planta. Para o controle de ruído em transformadores, o sinal de referência é normalmente extraído da própria rede elétrica. Por causa das características físicas dos transformadores, a freqüência com que ele vibra é o dobro da freqüência na qual ele é excitado. Portanto, é necessário um circuito que retire uma amostra da freqüência de rede e forneça na sua saída um sinal com o dobro dessa freqüência e com amplitude dentro da faixa dinâmica dos conversores A/D.

O circuito desenvolvido para o propósito é mostrado na figura 61. Primeiro o sinal da rede passa por um transformador de tensão, que reduz o sinal de $110 \mathrm{~V}$ para $5 \mathrm{~V}$, além de desacoplar o circuito da rede. O sinal que sai do transformador passa então por uma ponte 


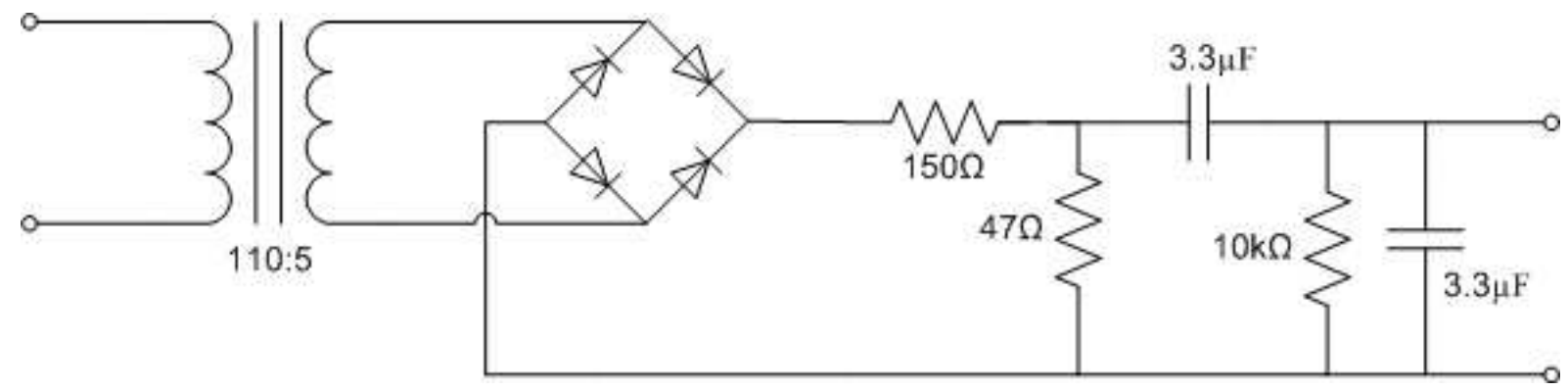

Figura 61: Esquema do gerador de referência.

de diodos, onde ocorre a retificação de onda completa, que efetivamente dobra a freqüência do sinal, além de inserir uma componente de corrente contínua e harmônicas superiores. O sinal que sai da ponte de diodos ainda passa por um divisor de tensão, para que sua amplitude fique dentro da faixa dinâmica do conversor A/D e por um filtro passa-bandas, para eliminar tanto a componente de corrente contínua quanto as harmônicas superiores inseridas pela retificação de onda completa.

\subsection{Testes em Laboratório}

O primeiro teste foi realizado usando um alto-falante como fonte primária de ruído, e um segundo alto-falante como fonte de controle. Foram usados três microfones como sensores de erro. Como o teste foi realizado em um campo reverberante (dentro de uma sala fechada), era esperado que medidas feitas em laboratório fossem essencialmente diferentes de medidas feitas em campo aberto. Em laboratório, uma boa atenuação (atenuação audível) foi obtida próximo aos alto-falantes. Primeiramente realizou-se a estimativa do caminho secundário pelo método do ruído aditivo. Os resultados verificados não foram satisfatórios, já que este método necessitava de que fosse usado um comprimento de filtro muito grande para os filtros de estimação do caminho secundário, tornando a convergência do algoritmo de controle muito lenta. Passou-se então a utilizar o outro método de estimação do caminho secundário disponível na placa EZ-ANC. Esse método utiliza o próprio sinal de controle para excitar o filtro de estimação e se mostrou mais adequado para situações de ruído tonal que o uso de ruído aleatório como sinal de excitação. Verificou-se que mesmo em um teste simples como este, o número de coeficientes do filtro adaptativo e sua taxa de adaptação têm grande influência no desempenho do sistema de controle. Como sinal de excitação usou-se um tom puro em $120 \mathrm{~Hz}$ fornecido por um gerador de ondas. 
Com a amplitude do sinal de excitação pequena o suficiente para que o alto-falante não gerasse distorção harmônica, verificou-se uma atenuação de 13,5dB em um dos microfones de erro na freqüência fundamental. Já com um sinal de excitação com amplitude quatro vezes maior, verifica-se a presença da primeira e segunda harmônicas, causadas pela distorção dos falantes. A atenuação na freqüência fundamental não é essencialmente alterada, sendo neste caso de 15,0dB.

Aumentando ligeiramente a complexidade do sistema, usando-se agora duas fontes de controle, verifica-se uma forte influência do posicionamento destas duas fontes em relação à fonte primária de ruído na atenuação global do sistema. O uso de um microfone próximo à fonte primária de ruído como sensor de referência não se mostrou uma boa alternativa, reforçando a idéia de extrair um sinal elétrico como sinal de referência para o caso do controle do ruído de transformadores. Verificou-se também que mesmo com um sinal elétrico como sinal de referência, se ele tiver amplitude muito baixa o sistema de controle não consegue convergir para uma solução adequada. É necessário, portanto, atenção especial com o ganho do sinal de referência. Com o nível do sinal de excitação baixo o suficiente para que não ocorra distorção harmônica no alto-falante, verifica-se em um dos microfones de erro uma atenuação de 18,4dB na freqüência de excitação. A figura 62 mostra a pressão no mesmo microfone de erro, agora com o sinal de excitação com amplitude quatro vezes maior que no caso anterior, evidenciando a presença de distorção harmônica. Neste caso, apesar de a atenuação na freqüência fundamental ser de 26,1dB, verifica-se a presença da segunda harmônica do sinal, que é gerada pela não-linearidade dos alto-falantes. Com o sistema de controle em funcionamento, a amplitude desta harmônica aumenta cerca de $3 \mathrm{~dB}$, ficando com nível praticamente igual ao nível da fundamental atenuada. Apesar da atenuação da freqüência fundamental, a sensação psicoacústica agora é mais desagradável que na situação anterior, já que a harmônica superior presente no sinal audível apresenta nível sonoro considerável, e a faixa de freqüência em que se encontra é mais sensível para a audição humana que a faixa de freqüência onde o tom fundamental se encontra.

Em uma nova configuração com dois alto-falantes de controle e dois microfones de erro, verifica-se uma atenuação de cerca de 10,2dB em um microfone de controle, posicionado entre os microfones de erro. Aumentando a amplitude do sinal de excitação, verifica-se novamente a presença das harmônicas superiores e uma piora na sensação psicoacústica. Com a amplitude do sinal de referência quatro vezes maior que no caso anterior, verifica-se novamente a presença de distorção do sinal, com a atenuação do tom fundamental nos mesmos 10,2dB. Nesta situação, a percepção auditiva é de que o ruído aumentou, por 


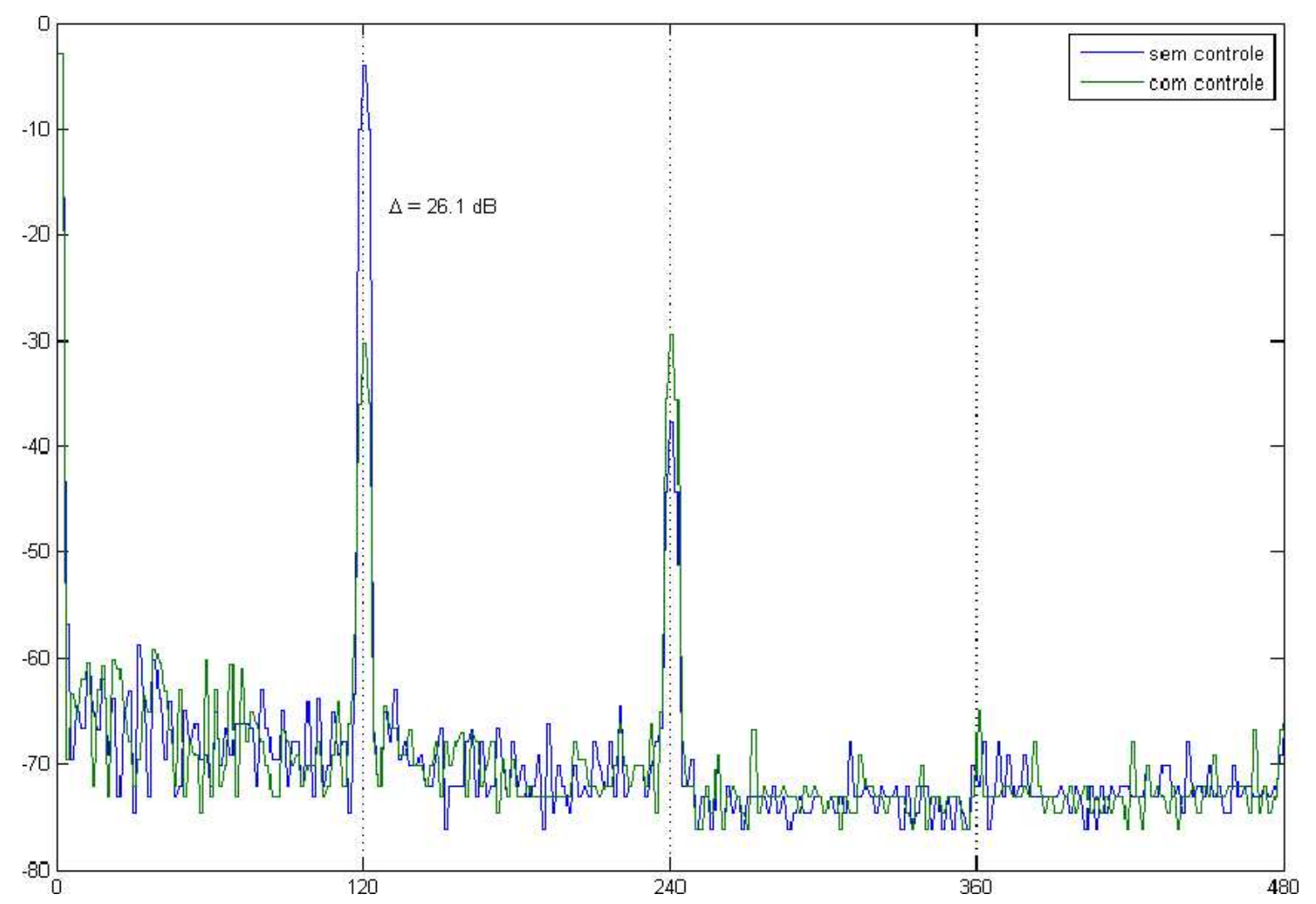

Figura 62: Espectro em microfone de erro com e sem controle.

causa da presença dessa harmônica superior.

Usando uma configuração com dois alto-falantes de controle e um microfone foi bastante difícil estabilizar o sistema de controle, e quando estável, a atenuação obtida era insignificante.

\subsubsection{Testes em Campo Aberto}

Após os testes em laboratório, o sistema foi levado para um gramado da Escola Politécnica, que se aproxima de uma condição ideal de campo semi-aberto. No primeiro dia de testes choveu, e aparentemente as caixas acústicas resistiram bem à água, um de seus requisitos de projeto.

Primeiramente, realizaram-se testes com um alto-falante como fonte de ruído senoidal, dois alto-falantes de controle (posicionados a cerca de $20 \mathrm{~cm}$ da fonte primária) e três microfones de erro (distantes cerca de $3 \mathrm{~m}$ dos alto-falantes). Novamente usando o próprio sinal de controle para a determinação do caminho acústico secundário, verificou- 
se atenuações na casa dos 10dB para a freqüência de excitação, e novamente a distorção harmônica estava presente, sendo que ocorreu um acréscimo de $3 \mathrm{~dB}$ na amplitude da segunda harmônica quando o sistema de controle foi ligado. Por se estar trabalhando em campo aberto, é necessário trabalhar com níveis de excitação mais elevados que o nível do ruído de fundo, caso contrário o sinal de excitação não pode ser ouvido, forçando o alto-falante a trabalhar numa faixa de resposta não-linear. Apesar de equipamentos adequados para atestar isso não estarem disponíveis, acredita-se que a atenuação obtida com esta configuração foi global, ou seja, houve atenuação em todas as direções ao redor da fonte primária de ruído.

Realizou-se o mesmo experimento, mas utilizando a estimação do caminho secundário com ruído pseudo-aleatório. Verificou-se que a atenuação obtida era igual à obtida no caso anterior, mas com a convergência mais lenta do sistema. A sensação psicoacústica também era mais desconfortável, por causa da presença do ruído branco no sinal emitido pelas fontes de controle.

Os mesmos testes foram realizados com a placa DSP desenvolvida pelo grupo. Essa placa possuía programado o método de estimação do caminho secundário com ruído pseudo-aleatório e com sinal de excitação tonal. Nos testes verificou-se que com ambos sinais, o algoritmo de estimação deixa de funcionar quando os microfones são posicionados muito longe das fontes de controle (distância maior que $6 \mathrm{~m}$ ), sendo que a excitação tonal se mostrou um pouco mais robusta que a excitação pseudo-aleatória. Outra vantagem verificada da excitação tonal é que ela apresentava resultados satisfatórios para filtros consideravelmente menores do que o tamanho de filtro necessário para a excitação pseudo-aleatória.

\subsection{Testes de Interferência Eletromagnética}

Realizaram-se alguns testes na própria subestação para verificar a imunidade dos equipamentos do sistema a eventuais interferências eletromagnéticas, que porventura poderiam ser causadas pelo campo eletromagnético dos transformadores de potência ou cabos de transmissão.

1. Esticou-se o cabo do microfone pelo caminho onde ele deverá passar. Uma ponta foi ligada à mesa mixadora (phantom power) e a saída "direct out" deste canal ligada 
a um osciloscópio. Na outra ponta colocou-se uma resistência de $680 \Omega$, impedância equivalente à do microfone, que é de $600 \Omega$. No osciloscópio, com "trigger" na rede, não foi possível verificar a presença da freqüência $60 \mathrm{~Hz}$ ou de suas harmônicas, mas apenas ruído branco de média nula.

2. Posicionou-se um alto-falante ao lado do transformador e seu cabo foi esticado pelo caminho que ele deverá percorrer, tendo sido colocada uma resistência de $4 \Omega$ na outra ponta do cabo. Não foi possível escutar ou medir nenhum sinal acústico proveniente do alto-falante.

3. Com um alto-falante e um microfone posicionados próximos ao transformador, excitou-se o falante em $150 \mathrm{~Hz}$, e verificou-se no osciloscópio o sinal medido pelo microfone. Verificou-se claramente o tom em $150 \mathrm{~Hz}$, e as componentes usuais do ruído do transformador em $n \cdot 120 \mathrm{~Hz}(n=1,2,3, \cdots)$. Nenhuma componente na freqüência de rede ou múltiplos ímpares da freqüência de rede pôde ser observada, evidenciando que não há interferência eletromagnética nos equipamentos eletrônicos.

\subsection{Testes de Controle Acústico na Subestação}

O sistema de controle de ruído foi montado em uma subestação, e várias combinações de quantidade e posicionamento de alto-falantes e microfones ao redor do transformador foram testadas, verificando-se a atenuação obtida tanto nos microfones de erro quanto em posições entre os microfones. Como a estimativa do campo sonoro obtida pelo método de Usry não se mostrou adequada, não foi possível realizar uma etapa de simulações e otimização previamente aos testes em campo, logo as posições testadas muito provavelmente não são as posições ótimas para o cancelamento do campo desse transformador. Para o sistema de controle foi usada a placa EZ-ANC, com a referência extraída da rede elétrica. A figura 6.6 mostra a disposição dos transdutores ao redor do transformador. Nos primeiros testes os alto-falantes usados estavam localizados na plataforma, como pode ser visto na foto. Posteriormente eles foram todos colocados mais próximos ao transformador, sobre a base de concreto, como os dois alto-falantes das extremidades nesta foto. A posição dos microfones variou bastante. 


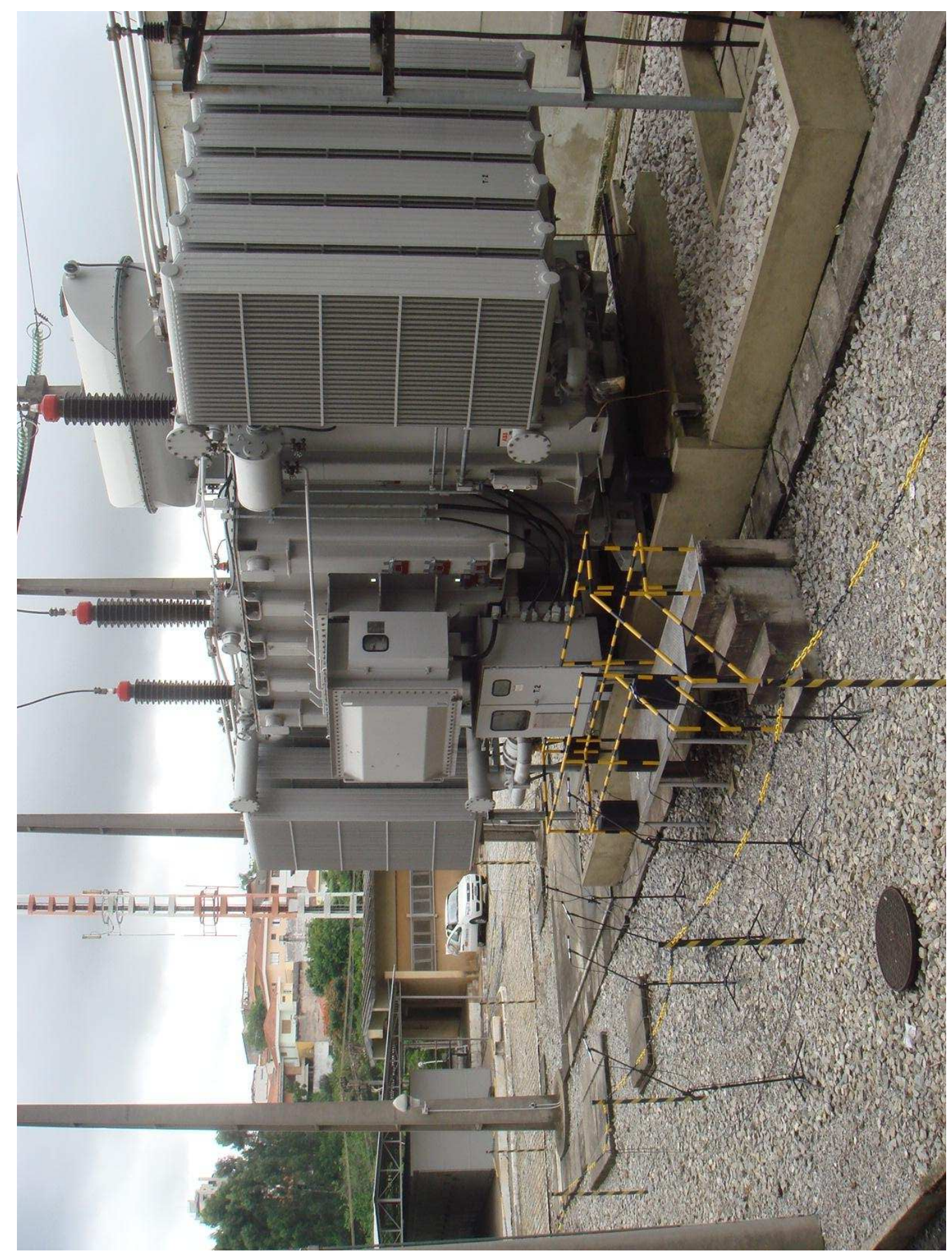

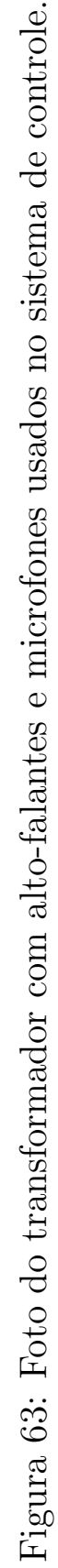




\subsubsection{Uma Fonte de Controle e Um Sensor de Erro}

Iniciou-se pela configuração mais simples possível, com apenas um alto-falante e um microfone. O alto-falante estava cerca de $1 \mathrm{~m}$ à frente do transformador (posicionado sobre a plataforma de acesso ao painel) e o microfone estava a cerca de $6 \mathrm{~m}$ do transformador, na mesma direção do alto-falante. Verificou-se uma atenuação de cerca de $10 \mathrm{~dB}$ no sensor de erro, mas ao seu redor houve um aumento da pressão sonora de até $3 \mathrm{~dB}$. Como era de se esperar, esta configuração conseguiu apenas cancelar o ruído presente no sensor de erro, mas ela foi útil para verificar o correto funcionamento do sistema de controle ativo de ruído montado na subestação.

\subsubsection{Uma Fonte de Controle e Dois Sensores de Erro}

A disposição dos transdutores é mostrada esquematicamente na figura 64, assim como a posição relativa onde a pressão sonora foi medida. O alto-falante estava cerca de $1 \mathrm{~m}$ à frente do transformador e os microfones estavam a cerca de $6 \mathrm{~m}$ do transformador, distando cerca de $1,5 \mathrm{~m}$ entre si.

A disposição dos transdutores é mostrada na figura 64, assim como a posição relativa onde se mediu a pressão sonora. Verifica-se, como esperado, que entre os dois microfones há uma região de atenuação. Foi surpreendente verificar que no lado externo dos microfones também ocorreu atenuação da pressão sonora. Já atrás dos microfones houve um acréscimo de pressão sonora, provavelmente efeito do muro que estava a cerca de $1 \mathrm{~m}$ deste ponto de medição. Os valores de atenuação medidos são mostrados na tabela 7.

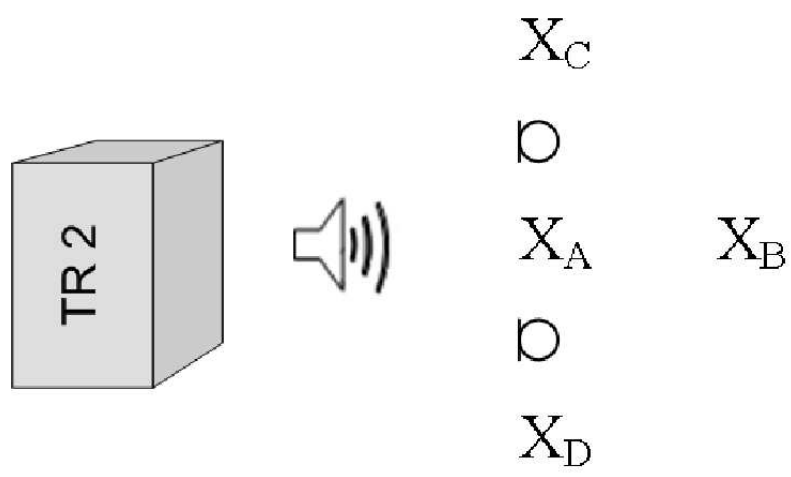

Figura 64: Posicionamento esquemático dos transdutores e dos pontos de medição (X) para uma fonte de controle e dois sensores de erro. 
Tabela 7: Atenuação medida em cada um dos pontos considerados para um sistema ANC com uma fonte de controle e dois sensores de erro.

\begin{tabular}{cc}
\hline Ponto & Atenuação $(\mathrm{dB})$ \\
\hline$X_{A}$ & 10 \\
$X_{B}$ & -6 \\
$X_{C}$ & 2 \\
$X_{D}$ & 5 \\
\hline
\end{tabular}

\subsubsection{Uma Fonte de Controle e Três Sensores de Erro}

Aumentou-se novamente o número de sensores de erro, agora para três. O alto-falante continuou cerca de $1 \mathrm{~m}$ à frente do transformador e os microfones continuaram a cerca de $6 \mathrm{~m}$ do transformador, distando cerca de 1,5m entre si. É de se esperar que a atenuação medida não seja muito diferente da obtida para apenas dois microfones de erro.

A disposição dos transdutores é mostrada de forma esquemática na figura 65, assim como a posição relativa onde a pressão sonora foi medida. Esta configuração mostrou-se bastante indesejável, já que produziu acréscimos consideráveis de potência sonora ao redor dos microfones, como é mostrado na tabela 8.

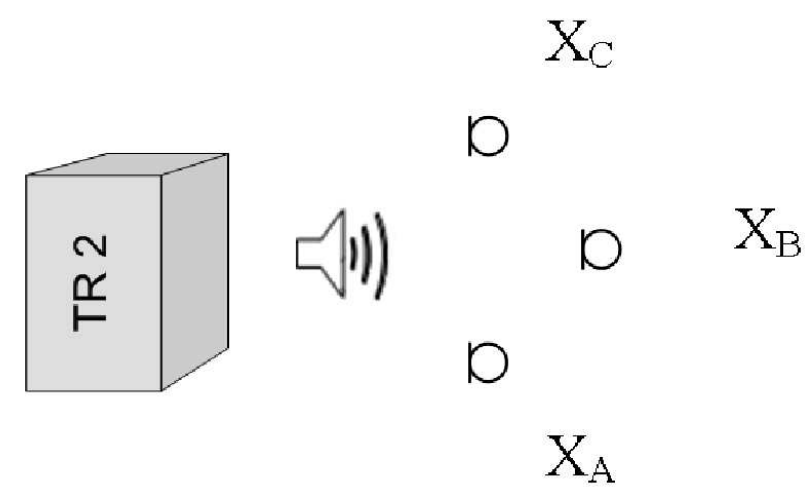

Figura 65: Posicionamento esquemático dos transdutores e dos pontos de medição (X) para uma fonte de controle e três sensores de erro. 
Tabela 8: Atenuação medida em cada um dos pontos considerados para um sistema ANC com uma fonte de controle e três sensores de erro.

\begin{tabular}{cc}
\hline Ponto & Atenuação $(\mathrm{dB})$ \\
\hline$X_{A}$ & -6 \\
$X_{B}$ & 0 \\
$X_{C}$ & -8 \\
\hline
\end{tabular}

\subsubsection{Duas Fontes de Controle e Três Sensores de Erro}

Agora, mantendo-se a posição dos microfones, aumentou-se para dois o número de alto-falantes, ambos cerca de $1 \mathrm{~m}$ à frente do transformador e distantes cerca de $2 \mathrm{~m}$ entre si. Os microfones mantiveram a posição da última configuração. Esperava-se com isto melhorar a atenuação ao redor dos três microfones de erro.

A disposição dos transdutores é mostrada de forma esquemática na figura 66, assim como a posição relativa onde a pressão sonora foi medida. Esta configuração não mostrou melhoria em relação à última configuração, já que os pontos ao redor dos microfones continuaram apresentando ganho de nível sonoro (tabela 9), apesar de na proximidade dos microfones verificar-se atenuações consideráveis do nível sonoro (tabela 10).

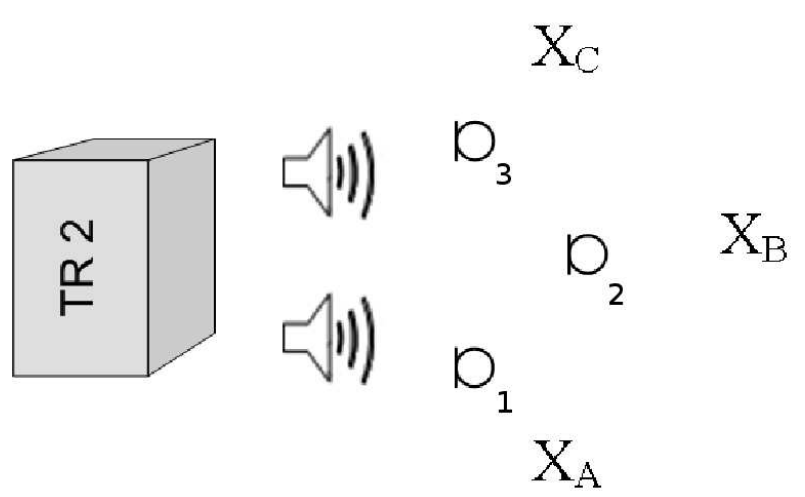

Figura 66: Posicionamento esquemático dos transdutores e dos pontos de medição (X) para duas fontes de controle e três sensores de erro. 
Tabela 9: Atenuação medida em cada um dos pontos considerados para um sistema ANC com duas fontes de controle e três sensores de erro.

\begin{tabular}{cc}
\hline Ponto & Atenuação $(\mathrm{dB})$ \\
\hline$X_{A}$ & -7 \\
$X_{B}$ & 0 \\
$X_{C}$ & -6 \\
\hline
\end{tabular}

Tabela 10: Atenuação medida nos microfones de erro para um sistema ANC com duas fontes de controle e três sensores de erro.

\begin{tabular}{cc}
\hline Microfone & Atenuação $(\mathrm{dB})$ \\
\hline 1 & 22 \\
2 & 13 \\
3 & 10 \\
\hline
\end{tabular}

\subsubsection{Duas Fontes de Controle e Quatro Sensores de Erro}

A quantidade de sensores de erro foi novamente aumentada, sendo agora 4 microfones em uso. Os alto-falantes estavam cerca de $1 \mathrm{~m}$ à frente do transformador, distando aproximadamente $1 \mathrm{~m}$ entre si, e os microfones estavam a cerca de $6 \mathrm{~m}$ do transformador, distando cerca de 1,5m entre si. Nesta configuração, mostrada na figura 67, mediu-se apenas a atenuação verificada nos microfones de erro.

Novamente o resultado não foi satisfatório, ou seja, as duas fontes de controle não estavam sendo capazes de atenuar a pressão sonora em todos os microfones de erro, mas apenas em dois deles, como é mostrado na tabela 11, sendo que em um dos microfones verificou-se inclusive um aumento do nível de ruído. O fato de esse único microfone apresentar ganho de ruído, ao invés de atenuação, pode estar relacionado com o fato de o nível de ruído do transformador medido nesse microfone ser cerca de $20 \mathrm{~dB}$ menor do que o nível de ruído medido nos demais microfones. Com o sistema ANC ativo, o nível de ruído medido no microfone 1 está no mesmo patamar do nível de ruído medido nos microfones 2 e 4 . 


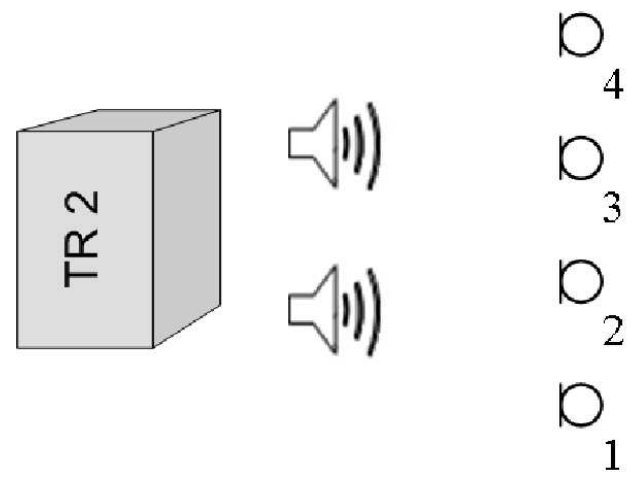

Figura 67: Posicionamento esquemático dos transdutores para duas fontes de controle e quatro sensores de erro.

Tabela 11: Atenuação medida nos microfones de erro para um sistema ANC com duas fontes de controle e quatro sensores de erro.

\begin{tabular}{cc}
\hline Microfone & Atenuação $(\mathrm{dB})$ \\
\hline 1 & -12 \\
2 & 10 \\
3 & 0 \\
4 & 8 \\
\hline
\end{tabular}

\subsubsection{Três Fontes de Controle e Quatro Sensores de Erro}

Mantendo-se a posição dos microfones, aumentou-se novamente a quantidade de altofalantes, sendo agora 3 fontes de controle em uso, todos distando cerca de $1 \mathrm{~m}$ do transformador e 1m entre si. A configuração esquemática é mostrada na figura 68 .

A atenuação nos microfones ficou praticamente inalterada, apesar da adição de mais uma fonte secundária, como se verifica na tabela 12. Isto aconteceu porque o sistema de controle convergiu para coeficientes de valores muito pequenos para a nova fonte de controle, praticamente excluindo-a do sistema de controle de ruído. A provável razão para este fato é que os alto-falantes estavam posicionados muito próximos uns dos outros. Alterou-se então a posição dos alto-falantes, para verificar se esta suposição era verdadeira. 


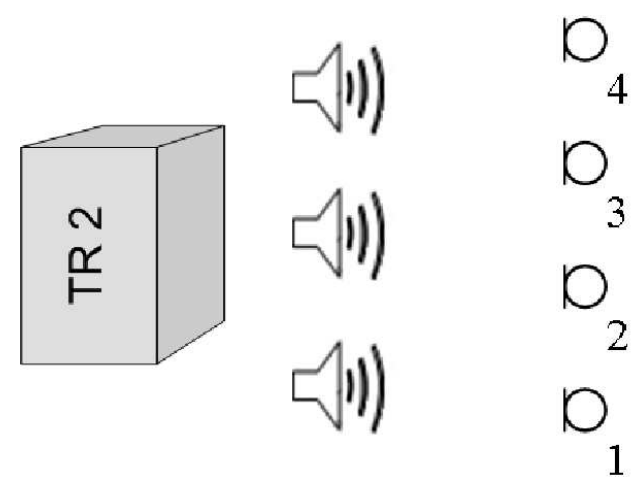

Figura 68: Posicionamento esquemático dos transdutores para três fontes de controle e quatro sensores de erro.

Tabela 12: Atenuação medida nos microfones de erro para um sistema ANC com três fontes de controle e quatro sensores de erro.

\begin{tabular}{cc}
\hline Microfone & Atenuação $(\mathrm{dB})$ \\
\hline 1 & -10 \\
2 & 20 \\
3 & -3 \\
4 & 10 \\
\hline
\end{tabular}

Os alto-falantes, que até então estavam dispostos sobre a plataforma de acesso ao painel, como é mostrado na figura 6.6. foram reposicionados sobre a base do transformador, com distância de aproximadamente 2,5m entre eles. A posição dos microfones foi mantida inalterada. Verifica-se agora uma melhora considerável nos níveis de atenuação medidos (tabela 14 $\left.\right|_{1} ^{1}$, evidenciando a influência do posicionamento dos transdutores no desempenho do sistema ANC, e justificando uma etapa de simulação para otimizar o posicionamento dos transdutores.

Mediu-se também a pressão sonora em pontos ao redor dos microfones, e pode-se verificar atenuação em todos os pontos entre os microfones, como é mostrado na tabela 13. que mostra a atenuação obtida nos pontos de medição relativos à figura 69 .

\footnotetext{
${ }^{1} \mathrm{O}$ microfone 1 , que apresenta pequena atenuação, está numa região onde o campo sonoro primário é bem menor que nos demais microfones, como já foi anteriormente comentado.
} 


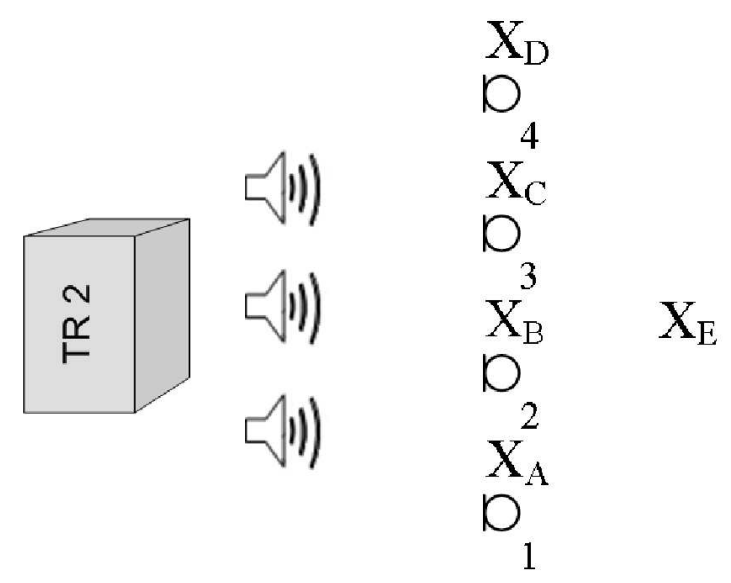

Figura 69: Posicionamento esquemático dos transdutores e dos pontos de medição (X) para três fontes de controle e quatro sensores de erro.

Tabela 13: Atenuação medida em cada um dos pontos considerados para um sistema ANC com três fontes de controle e quatro sensores de erro.

\begin{tabular}{cc}
\hline Ponto & Atenuação $(\mathrm{dB})$ \\
\hline$X_{A}$ & 8 \\
$X_{B}$ & 5 \\
$X_{C}$ & 5 \\
$X_{D}$ & 5 \\
$X_{E}$ & -10 \\
\hline
\end{tabular}

Tabela 14: Atenuação medida nos microfones de erro para um sistema ANC com as três fontes de controle reposicionadas e os quatro sensores de erro na mesma posição.

\begin{tabular}{cc}
\hline Microfone & Atenuação $(\mathrm{dB})$ \\
\hline 1 & 2 \\
2 & 11 \\
3 & 15 \\
4 & 20 \\
\hline
\end{tabular}




\subsubsection{Quatro Fontes de Controle e Quatro Sensores de Erro}

O último teste foi feito com um número igual de sensores de erro e fontes de controle. Os quatro alto-falantes foram posicionados sobre a base de concreto do transformador, distando cerca de 2,5m entre si, enquanto que os microfones tiveram sua posição inalterada em relação ao último teste. Com um número igual de fontes de controle e sensores de erro, é esperado que todos os microfones tenham a pressão sonora ao seu redor anulada. O que se pôde verificar é que todos os microfones apresentaram atenuação, mas nenhum deles teve atenuação maior do que 20dB. O microfone 1, que antes tinha uma atenuação de apenas $2 \mathrm{~dB}$, nesta configuração apresenta atenuação de $10 \mathrm{~dB}$.

A pressão sonora foi medida em alguns pontos ao redor dos microfones, pontos estes esquematizados na figura 70. Os pontos $X_{D}$ e $X_{E}$ foram medidos $1 \mathrm{~m}$ acima da linha horizontal dos microfones. A surpresa nestes testes foi verificar atenuação no ponto $X_{B}$, que já estava um pouco distante dos microfones. Os demais pontos apresentaram ou pouca atenuação $\left(X_{C}\right.$ e $\left.X_{D}\right)$ ou aumento da pressão sonora, como é mostrado na tabela 15.

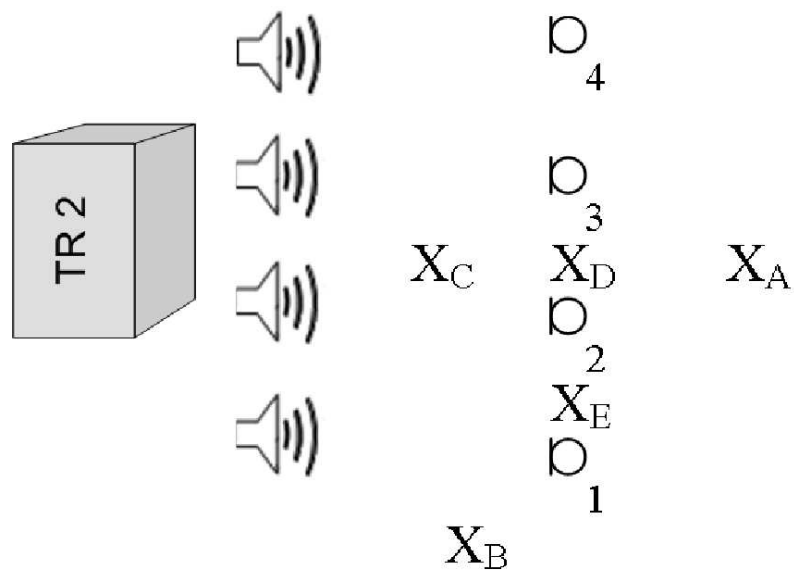

Figura 70: Posicionamento esquemático dos transdutores e dos pontos de medição (X) para quatro fontes de controle e quatro sensores de erro. 
Tabela 15: Atenuação medida em cada um dos pontos considerados para um sistema ANC com quatro fontes de controle e quatro sensores de erro.

\begin{tabular}{cc}
\hline Ponto & Atenuação $(\mathrm{dB})$ \\
\hline$X_{A}$ & -8 \\
$X_{B}$ & 5 \\
$X_{C}$ & 1 \\
$X_{D}$ & 0 \\
$X_{E}$ & -5 \\
\hline
\end{tabular}

\subsubsection{Discussão}

Os testes realizados na subestação com o equipamento adquirido para o sistema ANC comprovaram o funcionamento do sistema de controle e evidenciaram a influência da quantidade e do posicionamento dos transdutores nos níveis de atenuação obtidos, uma vez que foi verificada atenuação apenas no campo sonoro próximo aos microfones de erro e em algumas regiões entre esses microfones. Verificou-se também uma grande variação de desempenho com a quantidade e posição dos transdutores, confirmando a necessidade de uma fase de simulações previamente à instalação do sistema em campo, para que uma configuração adequada de transdutores possa ser definida, garantindo que o ruído seja atenuado na região de interesse, e não somente nas regiões próximas aos microfones de erro.

\subsection{Conclusões}

Neste capítulo foram apresentados os resultados práticos desta dissertação. Primeiramente, medições de nível de ruído realizadas na STD de interesse foram mostradas. Foi constatado que o nível de ruído emitido pelos transformadores está acima do limite permitido por lei. Confirmou-se a característica tonal do ruído emitido por transformadores, sendo a maior parte de sua energia concentrada na primeira harmônica, presente no dobro da freqüência da rede. O ruído causado pela bomba hidráulica e pelo fluxo de óleo são desprezíveis. Apesar dos radiadores terem nível de vibração comparável com o restante da estrutura do transformador, verificou-se que eles atuam como barreiras acústicas e não como fontes sonoras. 
Os equipamentos adquiridos para o sistema de controle ativo de ruído e o circuito desenvolvido para a extração do sinal de referência da rede foram descritos. Verificou-se por testes em campo que todos os equipamentos são imunes à interferência eletromagnética.

Os resultados de alguns testes realizados em laboratório foram apresentados. Nesses testes verificou-se a influência do algoritmo de estimação do caminho secundário no desempenho do sistema, sendo o método proprietário da Causal Systems o que apresentou melhor desempenho para o controle de sinais tonais. Verificou-se também o comportamento não-linear dos alto-falantes adquiridos, o que pode comprometer o desempenho de um sistema ANC.

Por fim, foram apresentados os resultados de medições realizadas na STD com o sistema ANC montado próximo ao transformador de interesse. O sistema apresentou atenuação do campo sonoro próximo aos microfones de erro e em algumas regiões entre estes microfones, mas não foi possível gerar uma região de atenuação, como inicialmente planejado. 


\section{CONCLUSÕES}

\subsection{Considerações Finais}

O objetivo desta dissertação foi identificar as principais dificuldades para a aplicação bem sucedida do controle ativo de ruído no caso de transformadores de potência e estudar algumas alternativas para a solução das dificuldades identificadas.

O controle de ruído é uma ciência de fronteira, que requer conhecimentos na área de acústica e na área de processamento digital de sinais, com foco em controle adaptativo. Esta dissertação apresentou a base dos conhecimentos necessários no campo da acústica e no campo do controle adaptativo para o estudo do controle ativo de ruído.

Verificou-se que no controle ativo de ruído, a quantidade e o posicionamento dos transdutores eletroacústicos é de suma importância no desempenho do sistema. Apesar de muitos métodos para a definição da quantidade e do posicionamento ótimo dos transdutores já terem sido publicados, ainda não existe um método objetivo comprovadamente eficiente para este fim. Nesta dissertação verificou-se o desempenho do método dos algoritmos genéticos para a otimização da posição dos transdutores. A desvantagem deste método é que ele não consegue definir a quantidade ótima de transdutores, sendo recomendável combiná-lo com outros métodos de otimização que definam a quantidade ótima de transdutores.

O desempenho da otimização do arranjo de transdutores feita por algoritmos de otimização é fortemente dependente da qualidade do modelo acústico utilizado. Para baixas freqüências, o uso de fontes pontuais esféricas em campo livre é uma boa aproximação para as fontes de controle. Nesta dissertação a principal dificuldade encontrada foi a caracterização do campo sonoro radiado pelo transformador. Verificou-se que o método de Usry não produziu uma estimativa adequada do campo primário, possivelmente pelo fato de o método desconsiderar a presença de obstáculos acústicos na vizinhança da fonte primária ou pelo fato de ele assumir uma geometria muito simples para a fonte primária. A falta de conhecimento sobre o campo gerado pelo transformador praticamente inviabilizou o 
uso de simulações para otimização do posicionamento dos transdutores.

Outra grande dificuldade encontrada na realização do sistema de controle ativo de ruído foi a estimação do caminho acústico secundário, cuja influência deve ser compensada para garantir a estabilidade do sistema de controle. Verificou-se que para os algoritmos de estimação do caminho secundário em geral, quanto mais distantes os sensores de erro estiverem das fontes de controle, mais difícil será para estimar o caminho acústico secundário. O problema está no fato de que os sensores de erro devem estar o mais próximo possível da região onde a atenuação é desejada. É para solucionar este impasse que foi proposto o uso da técnica de sensores virtuais, que permite que os sensores de erro sejam posicionados mais próximos das fontes de controle, mas garantindo a maior atenuação possível numa região distante das fontes de controle.

Nem todos os testes que se desejava realizar em campo puderam ser feitos. Desejavase verificar o desempenho do sistema com os microfones de erro posicionados em cima do muro que divide o terreno da STD com o prédio reclamante, para verificar se esta configuração conseguiria gerar uma sombra acústica no prédio. Outro teste seria posicionar os microfones nas janelas dos apartamentos reclamantes, e verificar se esta configuração conseguiria gerar uma atenuação dentro do apartamento reclamante. Estes testes não foram realizados por restrição de tempo e de acesso aos apartamentos.

Por causa do pouco tempo disponível para a realização desta pesquisa, não foi possível testar o desempenho do método de sensores virtuais em campo, mas acredita-se que esta técnica poderá proporcionar considerável melhora no desempenho dos sistemas de controle ativo de ruído em campo aberto.

No decorrer da pesquisa surgiram algumas idéias para reduzir o ruído do transformador de potência sem usar um sistema ANC. Como se verificou que os radiadores térmicos do transformador funcionam como barreira acústica, uma sugestão seria inverter a posição do transformador para que a face com os radiadores ficasse voltada para o prédio reclamante. Isso provavelmente iria reduzir o nível de ruído irradiado para o prédio. Outra sugestão seria utilizar o sistema de áudio não para gerar um "anti-ruído" que atenue o nível de ruído, mas para gerar um ruído que mascare o ruído do transformador ou para gerar um ruído que somado ao ruído do transformador gere um ruído "mais agradável" para os moradores vizinhos. 


\subsection{Contribuições}

Esta dissertação propõe um novo método de otimização por algoritmos genéticos. O método convencional presente na literatura de controle ativo de ruído otimiza primeiramente a posição das fontes de controle e depois a posição dos sensores de erro, com base nas posições de fontes de controle previamente definidas. Especialistas em otimização por algoritmos genéticos dizem que a otimização de problemas com múltiplas variáveis deve ser realizada conjuntamente, caso contrário a escolha de uma variável anteriormente às demais pode enviesar a escolha das outras variáveis. O método proposto otimiza o posicionamento das fontes de controle e dos sensores de erro conjuntamente. Verificou-se que este método converge, em apenas uma iteração, para um resultado similar ao que o método convencional converge após diversas iterações.

A técnica de sensores virtuais é uma técnica recente, que até o momento possui dois métodos distintos de realização publicados. Esta dissertação propõe um novo método de realização de sensores virtuais. Este novo método utiliza o conhecimento da função de transferência entre as fontes de controle e os sensores reais e virtuais para gerar uma janela de pesos para os sinais de excitação das fontes de controle. Em comparação realizada, o método proposto apresentou melhor desempenho que os outros dois métodos encontrados na literatura.

\subsection{Publicações}

Um artigo sobre o tema controle ativo de ruído foi apresentado no "5o Congresso de Engenharia de Áudio", realizado pela AES Brasil [20]. Esse artigo é divido em duas partes, sendo que a primeira parte apresenta uma revisão histórica e teórica do controle ativo de ruído, descrevendo as tendências mais recentes nesta área e aplicações práticas e a segunda parte apresenta resultados dos experimentos realizados para o controle de ruído ativo em transformadores de potência em campo (apresentados na seção 6.6 desta dissertação).

Pretende-se ainda publicar um artigo em periódico internacional apresentando o novo método de sensores virtuais e a comparação deste método com os outro dois métodos existentes na literatura e apresentar em congresso da área a proposta do método de otimização conjunta por algoritmos genéticos. 


\subsection{Trabalhos Futuros}

Os resultados apresentados nesta dissertação apontam novas direções que a pesquisa sobre controle ativo de ruído deve seguir.

Na área de modelagem do campo primário, é necessário desenvolver um método que não seja tão complexo como o Método dos Elementos de Fronteira, mas que permita a obtenção de uma boa estimativa do campo gerado pela fonte primária baseado em condições de contorno como a aceleração de pontos da superfície da fonte sonora. É importante que este método possa levar em consideração barreiras acústicas na vizinhança da fonte sonora.

Para otimizar o posicionamento dos transdutores, seria interessante desenvolver o método proposto por Asano, Suzuki e Swanson, baseado na ortogonalização de GramSchmidt, para que ele passasse a levar em consideração a influência dos sensores de erro, permitindo, assim, a otimização de transdutores também em campo aberto.

Na otimização por algoritmos genéticos, novas métricas deveriam ser testadas, possivelmente baseadas na minimização do nível de pressão sonora na região de interesse, e não na minimização do ganho (ou maximização da atenuação) na região de interesse.

A técnica dos sensores virtuais deve continuar sendo desenvolvida e sua eficiência ainda precisa ser testada na prática. Para aumentar a precisão do novo método proposto sugere-se o desenvolvimento de um método adaptativo para a definição da janela de pesos.

A estimação do caminho secundário também é um fator crítico no desempenho dos sistemas ANC, e novos métodos como o método de estimação por senóides mascaradas (proposto por outro membro do grupo de pesquisa) devem ser melhor estudados.

Para testes de campo, sugere-se realizar os testes mencionados na seção 7.1, que não puderam ser realizados durante esta pesquisa. 


\section{REFERÊNCIAS}

1 Federal Pacific Co. Transformer Noise. 2007. Disponível em: <http://www.federalpacific.com/university/transnoise/transnoise.html>. Acesso em: 19 jun. 2007.

2 VÉR, I. L. et al. Field study of sound radiation by power transformers. IEEE Transactions on Power Apparatus and Systems, v. 100, n. 7, p. 3513-3524, jul. 1981.

3 ELliOTT, S. J.; NELSON, P. A. Active noise control. IEEE Signal Processing Magazine, p. 12-35, out. 1993.

4 GUICKING, D. On the invention of active noise control by Paul Lueg. Journal of the Acoustic Society of America, v. 87, n. 5, p. 2251-2254, 1990.

5 OLSON, H. F.; MAY, E. G. Electronic sound absorber. Journal of the Acoustic Society of America, v. 25, n. 6, p. 1130-1136, nov. 1953.

6 CONOVER, W. B. Fighting noise with noise. Noise Control, v. 2, p. 78-82, 1956.

7 KIDO, K. Automatic control of transformer noise by synthesizing directivity. Journal of the Acoustic Society of America, v. 52, p. 156-156, 1972.

8 . Reduction of noise by use of additional sound sources. In: Proceedings of Inter-Noise '75. Sendai: Tohoku University, 1975. p. 647-650.

9 ROSS, C. F. Experiments on the active control of transformer noise. Journal of Sound and Vibration, v. 61, p. 473-480, dez. 1978.

10 HESSELMANN, N. Investigation of noise reduction on a 100kVA transformer tank by means of active methods. Applied Acoustics, v. 11, p. 27-34, 1978.

11 BERGE, T.; PETTERSEN, O. K. Ø.; SØRSDAL, S. Active cancellation of transformer noise: Field measurements. Applied Acoustics, v. 23, p. 309-320, 1988.

12 ANGEVINE, O. L. Active cancellation of the hum of large electric transformers. In: Proceedings of Inter-Noise 92. Toronto: INCE, 1992. v. 1, p. 313-317.

13 Active systems for attenuation of noise. International Journal of Active Control, v. 1, p. 65-78, 1995.

14 MARTIN, T.; ROURE, A. Optimization of an active noise control system using spherical harmonics expansion of the primary field. Journal of Sound and Vibration, v. 201, n. 5, p. 577-593, 1997.

15 . Active noise control of acoustic sources using spherical harmonics expansion and a genetic algorithm: Simulation and experiment. Journal of Sound and Vibration, v. 212 , n. 3 , p. 511-523, 1998. 
16 QIU, X.; HANSEN, C. H.; LI, X. An algorithm for active control of transformer noise with on-line cancellation path modelling based on the perturbation method. Journal of Sound and Vibration, v. 240, n. 4, p. 647-665, 2001.

17 QIU, X. et al. A waveform syntehsis algorithm for active control of transformer noise: implementation. Applied Acoustics, v. 63, p. 467-479, 2002.

18 QIU, X.; HANSEN, C. H. A comparison of near field acoustic error sensing strategies for the active control of harmonic free field sound radiation. Journal of Sound and Vibration, v. 215, n. 1, p. 81-103, 1998.

19 LI, X. Physical System for the Active Control of Transformer Noise. Tese (Doutorado) - University of Adelaide, nov. 2000.

20 MASIERO, B. S.; NASCIMENTO, V. H. Sistemas de Áudio no controle ativo de ruído. In: Anais do 5o Congresso de Engenharia de Áudio. São Paulo, Brasil: AES, Seção Brasil, 2007. p. 119-126.

21 NELSON, P. A.; ELliOTT, S. J. Active Control of Sound. Cambridge: Academic Press, 1992.

22 KEMPTON, A. J. The ambiguity of acoustic sources - a possibility for active control? Journal of Sound and Vibration, v. 48, n. 4, p. 475-483, 1976.

23 STRANG, G. Linear Algebra and Its Applications. San Diego: Harcourt Brace Javanovich, 1988.

24 PIERCE, A. D. Acoustics: An Introduction to its Physical Properties and Applications. New York: McGraw-Hill, 1981.

25 MORSE, P. M.; INGARD, K. U. Theoretical Acoustics. New York: McGraw-Hill, 1968.

26 HAYKIN, S. Adaptive Filter Theory. 4rd. ed. New Jersey: Prentice Hall, 2002.

27 SAYED, A. H. Fundamentals of Adaptive Filtering. New York: Wiley-Interscience, 2003.

28 KUO, S. M.; MORGAN, D. R. Active noise control: A tutorial review. Proceedings of the IEEE, v. 87, n. 6, p. 943-973, jun. 1999.

29 . Active Noise Control Systems - Algorithms and DSP Implementations. New York: Wiley, 1996.

30 TOBIAS, O. J.; BERMUDEZ, J. C. M.; BERSHAD, N. J. Mean weight behavior of the filtered-X LMS algorithm. IEEE Transactions on Signal Processing, v. 48, n. 4, p. 1061-1075, abr. 2000.

31 COSTA, M. H.; BERMUDEZ, J. C. M.; BERSHAD, N. J. Stochastic analysis of the filtered-X LMS algorithm in systems with nonlinear secondary paths. IEEE Transactions on Signal Processing, v. 50, n. 6, p. 1327-1342, jun. 2002. 
32 MASIERO, B. S. Estudo e Implementação de Métodos de Medição de Resposta Impulsiva em Salas de Pequeno Porte. 2004. Disponível em: <http://gsd.ime.usp.br/acmus/publi/relat \_medicao.pdf>. Acesso em: 19 jun. 2007.

33 ELliOTT, S. J.; STOTHERS, I. M.; A.NELSON, P. A multiple error LMS algorithm and its application to the active control of sound and vibration. IEEE Transactions on Acoustic, Speech and Signal Processing, v. 35, n. 10, p. 1423-1434, out. 1987.

34 WRIGHT, S. E.; VUKSANOVIC, B. Active control of environmental noise. Journal of Sound and Vibration, v. 190, n. 3, p. 565-585, 1996.

35 . Active control of environmental noise II: Non-compact acoustic source. Journal of Sound and Vibration, v. 202, n. 3, p. 313-359, 1997.

36 . Active control of environmental noise III: Implementation of theory into practice. Journal of Sound and Vibration, v. 220, n. 3, p. 469-496, 1999.

37 . Active control of environmental noise IV: Practical extensions to ecas theory. Journal of Sound and Vibration, v. 222, n. 4, p. 635-668, 1999.

38 WRIGHT, S. E.; ATMOKO, H. Active control of environmental noise V: The effect of environment change on the stability of electronically controlled acoustic shadow systems. Journal of Sound and Vibration, v. 244, n. 1, p. 107-122, 2001.

39 Active control of environmental noise VI: Performance of a fundamental free-field sound cancelling system. Journal of Sound and Vibration, v. 245, n. 4, p. 581-609, 2001.

40 Active control of environmental noise VII: Performance of multi-frequency, multi-channel, free-field sound cancelling systems. Journal of Sound and Vibration, v. 258, n. 2, p. 203-232, 2002.

41 WRIGHT, S. E.; ATMOKO, H.; VUKSANOVIC, B. Active control of environmental noise VIII: Increasing the response to primary source changes including unredictable noise. Journal of Sound and Vibration, v. 274, p. 323-349, 2004.

42 SNYDER, S. D.; VOKALEK, G. EZ-ANC User's Guide. Adelaide: Causal Systems, 1994.

43 SNYDER, S. D.; HANSEN, C. H. Using multiple regression to optimize active noise control system design. Journal of Sound and Vibration, v. 148, n. 3, p. 537-542, 1991.

44 ASANO, F.; SUZUKU, Y.; SWANSON, D. C. Optimization of control source configuration in active control systems using Gram-Schmidt orthogonalization. IEEE Transactions on Speech and Audio Processing, v. 7, n. 2, p. 213-220, mar. 1999.

45 BAEK, K. H.; ELLIOTT, S. J. Natural algorithms for choosing source locations in active control systems. Journal of Sound and Vibration, v. 186, n. 2, p. 245-267, 1995.

46 USRY, G. O. et al. Prediction of far-field sound radiation from transformers. IEEE Transactions on Power Apparatus and Systems, v. 99, n. 1, p. 358-364, jan. 1980.

47 PIERCE, A. D. Diffraction of sound around corners and over wide barriers. Journal of the Acoustic Society of America, v. 55, n. 5, p. 941-955, maio 1974. 
48 GAUTSCHI, W. Error function and fresnel integrals. In: ABRAMOWITZ, M.; STEGUN, I. A. (Ed.). Handbook of Mathematical Functions with Formulas, Graphs, and Mathematical Tables. New York: Dover, 1964.

49 CAZZOLATO, B. S. An adaptive LMS virtual microphone. In: Proceedings of Active. Southampton, UK: ISVR, University of Southampton, 2002. p. 105-116.

50 GARCIA-BONITO, J.; ELLIOTT, S. J.; BOUCHER, C. C. Generation of zones of quiet using a virtual microphone arrangement. Journal of the Acoustic Society of America, v. 101, n. 6, p. 3498-3516, 1997.

51 KESTELL, C. D.; CAZZOLATO, B. S.; HANSEN, C. H. Active noise control in a free field with virtual sensors. Journal of the Acoustic Society of America, v. 109, n. 1, p. 232-243, 2001.

52 MUNN, J. M. Virtual sensors for active noise control. Tese (Doutorado) University of Adelaide, out. 2003. 